\title{
THE \\ MACHINE STOPS
}

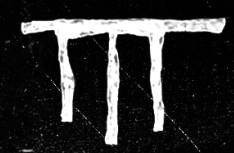





\title{
The Machine Stops
}

\author{
by
}

William Pierre du Toit

\begin{abstract}
A 120-point thesis
submitted to the Victoria University of Wellington

in partial fulfilment of the requirements for the degree of Master of Architecture (Professional)
\end{abstract}

Victoria University of Wellington

Wellington School of Architecture 


\section{$+$}

64

Our world, like a charnel-house,

is strewn with the detritus of dead epochs.

-Le Corbusier, Towards a New Architecture 
Before the discovery of gold, the majority of the South Island of Aotearoa was relatively uninhabited, until the 1860s gold rush which quickly propelled the Otago region into economic prosperity. Once the gold dried up, the mining operations were quickly abandoned, with many of the workers losing their jobs as the industry declined.

The historic goldfields in the Otago region now lie in various states of decay, with the industrial remnants and environmental scarring slowly being reclaimed by ecological processes. Each mining operation centred around a stamper battery, a giant stone-crushing machine used to separate the gold from the quartz ore. Consisting of a large timber framework and a number of half-ton weights used to crush the ore, they were deemed too difficult to remove after the mining operations had ceased - abandoned to slowly decay in the irrevocably damaged landscape.

Of these many sites, the Homeward Bound goldmining operation, located $30 \mathrm{~km}$ northwest of Arrowtown, offers one of the most complete examples of this historical process due to the area's dry climate - each stage of the mining process still being physically represented by a trace or fragment in the landscape. These remnants represent both the story of extracting the gold that led to the region's prosperity, as well as the story of irreversible environmental destruction that resulted. As such, each of the man-made and natural remnants represents a different point of view regarding this complex heritage event. This designled research investigation proposes to use speculative architectural drawing to provide a voice to each of seven unique points of view: the Mineshaft, Schist Tailings, Redirected Stream, Stamper Battery, Water Race, Aerial Cableway, and a Battery Footprint left behind when a previous stamper battery was swept away in a flood.

E.M. Forster's short story "The Machine Stops" is an example of allegorical narrative fiction that portrays a story with a similarly dialectic premise to the tale represented by the abandoned Otago stamper batteries. This designled thesis investigation uses Forster's short story as a literary provocateur to investigate how such a narrative can be conveyed using speculative architectural drawings. Forster's theme of technological dominance and disregard for the natural environment is effectively a type of 'morality play' also represented by the Homeward Bound goldmining site-where the economic prosperity of the region came at the cost of devastating the native landscape.

This thesis investigation proposes to preserve this heritage story though the lens of an allegorical architectural project - a way to safeguard it as a valuable lesson for future generations. It explores how orthographic drawing, architectural notation strategies, and layering techniques can be assimilated together in ways that help to reawaken and preserve a heritage story about New Zealand that is soon destined to be lost forever. 


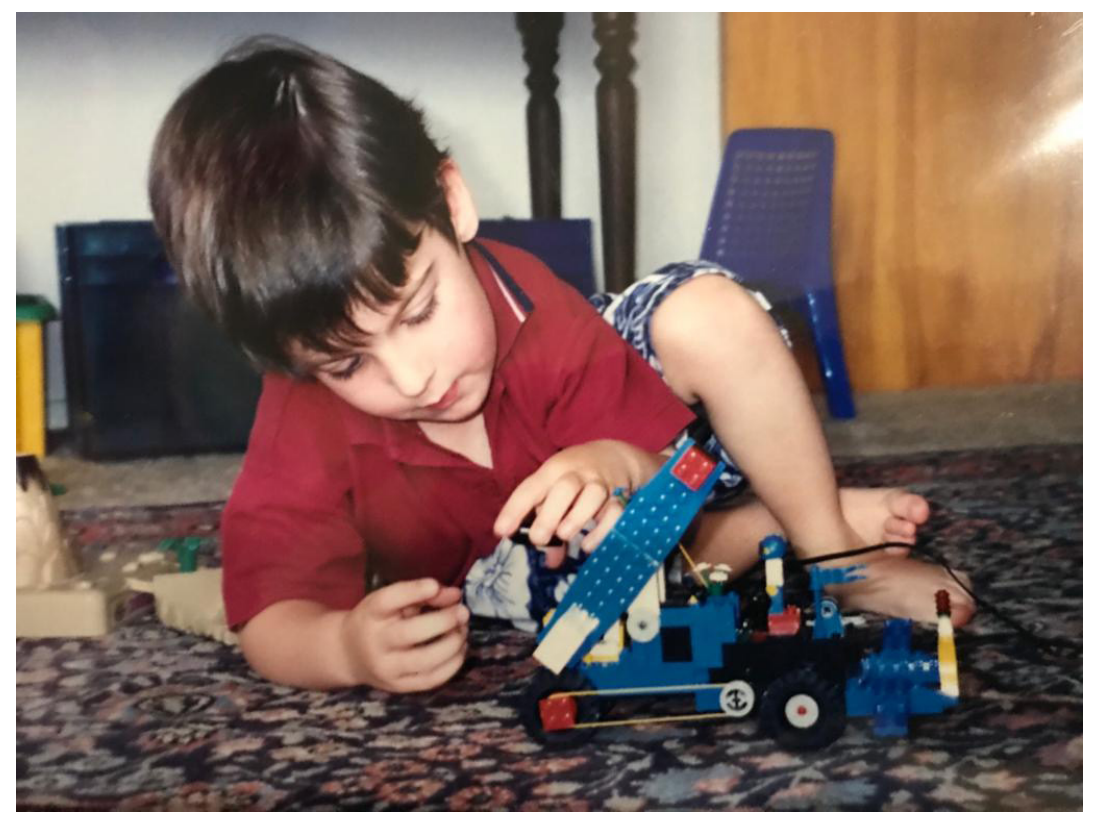




\section{PREFACE}

Ever since I was a young boy I have been obsessed with machines. My mum and I would regularly visit local construction sites so I could watch the machines at work. This mechanical obsession has constantly resurfaced throughout my studies, manifesting itself in both architectural forms and programmatic thinking. Now in my fifth and final year of academic study, I have the opportunity to incorporate my love of machines into my architectural education in this thesiswhich investigates a heritage story where the machine takes on an almost architectural identity.

Shortly after beginning my research, I was recommended E. M. Forster's "The Machine Stops", a short story depicting humanity's dependence on The Machine in a dystopian future. Forster's writing resonated with me, as it explores mankind's dependency on technology-specifically the dangers of blindly adapting to a mechanised world without consideration for the environment in which it is situated. This theme also resonated with our relationship with the internet as well as quarantine during the Covid-19 pandemic-making it a particularly poignant literary provocateur for this research investigation. 


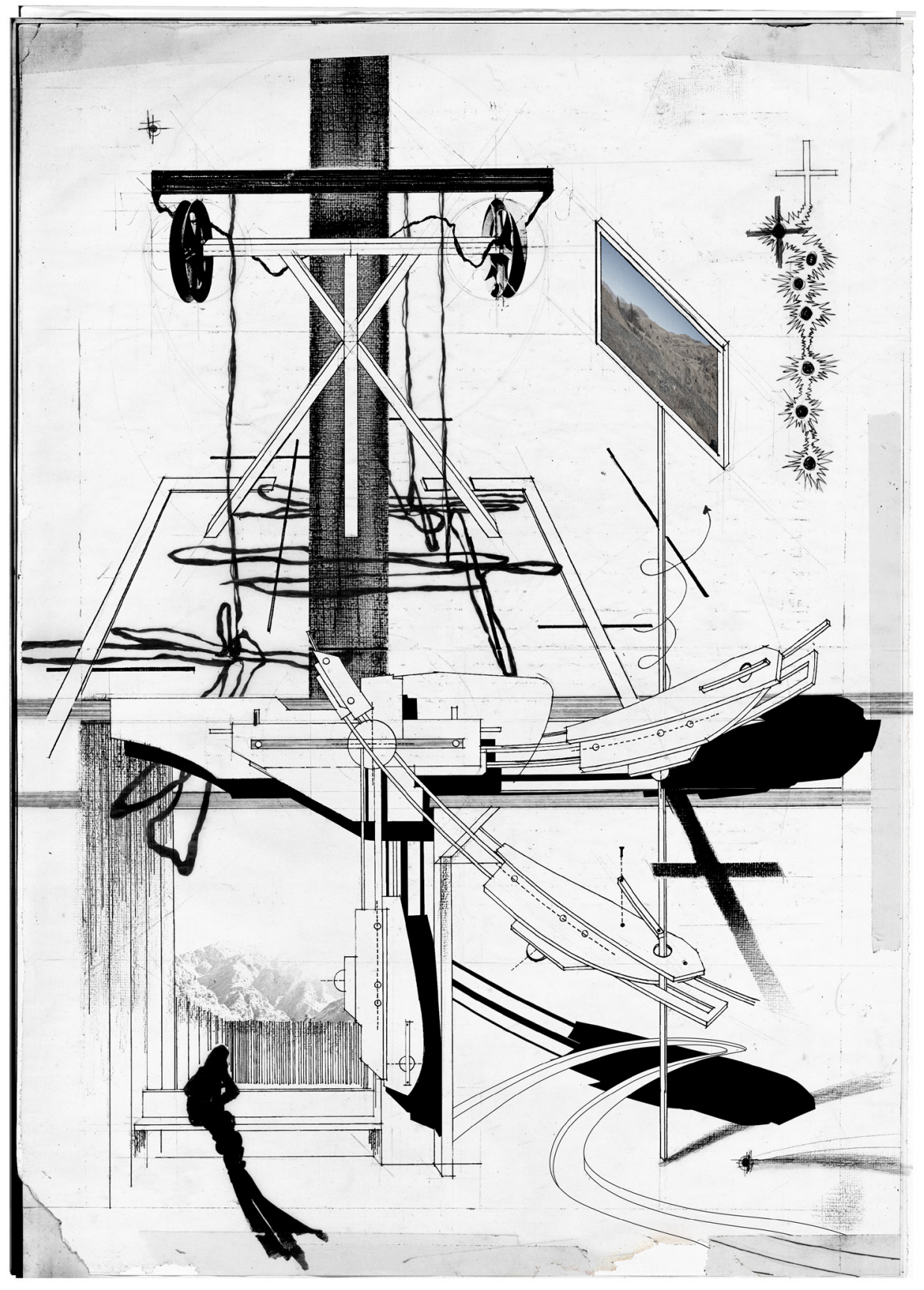

Fig 0.1 Early concept drawing exploring the transitional relationships of the Aerial Cableway. 


\section{ACKNOWLEDGEMENTS}

They say it takes a village to raise a child, and this thesis is no exception:

To my supervisor Daniel, for igniting, nurturing and fuelling my creativity. Your unwavering enthusiasm and support is something I will cherish forever;

To my friends, for listening and laughing, making the hard days good and the good days great;

To my family, for always believing in me and teaching me to believe in myself;

And to you, the reader, for taking the time to embark on this journey with me.

Thank you. 


\section{TABLE OF CONTENTS}

\subsection{Introduction}

1.1 Introduction 3

1.2 Problem Statement 4

1.3 Research Proposition 5

1.4 Research Question 6

1.5 Research Aim \& Objectives 7

1.6 Design Methods \& Process 9

1.7 Methodology Diagram 11

$\begin{array}{lll}1.8 & \text { Research Scope } & 13\end{array}$

$\begin{array}{lll}1.9 & \text { Thesis Structure } & 14\end{array}$

\subsection{Contextual Analysis}

2.1 Site Introduction 23

$\begin{array}{ll}2.2 \text { Topological Context } & 25 \\ 2.3 & 25\end{array}$

2.3 Historical Timeline 26

$\begin{array}{lll}2.4 & \text { Significant Events } & 27\end{array}$

2.5 Macro Site 30

2.6 Micro Site 33

$\begin{array}{lll}2.7 & \text { Site Visit } & 35\end{array}$

2.8 Critical Reflection $\quad 39$

\subsection{Literature \& Project Review}

3.1 Introduction 43

3.2 Speculative Drawing Strategies $\quad 45$

3.3 Orthographic Drawing 51

$3.4 \quad$ Notation Strategies and Devices 59

$\begin{array}{lll}3.5 & \text { Layering Techniques } & 67\end{array}$

$\begin{array}{lll}3.6 & \text { Critical Reflection } & 73\end{array}$

\subsection{Characters of Site}

$\begin{array}{lll}4.1 & \text { Allegorical Framework } & 79\end{array}$

4.2 Characters of Site 82

4.3 Proposed Interventions 92

4.4 Critical Reflection 95 


\subsection{Concept Design}

5.1 Introduction

5.2 Plan Experiments 102

$\begin{array}{lll}5.3 & \text { Interventions Sited } & 116\end{array}$

$\begin{array}{ll}5.4 \text { Critical Reflection } & 119\end{array}$

\subsection{Preliminary Design}

$\begin{array}{lll}6.1 & \text { Introduction } & 123\end{array}$

6.2 Principle Case Study 124

6.3 Axonometric Experiments 128

6.4 Critical Reflection Phase One 145

6.5 Preliminary Design Phase Two 149

6.6 Preliminary Design Final Outcomes 151

6.7 Critical Reflection Phase Two 157

\subsection{Developed Design}

7.1 Introduction 161

7.2 Principle Case Study 162

7.3 Polyvocal Drawings 165

7.4 The Mine Shaft 170

$\begin{array}{lll}7.5 & \text { The Aerial Cableway } & 174\end{array}$

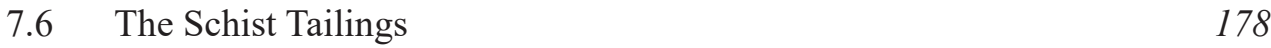

7.7 The Water Race 182

7.8 The Stamper Battery 186

7.9 The Battery Footprints 190

7.10 The Redirected Stream Drawings 194

7.11 Lamentations Series II 198

7.12 Developed Design Critical Reflection 205

7.13 Exhibition Curation and Testing 209

$\begin{array}{ll}7.14 & \text { Exhibition Critical Reflection } \\ 217\end{array}$

\subsection{Conclusion and Critical Reflection}

8.1 Conclusion and Critical Reflection 221

8.2 Principal Case Study 222

8.3 Proposed Architectural Intervention 224

8.4 Coda: Personal Reflection 235

9.1 Bibliography 240

9.2 Source of Figures 242 
Imagine, if you can...

-E.M. Forster, "THE MACHINE STOPS", P1 of 19 


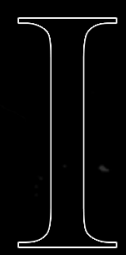

INTRODUCTION t tes 


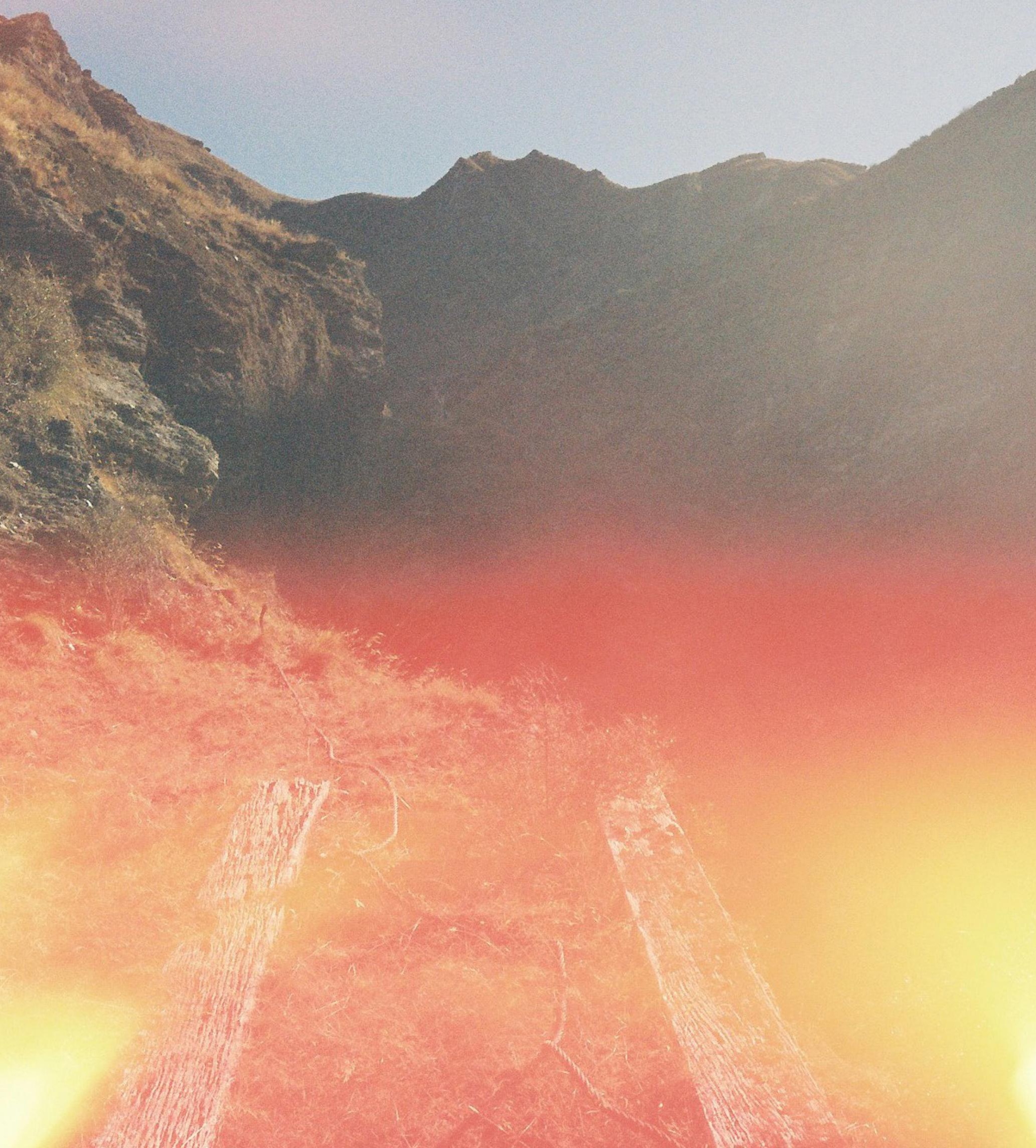




\section{$1.1 \quad$ INTRODUCTION}

This thesis is positioned within a research stream that investigates 'allegorical narrative' as a framework within which to design meaningful architectural outcomes. It proceeds on the premise that other narrative disciplines, such as literature and film, can convey important social, political and environmental ideas that traditional approaches to architecture often fail to achieve. In order to explore how architecture might strengthen its own narrative potential, works of literary fiction are interrogated and used as 'provocateurs' to initiate an allegorical architectural outcome.

The allegorical provocateur of this thesis is Edward Morgan Forster's "The Machine Stops", a short story depicting a world in which most of the human population is sustained by the technological framework of The Machine. Direct human contact is regarded as unmechanical or blasphemy against the nurturing Machine, with the human body reduced to "a swaddled lump of flesh" totally dependent on the technology to survive (Forster, 1909).

Forster's short story is about how people rely on the Machine, realising how the benefits from the Machine have actually come at a very high cost. Comparative literature lecturer Paul March-Russell argues that "The Machine Stops" is "not a tale of the future but an allegory of the present where formal inconsistencies describe tensions in contemporary cultural thought" (March-Russell, 2005). In the story, society fails to recognise the inherent conflict between prosperity and resulting loss. The price of this ignorance is an inability to adapt that ultimately leads to the demise of the mechanised community, brought down by the very system they worshipped. When interpreted as a reflection of our modern world, this allegory reminds us that humanity's dependency on technology risks blinding us to both our environment and the damage that we are causing to it.

This design-led research investigation addresses the role of the machine in both the prosperity and the resulting environmental damage that was brought about by the machine during Otago's gold rush era. By interrogating and reinterpreting the allegory of "The Machine Stops" in relation to the heritage story of the Homeward Bound stamper battery near Macetown, Otago, this thesis aims to bring this heritage story to life for future generations. The goal is to safeguard this important story, to awaken our recognition of its dialectic nature by seeing the story told from multiple points of view, and to safeguard this important heritage lesson for future generations.

Fig 1.1 Mining remnants of the Aerial Cableway, outside of Macetown, August 2020, photo by author. 


\subsection{PROBLEM STATEMENT}

The landscape of Aotearoa is replete with fragments of history, evidenced by both manmade elements that have been left behind as well as natural elements that have been removed, damaged or altered. These artefacts were witnesses to unique historical periods in our country's development, and they therefore embody vital heritage stories linked to the prosperity (or decline) of the regions. These periods of growth and development often had a devastating effect on the natural environment, an important part of a heritage story that is often not recognised, resulting in our lack of awareness that heritage tales of prosperity often also have a tragic side. In this sense, a visible tale associated with economic growth is often in reality a dialectic narrative also associated with environmental decline.

New Zealand's 1860s gold rush, foundational to the initial colonial settlement of the Otago region, yielded high economic gain at the cost of devastating the natural landscape. Approximately 160 years later, traces of this industry now lie fragmented across the landscape - quietly decaying and soon destined to become permanently lost - threatening to take their dialectic narrative with them. Once gone, the didactic lessons of regional identity associated with unchecked environmental damage will be lost for future generations. 
Before the discovery of gold, the majority of the South Island of Aotearoa was relatively uninhabited, until the 1860 s gold rush which quickly propelled the Otago region into economic prosperity. Once the gold dried up, the mining operations were quickly abandoned, with many of the workers losing their jobs as the industry declined.

The historic goldfields in the Otago region now lie in various states of decay, with the industrial remnants and environmental scarring slowly being reclaimed by ecological processes. Each mining operation centred around a stamper battery, a giant stone-crushing machine used to separate the gold from the quartz ore. Consisting of a large timber framework and a number of half-ton weights used to crush the ore, they were deemed too difficult to remove after the mining operations had ceased - abandoned to slowly decay in the irrevocably damaged landscape.

Of these many sites, the Homeward Bound goldmining operation, located $30 \mathrm{~km}$ northwest of Arrowtown, offers one of the most complete examples of this historical process due to the area's dry climate - each stage of the mining process still being physically represented by a trace or fragment in the landscape. These remnants represent both the story of extracting the gold that led to the region's prosperity, as well as the story of irreversible environmental destruction that resulted. As such, each of the man-made and natural remnants represents a different point of view regarding this complex heritage event. This designled research investigation proposes to use speculative architectural drawing to provide a voice to each of seven unique points of view: the Mineshaft, Schist Tailings, Redirected Stream, Stamper Battery, Water Race, Aerial Cableway, and a Battery Footprint left behind when a previous stamper battery was swept away in a flood.

E.M. Forster's short story "The Machine Stops" is an example of allegorical narrative fiction that portrays a story with a similarly dialectic premise to the tale represented by the abandoned Otago stamper batteries. This designled thesis investigation uses Forster's short story as a literary provocateur to investigate how such a narrative can be conveyed using speculative architectural drawings. Forster's theme of technological dominance and disregard for the natural environment is effectively a type of 'morality play' also represented by the Homeward Bound goldmining site-where the economic prosperity of the region came at the cost of devastating the native landscape.

This thesis investigation proposes to preserve this heritage story though the lens of an allegorical architectural project - a way to safeguard it as a valuable lesson for future generations. It explores how orthographic drawing, architectural notation strategies, and layering techniques can be assimilated together in ways that help to reawaken and preserve a heritage story about New Zealand that is soon destined to be lost forever. 


\subsection{RESEARCH QUESTION}

This design-led research investigation asks:

How can an allegorical architectural project be used as a critical method to explore new ways to preserve heritage stories that are destined to be lost, so that they may be recognised as important lessons for future generations?

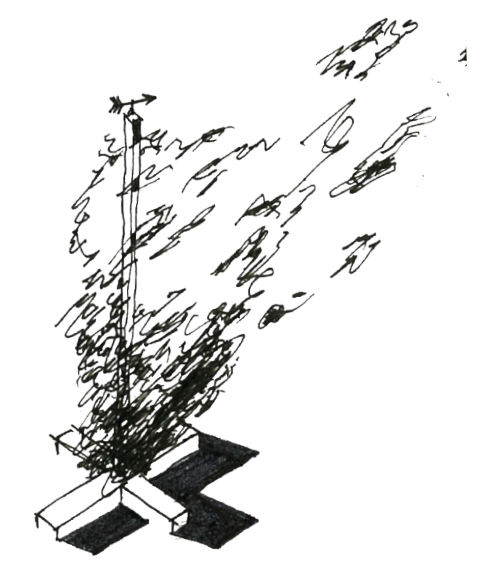




\subsection{RESEARCH AIM \& OBJECTIVES}

The principal Research Aim of the investigation is:

RA To explore how, through speculative architectural drawing, an allegorical architectural project can be used as a critical method to help preserve heritage stories that are destined to be lost.

The principal Research Objectives of the investigation are:

R01 To explore how orthographic drawing can help establish critical relationships within a dialectic narrative;

RO2 To explore how architectural notation strategies and devices can be used to establish allegorical relationships relating to time, place and point of view;

RO3 To explore how layering allegorical drawings can enable relationships of time, place and point of view to be simultaneously recognised as an overall metanarrative. 


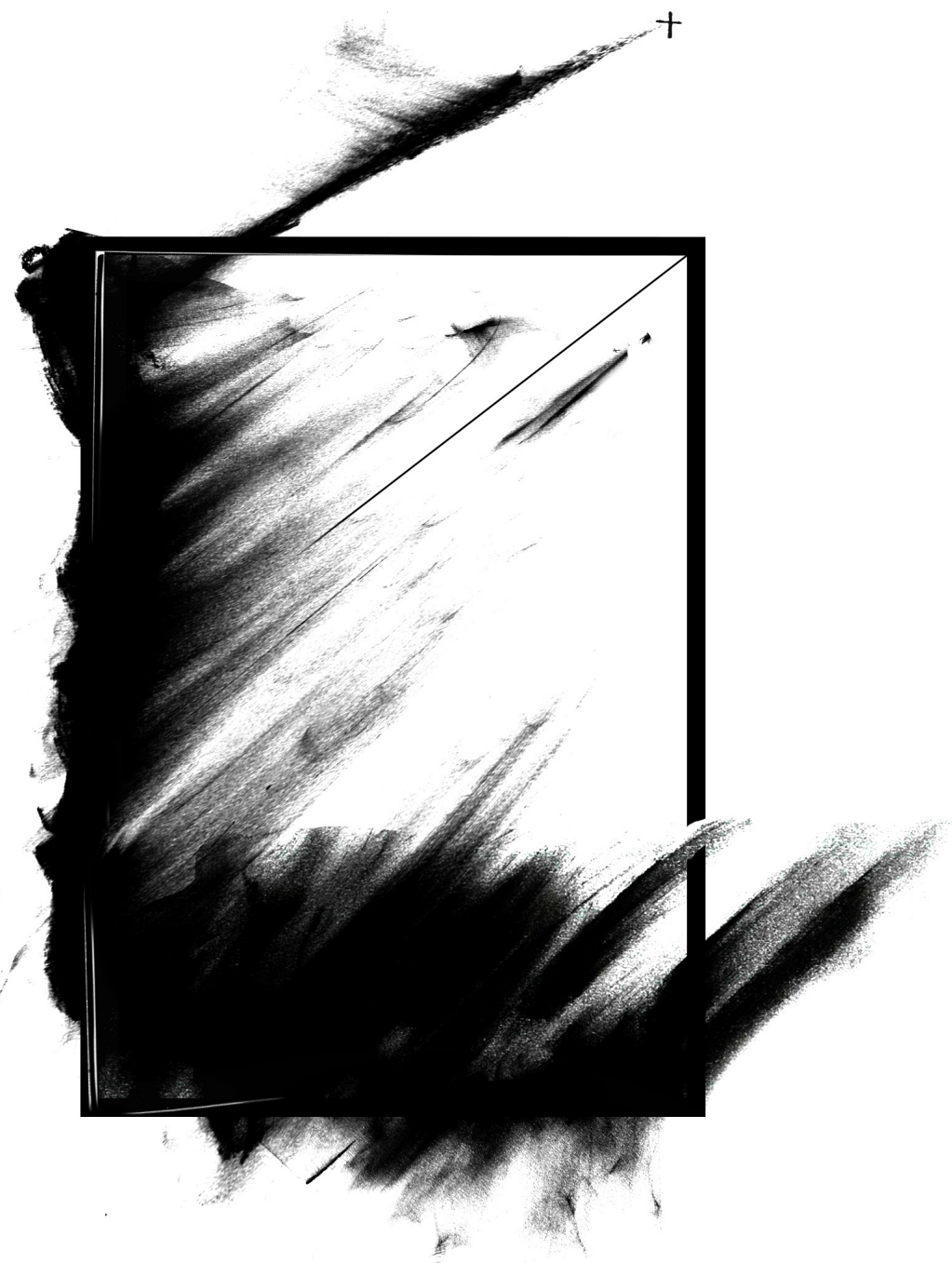

Fig 1.3 Framing device and registration marker, remnants left behind by author's drawings of seven overlapping voices. 


\subsection{DESIGN METHODS \& PROCESSES}

This research investigation follows the iterative processes depicted in the methodology diagram shown in Figure 1.4. Each research objective and its corresponding theorists/case studies are used to iteratively interrogate each stage of this investigation.

The methodology for this research investigation represents "research by design", as critically discussed in Peter Downton's 2013 book Design Research (Downton, 2003). This thesis engages an iterative design-led research approach, using a sequential workflow of analogue and digital techniques that progressively build upon one another. Each successive stage of the design research is used to conduct experimental research that is reflective of the previous stage and anticipates the stage to come. Each stage critically reflects on strengths and weaknesses, and each interrogates opportunities for the next design stage in relation to this critical reflection.

A combination of digital and analogue drawing methods are used as an exploratory method throughout this thesis. Analogue techniques involve handcrafted investigations primarily concerned with orthographic drawing and sketching, while digital drawing methods are used to compile and compose these elements into more polyvalent explorations. This digital drawing method is also used as a bridge between analogue drawings and 3D modelling, the latter of which involves digital reproduction and manipulation of site remnants. Each design stage is defined by a reflective workflow balancing analogue and digital techniques. This duality provides a strategic choice for progression, iteratively evaluating and comparing one to the other.

This research investigation focuses on analysis of industrial heritage artefacts to explore and understand how they have participated in a unique heritage story. Analysis of the artefacts unearths confrontational relationships within the site through axonometric drawing, to help unveil points of view representing both sides of a dialectic narrative relating to site identity. The approach critically reflects on key authors and case studies that explore: how orthographic drawing can enable a dialectic narrative; notation as a way to evidence relationships of time, place and point of view; and the use of layering to provoke simultaneous understanding of multiple stories from various points of view that lead to polyvocal design outcomes. The final design stage involves extracting and realising the speculative architectural form as a habitable intervention. This is followed by critical reflection focusing on the importance of the issue under investigation, reflective arguments, and reflective discussions about limiting factors, other applications and potential for further advancement. 


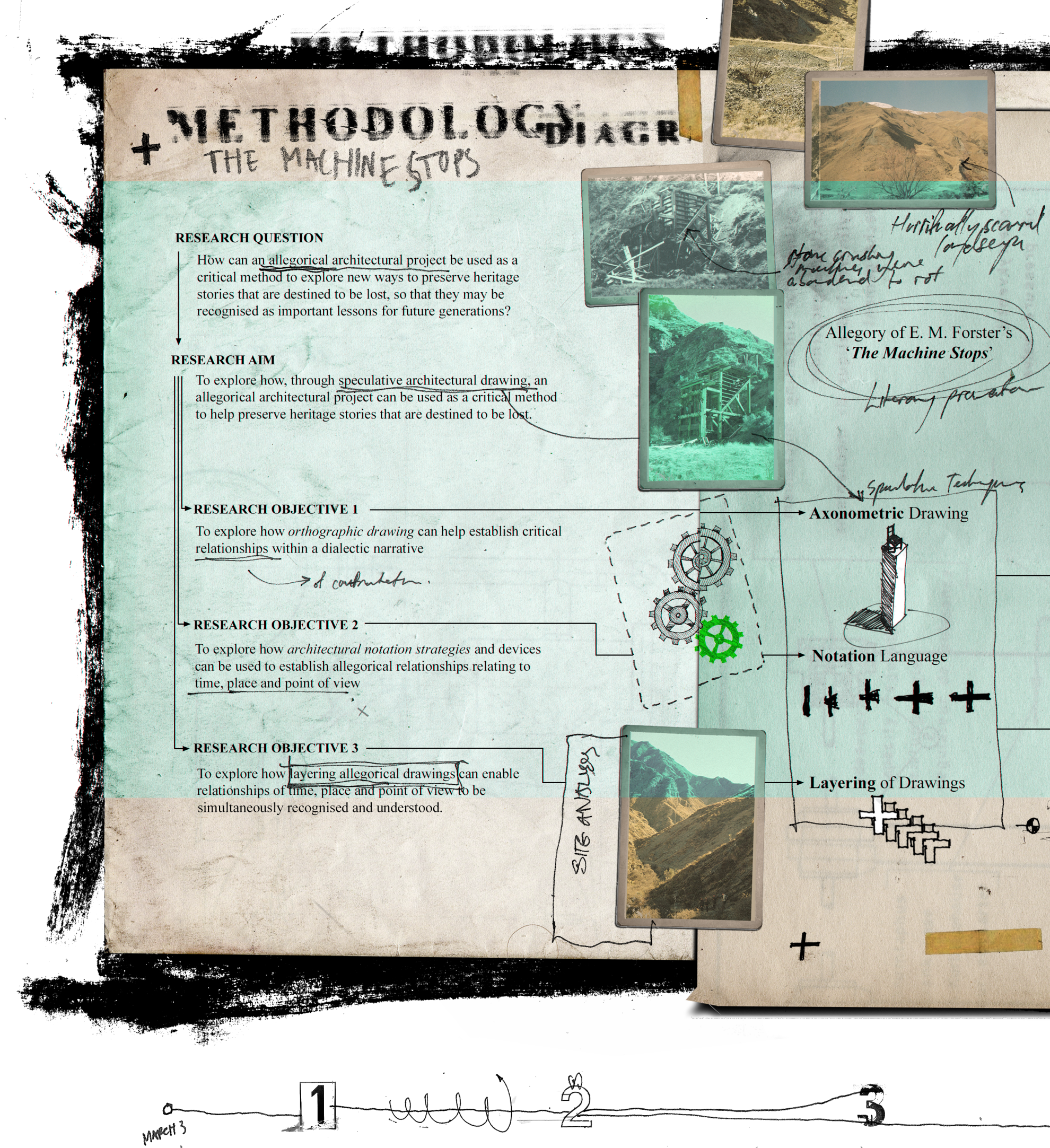




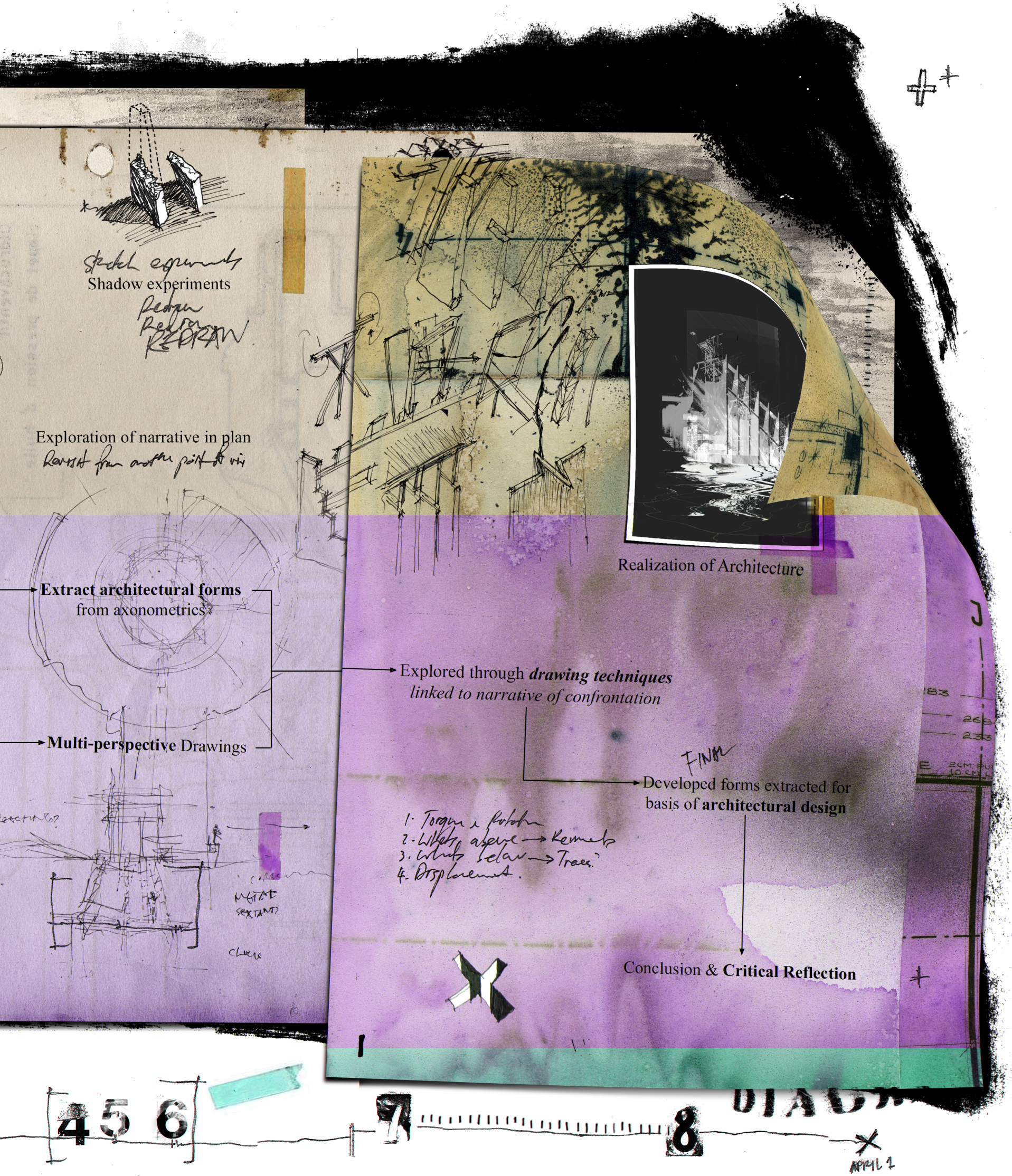




\subsection{RESEARCH SCOPE}

A site visit was essential to this investigation, but due to cost, time, travel restraints, and the 2020 Covid pandemic restrictions, only one visit was possible. This limited the ability of this thesis to reinvestigate areas of particular interest upon later reflection.

The industrial heritage remnants being examined by this thesis investigation cannot be fully restored without simultaneously destroying the important layers of decay and loss that represent vital chapters in their ongoing story. As such, and as a speculative and allegorical investigation, architectural outcomes from this investigation are in the form of speculative drawings that enable us to witness chapters that would otherwise be lost. As a speculative drawing investigation, architectural structure, technologies and costings are therefore outside the scope of this investigation.

While a number of sites in Aotearoa contain valuable heritage stories relating to the short-lived New Zealand gold rush, the scope of this investigation is restricted to one site in Otago. This restriction is due to the limited time available for the research, as well as the focus and depth of resolution anticipated. By selecting one particularly important site, there is an opportunity to convey a larger metanarrative about this heritage story, even within this focused limitation. 


\subsection{THESIS STRUCTURE

This investigation is structured in 8 chapters as follows:

\subsection{INTRODUCTION}

Chapter 1.0 introduces this investigation's problem statement, research question, aim and objectives as well as methodology and scope - articulating the focus of the thesis as well as its structure and direction.

\subsection{CONTEXTUAL ANALYSIS}

Chapter 2.0, explores the research site selected for this investigation: the four-storey high Homeward Bound stamper battery located 45 minutes walk from Macetown Historic Reserve (15km from Arrowtown) in the Otago hills. The chapter interrogates both topographical and socio-economic elements as a way to understand the contextual relationships inherent in both the built and the natural artefacts that relate to this heritage story.

\subsection{LITERATURE \& PROJECT REVIEW}

Chapter 3.0 presents, analyses and builds the theoretical framework from principles of key authors relevant to the Research Aim (Speculative Drawing) and the three principal Research Objectives (Orthographic Drawing, Notation Strategies and Layering). These principles are then interrogated in relation to architectural case studies to consider ways to interpret and integrate them into the project's iterative design process. 


\subsection{SPECULATIVE DRAWING}

This section of the chapter relates primarily to the Research Aim.

Neil Spiller, speculative architect and architectural professor at the University of Greenwich, is a key theorist for this section. He advocates for the role of speculative drawing in the modern day of architecture. He argues that architecture is the manipulation of space, which can be graphically represented to evoke imaginative interpretation - with drawing becoming a vital tool to speculate on the future and critique the past through architecture.

Other key theorists relating to the Research Aim include:

Professor of Architecture and Urbanism at the Bartlett School of Architecture C. J. Lim, Professors of Architecture at the Bartlett School of Architecture Mark Smout and Laura Allen, Architect and Associate Professor at the University of Michigan's Taubman College of Architecture Perry Kulper, Academic Leader in Architecture at the University of Greenwich Simon Herron, architect and former student at the AA School of Architecure in London Michael Hara, and American architect and urbanist Fred Koetter.

Lim advocates for the use of speculative drawing as a valid alternative to traditional practice. Smout and Allen build on Lim's theories and argue that speculative drawing can be used as a method with which to interrogate a site. Kulper argues that these drawing methods reveal alternative spatial possibilities often missed in traditional practice. Hara discusses how speculative drawings can capture moments across time, and Koetter identifies a realm of 'in-between' where fragments can be reassembled in a cohesive narrative through imaginative and open interpretation.

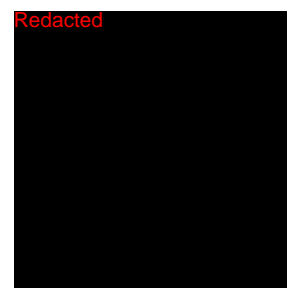

Key case studies relating to the principal Research Aim include:

Victims (1984) by American architect John Hejduk and Oritsunagumono (2011) by artist Takayuki Hori. These case studies illustrate how fragmented artefacts as presented through speculative drawing can both preserve and enable narratives through their treatment of time. 


\subsection{ORTHOGRAPHIC DRAWING}

This section of the chapter relates primarily to Research Objective 1.

Associate Professor at the University of Calgary School of Architecture, Planning and Landscape Catherine Hamel is a ket theorist for this section. She discusses how orthographic drawing can be used to bring elements into confrontation. She argues that in orthographic drawing there is always confrontation, as both an act of comparison and consideration - establishing orthographic drawing as a way to establish critical relationships within the dialectic narrative of site.

Other key theorists relating to Research Objective 1 include:

Austrian architect and former Professor at the Cooper Union School of Art and Architecture Raimund Abraham; Italian architect Giuseppe Terragni; Finnish photographer Ilkka Halso; sociologist, philosopher and critic Georg Simmel; architectural theorist and historian Mario Carpo; and theorist and former Dean of Princeton University School of Architecture Stan Allen. Abraham identifies confrontation as the catalyst for our process of remembering. Terragni advocates for the confrontation of literature and architecture as another method of interrogation. Halso and Simmel identify two dualities of confrontation relating directly to the narrative of site. Carpo advocates for planar drawing as a valid method even in the modern age of technology, and Allen highlights the importance of axonometric as a method of allegorical representation.

Key case studies relating to Research Objective 1 include:

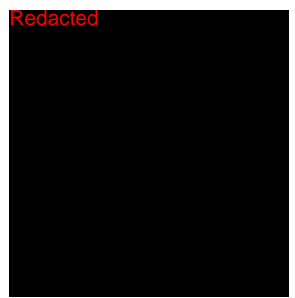

Castelvecchio (1958) by Italian architect Carlo Scarpa, Tsukuba Center Building (1979) by Japanese architect Arata Isoaki, and Cosmoslogy of the House (1974) by Austrian architect Raimund Abraham. Castelvecchio shows elements being placed into confrontation with one another to enable a dialectic narrative in the built world, while the other two case studies evidence this confrontation through speculative drawing. 


\subsection{NOTATION THEORY}

This section of the chapter relates primarily to Research Objective 2.

Architect and Dean of the School of Architecture at Princeton University Stan Allen is a key theorist for this section. He outlines how notations function within architectural drawing practice, working similarly to a musical score. He identifies five working definitions of notations, arguing that they act as a language of spatial and material elements that work across time and space-able to communicate the complexity and unpredictability of the real.

Other key theorists relating to Research Objective 2 include:

Narrative landscape theorists Matthew Potteiger and Jamie Purinton, landscape architect James Corner, and Professor of Design Theory at California State University Bryan Cantley. Potteiger and Purinton build on Allen's notational theory of working across time and space in relation to dynamic narratives that are framed within a passage of time. Corner builds on Hamel's theory of confrontation through projection, arguing that projection lines are a notational system that enables these relationships to be witnessed. Cantley outlines three important conditions of writing notation in traditional drawing practice and applies them in speculative drawing.

Key case studies relating to Research Objective 2 include:

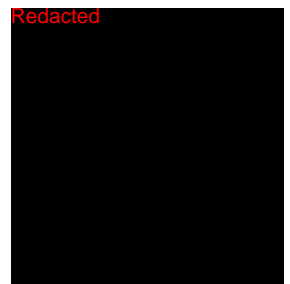

UL-9304/Living Unit (c1993) by speculative architect Mas Yendo, Hybriddrawings $\odot$ (2011) by Professor of Design Theory at California State Univerity Bryan Cantley, and The Object Beside Itself (1998) by Deputy Pro-Vice Chancellor of the University of Greenwich Neil Spiller. Each of these case studies are exemplars of notation strategies being used to enable an allegorical narrative through imaginative and open interpretation. 


\subsection{LAYERING}

This section of the chapter relates primarily to Research Objective 3.

Associate Professor at Wentworth Institute of Technology Anne-Catrin Schultz is the key theorist for this section. She discusses the role of layering in both real-world applications as well as in architectural drawing. She argues that the stratification of individual planes allows each layer to enable its own narrative, within the metanarrative of a multi-layered composition. She discusses the role of overlapping, transparency and reference markers as elements within layering that inform the narrative relationships while enabling spatial and polyvalent narrative understanding.

Other key theorists relating to the Research Objective 3 include:

Australian architect and heritage consultant Jennifer Hill, Lecturer at the Bartlett School of Architecture Simon Herron, and architect and Dean of the School of Architecture at Princeton University Stan Allen. Hill discusses the role of physical layers of history presented simultaneously to enable a narrative of transformation over time. Herron outlines how the layering of incomplete fragments in architectural drawing can not only enable a narrative but also invite imaginative interoperation, and Allen argues that the layering of fragments in a collage drawing joins their historical connotations and therefore allows them to work across time and space.

Key case studies relating to Research Objective 3 include:

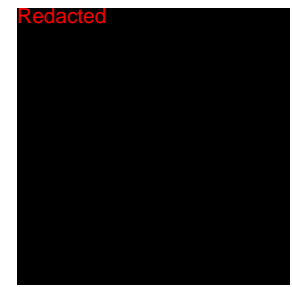

Layer Drawings (2010) by Nobuhiro Nakanishi and Sex Shop (1995) by Douglas Darden. Both of these provide a strong example of layering being physically used to compose fragmented artefacts into a meta-narrative, while simultaneously enabling a viewer to witness relationships of confrontation through a passage of time. 


\subsection{CHARACTERS OF SITE}

Chapter 4.0 explores individual narratives relating to the unique 'points of view' of seven key 'witnesses' to this historic event: the Mineshaft, Schist Tailings, Redirected Stream, Stamper Battery, Water Race, Aerial Cableway, and a Battery Footprint left behind when a previous stamper battery was swept away in a flood. These narratives are explored with a particular focus on their dialectic relationships of confrontation, with each element categorised as either man-made or environmental.

\subsection{CONCEPTUAL DESIGN}

Chapter 5.0, the conceptual design stage, critiques the allegory of "The Machine Stops" by E. M. Forster as a literary provocateur. It then conceives and reflects upon initial experiments that begin to explore how the allegorical architectural project as a critical method can help bring to life the litany of fragmented and overlapping story lines relating to this heritage tale, that were uncovered in Chapter 3: Contextual Analysis. The conceptual design experiments are generated through an iterative process of orthographic drawing in response to Research Objective 1.

\subsection{PRELIMINARY DESIGN}

Chapter 6.0, the preliminary design stage, develops and reflects upon preliminary design experiments that investigate how the application of notation theory can critically unveil relationships of time, place and point of view in response to Research Objective 2. The preliminary design experiments produce individual allegorical representations of each of the seven unique points of view represented by the seven selected 'characters of site'.

\subsection{DEVELOPED DESIGN}

Chapter 7.0, the developed design stage, extracts architectural form from the preliminary design drawing series, and it applies layering theory to allow the individual points of view represented by the seven selected 'characters' to all be experienced simultaneously_addressing Research Objective 3.

\subsection{CONCLUSIONS \& CRITICAL REFLECTION}

Chapter 8.0 is a critical reflection of the developed design drawings and final design in relation to the research question, aim and objectives. It evaluates the importance of the issue under investigation through critical reflection of each design stage, its application of theoretical principles, its limitations and opportunities for further research in the future. 
46

To such a state of affairs it is convenient to give the name of progress. No one confessed the Machine was out of hand. Year by year it was served with increased efficiency and decreased intelligence. The better a man knew his own duties upon it the less he understood the taties of his neighbour, and in all the world there was not one who understood the monster as a whole Those master brains had perished. 


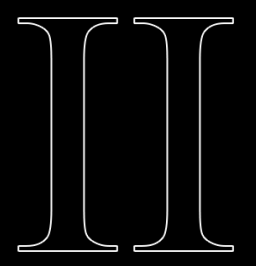

\section{CONTEXTUAL ANALYSIS}

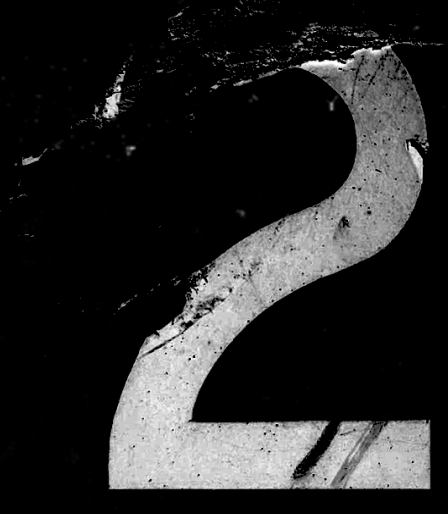




\subsection{SITE INTRODUCTION}

Chapter 2 explores the research site of the Homeward Bound stamper battery, identifying and excavating a selection of narrative layers and fragments to be used as the basis for this design-led research investigation. This chapter interrogates the site with a specific focus on how architectural drawing can be strategically used to preserve important heritage stories that are in danger of being lost.

The first stage of this chapter investigates the history of the selected stamper battery, as well as its relationship to other goldmining operations near the site. It then focuses on the operational areas of the Homeward Bound mine and their impact on the landscape. As an allegorical architectural project representing two distinctly different points of view (economic prosperity at the expense of the natural environment), seven natural and man-made elements ('characters') of the site were selected in order to represent seven points of view that all contributed to this heritage tale. These 'characters' are all located in close proximity to one another, and they become the focus of the site's multi-layered narrative: the Mineshaft, Schist Tailings, Redirected Stream, Stamper Battery, Water Race, Aerial Cableway, and the Battery Footprint left behind when a previous stamper battery was swept away in a flood.

Each of these characters is categorised into either an environmental or mechanical faction (Table 2.1), interrogating them against the theme of nature vs the machine to draw out their unique role in the history of site. This categorisation unveils two primary narratives: 1) the machine processes that led to the prosperity and settlement of this rural wildernesses region, and 2) the environmental elements that were victimised by these processes. 


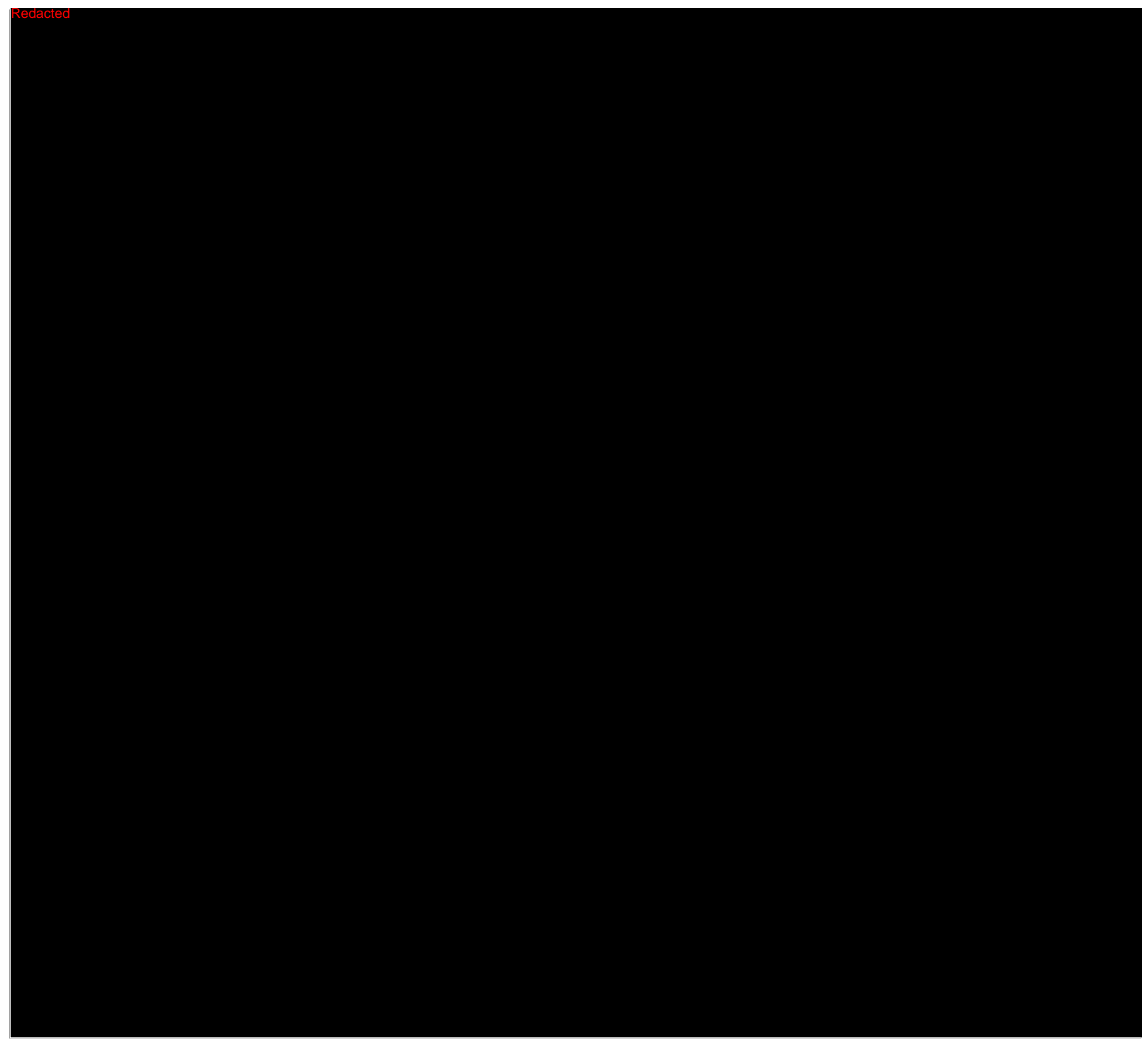

Fig 2.2 Historic map of the Otago goldfields with the Homeward Bound site circled, Hocken Collection, 1866 


\subsection{TOPOLOGICAL CONTEXT}

Deep in the hills $30 \mathrm{~km}$ north of Arrowtown lies the Macetown Historic Reserve, a heritage area associated with the remains of various goldmining operations from around the 1860s. An hour hike beyond this reserve lies the Homeward Bound stamper battery, a huge architectural stone-crushing machine that was abandoned once the gold ran out. Other very similar mining operations lie in close proximity, with the Homeward Bound operation selected as a focus for this investigation due to the well preserved nature of its remains. This thesis proposes that by bringing its story to life, the related stories of other batteries in the immediate area will be recognised as well.

Originally drawn to the alluvial gold in the Arrow River, miners quickly depleted this easy source of gold and started mining using more invasive methods. Sluicing and quartz reef mining involving deep horizontal mineshafts into the landscape became the alternative methods, the latter extracting hard quartz ore with the desired gold held within (Petchey, 2002). To separate the gold from the quartz, industrial machines called stamper batteries were laboriously brought in, transported by donkey and man-power from Arrowtown. These batteries were primarily located on the valley floor for ease of transport, while the mines were dug in the hills above.

\section{SITE SPECIFIC GOLDMINING PROCESSES}

The stamper battery acted as a convergence point where various natural resources and mechanical systems met and mixed:

- Water Races were cut into the landscape, feeding water from sources above into the battery to wash the ore through the machine as it worked;

- Mineshafts were dug horizontally in the hills to reach the quartz veins within the landscape;

- An Aerial Cableway system transported buckets of ore from the mine above to the battery below, suspended on steel cables over the steep landscape;

- Unwanted material from the rock-crushing process is discarded in piles on the valley floor, creating barren rock forms known as Schist Tailings;

- A natural Stream was used to power the battery and rinse the schist tailings. 

150 Million $B C$
12 million $B C$
$100,000 B C$
23 May 1861
$c 1863$
Jul-Aug 1863
Jan 1863
$c 1865$
1878
Schist bedrock is formed along the Alpine Fault. Gold forms within cracks in the schist during metamorphism.
The Pacific and Indo-Austrialian tectonic plates collide and create a reverse fault condition, pushing the schist to the surface and forming the Southern Alps.
Glaciers grind away the bedrock, eroding the gold and schist, which is deposited as alluvial gold in the riverbeds.
Australian prospecter Gabriel Read discovers gold 'shining like the stars in Orion' at Tuapeka, kickstarting the goldrush in Otago.
Peak of the Otago gold rush era with an estimated goldfield population of 24,000.
Blizzards, snowstorms and floods kill 51 miners, with 5 killed on the Arrow River just North of Macetown.
The Otago Quartz Mining Company erects a four head stamper battery in Otago and begins crushing at Shetland Reef near Waipori. This is quickly replaced by a larger ten head stamper battery imported from Melbourne.
The easily-won alluvial gold is mostly depleted and miners begin to cooperate to work the quartz reefs. The industry turns to cyanide processing in stamper batteries, bucket dredging in rivers and hydraulic elevators in sluicing claims.
Torrential rain and flooding destroys 'Little Wonder', the first battery erected at the Homeward Bound site, along with the mine office and other machinery. A replacement battery is erected above the flood level, along with a self-acting tramway spanning a distance of 22 chains.

Nov 1883

1899

1909

1910

C

Heavy rain causes a slip to completely destroy the tramway to the battery, and lack of successful prospecting puts a hold on quartz mining at the Homeward Bound site.

The OPQ stamper battery arrives from England and is erected at Waipori by the Otago Pioneer Quartz Gold-Mines Limited.

A new company acquires the mine and announces payable quartz has been located. An aerial cableway connecting the mines to Twelve Mile Creek is constructed.

The OPQ stamper battery is relocated $1 \mathrm{~km}$ northeast of Macetown to work the Homeward Bound Mine and is consequently renamed. The operation only runs for a few years before being abandoned due to international financing being withdrawn at the outbreak of WW1.

The Homeward Bound stamper battery still stands today, with minor intervention from the Department of Conservation in the form of a corrugated iron roof. 


\subsection{SIGNIFICANT EVENTS}

From the historical analysis of the Homeward Bound mining operation, three key events emerge as transformative moments in the narrative of site. Each event is concerned with the confrontation of the natural environment and the mining operation - presenting the opportunity to explore both points of view as the balance of power changes over time.

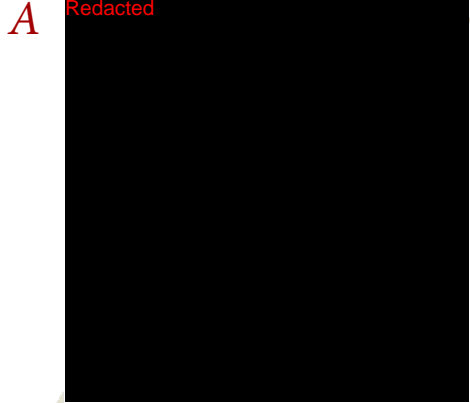

Fig 2.3

Original installation of industrial machinery such as a stamper battery and aerial cableway to begin the crushing the quartz ore taken from the hill. Image of Homeward Bound Stamper Battery under construction, Hocken Collection n.d.

$B$

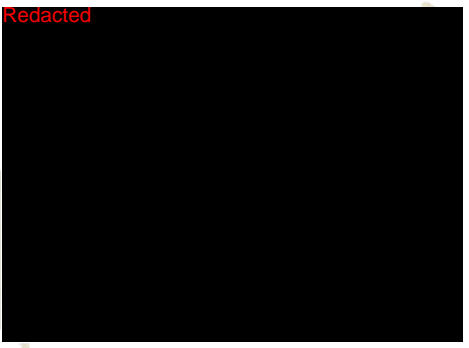

Fig 2.4

Destruction of the first stamper battery installed at the Homeward Bound Site by the stream flooding. Image of Stamper battery destroyed and decaying, Hocken Collection n.d.
C

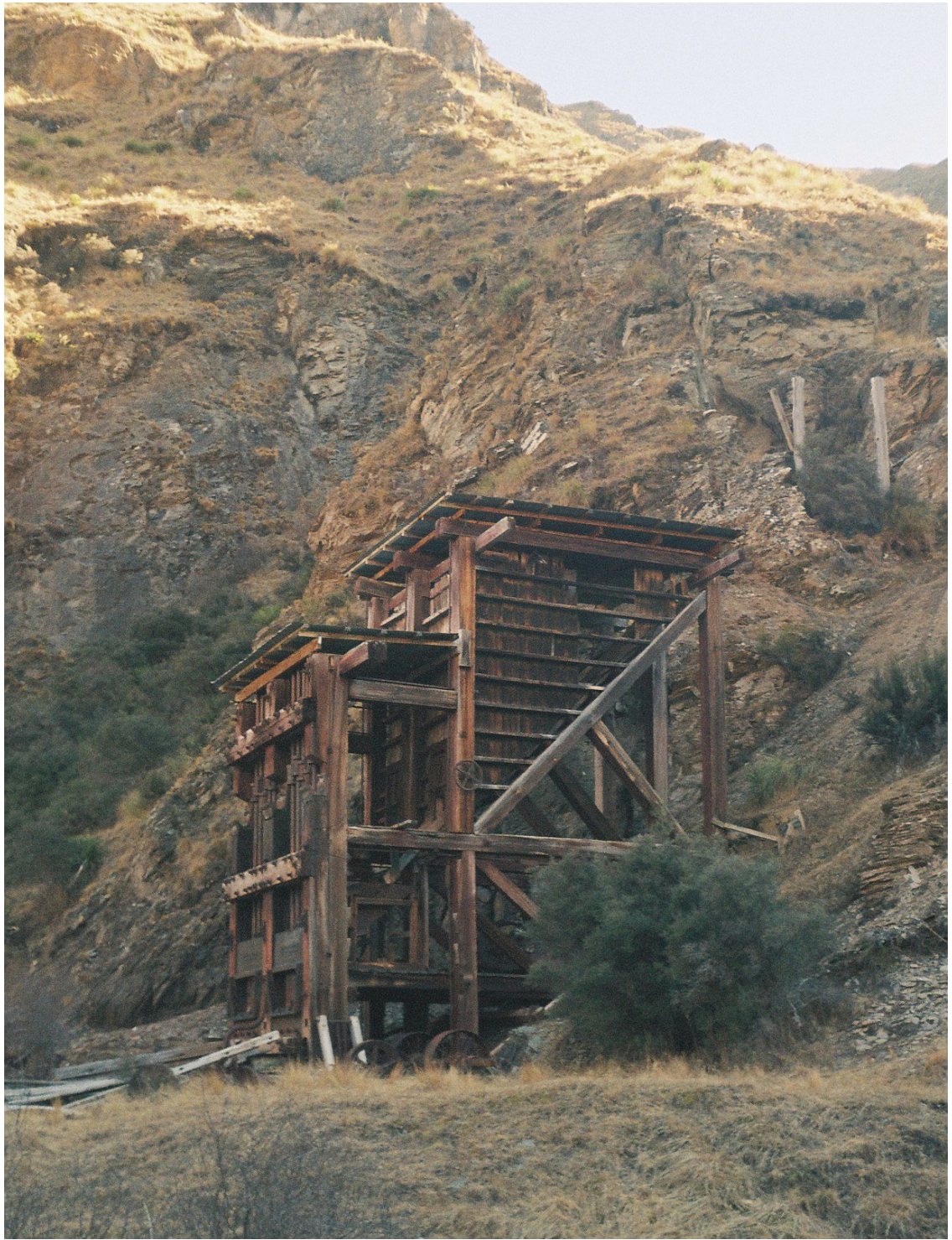

Fig 2.5 The abandonment of the mining site due to lack of financial viability, leaving the industrial machinery and scarred landscape. Image of Stamper battery today, outside of Macetown, August 2020, digital photograph, photo by author. 


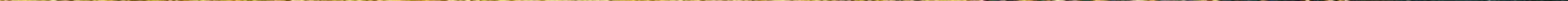




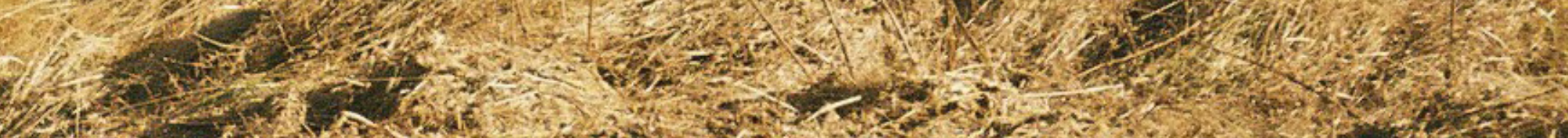

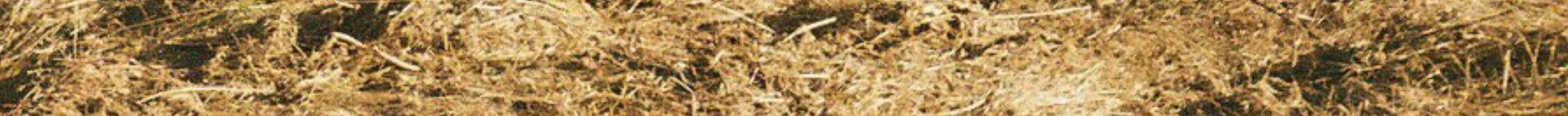

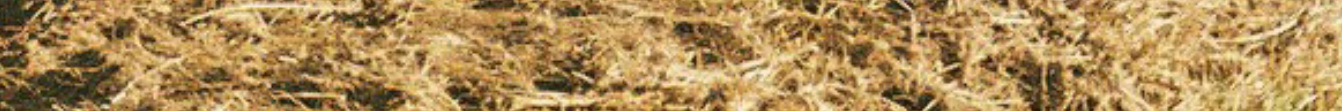

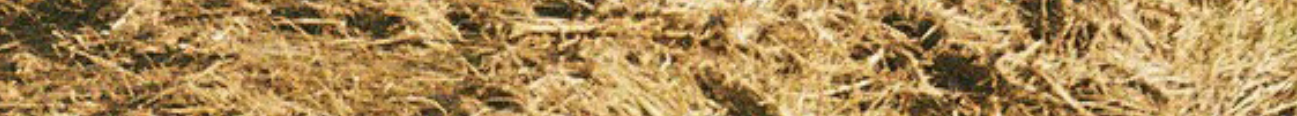
$50, \frac{1}{20}$

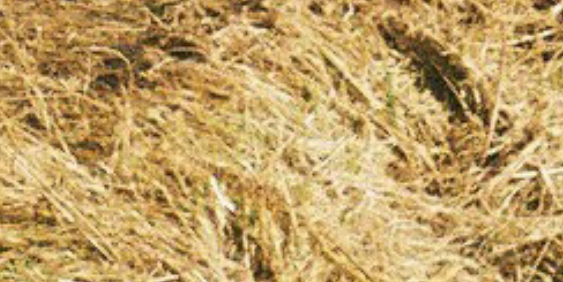

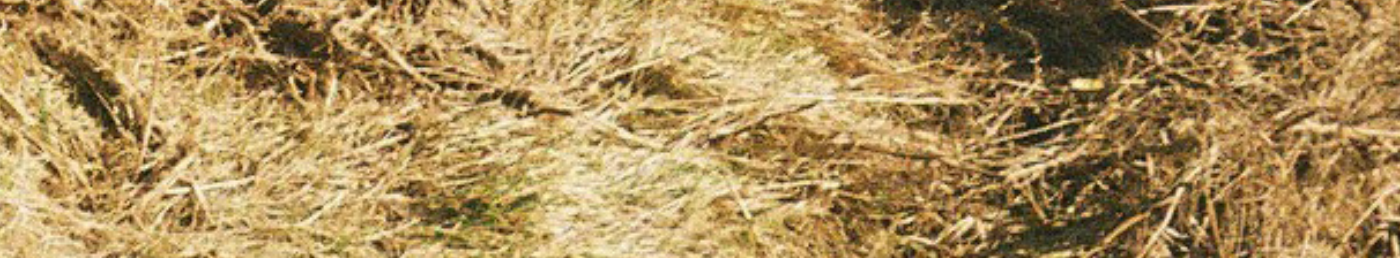

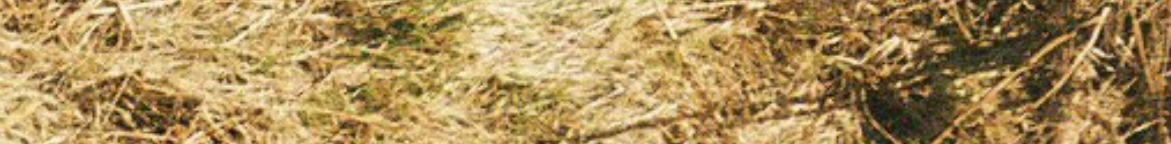

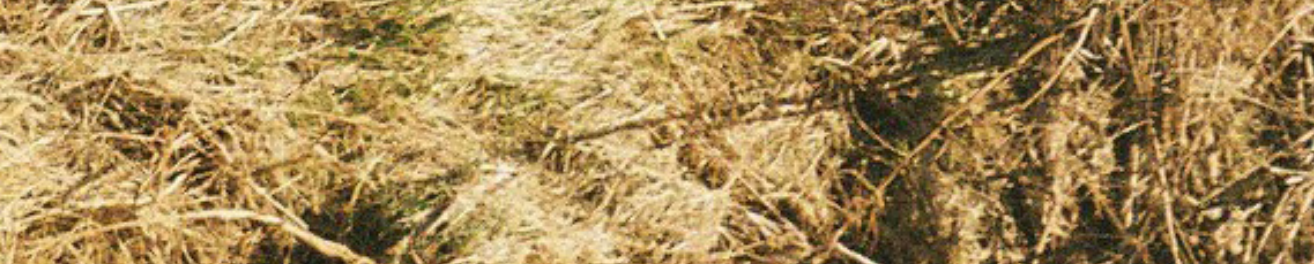
S.

(i)

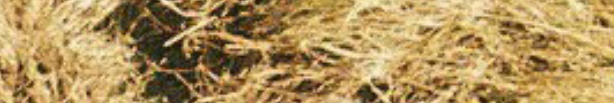
a.t. (8)

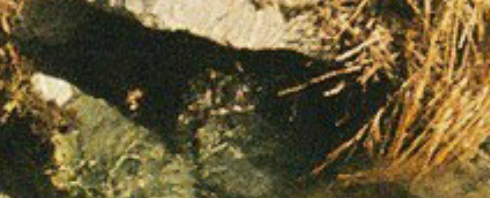

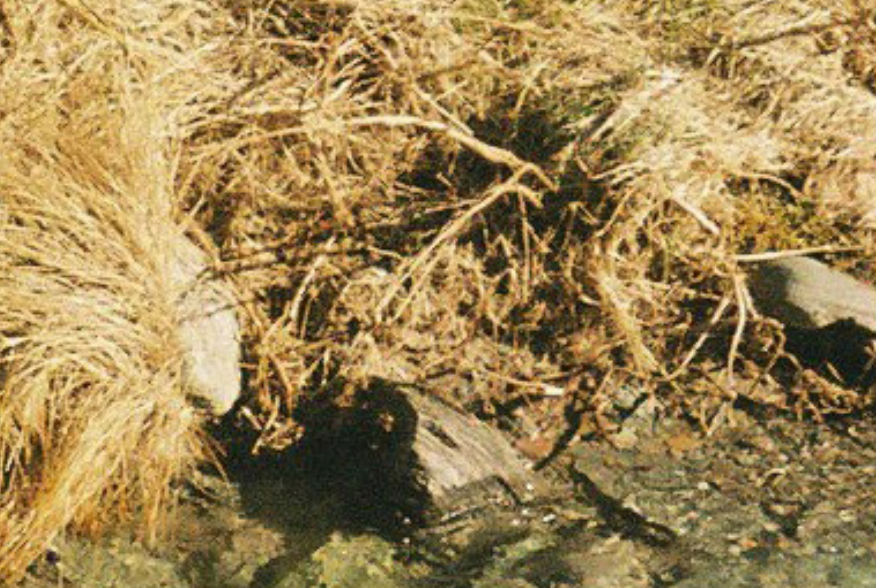
e.27) Let

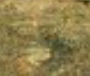

1. $x^{2}$

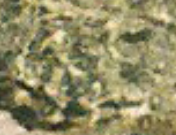
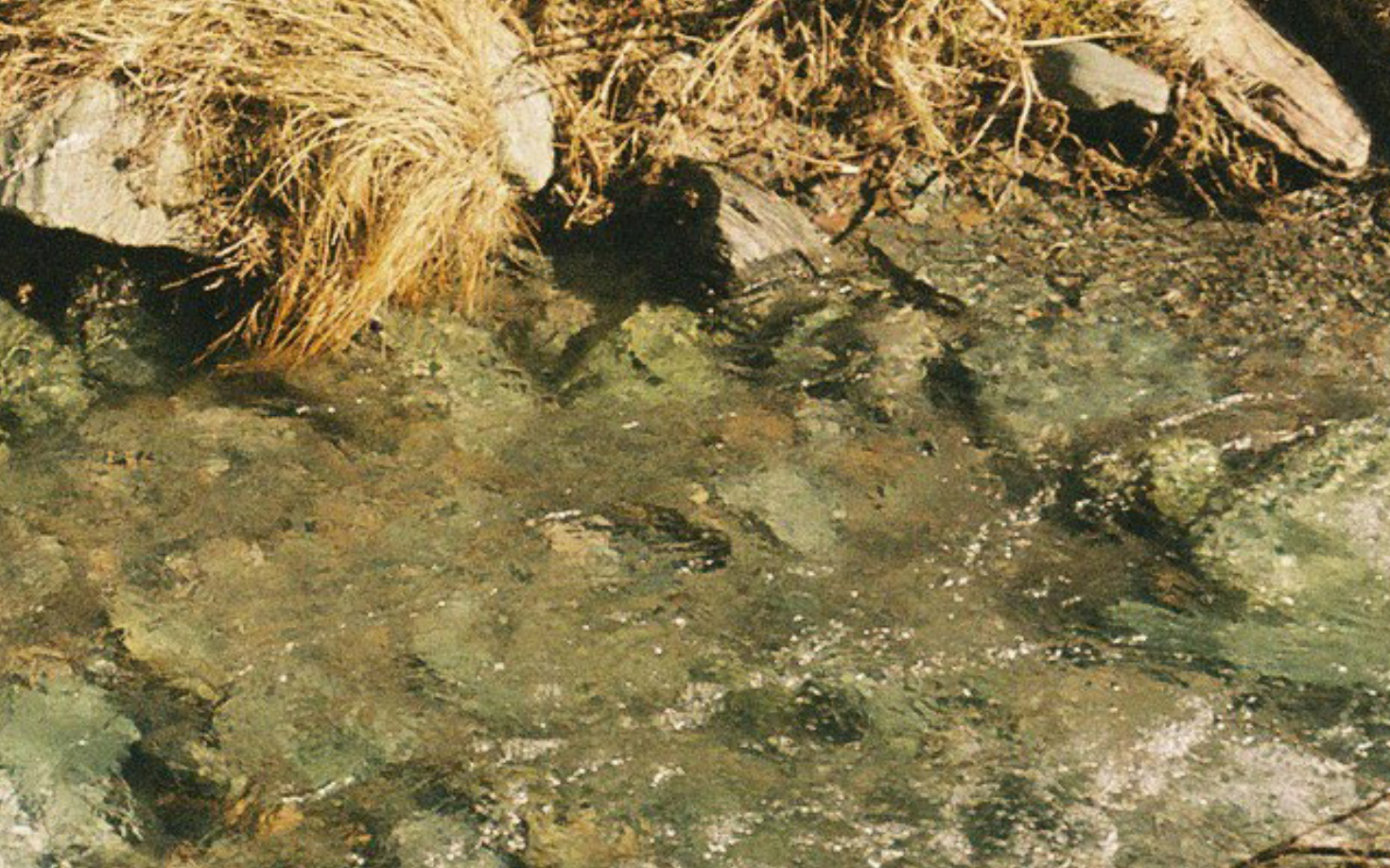
tos

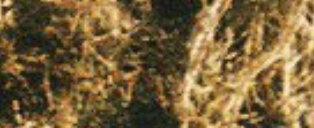
tos?

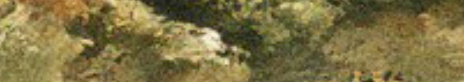

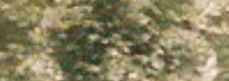

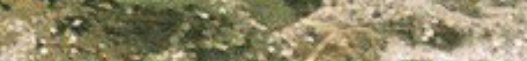

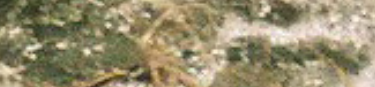
$\frac{12}{4}$ Q69: 


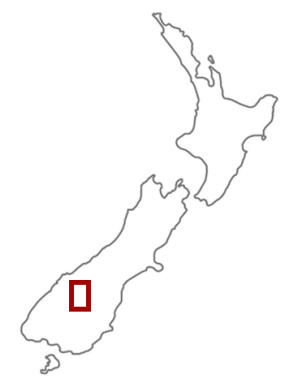

QUEENSTOWN

\subsection{MACRO SITE}

These maps illustrate the goldmining fields directly north of Macetown Historic Reserve. Figure 2.7 shows the site in relation to the nearby centres of Queenstown and Arrowtown. Figure 2.8 shows the goldfields in realtion to one another, identifying a number of quartz reef mining operations similar to the Homeward Bound mining operation. These operations all share similar relationships of mineshafts near the top of the hills, with the stamper batteries located on the valley floor.

All of the miners who worked these sites operated out of Macetown, a goldmining community whose prosperity quickly declined after the mines were deemed no longer financially viable. 


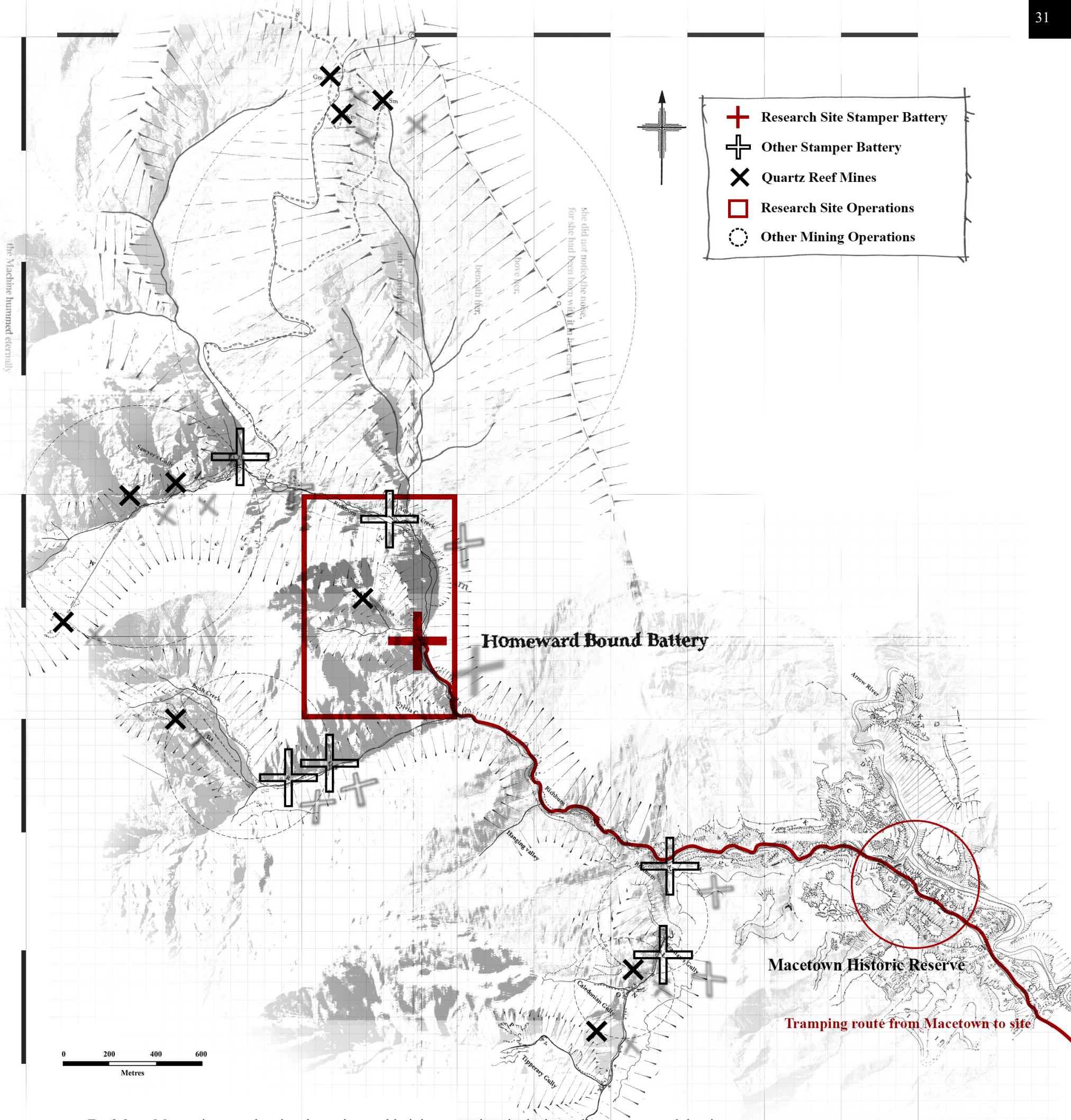

Fig 2.8 Macro site map showing the various goldmining operations in the immedrate area around the site. 


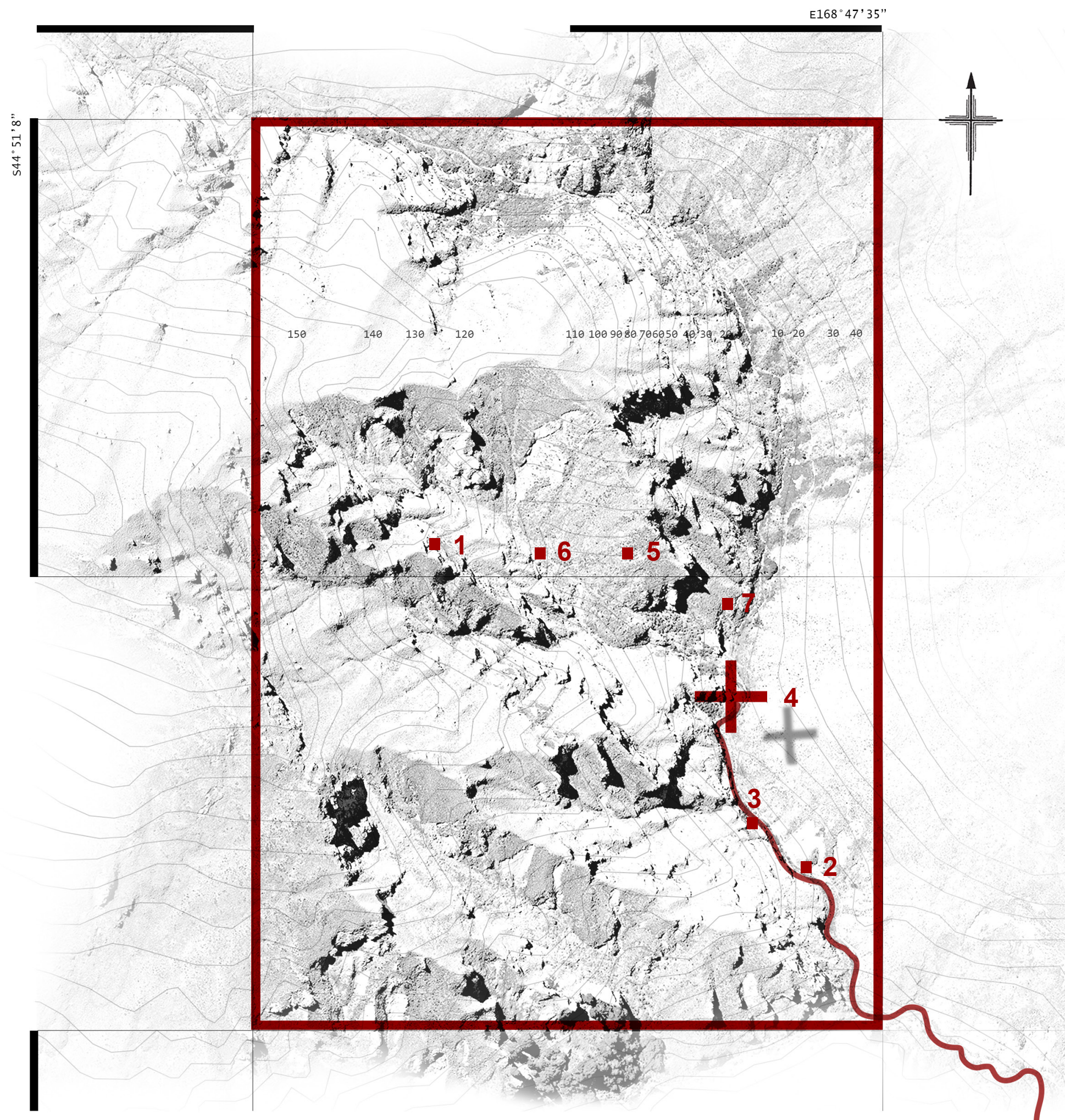

Fig 2.9 Micro site plan detailing position of seven remnants within the site.

Tramping route from Macetown to site 


\subsection{MICRO SITE}

Figure 2.9 illustrates the contextual relationships of each remnant of the Homeward Bound Site. Some remnants such as the Stamper Battery have visual lines of sight to nearly all the others, while artefacts like the Schist Tailings are blocked from view.

To explore these relationships further, each remnant is categorised as a part of either the natural environmental systems or the man-made system-providing a perspective on its 'point of view' in telling this dialectic story (Table 2.1). Each remnant is allegorically anthropomorphised as a 'character' who was involved in the overall meta-narrative, each providing its own point of view as a unique fragment or a layer of the allegorical narrative.

Natural

Natural

2 Schist Tailings

Natural

3
Redirected Stream

Convergence

4 Stamper battery

Water Race

Man-made

6 Aerial Cableway

Man-made
Dug horizontally in the hill to reach the quartz veins within the landscape

Unwanted material from the rock-crushing process discarded in piles on the valley floor

Redirected from its natural route by the unwanted tailings on the valley floor

Convergence point where natural resources and man-made systems met and mixed

A man-made cut dug into the hills to transport water across the landscape

Transitional element that brought buckets of ore from the mines above to the battery below by steel cables suspended over the steep landscape

Traces of a previous stamper battery swept Trace away in a flood
Void

Displacement

Deviation

Convergence

Cut

Transition 
Fig 2.10.a Fueling up before beginning the hike, the valley leading to the Homeward Bound Site directly behind, August 2020.

(2)

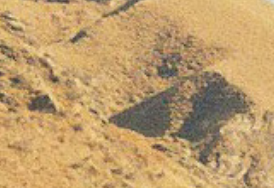

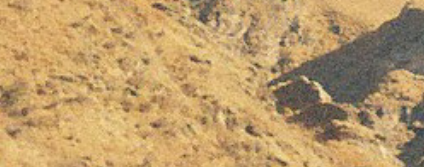

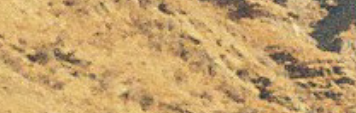

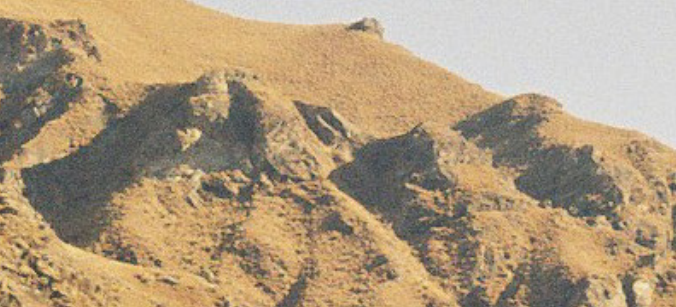

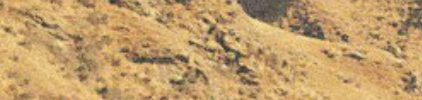

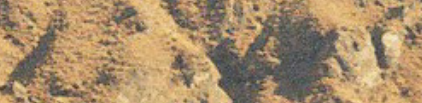

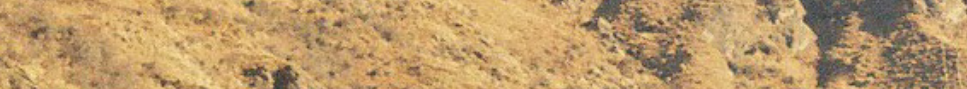

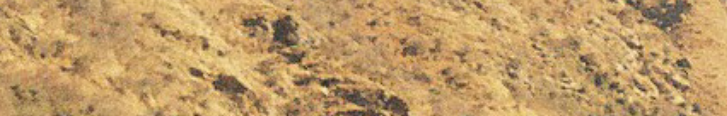

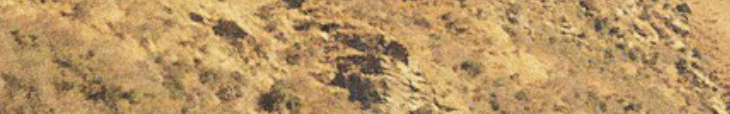

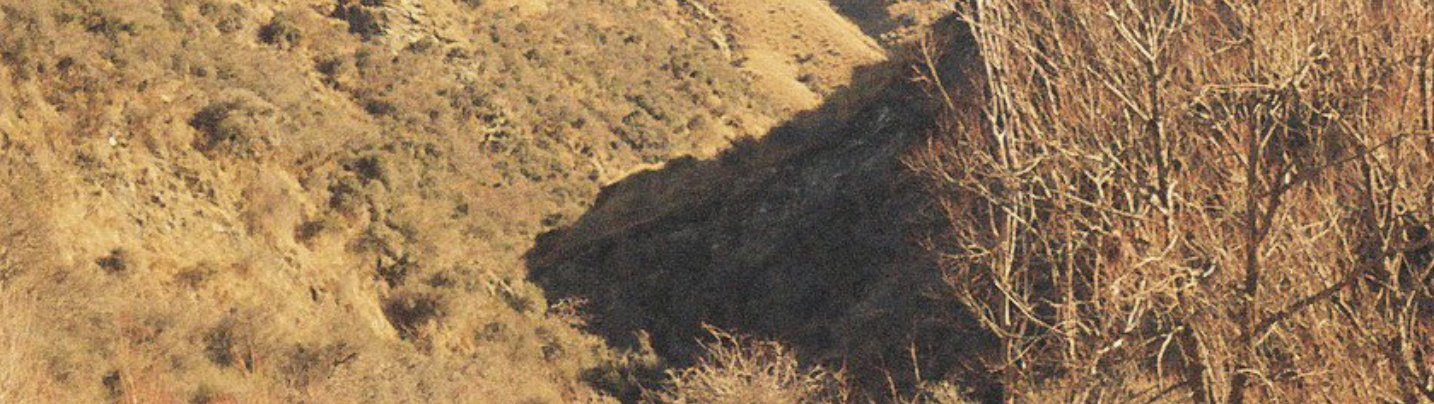

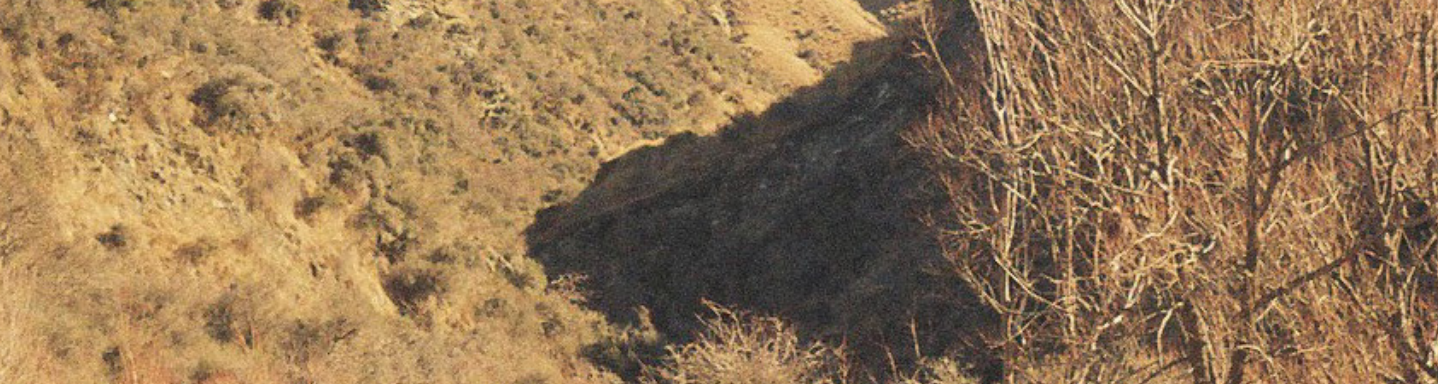

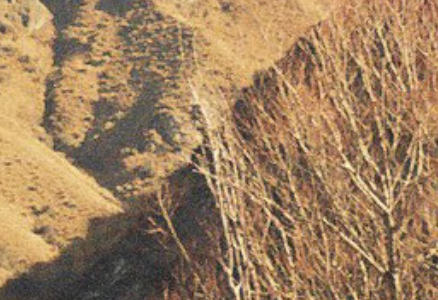

(⿻)

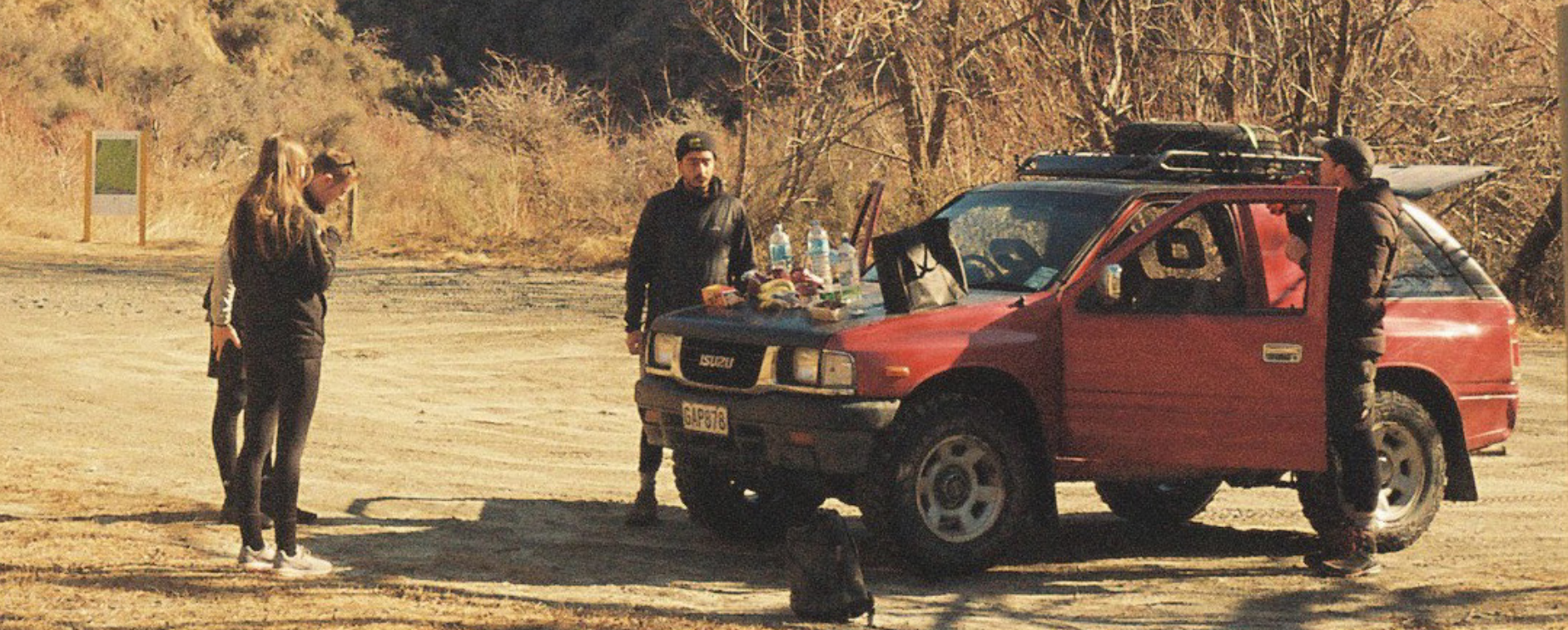

(I)

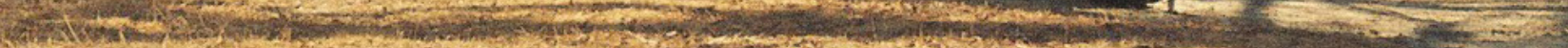

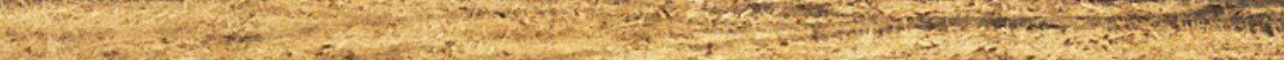

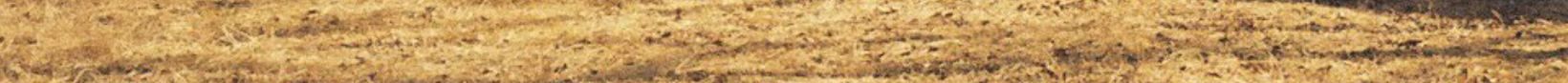

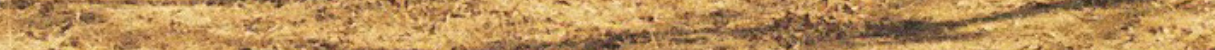

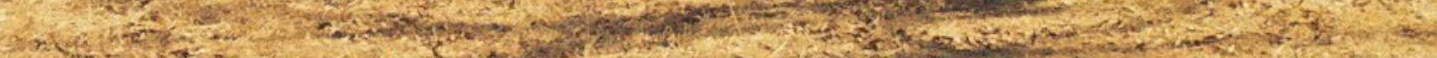




\section{$2.7 \quad$ SITE VISIT}

The journey to the Homeward Bound mining remnants was a pivotal moment in this research investigation, allowing me to truly understand the immense scale of the historical artefacts and landscape scars.

To get there was another matter.

It required a flight to Queenstown, a 1-1/2 hour drive along an icy 4WD track (including 23 river crossings) and finally a one hour hike to reach the stamper battery - and then back again, in the middle of winter. We slipped on black ice, almost submerged the truck, dropped the film camera (nearly compromising the film) and made it back just as the sun was setting.

This trip was one of the best experiences of my life and would not have been possible without Abhie, Maddy, Matt and Scott—-thank you so much.

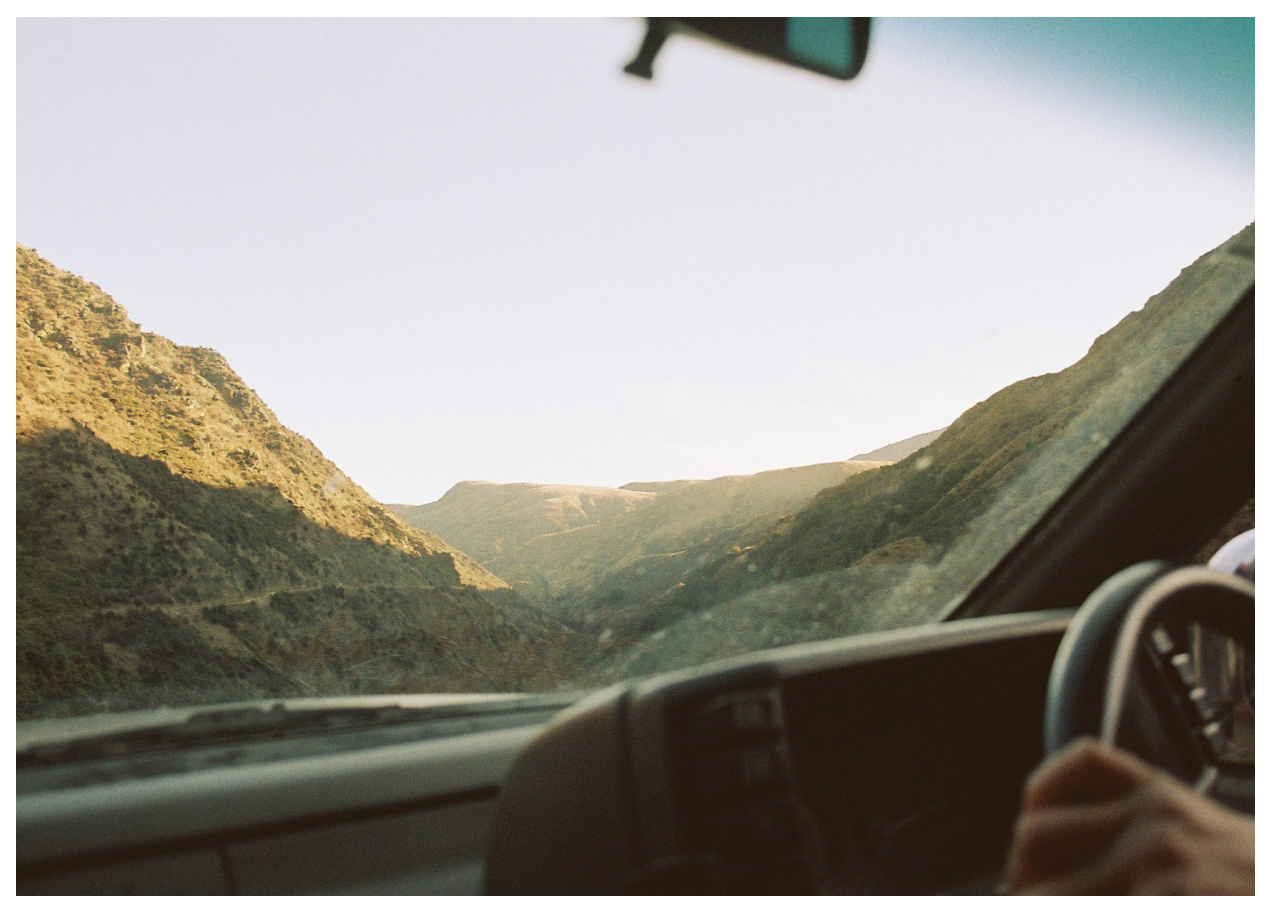

Fig 2.10.b Heading deep into the golden hills 
The site as received is never cleared or empty; indeed it is not possible for the architect to clear the site of its own constituent formal content. ... The site is a work, a human or social trace. It is comparable to a myth, temple, or city in that it is open to archaeological deciphering

—Carol J. Burns, On Site: Architectural Preoccupations, 1991 
Fig 2.10.d Scaling the ridge behind the stamper battery, fragments of the cableway visible in the forefront.
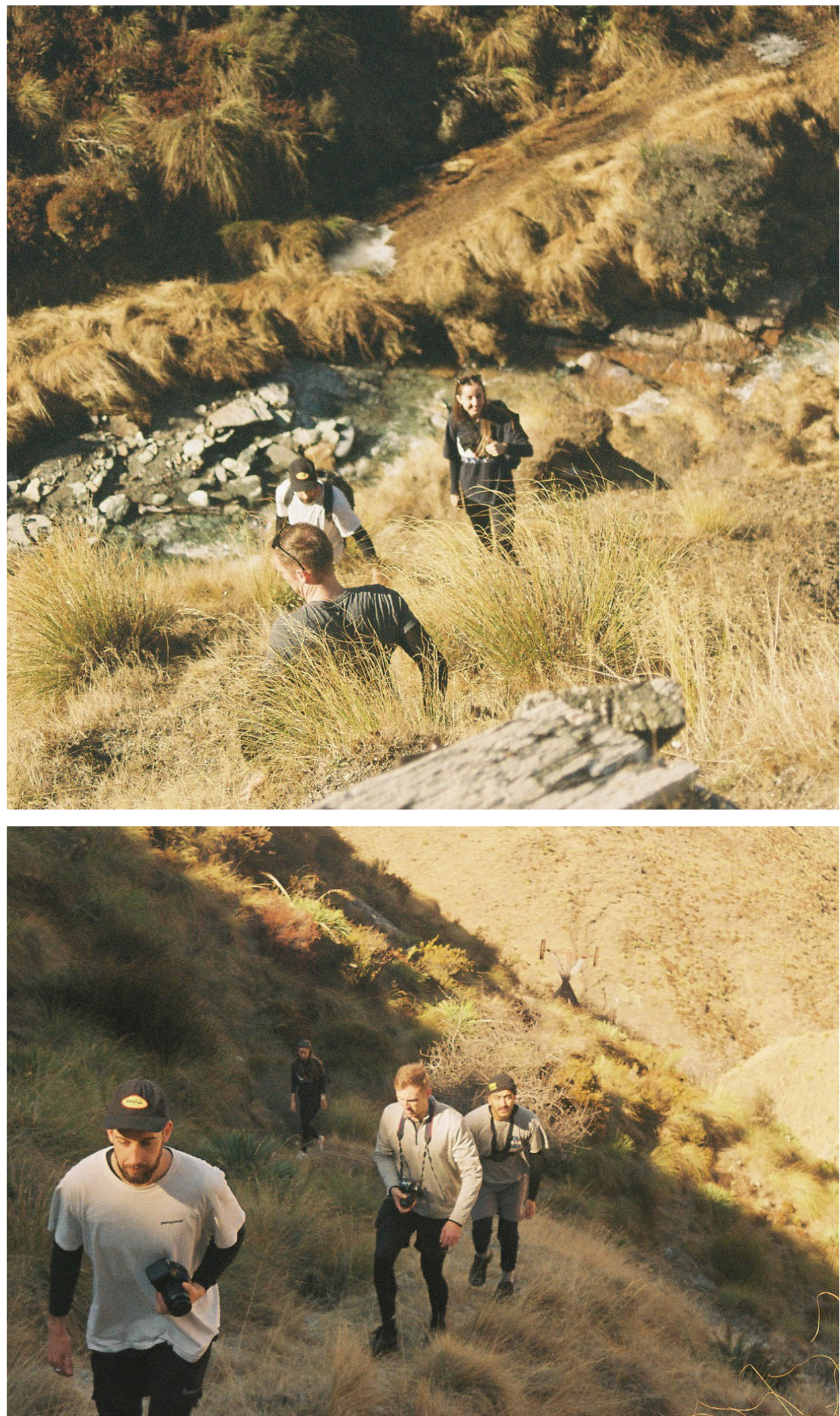

Fig 2.10.e Following the old cableway trail up to the mineshaft. 


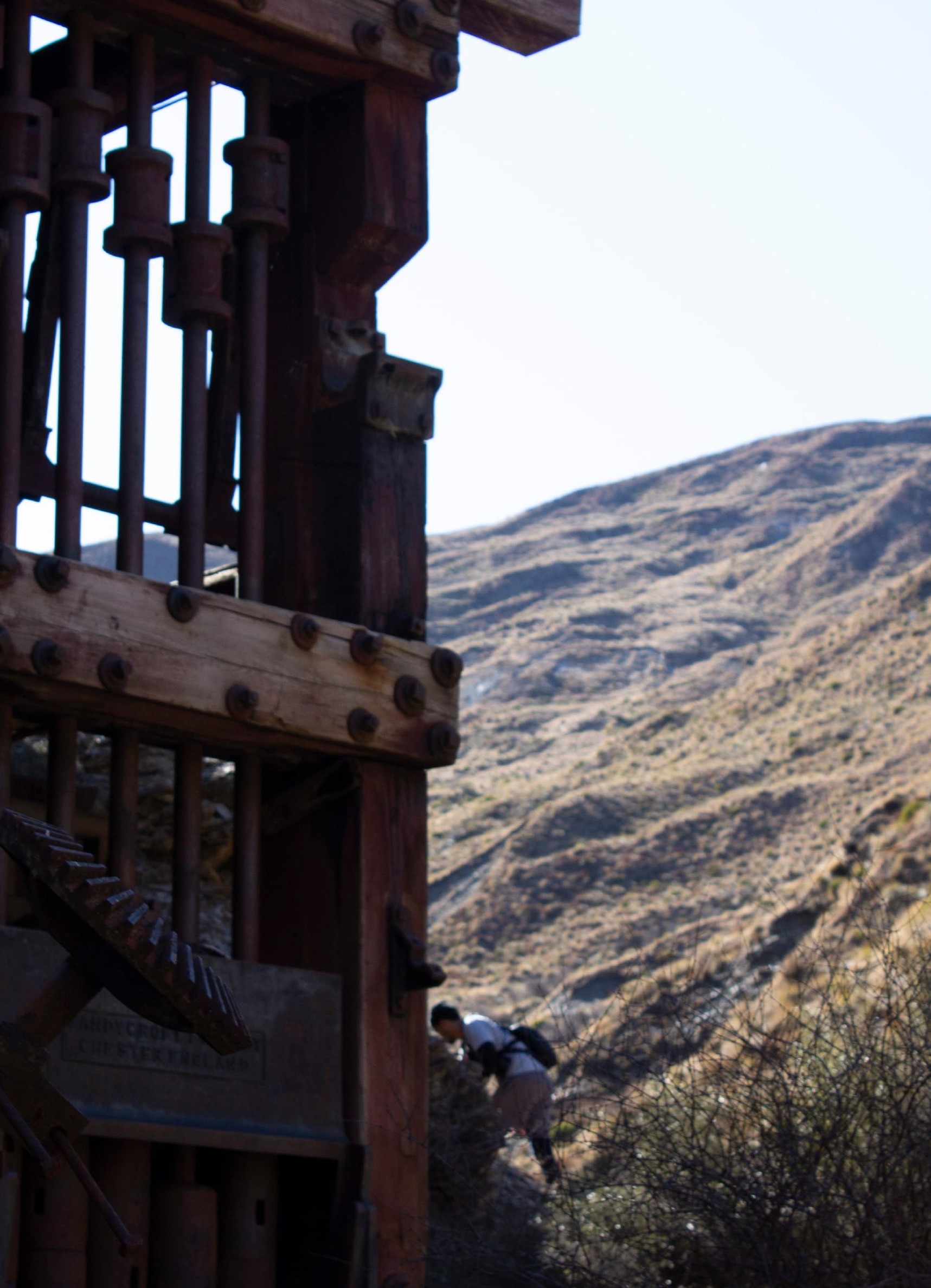




\subsection{CRITICAL REFLECTION}

Investigation into the historical context of the Homeward Bound site combined with a first-hand site visit and documentation unveiled a complex and rich narrative. Seven different remnants of the goldmining process are identified as unique fragments that can be pieced together to reconstruct the narrative of site. Within this narrative a conflict of environmental systems and man-made systems has emerged, with each remnant belonging to one dialectic faction or another and thus having a different perspective on the site's story.

Each of these remnants will also have their own unique story to tell as they are situated in different places with varying lifespans within the confrontational meta-narrative of site - with some stories taking place over years and others over centuries. To preserve this complex heritage story, an allegorical architectural project can be developed that interrogates each of these points of view over varying passages of time. 


\section{4}

You, who have just crossed the Roof of the World, will not want to hear an account of the little hills that I saw - low colourless hills. But to me they were living and the turf that covered them was a skin, under which their muscles rippled, and I felt that those hills had called with incalculable force to men in the past, and that men had loved them. Now they sleep - perhaps for ever. 


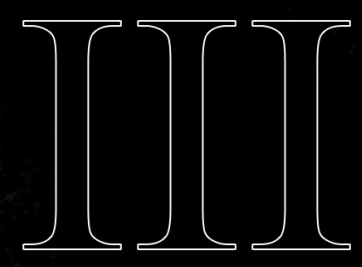

\section{LITERATURE \& PROJECT REVIEW}

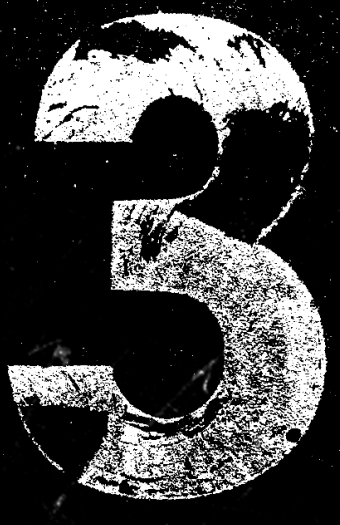




\section{LITERATURE \& PROJECT REVIEW}

\subsection{INTRODUCTION}

\subsection{SPECULATIVE DRAWING STRATEGIES}

3.2.1 Preserving the Past and Speculating on the Future

3.2.2 Transformation Over Time

3.2.3 Narratives from Fragments

\subsection{ORTHOGRAPHIC DRAWING}

3.3.1 Confrontation within an Allegorical Narrative

3.3.2 Environmental versus Man-made Confrontations

3.3.3 Confrontation through Orthographic Drawing

\subsection{NOTATION STRATEGIES AND DEVICES}

3.4.1 Traditional Notation Devices

3.4.2 Notations in Speculative Drawing

3.4.3 Notations and Transformation Over Time

3.4.4 Dual Responsibility of Notation

\subsection{LAYERING TECHNIQUES}

3.5.1 Layering Fragments

3.5.2 Overlapping and Transparency

\subsection{CRITICAL REFLECTION}




\subsection{INTRODUCTION}

This chapter discusses principal theorists and interrogates relevant case studies in relation to the Research Aim and the three principal Research Objectives. These theories are integrated to help frame a theoretical argument, providing a method as well as a strategic framework for the interrogation of the site. This investigation employs the Allegorical Architectural Project as a critical method of interrogation, using speculative architectural drawing as a strategic framework to unravel the narrative of site.

In her article "The Fall: The Allegorical Architectural Project as a Critical Method", Penelope Haralambidou, Associate Professor and Director of Communications at the Bartlett School of Architecture, defines allegory as saying one thing and meaning another. She proposes the allegorical architectural project as an alternative critical method that engages a dialogue between literary text and architectural drawing to articulate something 'other'-inviting imaginative, open-ended interpretation of a narrative propositon (Haralambidou, 2007). This method will be used to interrogate and extract the underlying syntax of this investigation's proposed site, inviting critical reflection on a complex and dialectic narrative.

This investigation proposes to apply Haralambidou's method of interrogation of a site using speculative architectural drawing as its primary outcome. Orthographic drawing is initially used to establish critical relationships between fragments, extracting narrative from the dialogues between them. Notational devices are then employed to establish relationships of time, place and point of view. In the final stage, layering techniques are used to invite simultaneous interpretation of these relationships. Theorists and case studies relating to these strategies (speculative drawing, orthographic drawing, notation strategies, and layering techniques) are analysed sequentially in this chapter to help establish the theoretical foundation of this design-led research investigation. 


\section{6}

The world you want to live in...

is not the world you see

but the world you build out of what you see.

-Northrop Frye, The Educated Imagination, 7 


\subsection{SPECULATIVE DRAWING STRATEGIES}

Preserving the Past and Speculating on the Future

Transformation over Time

Narratives from Fragments

This section of the Literature and Project Review discusses theoretical arguments in relation to the Research Aim:

To explore how, through speculative architectural drawing, an allegorical architectural project can be used as a critical method to help preserve heritage stories that are destined to be lost.

The Research Aim is addressed by critically reflecting on theoretical arguments that interrogate speculative drawing as a methodology that can be used to help preserve essential narratives of the past, while speculating on the future. To achieve this goal, speculative drawings acknowledge transformation over time and the importance of acknowledging narrative fragments. 


\subsubsection{PRESERVING THE PAST \\ AND \\ SPECULATING ON THE FUTURE}

In his article "London Short Stories: Drawing Narratives", C. J. Lim, Professor of Architecture and Urbanism at the Bartlett School of Architecture, writes about how traditional architectural drawing practice is designed to prevent ambiguity or various interpretations through a strict system of notation (Lim, 104). He considers that while this is a strength of traditional drawing, especially in regard to construction, it is also a weakness - where the reality of the image is so plausible that no interpretation of the architecture is needed. Lim argues that representation can be more than just an outcome, highlighting the importance of speculative drawing in the conceptual design process as a valid alternative to traditional practice methods.

Mark Smout, Professor of Architecture and Landscape Futures, and Laura Allen, Professor of Architecture and Augmented Landscapes at the Bartlett School of Architecture, describe how drawing acts as "a speculative method with which to examine the dynamic force of environmental and architectural processes" (Smout \& Allen, 2013). They argue, similar to Lim, that speculative drawing simultaneously generates and informs design-while having the dual function of examining and narrating the 'spectacular' qualities of site.

Neil Spiller, Deputy Pro-Vice Chancellor of the University of Greenwich, builds on the theory of speculative drawing practice, highlighting its importance to the future of architecture. Spiller defines architecture as the manipulation of space in all its manifestations, which can be both imagined and graphically represented. He argues it can be a vital tool that allows one to draw across time and space, interrogating the future of the virtual and sustainable world through architecture (Spiller, 2016, 146).

Time-based sensitivities are mixed in the cauldron of the virtual world, seen by augmented eyes enhanced by dimensions of chronological slippage, coalescing in a digital dance above and beyond the pragmatics of actuality. 
Another approach to speculative drawing is discussed by Perry Kulper, architect and Associate Professor at the University of Michigan's Taubman College of Architecture, who describes his speculative drawings as populated with "...errant trajectories [and] illicit behaviours..." (Kulper, 63) that are fundamental to the conversations they make possible. He argues that the misalignments, unresolved thoughts and imperfections offer alternative relational and spatial possibilities often missed in traditional drawing practice. These descriptions can be translated into further methods for this investigation's speculative drawing interrogations such as extending beyond the page, embracing imperfections and incorporating enigmatic qualities into drawings.

A case study exemplar of time-based speculative architecture is the 1984 project Victims by the late American architect and educator John Hejduk. The architect's proposal for the memorial park in Berlin was comprised of 67 structures, each representing a 'character' who inhabits the site. Designed to be constructed over 60 years, the citizens of Berlin were invited to choose which structures were built, with the 'characters' becoming subject to the ravages of time and nature - each new piece a momentarily spotless member of the evolving space before ultimately lapsing into decay.

This notion of characters' transformations over time is celebrated by Hejduk through the embrace of natural decay and the identification of absence/erasure. He describes the project as follows:

... architectural tracings are apparitions, outlines, figments. They are not diagrams but ghosts. Tracings are similar to X-rays, they penetrate internally. Erasures imply former existences. Drawings and tracings are like the hands of the blind touching surfaces of the face in order to understand a sense of volume, depth and penetration. The lead of an architect's pencil disappears (drawn away) / metamorphoses / To take a site: present tracings, outlines, figments, apparitions, X-rays of thoughts. Meditations on the sense of erasures. To fabricate a construction of time / To draw out by compacting in / To flood (liquid densification) / The placesite with missing letters and disappeared signatures / To gelatize forgetfulness (Hejduk, 2006, 167).

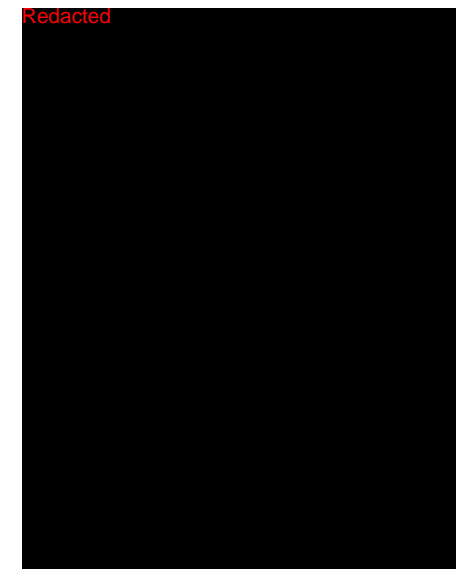

Fig 3.2.1 John Hejduk, Victims, 1984

Hejduk's use of allegory has direct relation to architectural drawing techniques such as erasure, tracing, outlines and x-ray [layering], thus translating time-based architectural methods from a character-inhabited project into speculative drawing techniques. 


\subsubsection{TRANSFORMATION OVER TIME}

In relation to his project Victims Hejduk proposed these speculative architectural drawing techniques in relation to a real world project. Simon Herron, Academic Leader in Architecture at the University of Greenwich, discusses achieving similar aims and objectives in relation to paper-based architecture. He argues that a sequence of drawings can enable the architectural vessel to be perceived as transforming over time, where the host terrain of paper becomes a record of this through shadow and light (Herron, 2013). Therefore the shading throughout a series of drawings becomes another method of speculative drawing to activate a site's narrative, enabling our understanding of the transformation of time through the morphing of shadows. Figure 3.2.2 shows a concept sketch by author exploring Herron's theoretical argument in relation to the Homeward Bound stamper battery site.

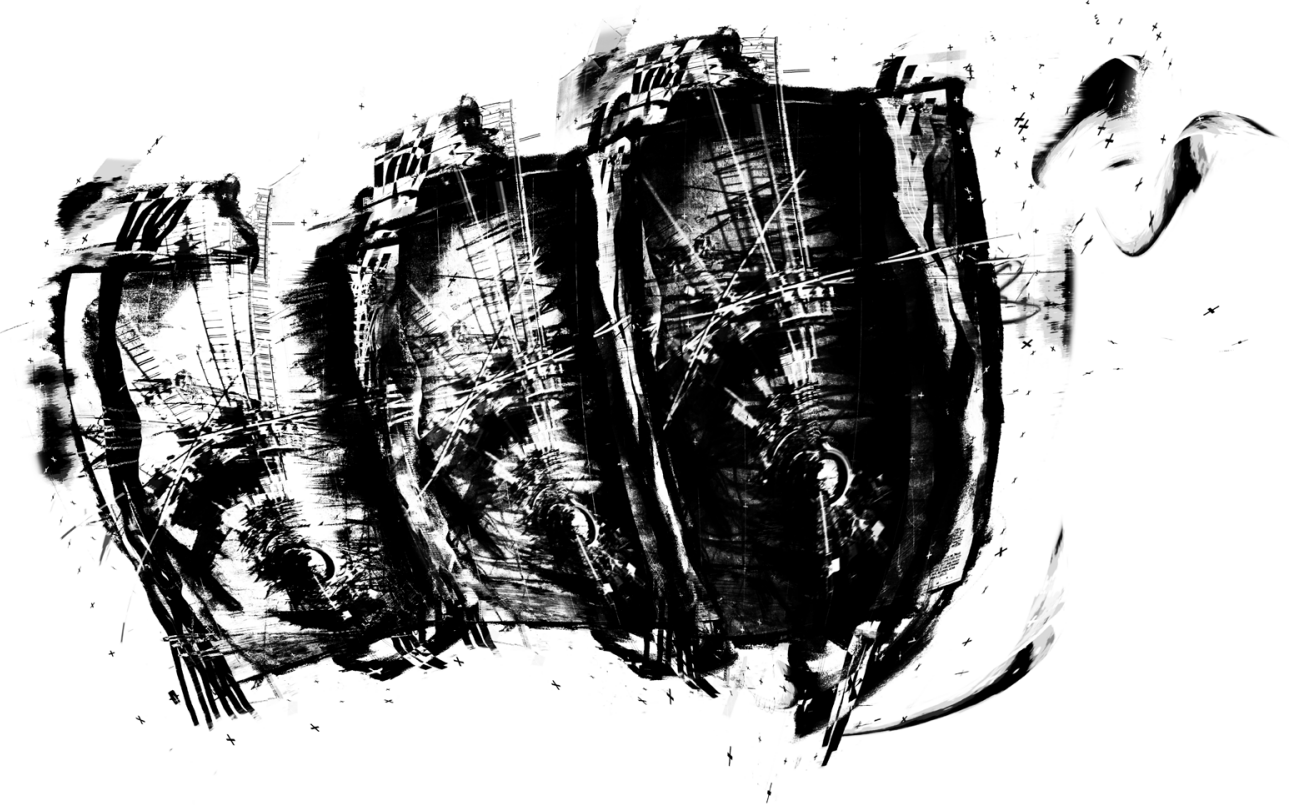

Fig 3.2.2 Transformation over time experiment, shadows growing and redrawn, by author.

Michael Hara, former award-winning student at the Architectural Association in London, discusses how drawings can capture a moment in time, when presenting them as temporal phenomena that are constantly shifting (Hara, 2010). Hara interrogates this state of flux by drawing it and redrawing it, in an effort to illustrate the subject's transformation over time. 


\subsubsection{NARRATIVE FROM FRAGMENTS}

American architect and urbanist Fred Koetter reflects that the realm of conscious and unconscious speculation (which he defines as the 'inbetween') is where fragments are intermingled with ideas, dissected and then reassembled-forming an amalgamation of memory, values and intentions (Koetter, 71). Koetter's theory suggests that the remnants of site can be brought into confrontation in this 'in-between' thresholdexploring their point of view within the meta-narrative of site and enabling their voices to be heard.

A case study example of incomplete fragments being brought together to impart a dialectic narrative is Oritsunagumono by artist Takayuki Hori. Translucent sheets are printed with fragments of animal skeletons or pieces of pollutants they have ingested, and then re-assembled using origami to recreate the three-dimensional form.

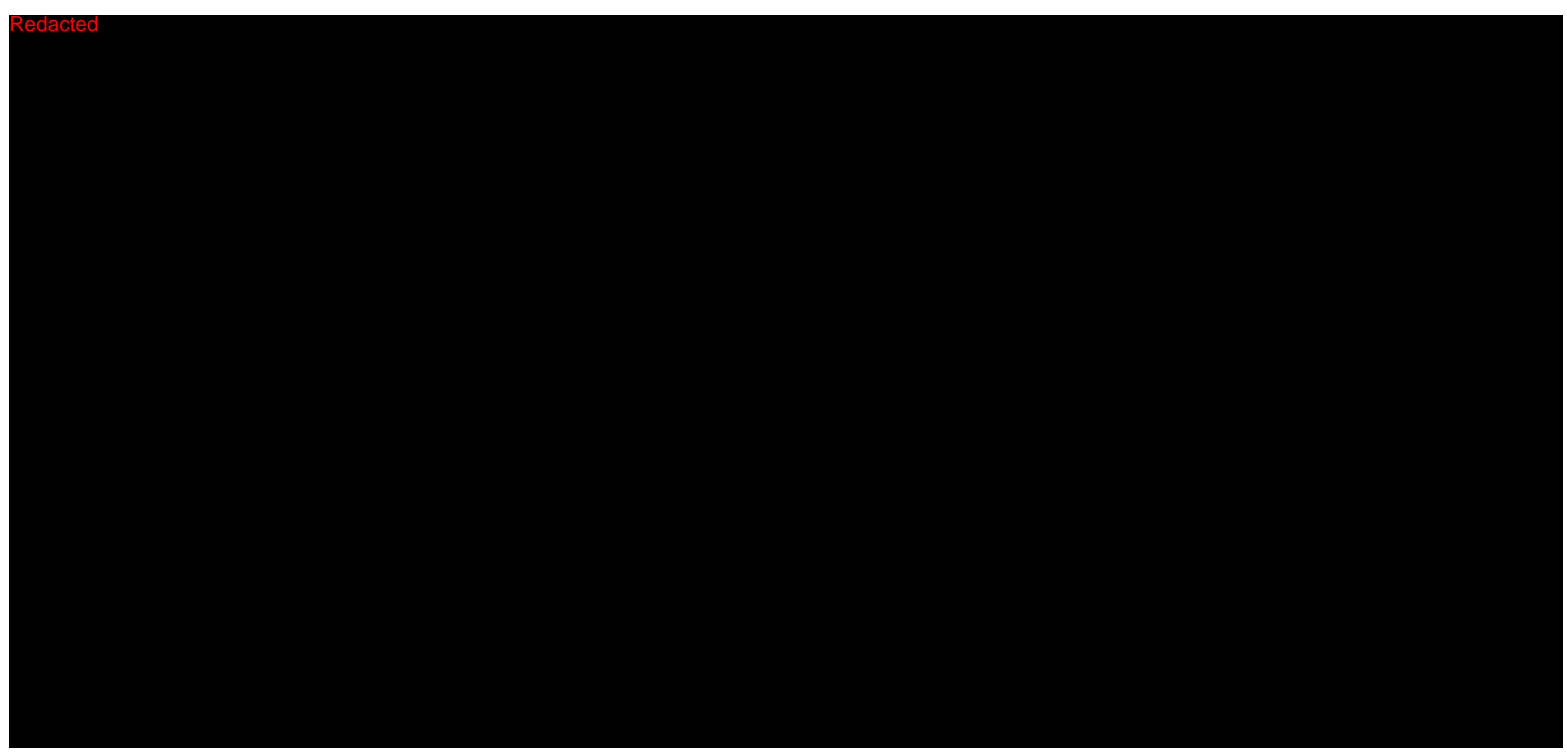

The result is forms that are totally removed from their original context, situated as incomplete 'ghosts' that invite users to imagine and reflect on the tragic narrative underlying the artwork and establishing its allegorical intent.

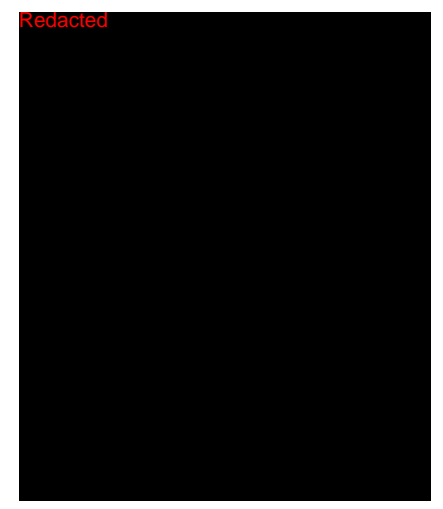




\section{6}

In drawing, there is confrontation... To confront is not always a hostile act. To confront is also an act of comparison, of consideration. 


\subsection{ORTHOGRAPHIC DRAWING}

Confrontation within an Allegorical Narrative

Environmental versus Man-made Confrontations

Confrontation through Orthographic Drawing

This section of the Literature and Project review discusses theoretical arguments and case studies in relation to Research Objective 1:

To explore how orthographic drawing can help establish critical relationships within a dialectic narrative.

This Research Objective is addressed in three sections. Each builds upon one another and helps establish a method for speculative drawing to reawaken the dialectic heritage stories of site. Many of the theorists discussed in this chapter are also architectural designers, which therefore invites case studies to be selected and examined that represent how their theoretical arguments have been translated into design outcomes. 


\subsubsection{CONFRONTATION WITHIN AN \\ ALLEGORICAL NARRATIVE}

American literary critic Angus Fletcher argues that allegorical narratives can be categorised as either a 'battle' or 'progress' (Fletcher, 147). The confrontation between environmental and man-made systems that forms the basis of the research site's narrative can therefore be seen as a 'battle', where the allegory is conveyed through the dialectical interactions of opposing forces.

Raimund Abraham, Austrian architect and Professor at the Cooper Union School of Art and Architecture, discusses how the manifestation of memory of a spatial event from the history of site is idealised through the language of architectural elements (Abraham, 101). He describes how these elements become the catalyst for our process of remembering through a "process of dialectical confrontation: equilibrium through tension", suggesting that the narrative of site is most poignantly expressed through confrontation.

When writing about his Danteum (1938-1943) proposal for Rome, Italian architect Giuseppe Terragni argued that when architecture and literature share a structure or harmonic rule, they can be positioned as a confrontation, unveiling a relationship of parallelism or subordination (Terragni, 97). This relationship provides a framework to explore the other confrontations within a narrative by expressing them as oppositions.

A relevant case study that evidences how narrative can be achieved by bringing fragments into confrontation across time is the Castelvecchio Museum by Italian architect Carlo Scarpa. During this 1964 restoration, Scarpa unveiled various pieces of the castle's layered history dating back to 1356 , before carefully curating them into his architectural and exhibition outcomes. The balance of heritage restoration and modern intervention enables the voices of fragments to be heard as individuals, in dialogue with others, and within the meta-narrative of the castle's history. 


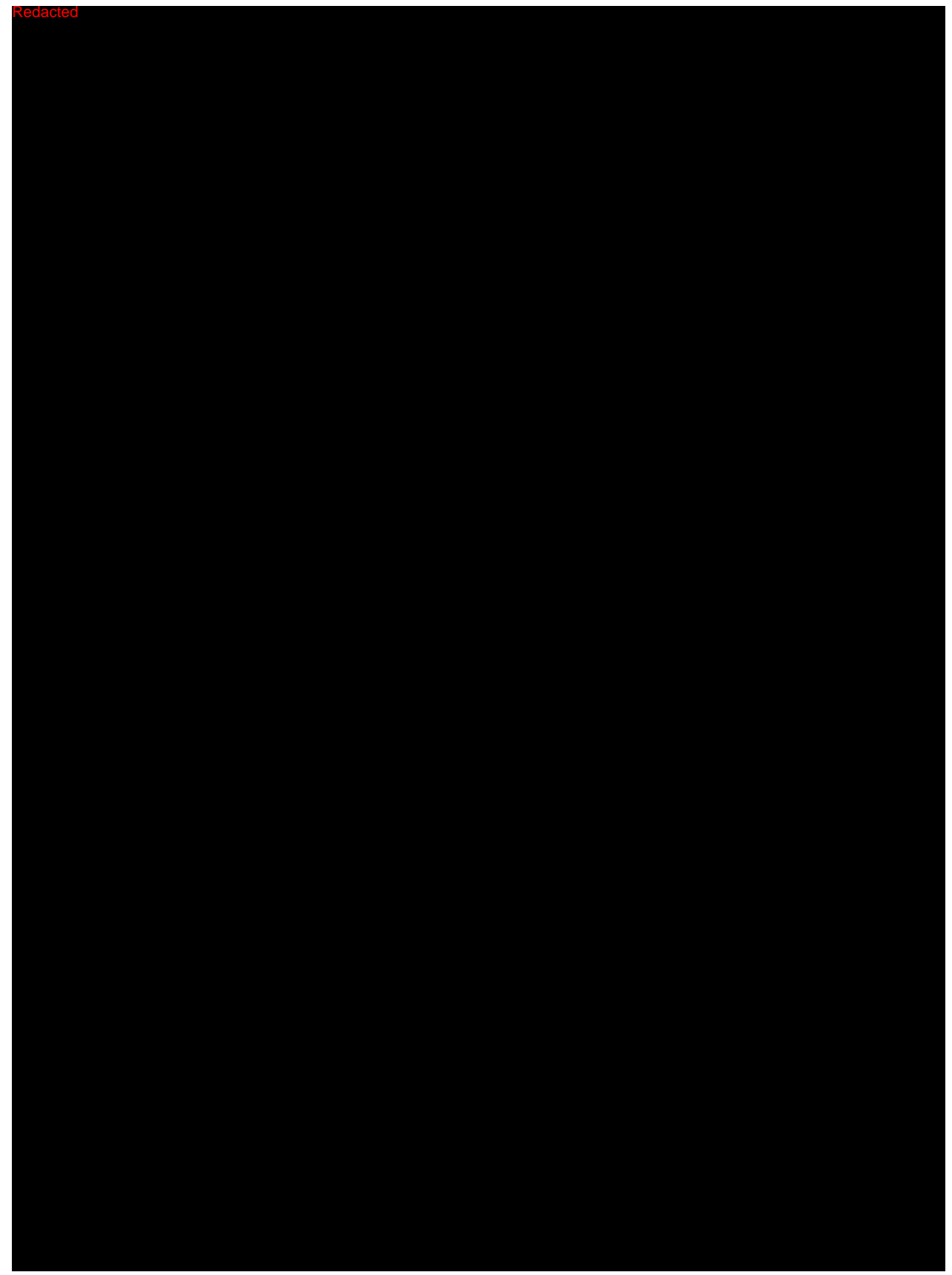




\subsubsection{ENVIRONMENTAL VERSUS \\ MAN-MADE CONFRONTATIONS}

Finnish photographic designer and theorist Ilkka Halso reflects upon the confrontation of nature and the man-made, the overarching narrative of the Homeward Bound site in this design-led research investigation.

Halso's speculative design (Figure 3.3.2) approach demonstrates how confrontations between man-made and environmental systems that are investigated through the artefacts and transformations to ecological systems, where natural and man-made [machine] elements are placed in a balance of subordination to inform the dialectic narrative.

In my vision countryside is a thousand-year old remnant of the battle and co-operation between man and nature. Man shapes the land with mechanic devises (sic) to serve his own purposes and aims to create an order based on his utilitarian tendencies. Only gradually does nature, in all its diversity repossess the temporary order governed by man... Cultural marks, imprinted on land by man, manifest themselves in numerous ways. Man leaves behind him various objects and articles, waste matter, constructions and cultivated plants run wild, or he initiates less desirable processes such as erosion, pollution, and land drainage (Halso, 1994).

Georg Simmel, sociologist, philosopher and critic, also addresses the confrontation of the built environment and nature. He argues that when a building transitions to a ruin, nature's reclamation allows a new, romanticised unity to emerge (Simmel, 1958). Thus the confrontation of nature and decay draws directly from the man-made versus nature, with architecture ultimately subordinating to the environmental systems.

A relevant speculative drawing case study that interrogates the confrontation between natural versus man-made systems is Neil Spiller's Nighttime in the Frustum. The first of the three plates depicts architectural forms on the lower half with organic foliage situated in the top half just starting to grow over the architecture. The second plate shows the foliage growing further out and over the drawing, concluding with half of the final plate consumed in dark organic growth - the architectural forms now at risk of being lost to the reclaiming forces of nature. Spiller's project uses notation devices, transforming line work and a range of scales and orientations, as techniques to depict the allegory of confrontation between natural versus man-made systems through representation. 


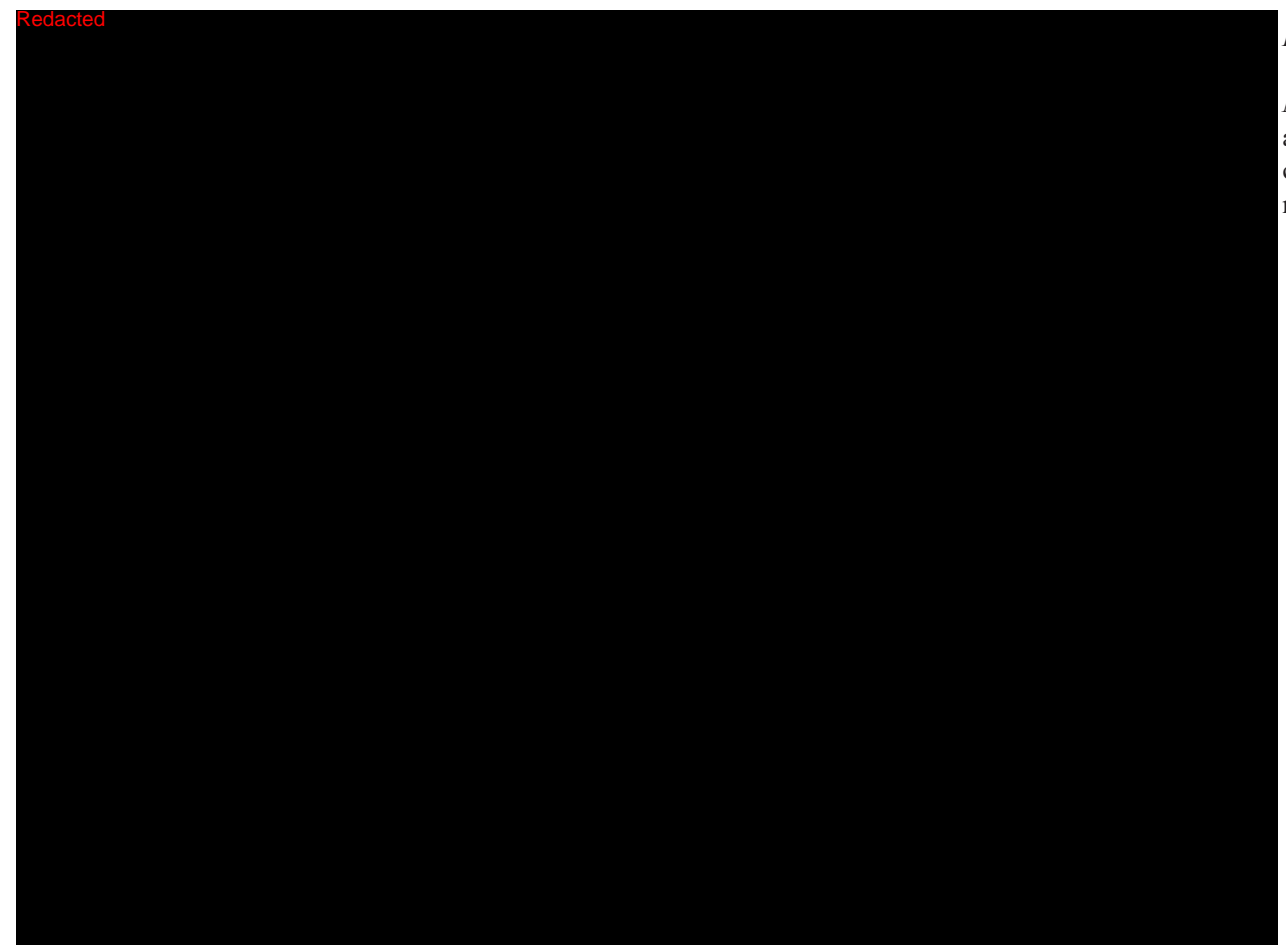

Fig 3.3.2

Museum of Nature: Speculative

allegorical design showing the

confrontation between man and

nature, Ilkka Halso, 2000

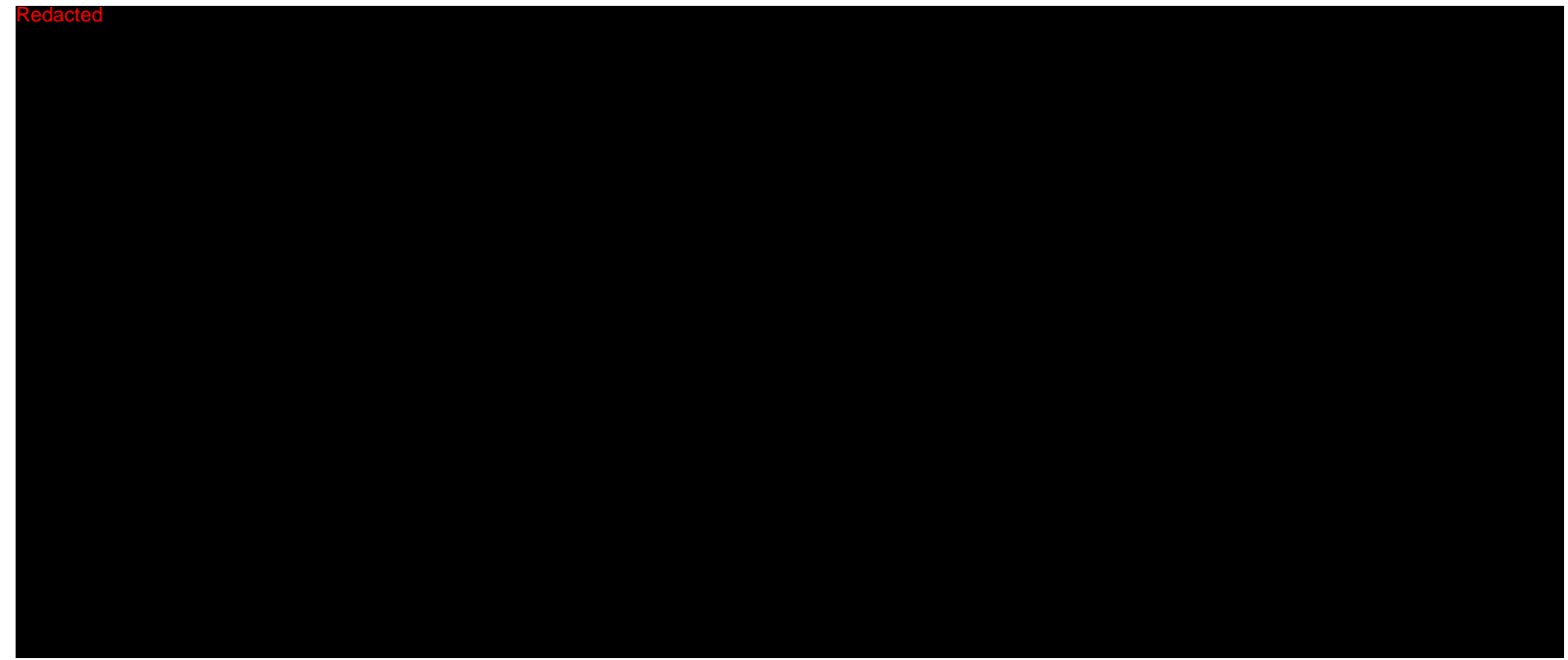

Fig 3.3.3 Night time in the Frustrum 1, 2 \& 3, Neil Spiller, 2014 


\subsubsection{CONFRONTATION THROUGH ORTHOGRAPHIC DRAWING}

In his article "The Art of Drawing", architectural theorist and historian Mario Carpo argues that despite the rise in digital methods of representation, analogue drawings are still an essential method of architectural interrogation. He reflects that they provide an important way to record and transmit visual ideas, possessing a unique capacity to suggest an alternative to the present by speculating on the past and / or future (Carpo, 129).

Stan Allen, American architect, theorist and former Dean of Princeton University School of Architecture, discusses how parallel projection is used as an important investigative method when questions of measurability, prediction and verifiability arise. He explicitly highlights axonometric representation as a method that communicates truthfully. It is primarily concerned with construction and consistency of measurement, with its distanced point of view enabling the subject to be freely rotated, dismantled and reconstructed (Allen, 19). Allen's proposition is examined in this thesis as a way to interrogate the fragmented remnants on site, exploring their relationships through consistent spatial representation.

In her essay "Drawing Lines of Confrontation", Associate Professor at the University of Calgary School of Architecture, Planning and Landscape Catherine Hamel discusses the role of drawing as an investigative method of confrontation. Hamel compares architectural drawing and lines of confrontation in warfare, suggesting that they both work through acts of demarcation, geographical knowledge, and staging, where opposing ideologies and contexts meet (Hamel, 202). By integrating Carpo and Allen's theoretical arguments, lines of confrontation are explored in this thesis's design chapters through the use of projections and axonometric drawing techniques.

Raimund Abraham's 1974 project The Cosmology of the House applies speculative axonometric drawing techniques to bring both architectural and landscape elements into confrontation. Sited on a rectangular plane, Abraham curates a combination of elements to situate them into critical dialogues. He uses projection lines in some areas to bring elements into direct confrontation, while others are staged to face one another. This allegorical approach enables the viewer to interpret these relationships of confrontation and understand the meta-narrative of the drawing through the axonometric configurations and notation relationships. 
64

If perspective, dependent on a fixed point of view, seemed to freeze time and motion, the atopical space of axonometric suggested a continuous space in which elements are in constant motion.

-Stan Allen, 2000, 19 


\section{4}

An abstract machine in itself is not physical or corporeal, any more than it is semiotic; it is diagrammatic... It operates by matter, not by substance; by function, not by form... The diagrammatic or abstract machine does not function to represent, even something real, but rather constructs a real that is yet to come, a new type of reality.

—Gillies Deleuze and Félix Guattari, A Thousand Plateaus : Capitalism and Schizophrenia, 141 


\subsection{NOTATION STRATEGIES AND DEVICES}

Traditional Notation Devices

Notations in Speculative Drawing

Notations and Transformation over Time

Dual Responsibilities of Notation

This section of the Literature and Project review builds on theoretical arguments in relation to Research Objective 1 and discusses then in relation to Research Objective 2:

To explore how architectural notation strategies and devices can be used to establish allegorical relationships relating to time, place and point of view.

This Research Objective is addressed in three sections that build upon one another and help to establish a method for speculative drawing to reawaken the dialectic heritage stories of site. 


\subsubsection{TRADITIONAL NOTATION DEVICES}

A number of speculative architectural theorists such as Stan Allen, Neil Spiller, Mas Yendo, Bryan Cantley and James Corner employ notation explicitly as a device to propel an allegorical project.

Stan Allen, architect and Dean of the School of Architecture at Princeton University, discusses how architectural drawings work notationallysimilar to musical scores, codes or scripts. He describes them as 'abstract machines' that are not necessarily reductive or abstract, but rather act as a language of spatial and material elements that can be decoded into a realisation (Allen, 2009). He discusses notations in relation to five principal working definitions;

ANTICIPATION
INVISIBLE
TIME
COLLECTIVE
DIGITAL DIAGRAM

Notations that typically describe a work that is yet to be realised

Notations that go beyond the visual to engage invisible aspects of architecture

Notations that include time as a variable

Notations that presume a social context and shared conventions of interpretation

Notations that work through difference, not resemblance

Allen argues that, because the experience of architecture can never be totally predicted by representational drawing, notations can be used to work across gaps of time and space to facilitate the experiential or the imaginary. He suggests that the less representational the drawing, the better it is able to communicate the complexity and unpredictability of the real-with notations being essential language to bridge these two worlds.

The ability of a notational language to work across time and space transforms the nature of the narrative of site. Narrative landscape theorists Matthew Potteiger and Jamie Purinton reflect that there are three conditions of visual narratives, what they refer to as 'representing time in spatial form': a single point in time (frozen moment), a linear narrative (series of individual episodes), and a continuous narrative (representing a passage of time) (Potteiger \& Purinton, 7). This design-led research investigation examines through a series of design experiments how Potteiger and Purinton's approach to representing time and spatial form can be interrogated in relation to Stan Allen's approach to notation as spatial and material elements that can be decoded into a realisation. 


\subsubsection{NOTATIONS}

IN

\section{SPECULATIVE DRAWING}

Bryan Cantley, Professor of Design Theory at California State University and founder of Form:uLA, discusses the role of notation in speculative architectural drawing, theorising how a speculative drawing can draw upon itself. Cantley argues that this creates a cyclical process of interrogation, where the drawing simultaneously creates and critically reflects on itself, resulting in a series of narrative drawings that invites a multiplicity of interpretations (Cantley, 2018, 51).

He describes three conditions of notation used in traditional drawing practice that can be evolved into a new drawing typology he labels Taxonometric Drawing (C)

\begin{tabular}{l|l}
$\begin{array}{l}\text { DENOTATION } \\
\text { (Object) }\end{array}$ & State the objective and architectural object. \\
$\begin{array}{l}\text { CONNOTATION } \\
\text { (Environment) }\end{array}$ & $\begin{array}{l}\text { Interpret existing and new meanings of said ontological artefacts. } \\
\begin{array}{l}\text { ANNOTATION } \\
\text { (Residue) }\end{array}\end{array}$ \\
$\begin{array}{l}\text { Continuously record the observations and said interpretations onto and into the } \\
\text { surface of the drawing itself, as the drawing continues to evolve. }\end{array}$
\end{tabular}

By applying these three working conditions in this method, Cantley argues that this allows notational devices to be interpreted with equal importance to the architectural object. This is shown throughout his portfolio of work and in particular in his interrogation of his project Hybriddrawings $($ C (Figure 3.4.2), which illustrates notation devices integrated into the architectural form itself.

By integrating notational devices with the architectural object, the drawing is able to enter a self-reflective evolution that explores relationships of time, place and point of view. Traditional and familiar notations can be redrawn and developed into a unique language that occupies the liminal space between architecture and representation. In this 'in-between' space described earlier by Fred Koetter, notation devices and architectural form begin to blur and overlap, enabling relationships of contradiction and conflict to be evidenced. This will be essential in this investigation when seeking design outcomes that represent a dialectic confrontation between natural and man-made systems. 


\subsubsection{NOTATIONS}

AND

TRANSFORMATION OVER TIME

As discussed previously, Hamel argues that projection lines of axonometric drawings can be used to establish relationships of confrontation. In his essay "Drawing and Making in the Landscape Medium", landscape architect James Corner reflects that some systems of projection belong to a family of drawing called notation-a system that identifies parts of a schema, enabling them to be reproduced or performed (Corner, 174). He uses philosopher Nelson Goodman's definition of notation as schemes that employ a symbol system that is "syntactically differentiated within unambiguous and finite parameters." (Goodman, 1968). Corner argues that these systems are not only used for their communication status, but also for enabling the "simultaneous understanding of various layers of experience, including movement and time" (Corner, 2014) - suggesting a language of notation can be used as a speculative drawing tool to establish relationships across time.

Speculative architect Masahiko Yendo's project UL-9304/Living Unit illustrates the use of notation to inform transformation over time. Even though the project already embodies an aesthetic of decay over time, Yendo presents the model from eight different perspectives, underscoring it with two timelines on the $\mathrm{X}$ and $\mathrm{Y}$ axis that evidence compression and decay. By manipulating a standard notation of ruled measurements, Yendo implies that the design is destined to decay through his representation of notation - enabling the allegorical project to be understood as a dynamic continuous narrative representing a passage of time (Yendo, 2001).

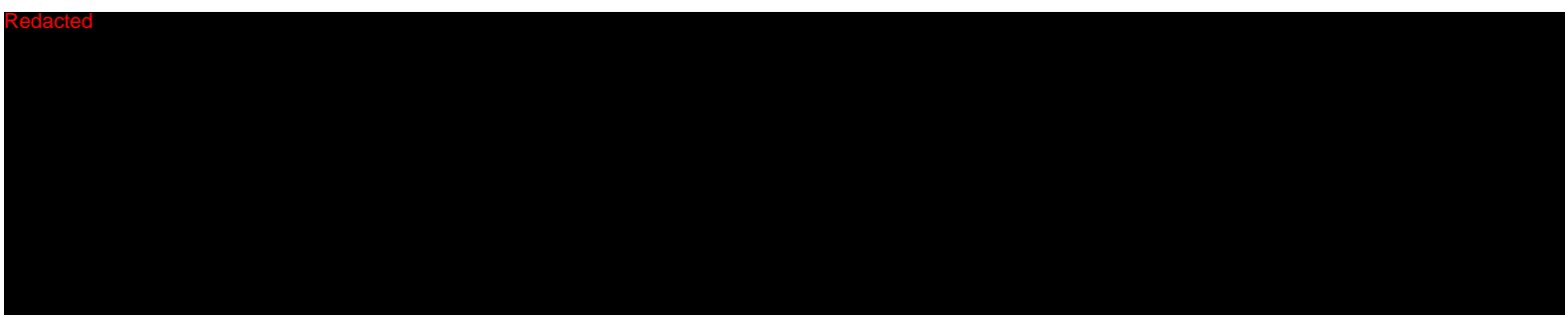


Bryan Cantley includes extensive use of notation in his speculative architectural drawings, and he writes about the use of notation in speculative architecture. His project Hybriddrawings $(\mathrm{C}$ develops 3D forms from 2D drawings, where notations such as reference and section markers that begin as notation are evolved into the architecture itself-blurring the end of the drawing and the start of the building (Cantley, 2011, 54). The drawings do not try to inform a set of building instructions; instead the cyclical process manifests itself as a fluid, boundaryless, unpredictable environment that is timeless - capturing the narrative while simultaneously inviting infinite interpretation.

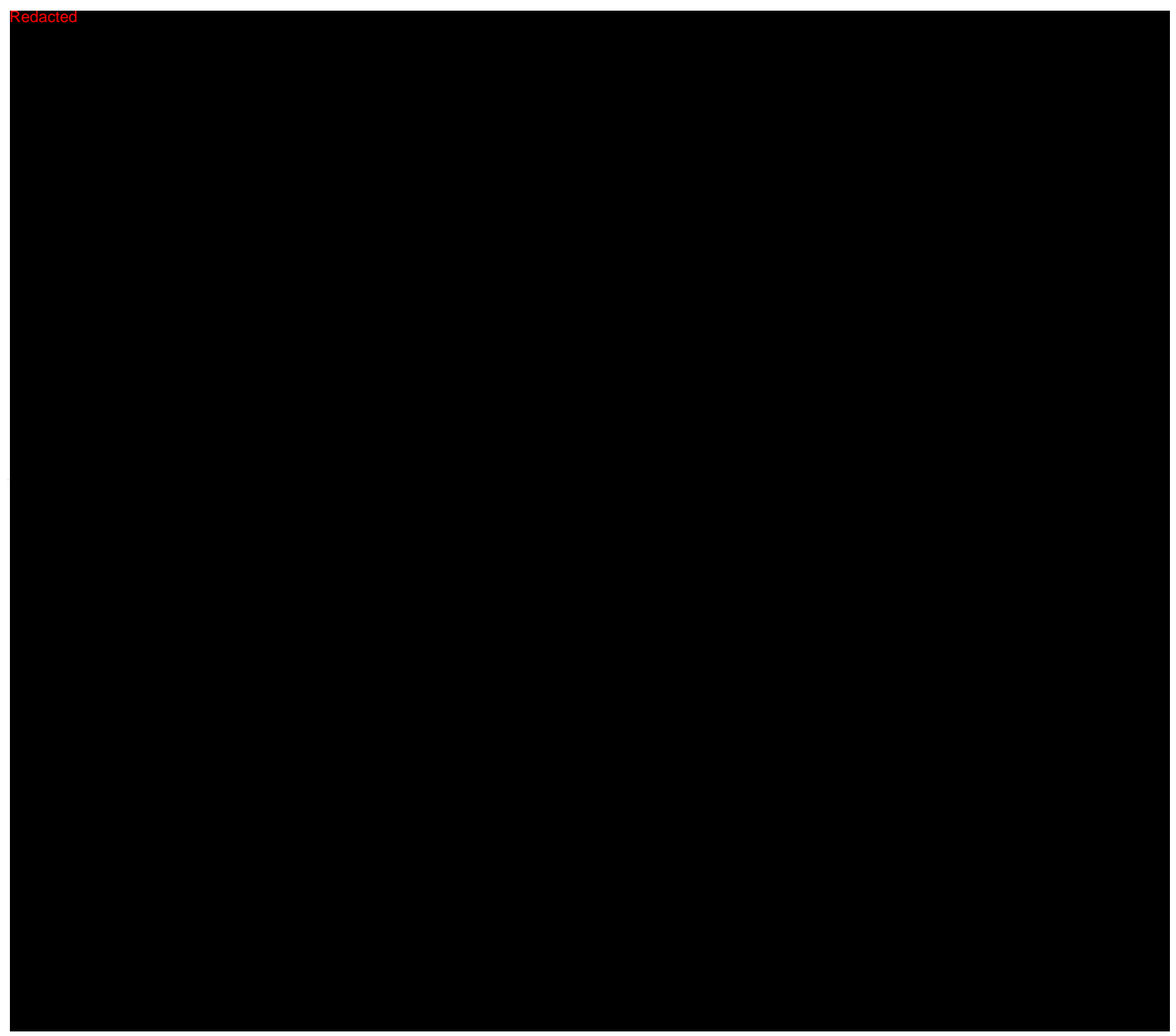




\subsubsection{DUAL RESPONSIBILITIES \\ OF \\ NOTATION}

64

... architectural notations are/were generally intended as a method of filling out the readings and disclosure of a text or objects within a drawing. They lent completeness in the sense that they represent both denotation (indications of sizes, geometries, heights, materialities, etc.) of an object and keys to said object's interpretations as an entity that extends beyond its limits of self-representation...

—Bryan Cantley, “Towards a Taxonometric Architecture: D-con: an”, 53

In application to speculative drawing, notation therefore becomes an important tool to enable narratives to extend and transform over a passage of time. James Corner reflects that notations enable unambiguous interpretation of a drawing while also inviting the viewer into "...the realm of myth and poetry wherein things make sense and ring true without necessarily being explicit or accountable" (Corner, 188). In this way notations have a dual responsibility in speculative drawing, which can be used to invite imaginative interpretation of a narrative.

Neil Spiller's drawing The Object Besides Itself embodies a combination of Yendo and Cantley's notational techniques, resulting in an abstracted speculative project that uses unique symbols to evidence its narrative. Spiller employs two main devices: the linear timeline and the fluid dashed line (shown in fig 3.4.3). The horizontal timeline acts as a measuring device, marked with characters at various positions that evolve as they move towards the future. These characters are linked by a fluid dashed line, which acts as a datum to inform (map) their moments of transformation and movement through the passage of time. While these notational devices are abstracted, they are also familiar and thus interpretable, inviting the viewer to understand the narrative using their own imagination - the notation establishing relationships of time, place and points of view simultaneously. 


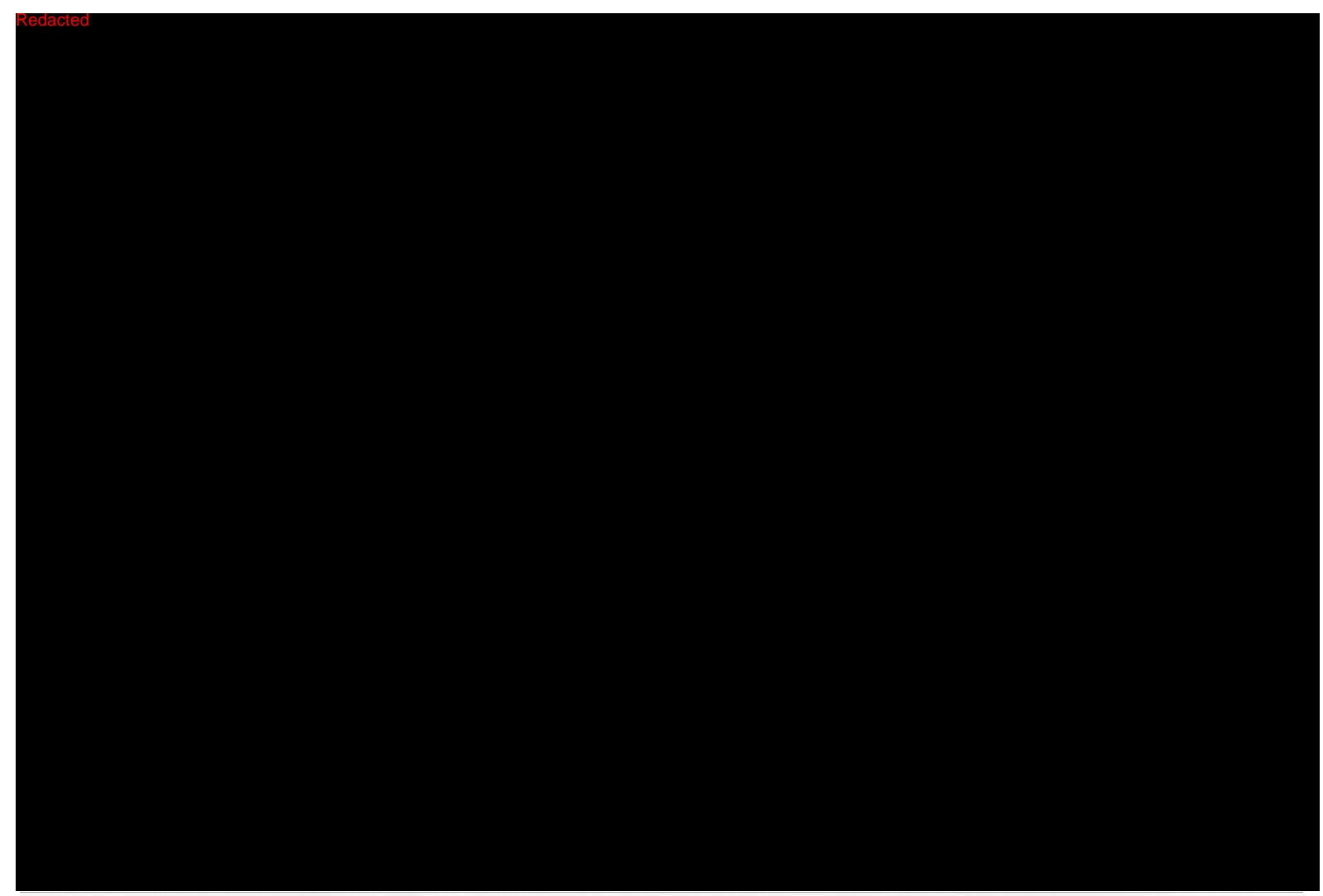

Fig 3.4.3 The Object Bedside Itself, Neil Spiller, 1998 


\section{6}

Architectural tracing is also more than transcriptive. It plays an important part in the design process; layers and layers of butter paper are built up, traced over, scribbled on and retraced. Tracing is a site of inventiveness as well as apparently simple transcription.

—Justine Clark, Drawing on Architecture : Gender, Subjectivity, Surface 


\subsection{LAYERING TECHNIQUES}

Layering Fragments

Overlapping and Transparency

This section of the Literature and Project review builds upon the theoretical arguments discussed in relation to Research Objectives 1 and 2 and interrogates them further in relation to Research Objective 3:

To explore how layering allegorical drawings can enable relationships of time, place and point of view to be simultaneously recognised as an overall metanarrative.

This Research Objective is addressed in two sections that build upon one another and help to establish a method for speculative drawing to reawaken the dialectic heritage stories of site. 


\subsubsection{LAYERING FRAGMENTS}

In her book Carlo Scarpa Layers, Anne-Catrin Schultz defines layering in architectural drawing as stratification, meaning the superposition and apposition of layers of material. She argues that the process of layering separates individual planes, which are able to embody their own narrative meaning as well as simultaneously contribute to the meta-narrative of the composition. In relation to Research Objective 3, this suggests that layering can enable relationships of confrontation to be understood in relation to an individual context, as well as multiple integrated contexts.

66 If one spatial form obstructs our view of another form, we do not assume that the second ceases to exist because it is hidden. We recognize, as we look at such overlapping figures, that the first or uppermost has two spatial meanings-itself and beneath itself.

Australian architect and heritage consultant Jennifer Hill discusses stratification in relation to the physical layers of history in heritage buildings. She reflects that heritage restorations that remove unnecessary obstructing elements and unveil the previous layers of history are thereby able to allow each transformation to be seen within the metanarrative of the building's ongoing evolution (Hill, 2004). Allowing the layered fragments of history to co-exist highlights relationships between each transformation as well as conveying the passage of time through the multiplicity of layers.

Simon Herron, Lecturer at the Bartlett School of Architecture, discusses reconstruction of fragments in terms of layered drawings. He argues that removing the original context destabilises the image's anticipated composition - assembling, re-cutting, realigning and rescaling the pieces until the final image is presented in a 'delicate incompleteness' (Herron, 98). This incompleteness then invites the viewer to fill the gaps between the fragments with their own imagination, reflections and speculations - enabling a deeper engagement while experiencing the narrative of multiple fragments simultaneously. 
American architect and theorist Stan Allen reflects on the reassembly of fragments in relation to montage or collage drawings. He argues that montages are comprised of elements spread across time and space, and composing them together can therefore join their historical and cultural connotations through direct confrontation.

In his article discussing allegorical architectural designer Douglas Darden's drawing techniques, Peter Schneider, Professor of Architecture at the University of Colorado, argues that drawing is an architect's unique mode of research and is often the location of crucial speculation (Schneider, 2007). Schneider highlights Darden's preliminary drawing process involving layering information such as formal explorations, materials and photographic imagery on sheets of yellow trace paper.

Figure 3.5.1 from Darden's speculative project Sex Shop illustrates how his layering techniques form 'visual fields', allowing information representing different times and places to be seen at once. This speculative drawing technique composes fragments into a comprehensible narrative, engaging viewers through a range of artefacts.

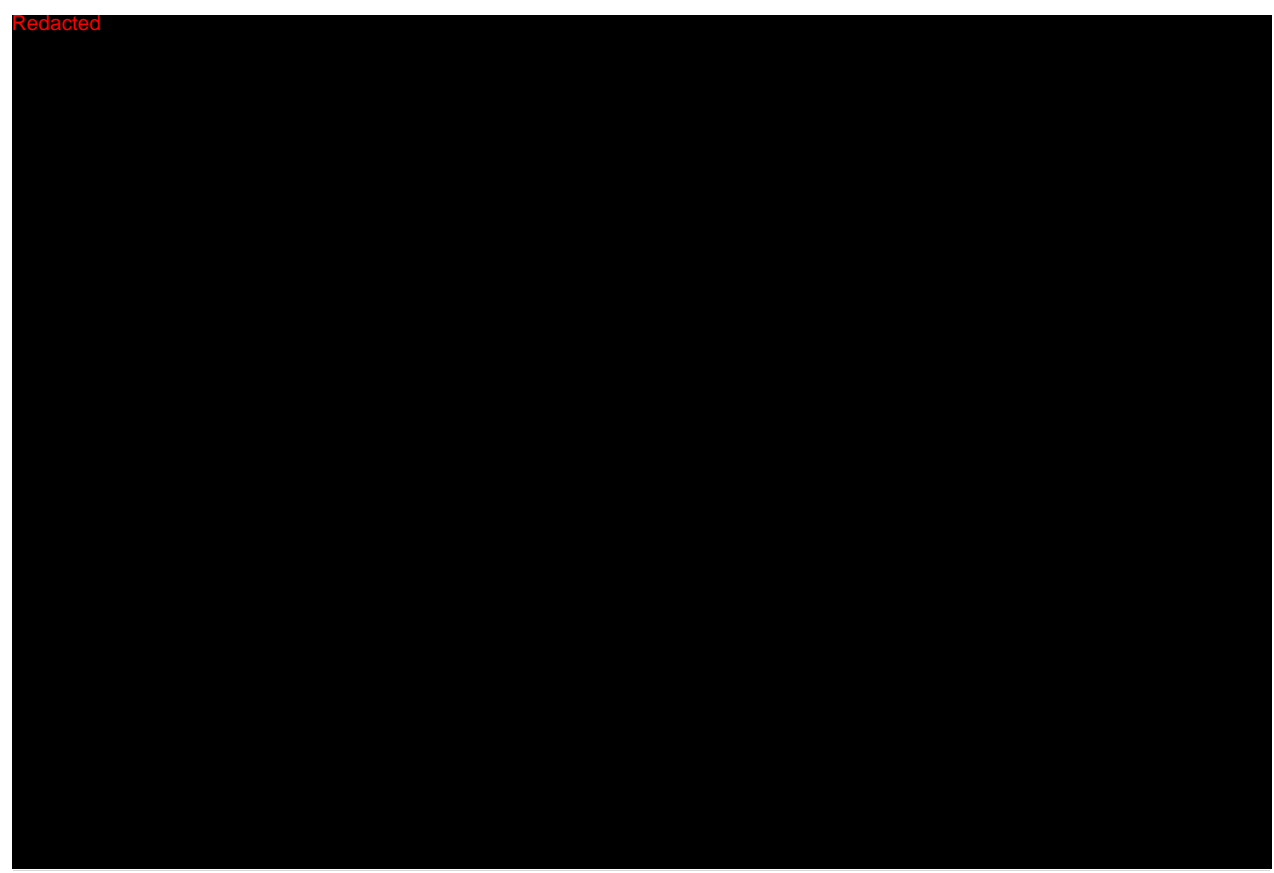

Fig 3.5.1 Layering fragments in a drawing, Sex Shop, Douglas Darden, 1995 


\subsubsection{OVERLAPPING \\ AND \\ TRANSPARENCY}

In her discussion of layered drawing techniques, Anne-Catrin Schultz identifies the role of transparency to allow the composition to be experienced as a whole. She argues that the placement of one layer in relation to other layers determines the extent of the effect, where overlapping planes merge material qualities, information and narrative - enabling the viewer to perceive depth and thus a new spatial relationship (Schultz, 13). Schultz quotes artist, educator and art theorist Gyorgy Kepes in describing the application of this approach:

64

Transparency means a simultaneous perception of different spatial locations. Space not only recedes but fluctuates in a continuous activity. The position of the transparent figures has equivocal meaning as one sees each figure now as the closer, now as the further one.

— Gyorgy Kepes, Language of Vision, 1969, 13

This suggests that the layering of fragments using transparent drawings can allow one layer to be the focus while others are still seen (at a distance) simultaneously.

The role of transparency in layering can be seen in artist Nobuhiro Nakanishi's Layer Drawings installation. By suspending each semitransparent layer vertically, the viewer is able to understand both the layers behind as well as their spatial relationship to each other. This allows the images in the immediate vicinity to blur into a single composition, while the fluid nature of the rest of the images hints at different relationships - forcing the viewer to walk along a timeline to experience the entire narrative. 


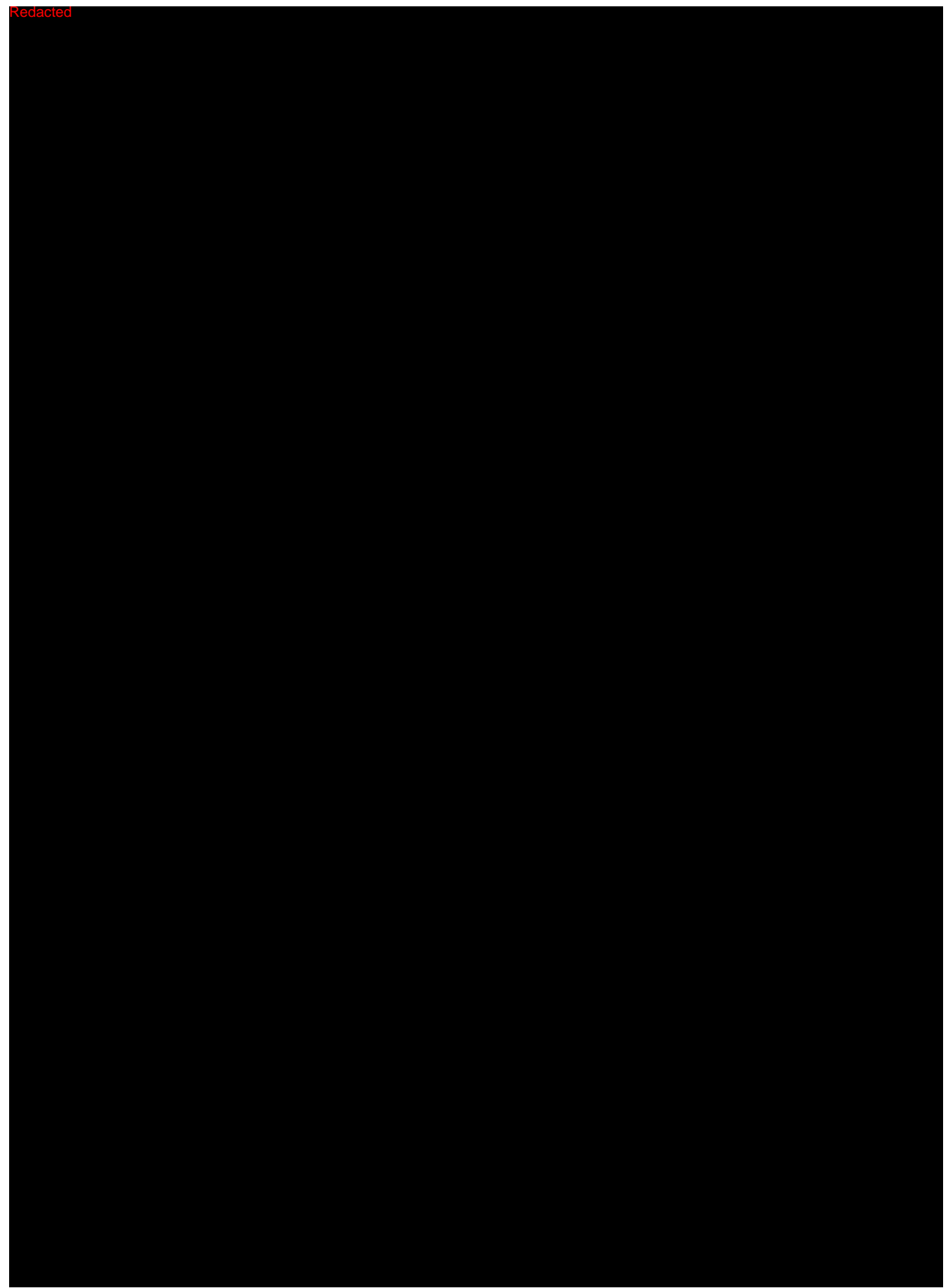

Fig 3.5.2 Layer Drawings using transperancy to create spatial relationships, Nobuhiro Nakanishi, 2005 
Fig 3.6 Industrial fragments decaying in a tailings deposit, outside of Macetown, August 2020, photo by author.

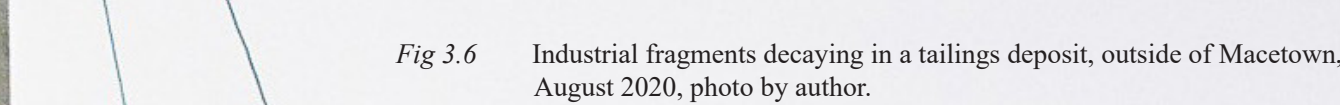




\subsection{CRITICAL REFLECTION}

In this chapter, principal theorists were discussed and relevant case studies were interrogated in relation to the Research Aim and the three principal Research Objectives. The chapter outlined Penelope Haralambidou's concept of the "Allegorical Architectural Project" as a primary framework, with a speculative drawing strategy being proposed as a method to interrogate, extract, and evidence the narrative of site as an allegorical architectural project.

Theorists' arguments in relation to the speculative drawing strategy have reflected its ability to preserve the past while simultaneously speculating on the future, to enable an understanding of transformation over time using paper-based architecture, and to reconstruct a fragmented narrative-preserving its story even if the fragments are not complete. Within the speculative drawing strategy, orthographic drawing emerged as a principal method to establish critical relationships of fragments within a dialectic narrative. By placing fragments in confrontation with each other, their relationships can be explored further, in the case of this thesis investigation while reflecting the allegorical confrontation between environmental and man-made systems. To illustrate this using drawing, the axonometric and the plan are both investigated, due to their ability to place fragments in a dialogue of confrontation.

With critical relationships established through plan and axonometric drawing, relationships of time, place and point of view are also required to explore a multi-layered narrative in detail. The development of a notational language is proposed to enable the speculative drawing interrogations to work across time and space. The notational language is then integrated into the drawings in a cyclical process, creating drawings that blur and overlap representation and architecture to invite allegorical interpretation of the relationships between individual fragments.

Techniques of layering are then proposed to allow the simultaneous experience of these relationships of time, place and point of view through three methods: the layering of fragments to create 'visual fields' that tell the entire story of each artefact at once, the use of overlapping to represent parts of stories in relation to each other, and the strategic implementation of transparency to prioritise certain narratives even while the others are experienced simultaneously.

In the next chapter of the thesis, Concept Design, individual stories of the site's narrative will be extracted and assigned notational representations. The later chapters of Preliminary Design and Developed Design will present further iterative experiments incorporating orthographic drawing, notational language and layering techniques as integrated learnings from the Literature and Project Review. 
46

But Humanity, in its desire for comfort, had over-reached itself. It had exploited the riches of nature too far. Quietly and complacently, it was sinking into decadence, and progress had come to mean the progress of the Machine.

—E.M. Forster, "THE MACHINE STOPS", P 15 of 19 

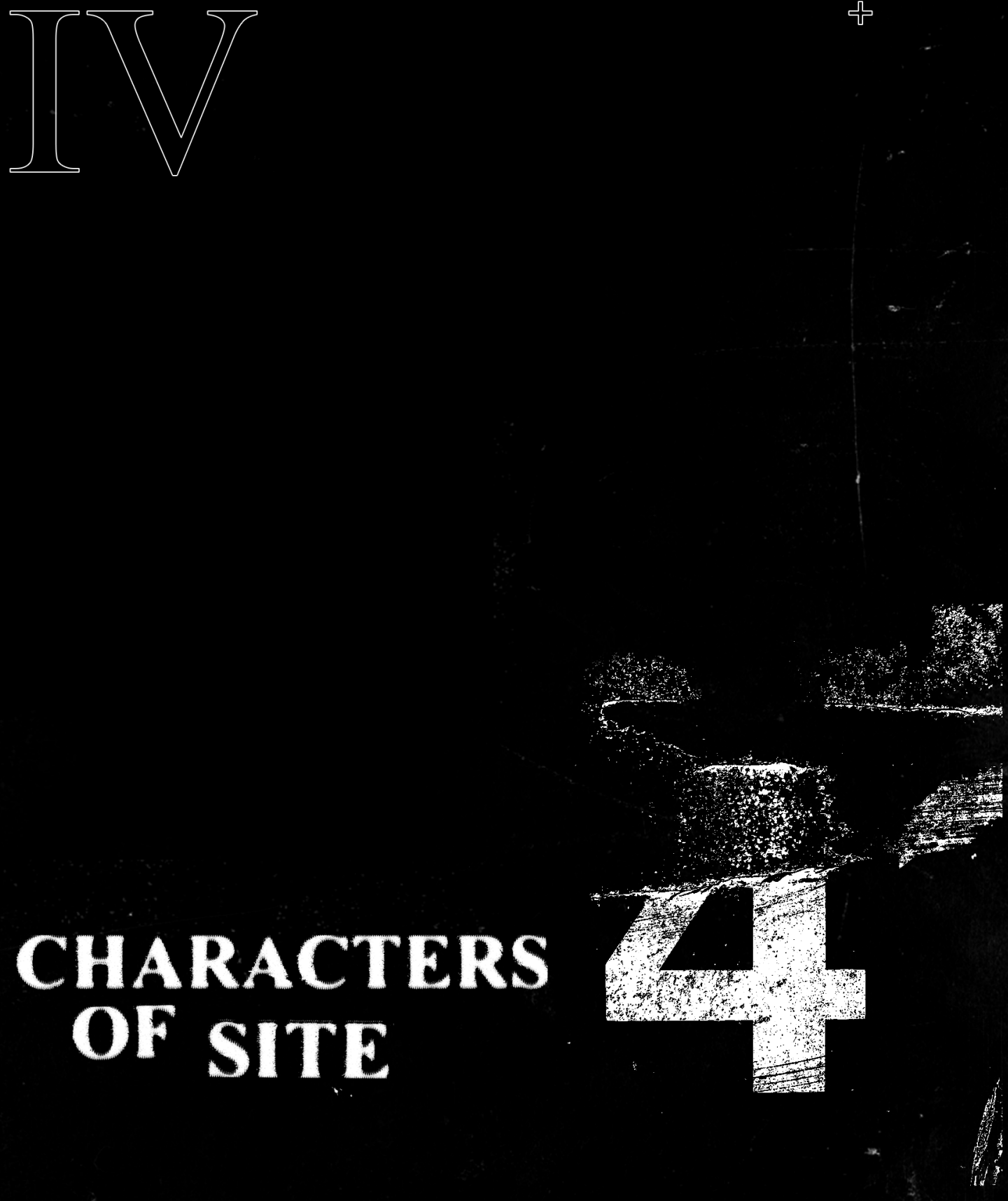
Fig 4.0 The Stamper Battery, Redirected Stream and Mountain all witnessed simultaneously, outside Macetown, August 2020, photo by author.

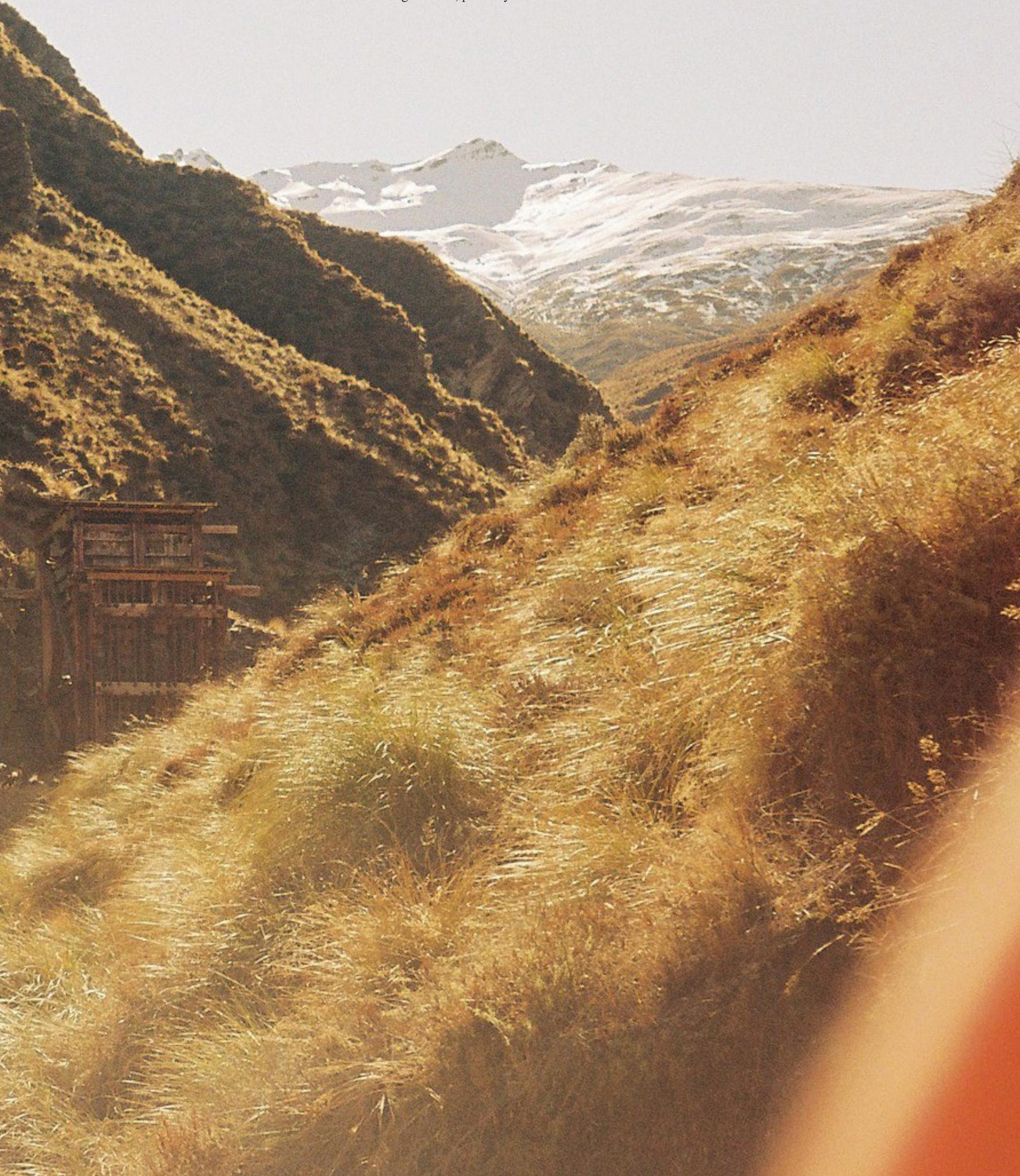


$+$

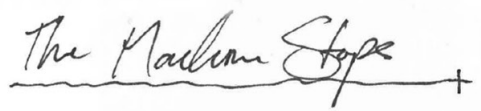

- shat stan broker nto 3 chaptar

1 The tirslop

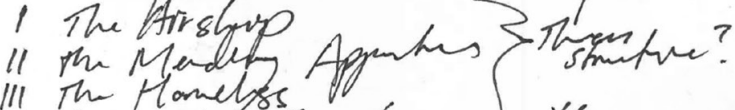

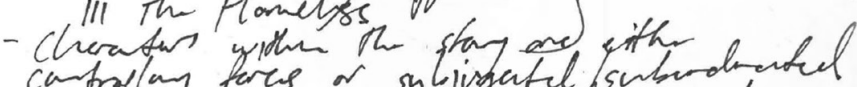

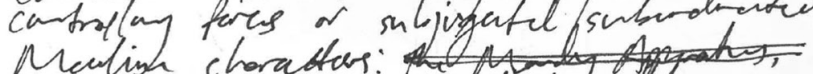

the sirshits, the ommipifut malome,

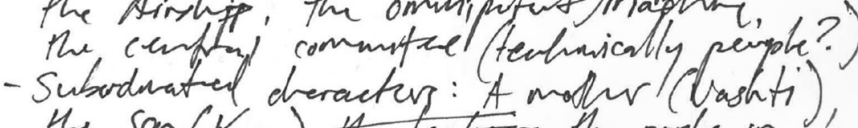

the son (Kuno), A tectanas, the popbe in

- Confranfoction bitmen th Machme e people Arship i moth Comitce s son

66 'The Maelian Ler beuse most merciful.'

"I prefar the revay of Gal.

- Mothar and son copreated materally, simila to the gafd a sechist as prountint bate hes contingation of 3

mecelion elements os 3 ratural elenats.

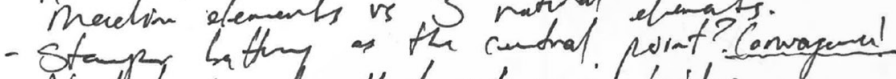

- Nenthal chroutar that asts or a lividge betwern the forctios $\longrightarrow$ the Book.

- Book of the Madian os the cantiat ratiral charactur just tike the staper Lotting. 
Fig 4.2 Sketch exploration of void and displacement.

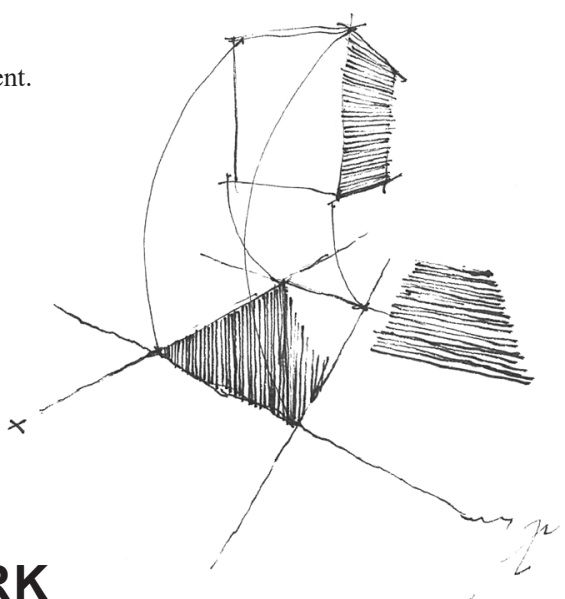

\subsection{ALLEGORICAL FRAMEWORK}

This chapter outlines the two allegorical frameworks applied to the Homeward Bound Site. The first uses E. M. Forster's short story "The Machine Stops" as a literary provocateur that explores the confrontation between controlling and subjugated characters. The second outlines how the remnants on site can be seen as 'characters' within an allegorical theatrical play, allowing visitors to witness their dialectic narrative of confrontation.

\subsubsection{ALLEGORICAL FRAMEWORK LITERARY PROVOCATEUR}

The allegorical framework of E.M. Forster's literary narrative "The Machine Stops" is centred around a 'confrontation' between two opposing points of view: the controlling forces and the subjugated people.

The controlling forces are represented by three principal characters: the Machine, the Air Ship, and the Central Committee. The subjugated people are represented by three principal characters: a mother (Vashti), her son (Kuno), and unnamed individuals in the background. A central element acts as the 'convergence point' where the two groups come together: the Book.

This design-led thesis investigation engages this framework taken from allegorical literary fiction to tell a similar story about the Homeward Bound site. It uses three main characters to represent the Man-made world, three main characters to represent the Natural World, and the Stamper Battery to represent the convergence point between these worlds. 


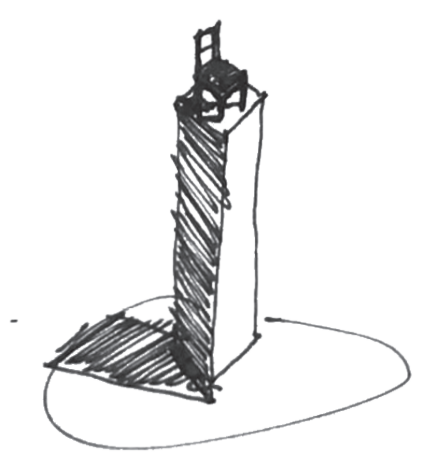

46

I can take any empty space and call it a bare stage. A man walks across this empty space, whilst someone else is watching him, and this is all that is needed for an act of theatre to be engaged.

—Peter Brook, The Empty Space: A Book About the Theatre: Deadly, Holy, Rough, Immediate, 1995 , 9 


\subsubsection{ALLEGORICAL FRAMEWORK THE STAGE SET}

Due to the large scale of the site and complex variety of narratives, an allegorical framework is used to help manage the interrogation of the remnants in relation to Research Objective 1:

To explore how orthographic drawing can help establish critical relationships within a dialectic narrative.

American literary critic Angus Fletcher sets out a structure for allegory that is established by either 'battle' or 'progress' (Fletcher, 1964). This design-led research investigation reflects on the allegorical narrative of the Homeward Bound site as a function of 'battle' or 'confrontation' - a dialectic narrative about the opposing viewpoints of mankind and nature.

As an allegorical confrontation, the investigation looks at the principal man-made and natural elements of this story as 'characters' in the dialectic narrative. Using speculative drawing techniques, the exploration anthropomorphises the seven main 'characters' allegorically as 'actors' in a play staged on a piece of drawing paper. Each actor plays a unique role in conveying the message of this 'morality play', and each actor's point of view is interrogated separately before exploring them all in a combination as one. Using speculative architectural drawing, their points of view are presented on the following pages, beginning with the voices of the three 'actors' representing natural remnants, followed by the Stamper Battery, and then the voices of the three 'actors' representing man-made remnants.

Natural Remnants of Remnants
Man-made Remnants $\left[\begin{array}{c}5 \\ 6 \\ 7\end{array}\right.$

The Mineshaft represents a Void, dug horizontally in the hill to reach the quartz veins within the landscape;

2 The Schist Tailings represent a Displacement of unwanted material from the rockcrushing process, which is discarded in piles on the valley floor;

3 The Redirected Stream represents a Deviation, redirected form its natural direction by the unwanted tailings discarded on the valley floor;

4 The Stamper Battery represents a Convergence point where natural resources and man-made systems met and mixed;

The Water Race represents a Cut dug horizontally in the hills to reach the quartz veins within the landscape;

6 The Aerial Cableway represents a Transition element; buckets of ore from the mine above were transported to the battery below by steel cables suspended over the steep landscape;

7 The Battery Footprint left behind when a previous stamper battery was swept away in a flood represents a Trace. 


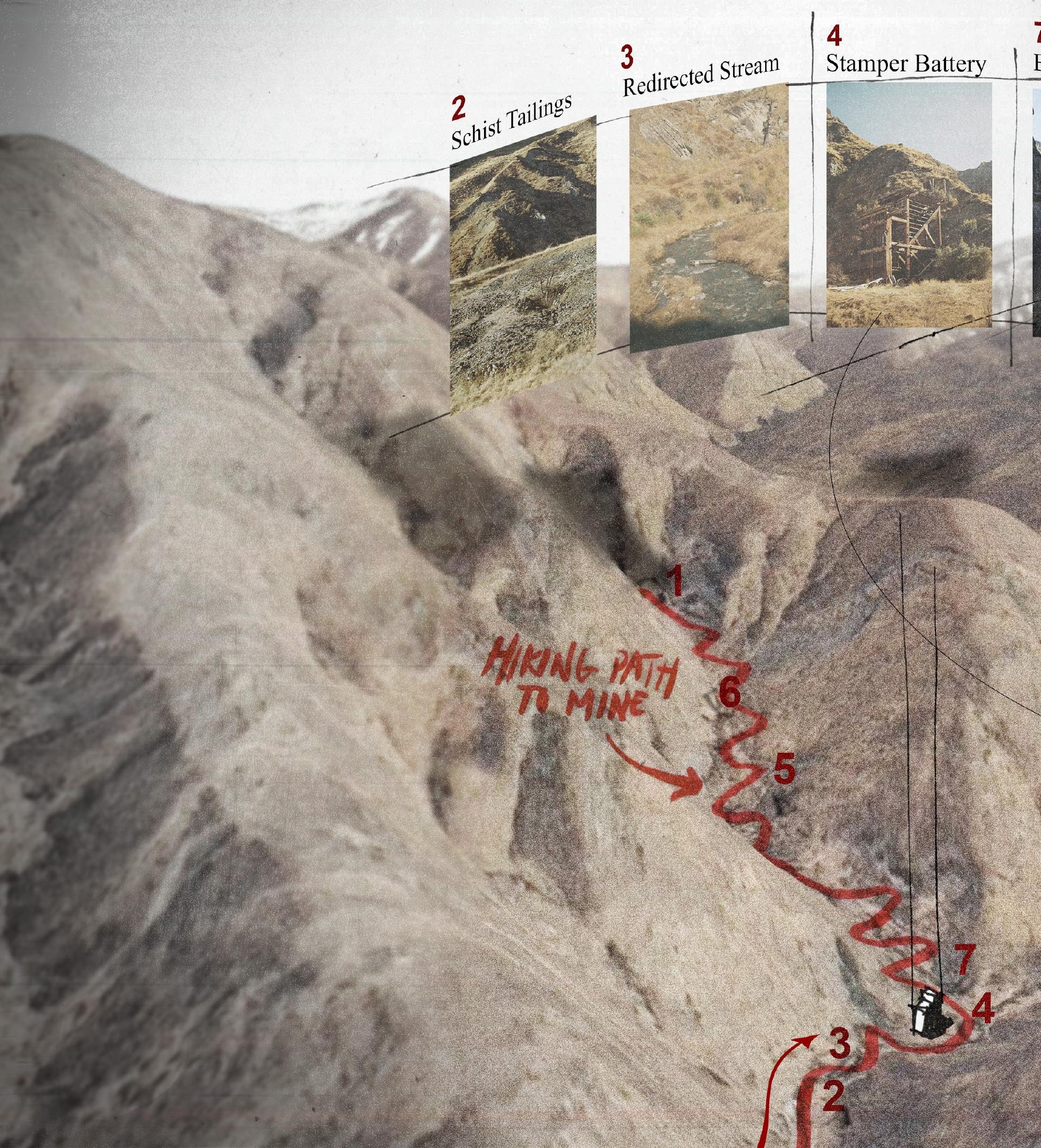




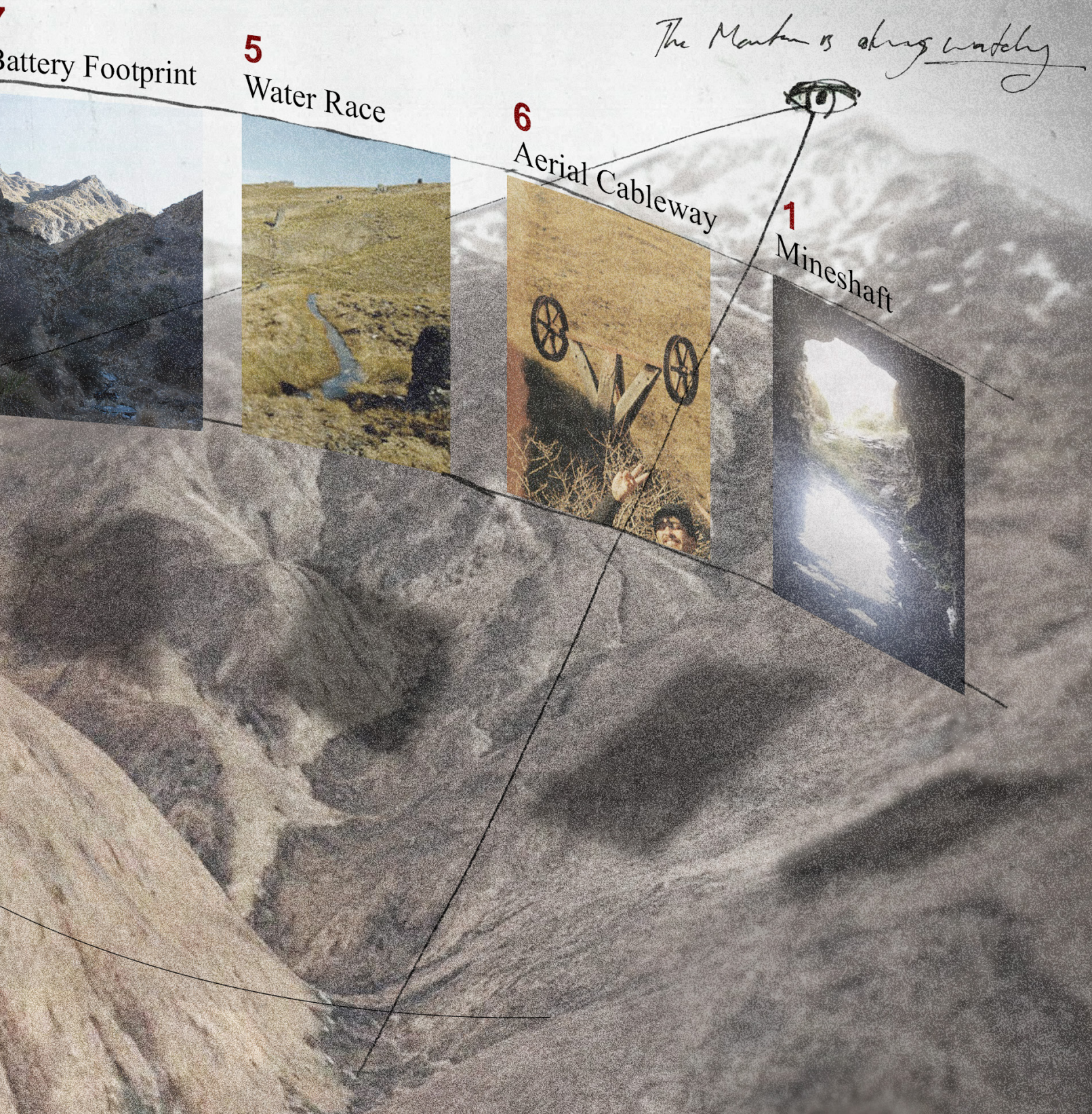




\section{THE MINESHAFT}

Dialectic Voice of Remnant

Location

Narrative Identity

\section{Natural \\ Top of the hill \\ Void}

High in the hills lies a deep, permanent wound, a horizontal mineshaft cut into the landscape. It is a void from which both gold and schist have been gouged, transported away, never to return. Its interior is now flooded, the water denying entry and inviting reflection. It represents a story about place identity established by a void-something that is missing, rather than present.

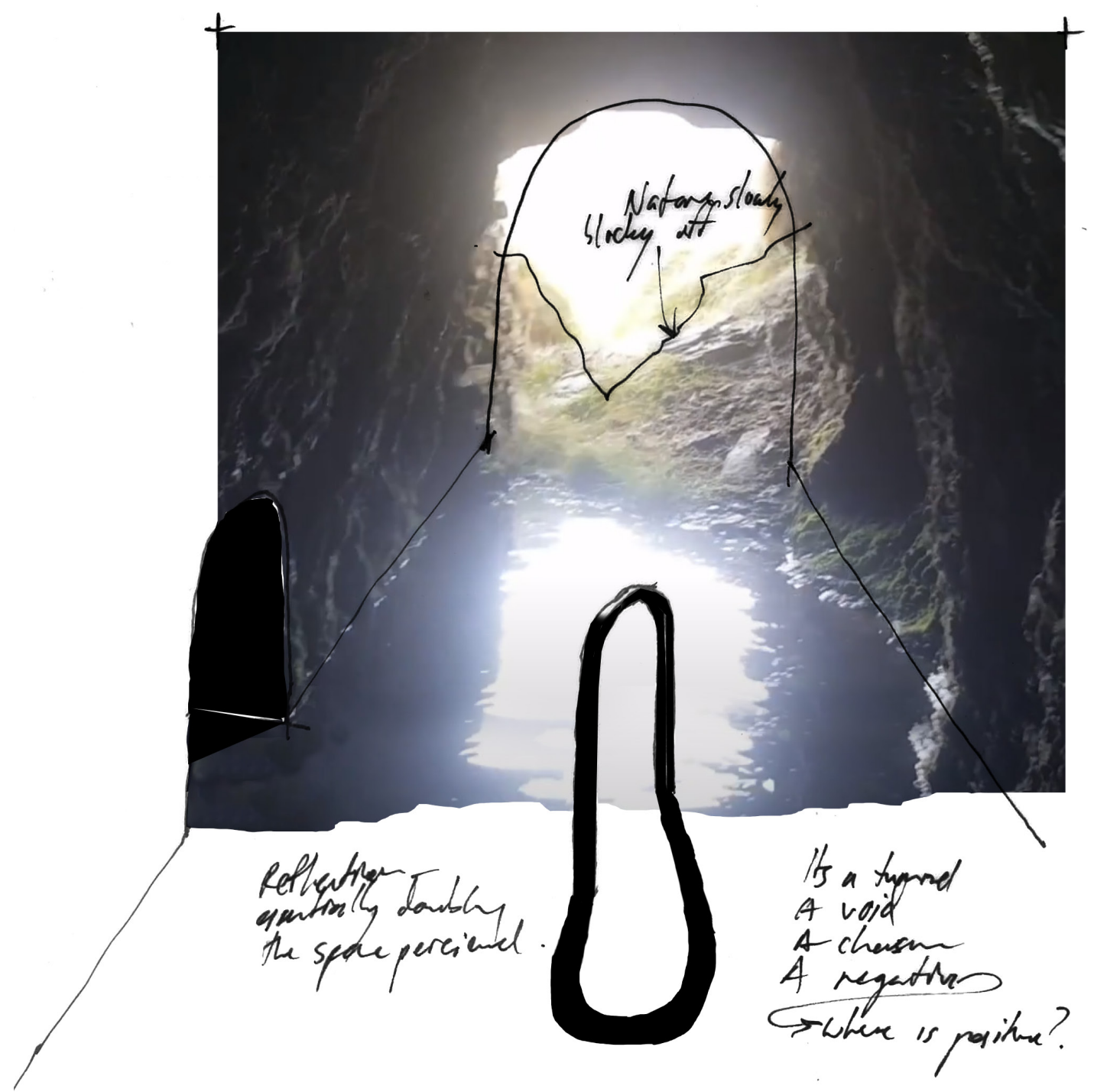

Fig 4.5 Site photo of the Mineshaft with sketch analysis. 


\section{2 .2}

\section{THE SCHIST TAILINGS}

\section{Dialectic Voice of Remnant Location \\ Narrative Identity \\ Natural \\ Valley Floor \\ Displacement}

Once the quartz ore is crushed in the battery to extract the gold, the excess material is gathered and discarded in deposits along the valley floor. These piles of schist tailings are still visible today, with the natural ecosystems struggling to reclaim them. They represent a story about place identity defined by displacement.

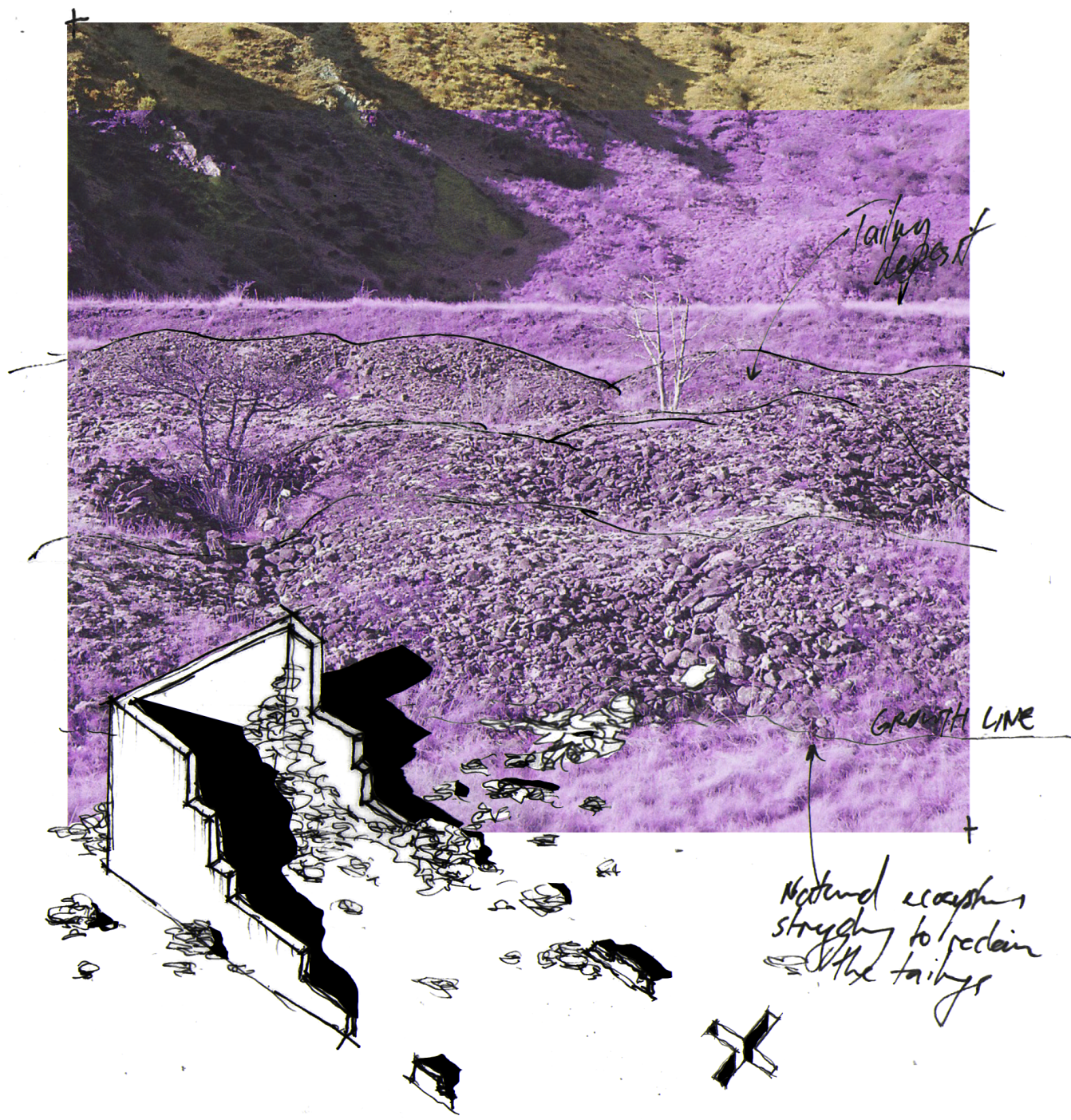

Fig 4.6 Site photo of Schist Tailings with sketch analysis. 


\section{THE REDIRECTED STREAM}

\section{Dialectic Voice of Remnant Location \\ Narrative Identity}

\section{Natural \\ Valley floor \\ Deviation}

Carving out the valley over millions of years, the stream's path is disrupted by the tailing deposits discarded from the mining process. Known by the miners as 'Twelve Mile Creek', the stream is forced by the tailings to deviate from its natural path-changing the course of the valley's future. It represents a story about place identity defined by deviation.

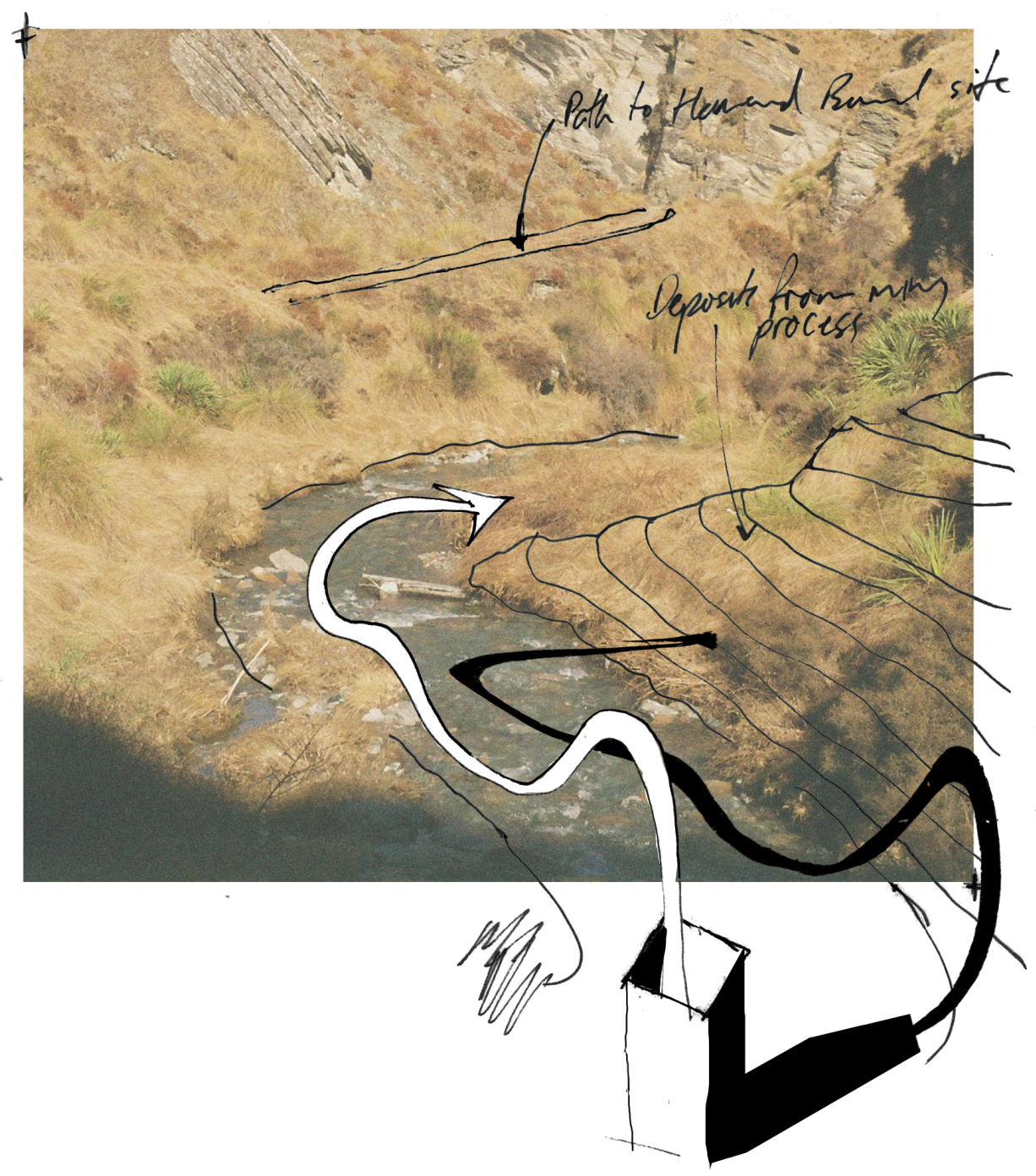

Fig 4.7 Site photo of the Redirected Stream with sketch analysis. 


\section{2 .4}

\section{THE STAMPER BATTERY}

\section{Dialectic Voice of Remnant Convergence \\ Location \\ Narrative Identity \\ Near the stream \\ Convergence}

The huge stone-crushing stamper battery lies just above the stream, slowly crumbling to pieces. All of the characters of this allegorical story have either entered into this architectural construct, moved around it, or been caused by itmaking the battery a convergence point. It represents a story about place identity defined by convergence.

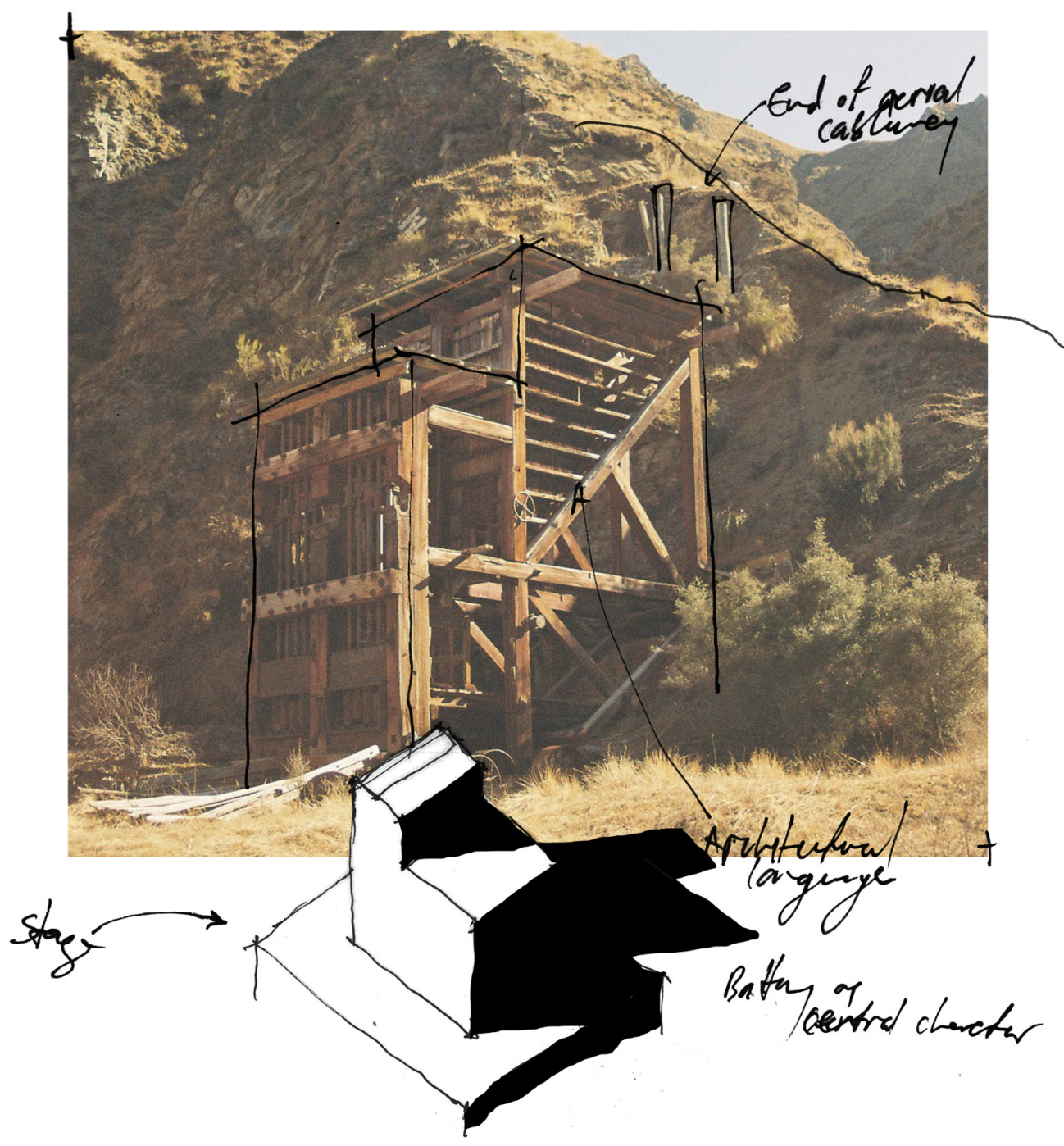

Fig 4.8 Site photo of the Stamper Battery with sketch analysis. 


\section{2 .5}

\section{THE WATER RACE}

Dialectic Voice of Remnant

Location

Narrative Identity

\section{Man-made \\ Along the hills \\ Cut}

The hills leading to the mine are lined with a shallow water race, cut into the hill to feed water from sources up high to the stamper battery below-drawing deep scar lines across the landscape. It represents a story about place identity defined by a cut.

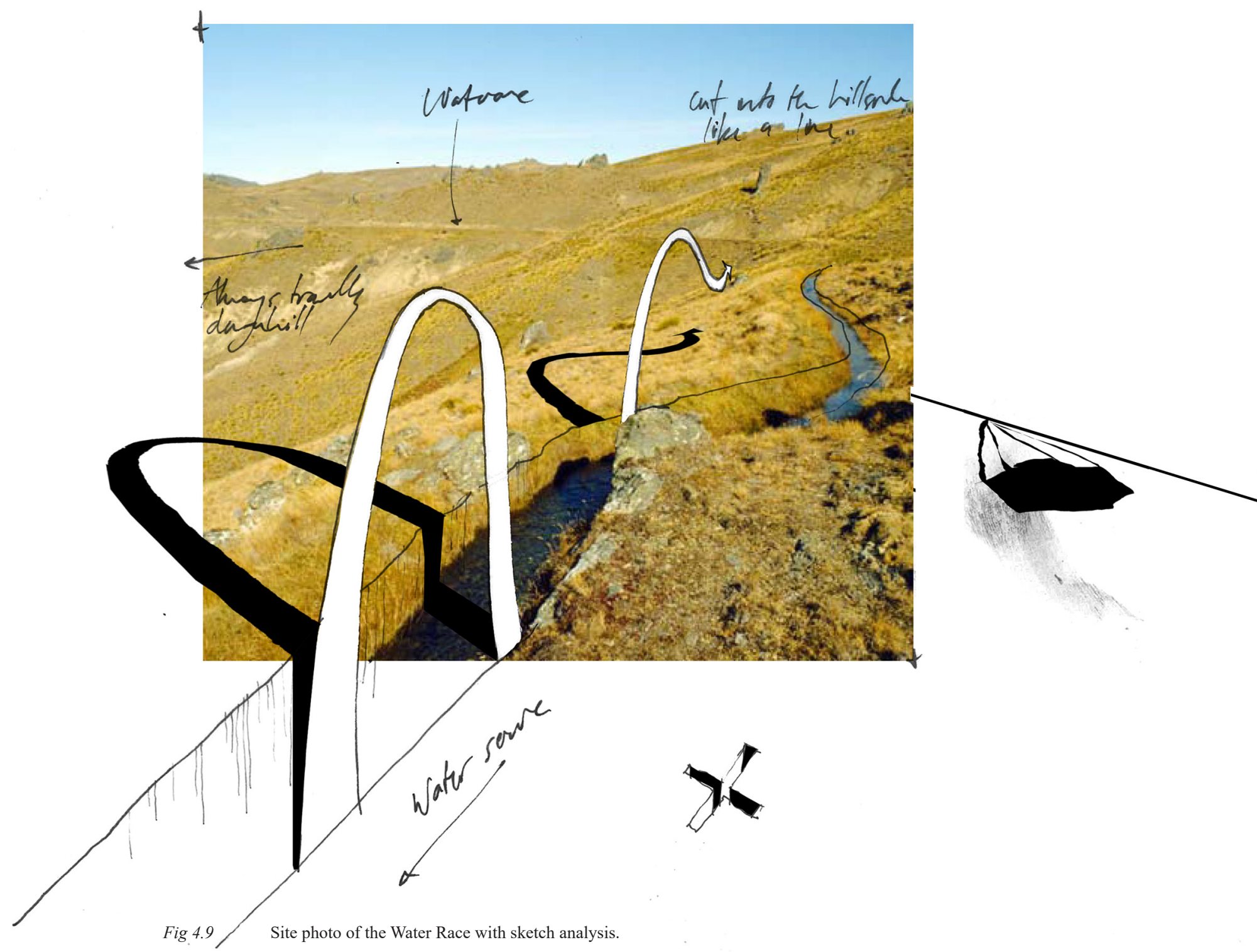




\section{THE BATTERY FOOTPRINT}

\section{Dialectic Voice of Remnant Man-made \\ Location \\ Narrative Identity \\ Stream floodplains}

The stone foundations of a previous stamper battery lie just $20 \mathrm{~m}$ below the Homeward Bound battery. Destroyed by the stream in a flood, these footprints represent the last traces of the huge machine-slowly being erased by nature until it is only a ghost. It represents a story about place identity defined only by traces left upon the landscape.

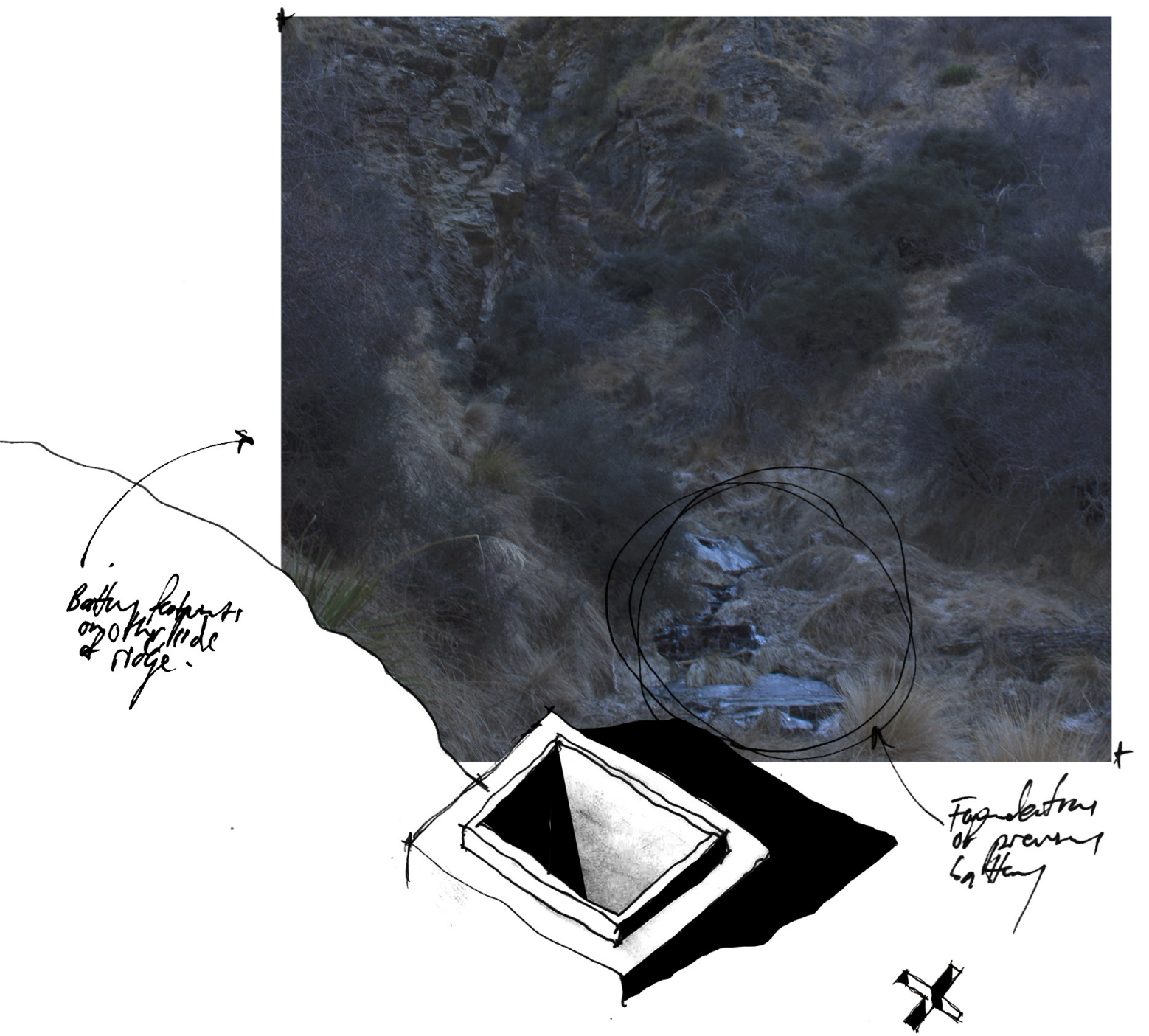

Fig 4.11 Site photo of the remains of the Battery Footprint with sketch analysis. 


\section{THE MOUNTAIN}

Advance Peak is the highest mountain overlooking the valley, sitting at $1749 \mathrm{~m}$ tall. While not an active participant in the meta-narrative of the site, the mountain has stood as the everpresent silent witness - watching the story play out over time.

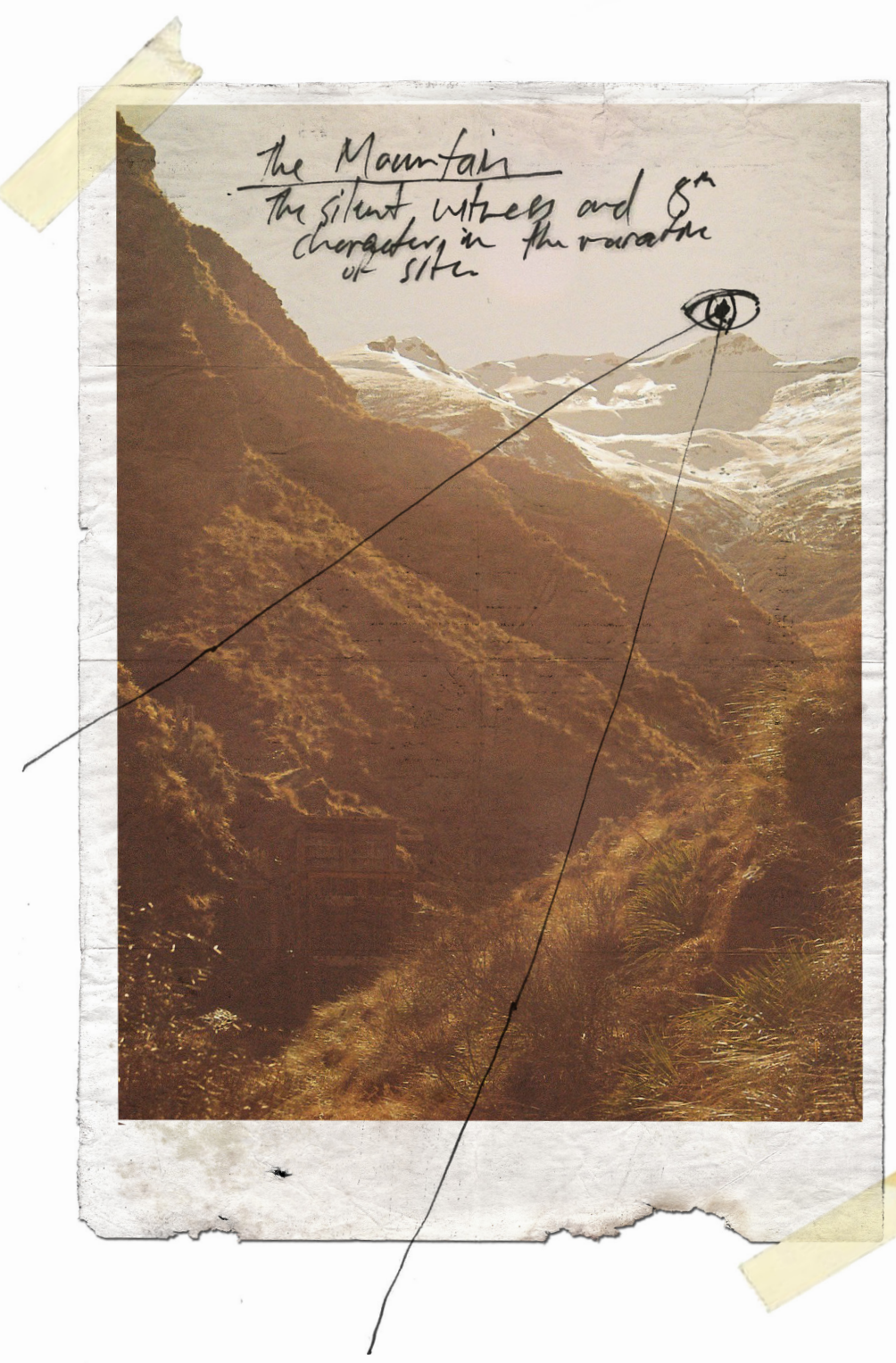

Fig 4.12 Site photo of the Mountain watching over the other characters. 


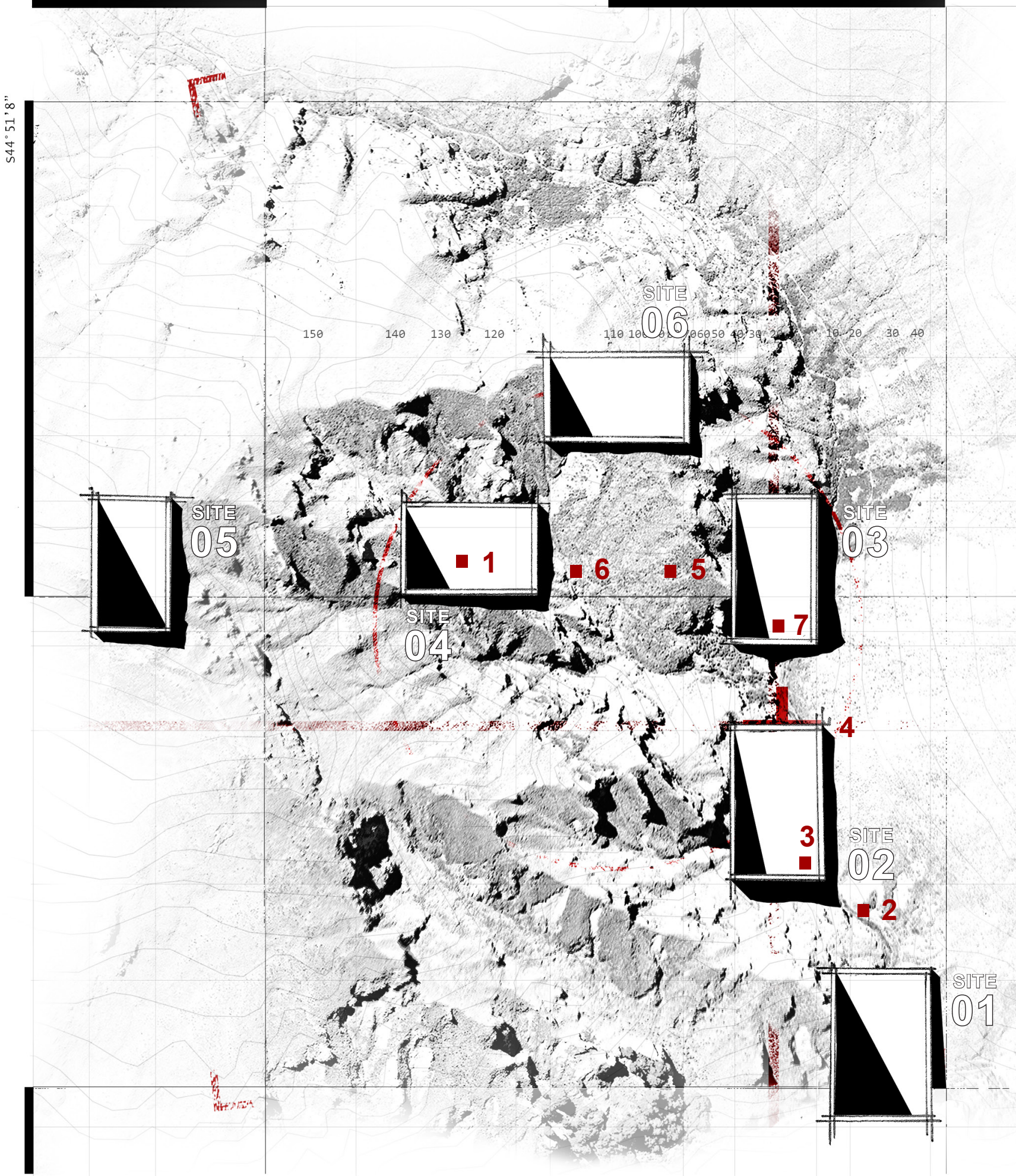

Fig 4.13 Proposed location of seven interventions that act as points of pause in the landscape, enabling visitors to witness the confrontational relationships of one or more characters. 

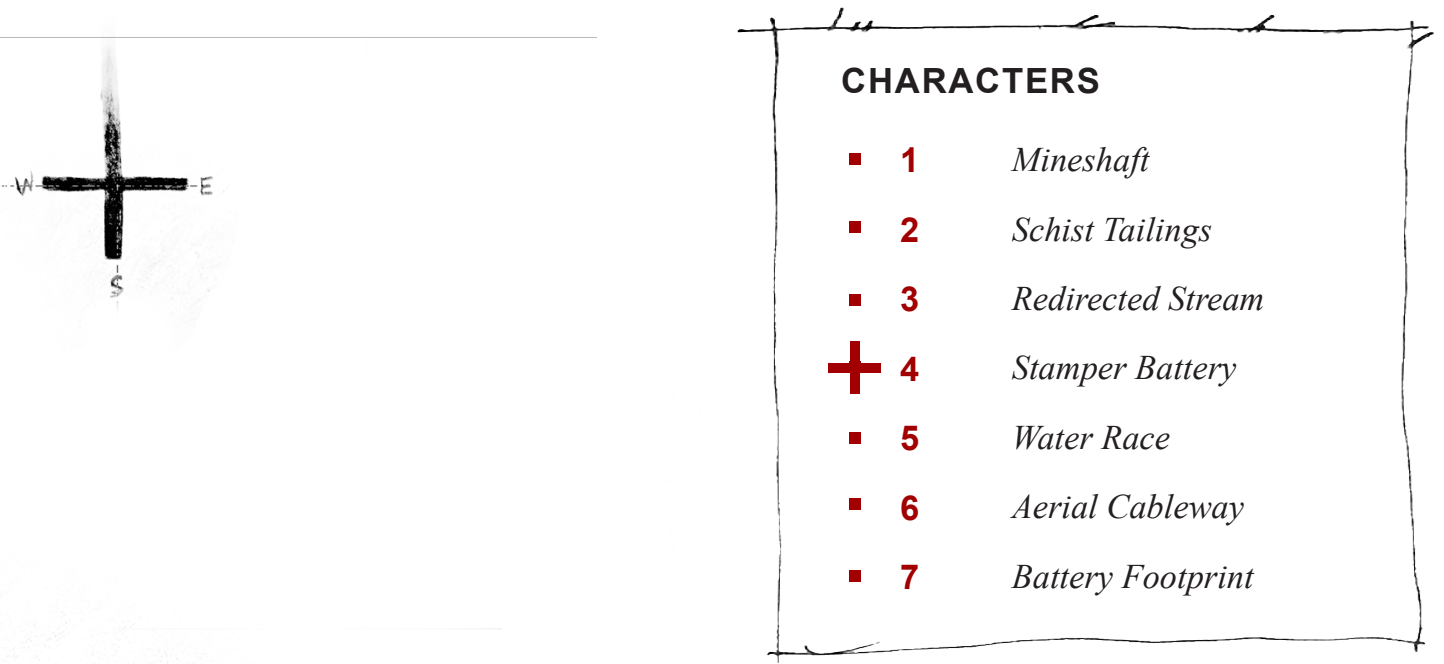

\subsection{PROPOSED INTERVENTIONS}

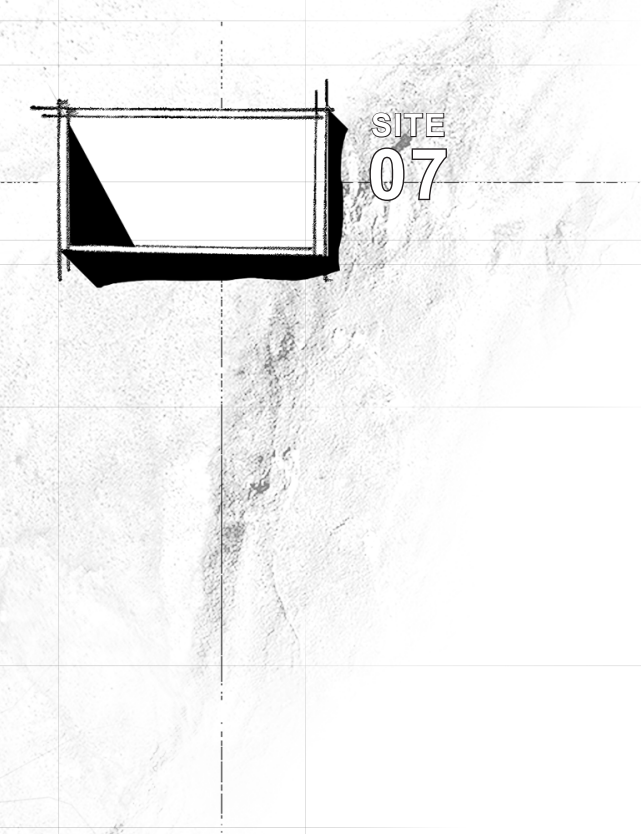

To interrogate the narrative of each of these remnants, seven proposed locations relating to each 'character' are conceived as points of pause within the site - each position witnessing this dialectic narrative from its own unique point of view.

Figure 4.13 shows the seven proposed points of pause to be explored through speculative drawing in relation to the seven characters on site. Some interventions are located in close proximity to the remnants, while others view them from afar.

Each of these locations has been chosen to illustrate one of the two opposing sides of this allegorical tale of prosperity brought about by environmental devastation - a tale of the manmade in conflict with the natural systems. Each site also brings its own unique point of view into the confrontations that frame and establish the narrative of the Homeward Bound site. 


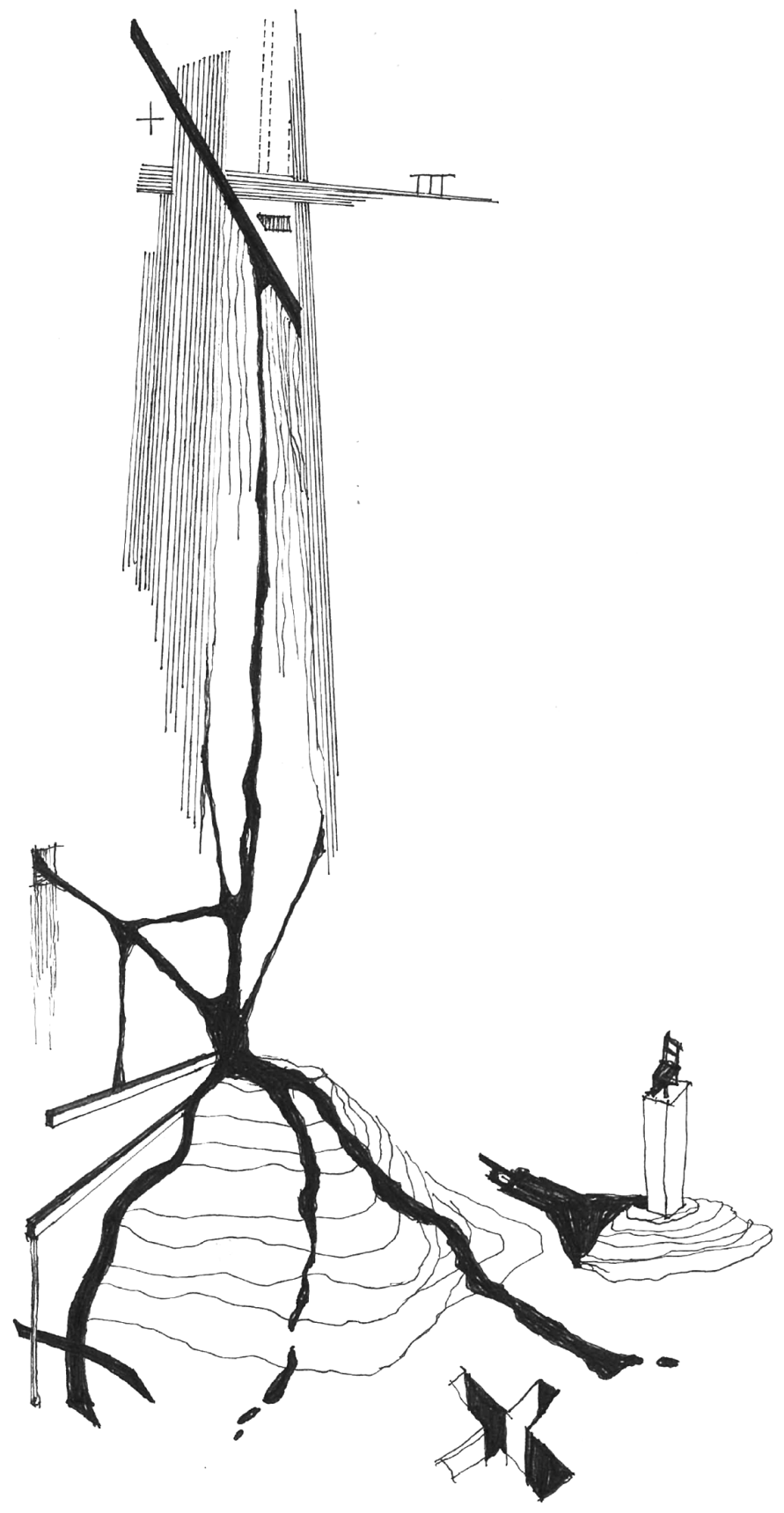

Fig 4.14 Conceptual sketch exploration of deviation and displacement as witnessed by an 'actor' (the chair) on the stage. 


\subsection{CRITICAL REFLECTION}

The contextual analysis of the Homeward Bound mining operation has identified seven key remnants of the goldmining process, each affected differently and thus adding their own important and unique point of view to the allegorical tale. These remnants exist in varying states of decay, where some are recognisable while others are hidden beneath other layers, remaining visible only as fragments and traces, or almost completely erased by nature reclaiming the site. Three artefacts belong primarily to the natural systems, three belong primarily to the man-made systems, and one (the Stamper Battery) represents a convergence between the two systems. This helps provide a framework to interrogate their dialectical relationship of confrontation in response to Research Objective 1:

To explore how orthographic drawing can help establish critical relationships within a dialectic narrative.

An allegorical framework treating the site as a theatrical play with seven characters is applied, effectively anthropomorphising the remnants within an allegorical narrative with an important underlying message to preserve and convey. In this chapter, the narrative identity and the point of view of each character has been introduced, enabling the viewer to also appreciate their potential relationships with one another. In the Preliminary Design stage, these characters will be translated into drawn notational language in response to Research Objective 2:

To explore how architectural notation strategies and devices can be used to establish allegorical relationships relating to time, place and point of view.

The seven 'characters' in the allegorical play each occupy a discrete point of pause upon the actual site as well as the allegorical 'stage'. As an investigation into speculative drawing, this 'stage' becomes the piece of drawing paper. In the next phase, each character's story will be presented on the 'stage' in ways that impart its own unique point of view. These seven points of view will ultimately be overlayed, as a way to convey the broader meta-narrative that this design-led research investigation seeks to preserve. 

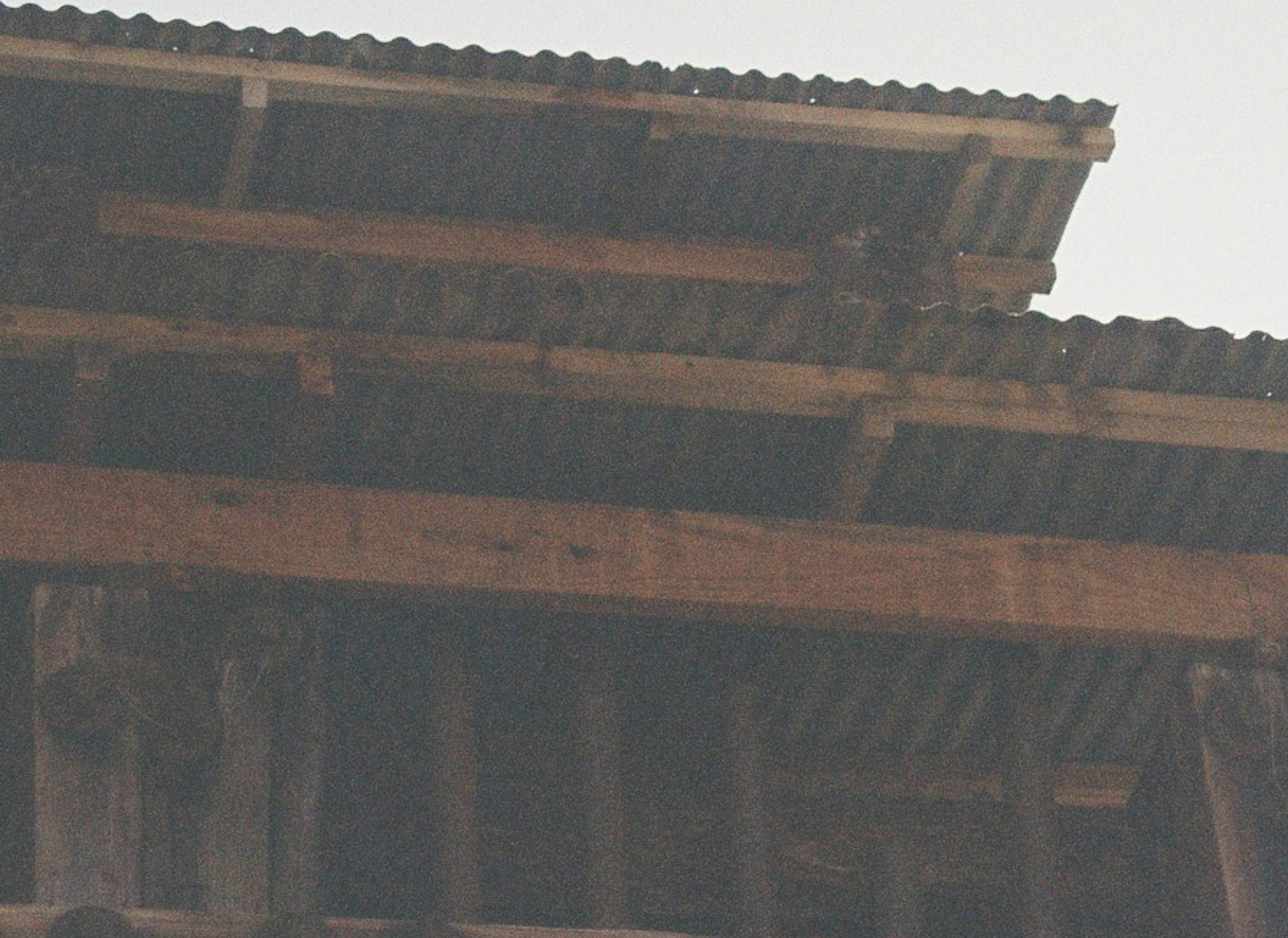


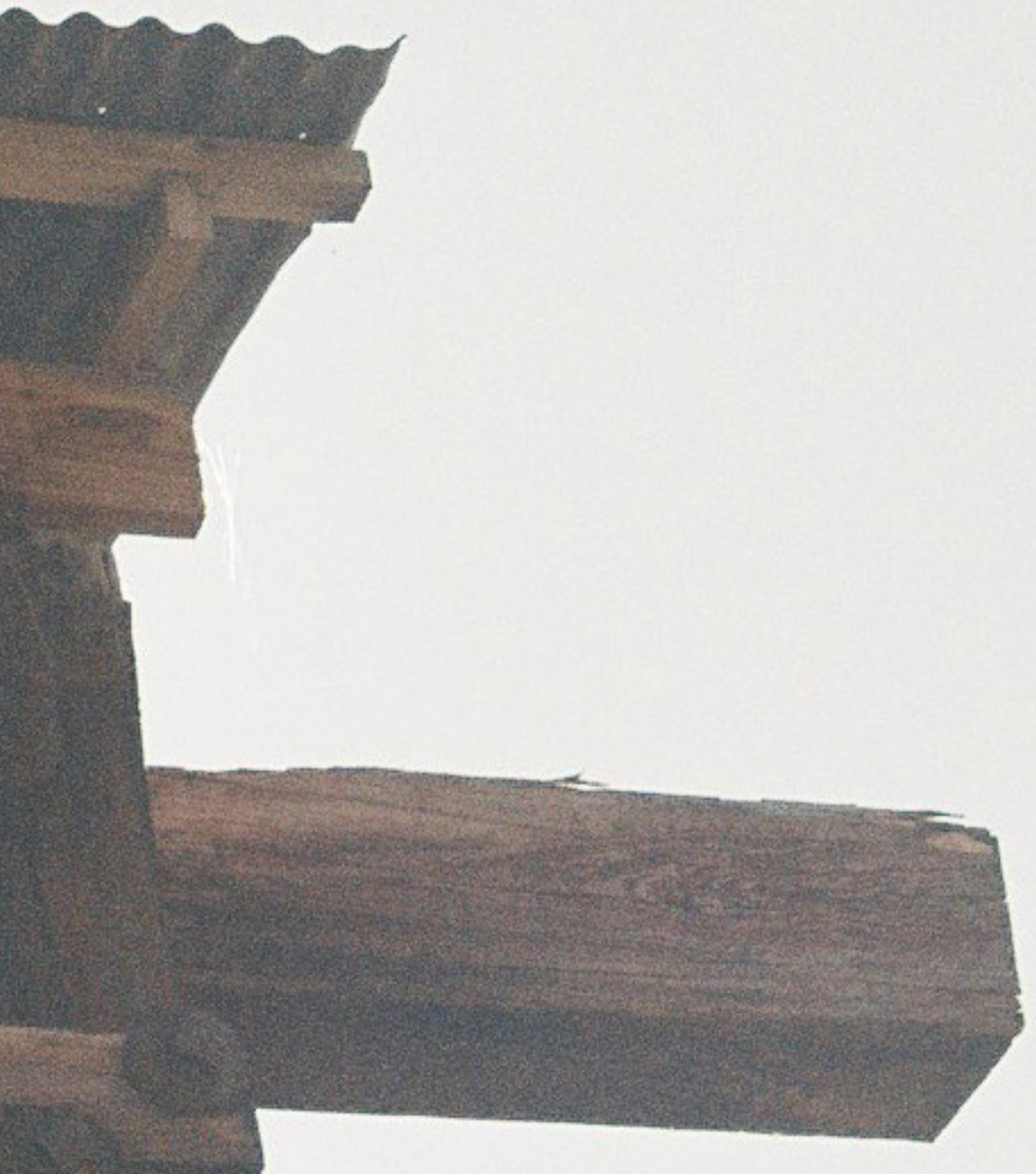


66

Night and day, wind and storm, tide and earthquake, impeded man no longer. He had harnessed Leviathan. All the oId literature, with its praise of Nature, and its fear of Nature, rang false as the prattle of a child. 


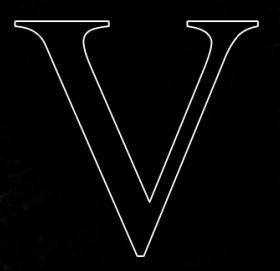

\section{CONCEPT DESIGN}

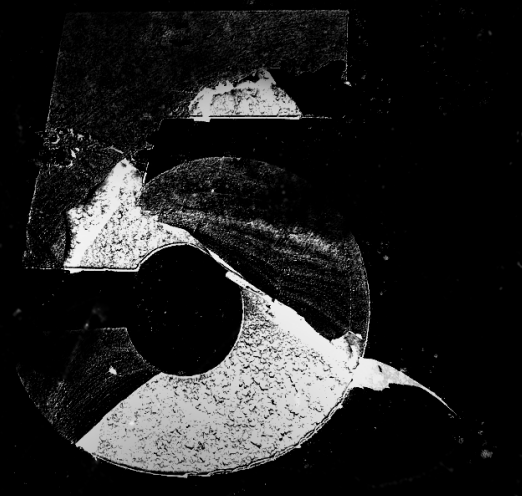




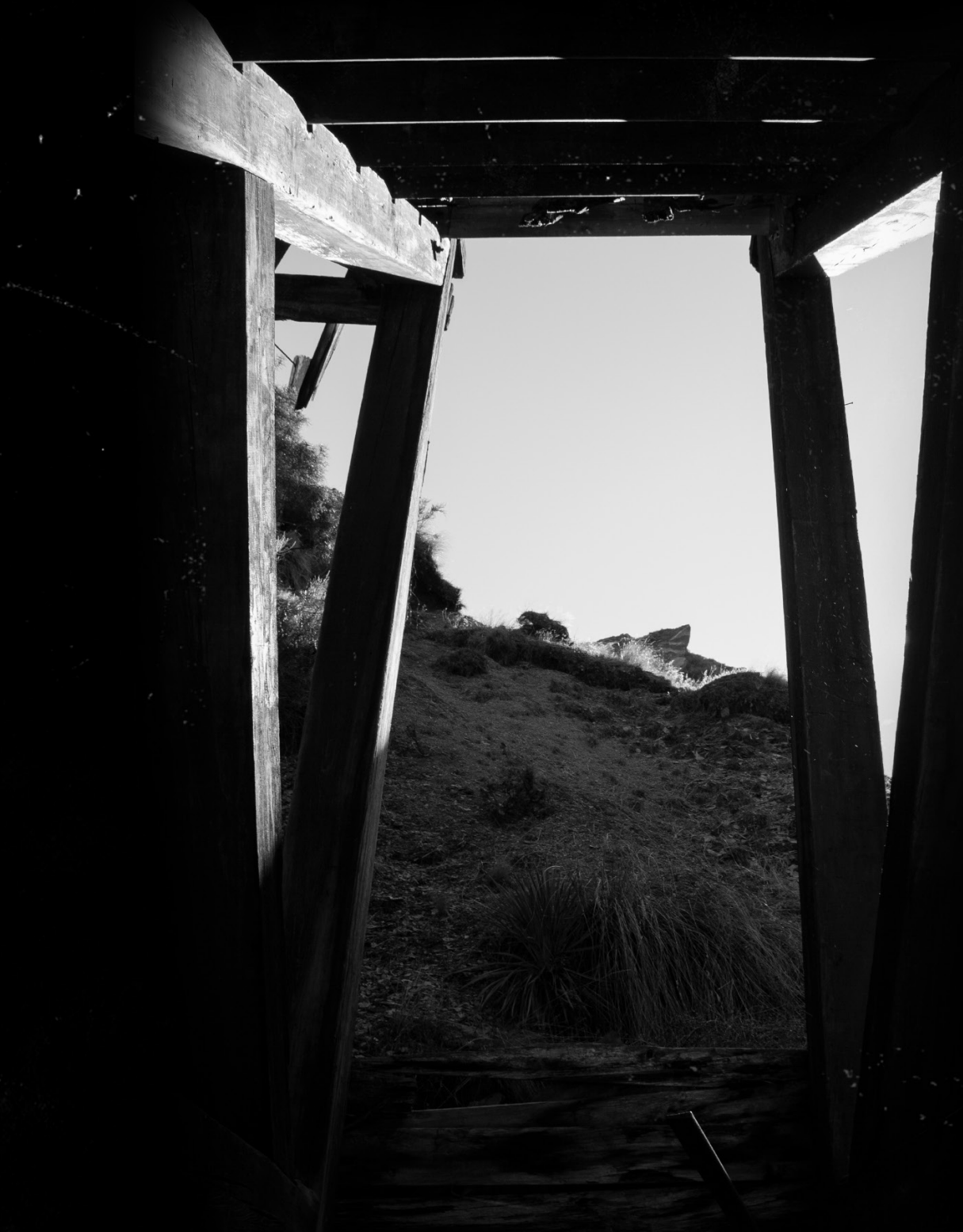




\subsection{INTRODUCTION}

The Concept Design chapter explores the allegorical architectural project as speculative drawings in plan view. The Preliminary Design chapter explores the project as speculative drawings in axonometric view. The Developed Design chapter explores the allegorical architectural project as layered views - inviting each individual character's voice to be heard, while the fragmented voices of the other characters still resonate in the background.

This chapter applies the learnings from the literature and project review chapter and begins to interrogate seven specific areas within the Homeward Bound Site using the theoretical framework of a theatrical play. Speculative plan drawings are used to begin to interrogate each proposed point of pause within the site, using orthographic projection lines as a primary method of identifying the confrontational relationships between the characters in response to Research Objective 1:

To explore how orthographic drawing can help establish critical relationships within a dialectic narrative.

The critical relationships explored in this series are also illustrated using a range of notation strategies and devices - some traditional and others speculativeenable their narratives further and begin developing a language unique to this investigation in response to Research Objective 2:

To explore how architectural notation strategies and devices can be used to establish allegorical relationships relating to time, place and point of view.

Relevant case studies are interrogated and applied with a particular focus on the narrative ability of their primary architectural device-exploring how the proposed interventions can enable seven unique stories of site. 


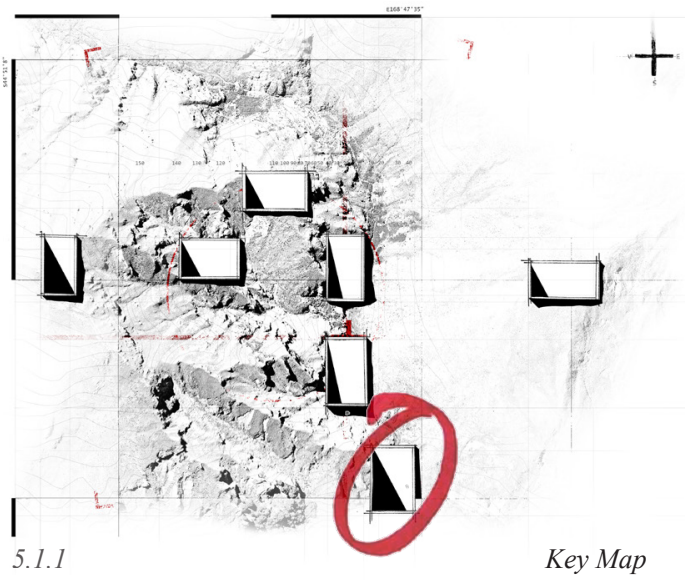

\section{2 .1}

\section{PLAN EXPERIMENT 1}

\section{Introducing the Stamper Battery}

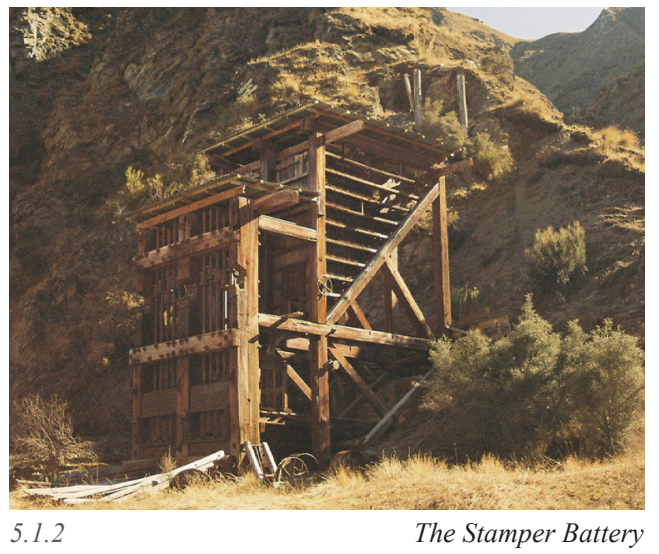

The Stamper Battery represents a Convergence point where natural resources and man-made systems met and mixed. This Concept Design experiment is sited at the threshold of the Homeward Bound operational area. It acts as the gateway entry into the site, conveying the principal character of the narrative by using a framing device to introduce the main actor-the Stamper Battery.

Slow House by American interdisciplinary studio Diller Scofido + Renfro is interrogated as a case study for its use of two apertures to frame a view. The first aperture is a door, acting as both a threshold and framing device for the interior space, while the window at the rear dominates the end façade - framing the view beyond.

This is applied in Experiment 1 through the use of an entry gateway as well as a raised frame, requiring visitors to climb a central staircase to see over the obstructing landscape to the stamper battery beyond. 


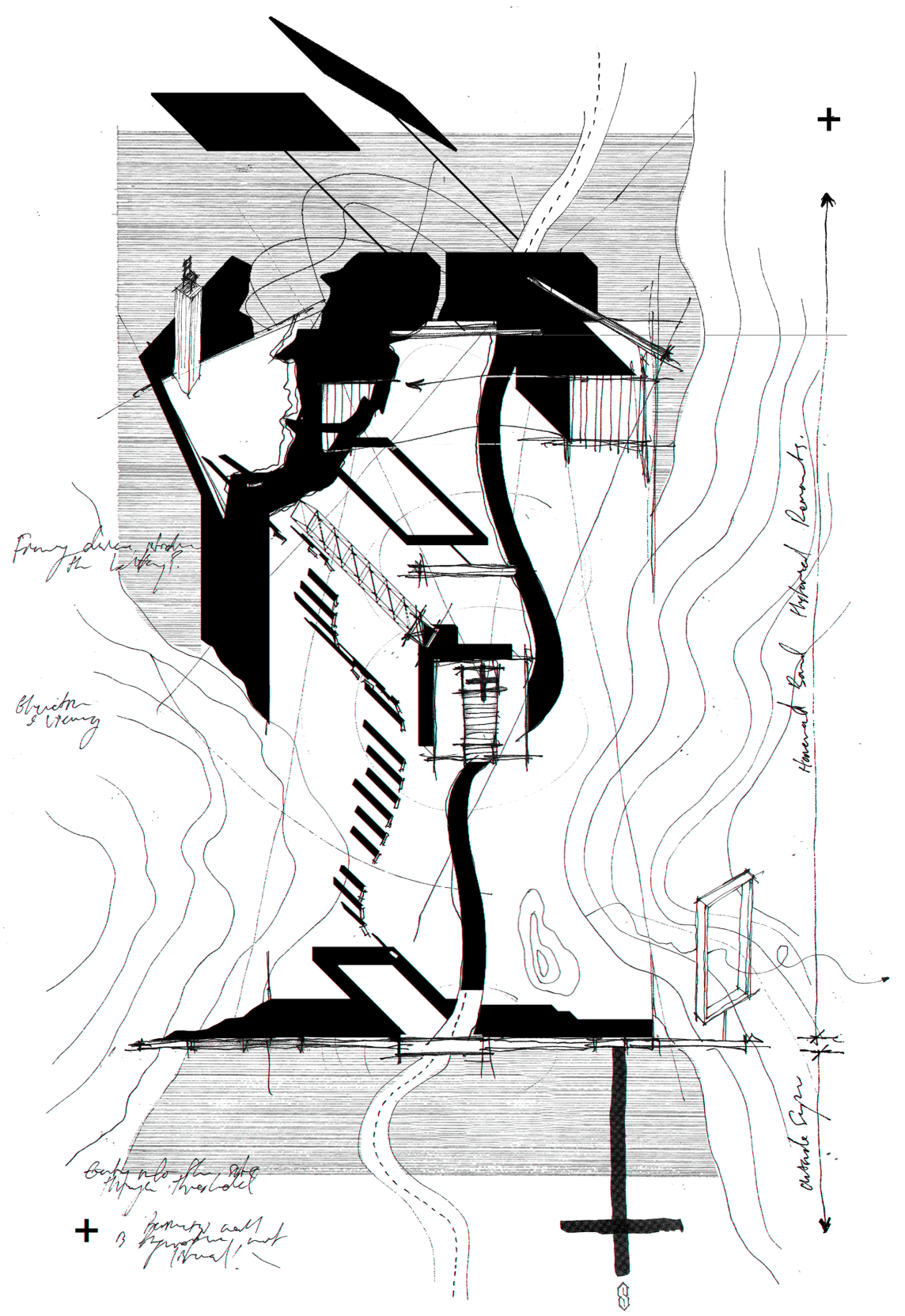

5.1.4 Conceptual plan exploring the confrontational relationships of the Stamper Battery converging on the threshold of the site - the shear cliff faces threatening to reclaim the interventions. 


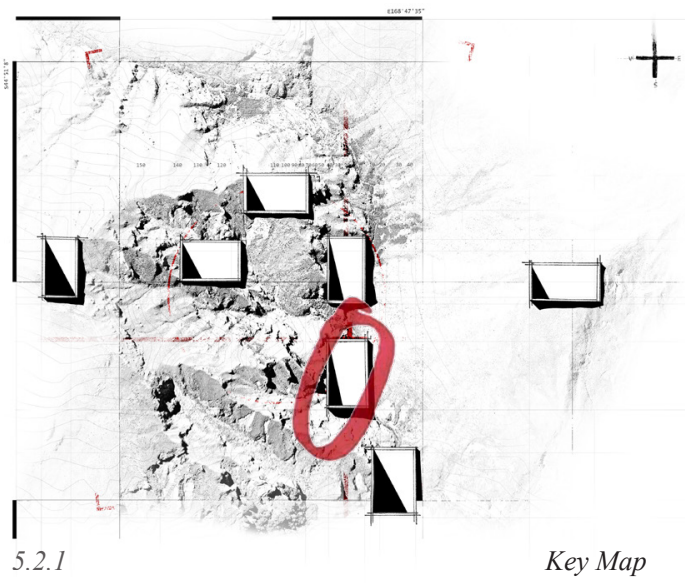

\section{2 .2}

\section{PLAN EXPERIMENT 2}

\section{Introducing the Schist Tailings}

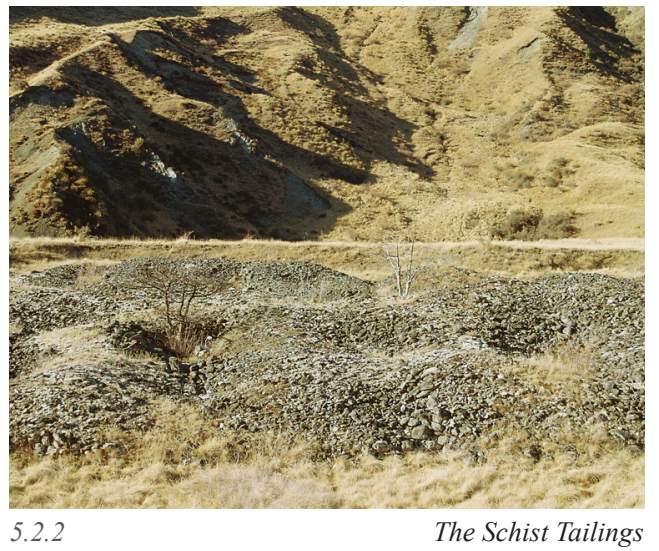

The Schist Tailings represent a Displacement of unwanted material from the rock-crushing process, which is discarded in piles on the valley floor. Concept Design Experiment 2 interrogates an area of the site just downstream from the Stamper Battery, where the tailings have been deposited post-processing. It explores the displaced relationship of these remnants by using projection lines to place them in a dialogue of confrontation.

Rocks and Mirror Square II by artist Robert Smithson is interrogated as a case study about displacement, which encloses a select area of the scattered stones to highlight their relationship to the metal square. Smithson's work represents a similar story to the Schist Tailings.

In Concept Design Experiment 2 notational devices from the previous experiment are re-introduced to enable the characters to be recognised as related to one another, while new notation devices are added to represent the unique voice of the Schist Tailings, and the landscape trying to reclaim this narrow area of site. 


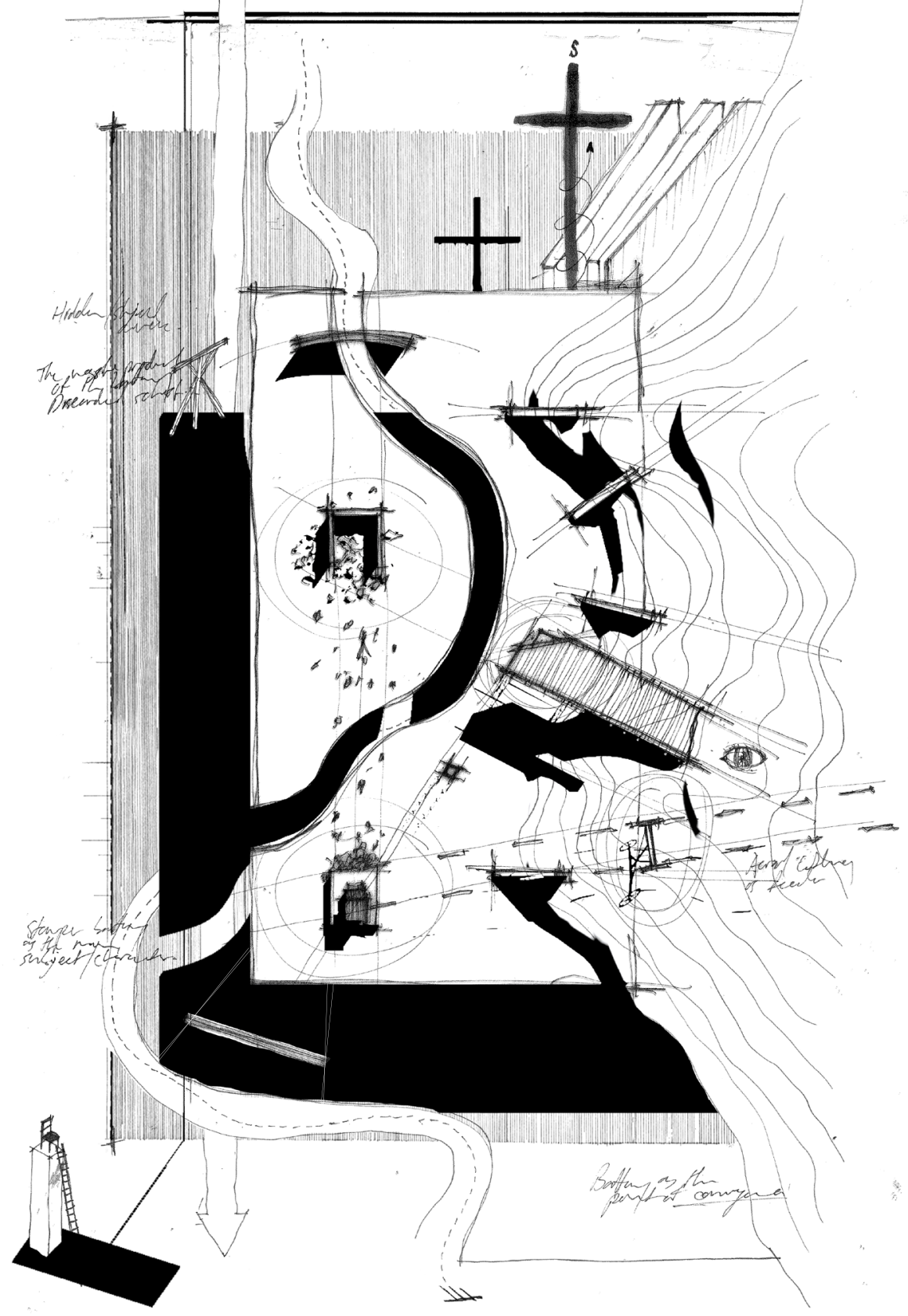

5.2.4 Conceptual plan exploring the confrontational displacement relationships of the Schist Tailings and how they redirect the stream. 

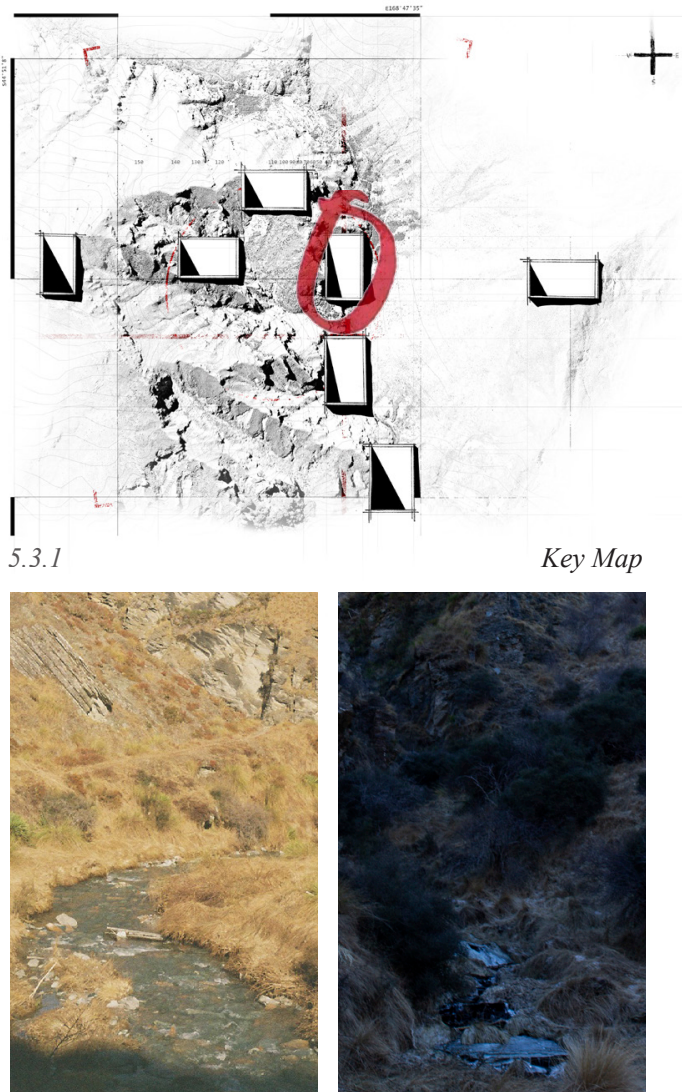

5.3.2 Redirected Stream 5.3.3 Battery Footprints

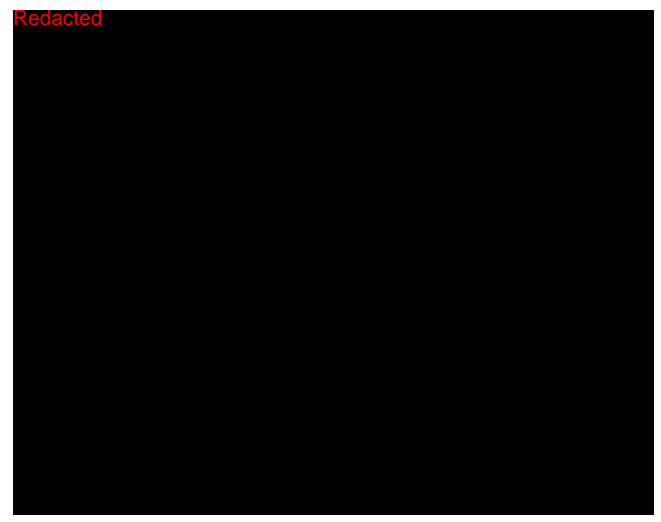

5.3 .4

Pier 40, 22001 Mas Yendo

\section{2 .3}

\section{PLAN EXPERIMENT 3}

\section{Introducing the Redirected Stream and Battery Footprint}

The Redirected Stream represents a Deviation, redirected from its natural direction by the unwanted tailings discarded on the valley floor. The nearby Battery Footprint left behind when a previous stamper battery was swept away in a flood represents a Trace. The third Concept Design experiment focuses on the area directly behind the Stamper Battery, where the stream's floodplain holds the foundations of a previous stamper battery. This drawing uses fluid lines to represent deviation away from the orthogonal grid. It uses orthogonal walls on monolithic fins to hold the steep terrain back, exposing the void where the previous battery once stood.

Speculative architect Mas Yendo's project Pier 40 is interrogated for its use of a deviation and trace. The deviating orthogonal void descends below the water level, indicating a potential conflict only averted by the traces protecting the architectural form.

With the conflict of the Redirected Stream and Battery Footprint established, other relationships begin to appear from the notational devices carried through from the previous experiments. The deviating landscape is now pushed off the page, with the drawing language translating landscape elements into architectural forms and traces left behind. 


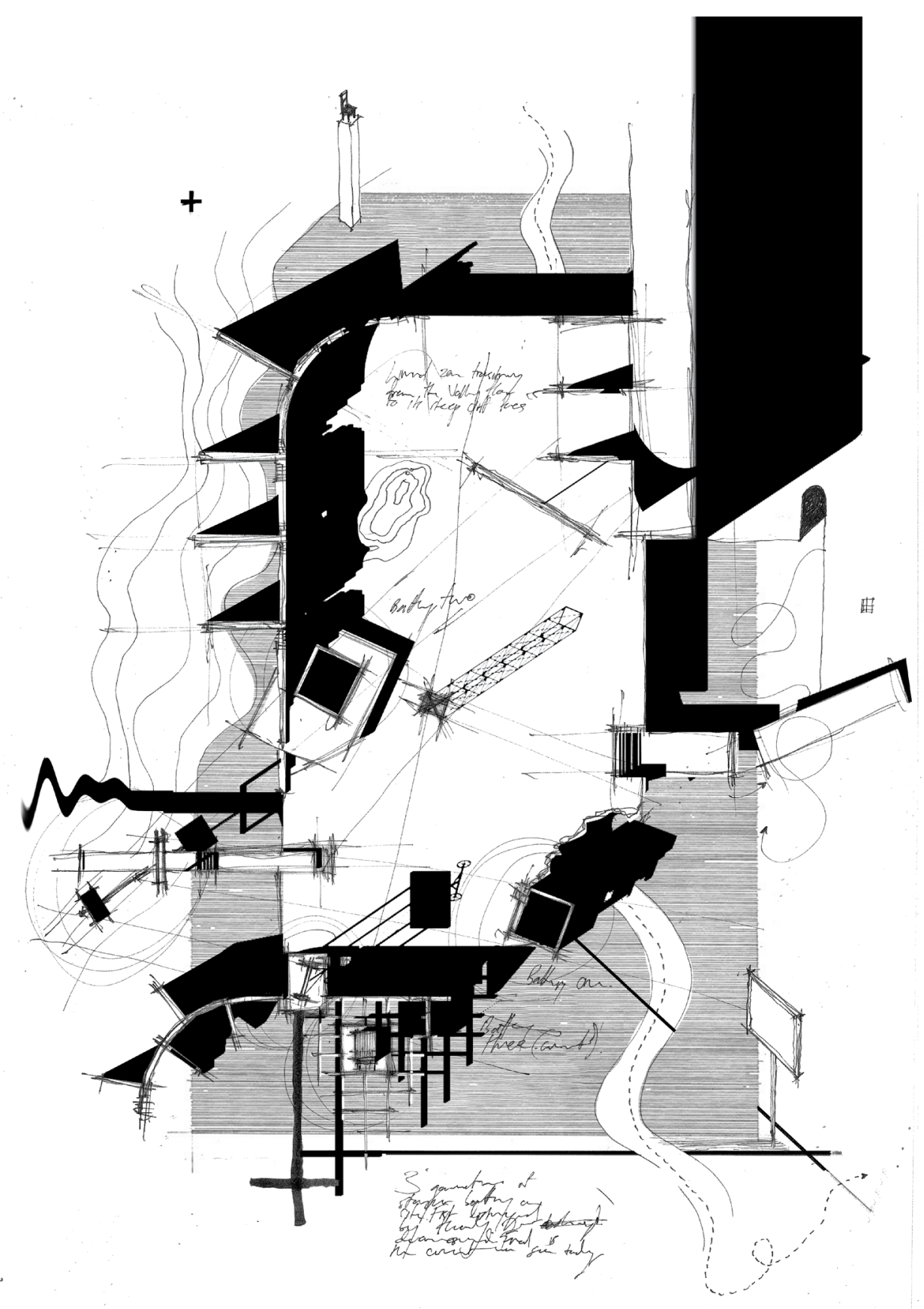

5.3.5 Conceptual plan exploring the eroding and deviating nature of the Redirected Stream and the traces of the Battery Footprint in relation to the Stamper Battery. 


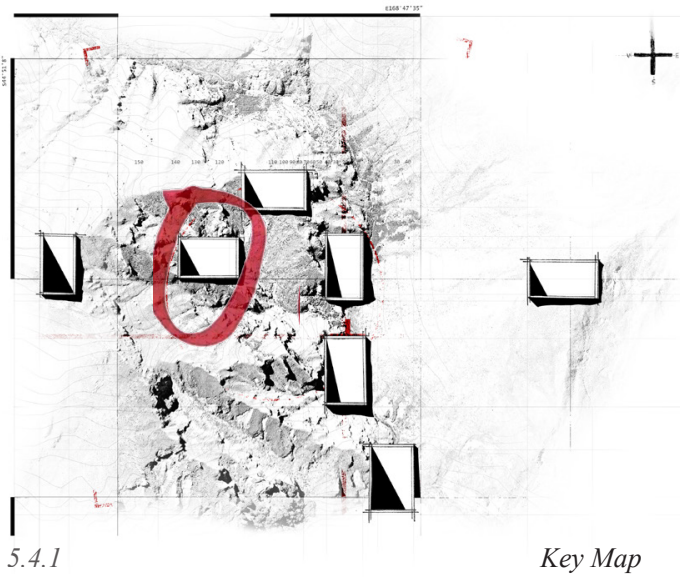

\section{2 .4}

\section{PLAN EXPERIMENT 4}

\section{Introducing the Mineshaft}

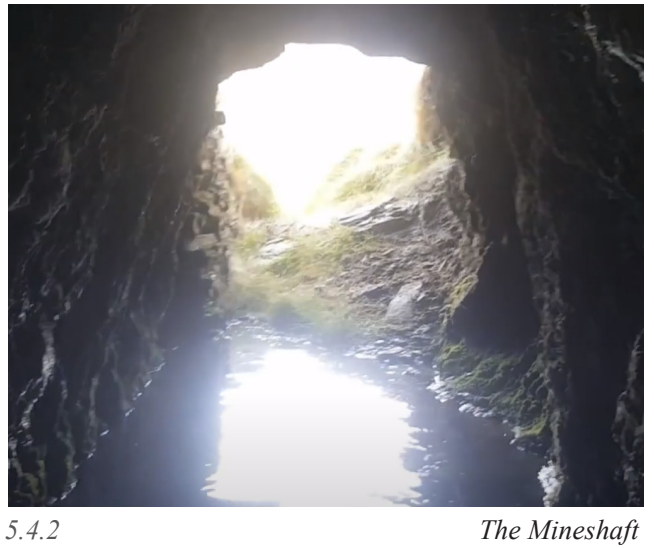

The Mineshaft represents a Void, dug horizontally in the hill to reach the quartz veins within the landscape. This Concept Design experiment is sited up the steep terrain, near the entrance to the Mine Shaft. It explores the increase in altitude by lifting the elements from previous drawings up on columns, with the page also being lifted by a structural grid that reveals the landscape and resulting void beneath.

American Artist Mary Miss's project Field Rotation is interrogated for its composition around a central void, where timber posts appear to torque around a fulcrum. This references the notion of the Mine Shaft being drilled into the landscape, as well as enabling a perception of time, as the posts act as a physical representation of a timeline originating from the void.

The Stamper Battery and Aerial Cableway are positioned in relation to the Mineshaft, using a pathway linking from the previous drawing. A mechanical clock is implied by the centre of the page, driven by a mechanism hidden in the void below the page. 


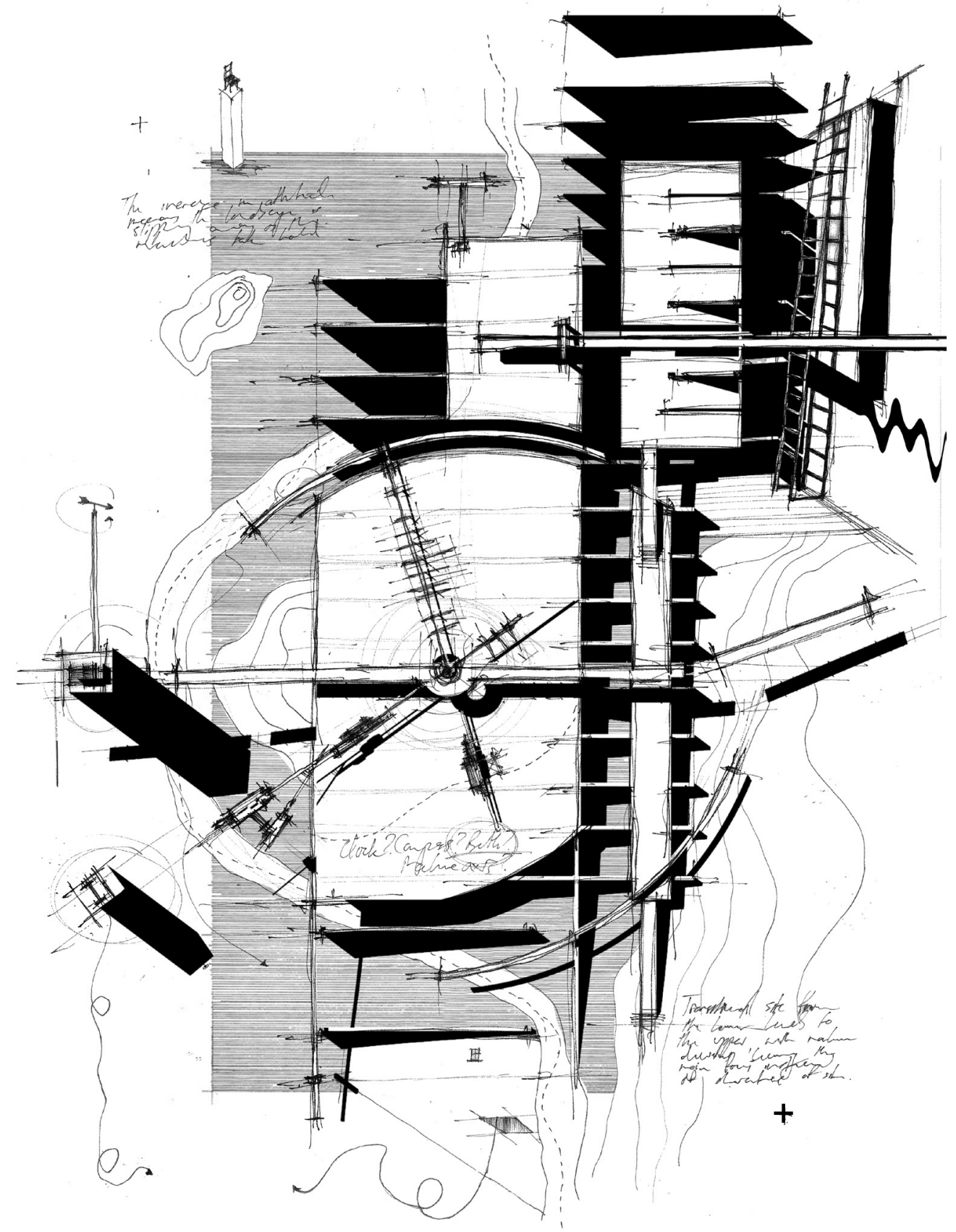

5.4.4 Conceptual plan exploring the elevated position of the mine shaft in relation to other remnants - the rectangular plane begins to decay, revealing a substructure in the void, informing the increase in altitude. 


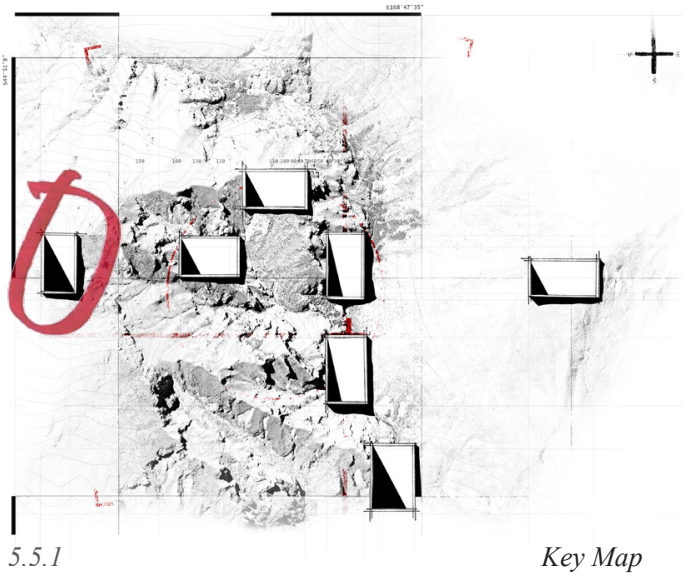

\section{2 .5}

\section{PLAN EXPERIMENT 5}

\section{Introducing the Aerial Cableway}
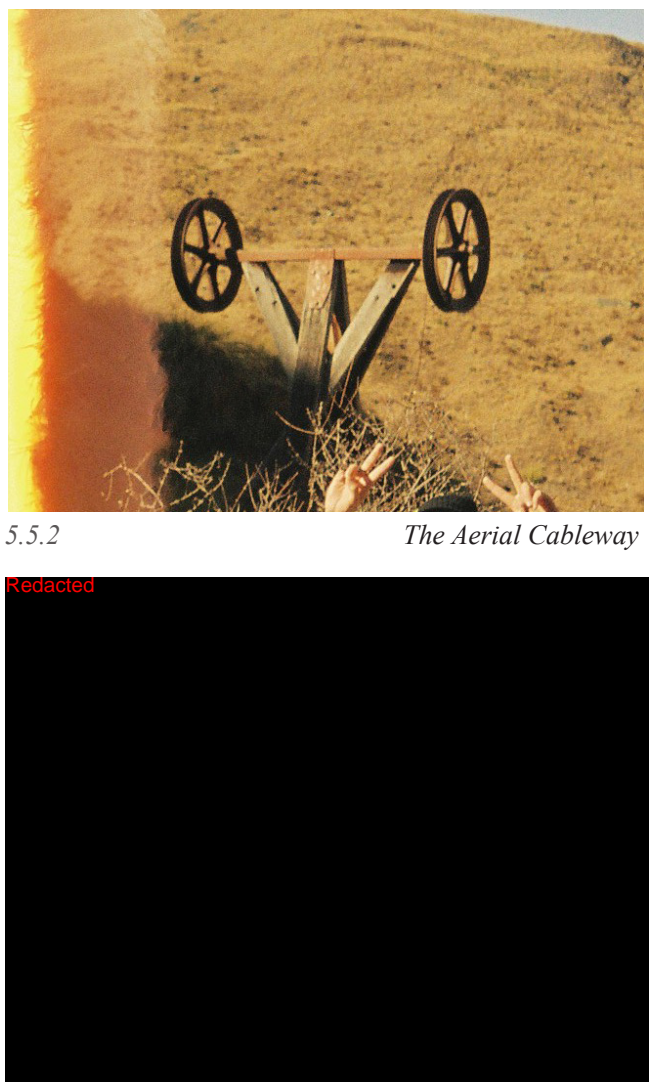

The Aerial Cableway represents a Transition element; buckets of ore from the mine above were transported to the battery below by steel cables suspended over the steep landscape. Concept Design Experiment 5 is situated on the outer edge of the site, looking down the axis of the Aerial Cableway. Notation devices of the break line and reference markers represent how a drawing transitions into architectural forms, while identifying the edge of the Homeward Bound operational area.

Italian studio SET Architects' project Bologna Shoah Memorial provides an example of a transition device being used to enable a narrative. The project consists of two metal walls, positioned to create a narrow interior transition zone that funnels towards a framed view.

On the outskirts of the research site, characters such as the Aerial Cableway are no longer in close proximity, so a framing device is aligned on their axis. The mechanised device passes the other site's transitional threshold wall, shifting and rotating on its track to frame the machine remnants below. 


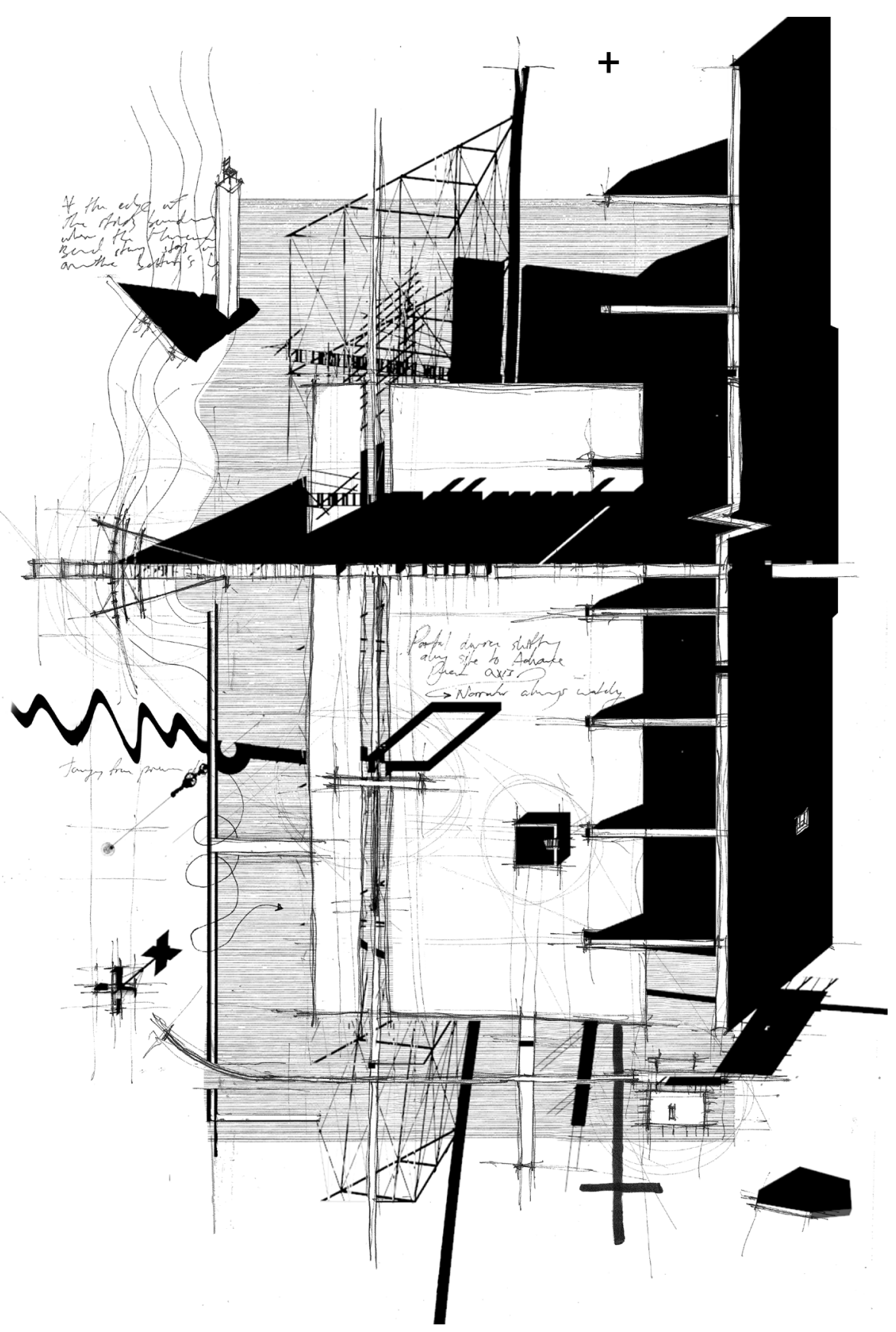

5.5.4 Conceptual plan exploring the Aerial Cableway's axis and its relation to the border of the site. Interventions on mechanised tracks populate the rectangle as explorations of the cableway's transitional connection. 


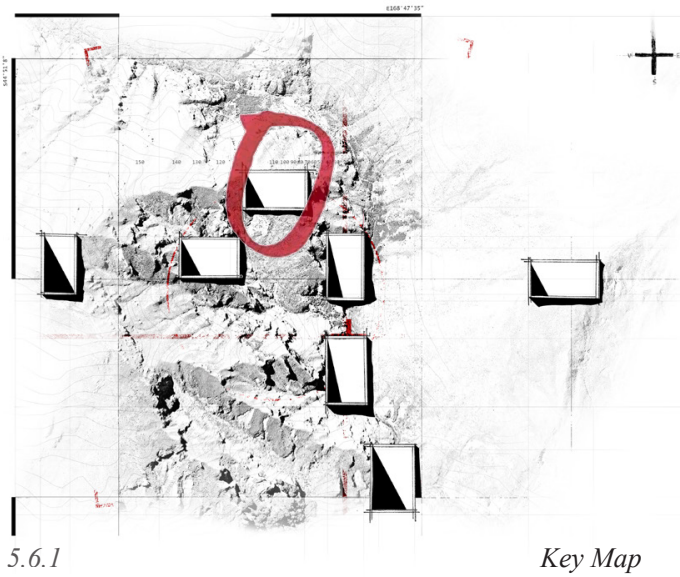

\section{2 .6}

\section{PLAN EXPERIMENT 6}

\section{Introducing the Water Race}

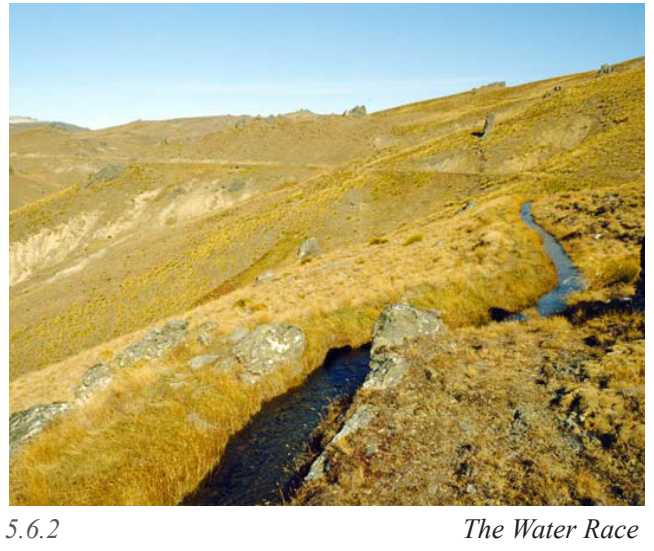

The Water Race represents a Cut dug horizontally in the hills to reach the quartz veins within the landscape. This Concept Design experiment is sited on top of the hill above the redirected stream, in view of the surrounding hills where the Water Races were cut. The edge of the site is represented by a monolithic wall, with the page held above the landscape. Two primary cuts are identified; the first is aligned with true North, and the second is aligned with the man-made machine remnants on site.

Landscape artist Michael Heizer's project Double Negative is interrogated due to its exploration of the cut as well as its connotations of something that is no

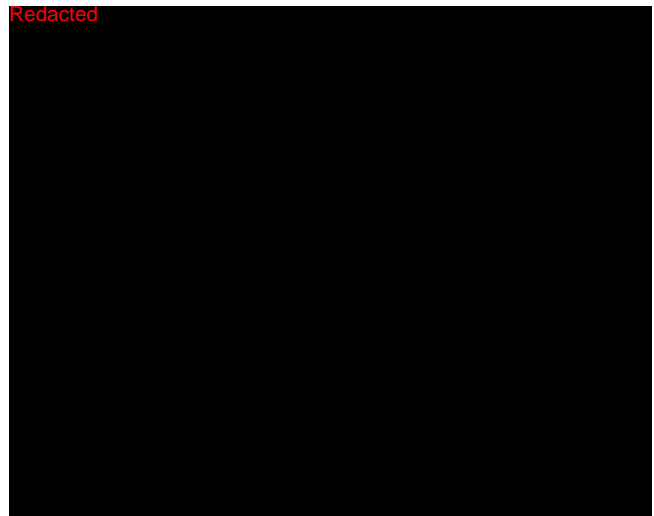
longer there. Heizer's project cuts two deep trenches over a canyon, suggesting a connection has now been severed - similar to the Water Races that now lie dry.

Solid walls on the North axis represent natural systems of the site, while machine remnants are explored through the development of mechanised interventions - interrogating their confrontational relationships through the allegory of the cut. 


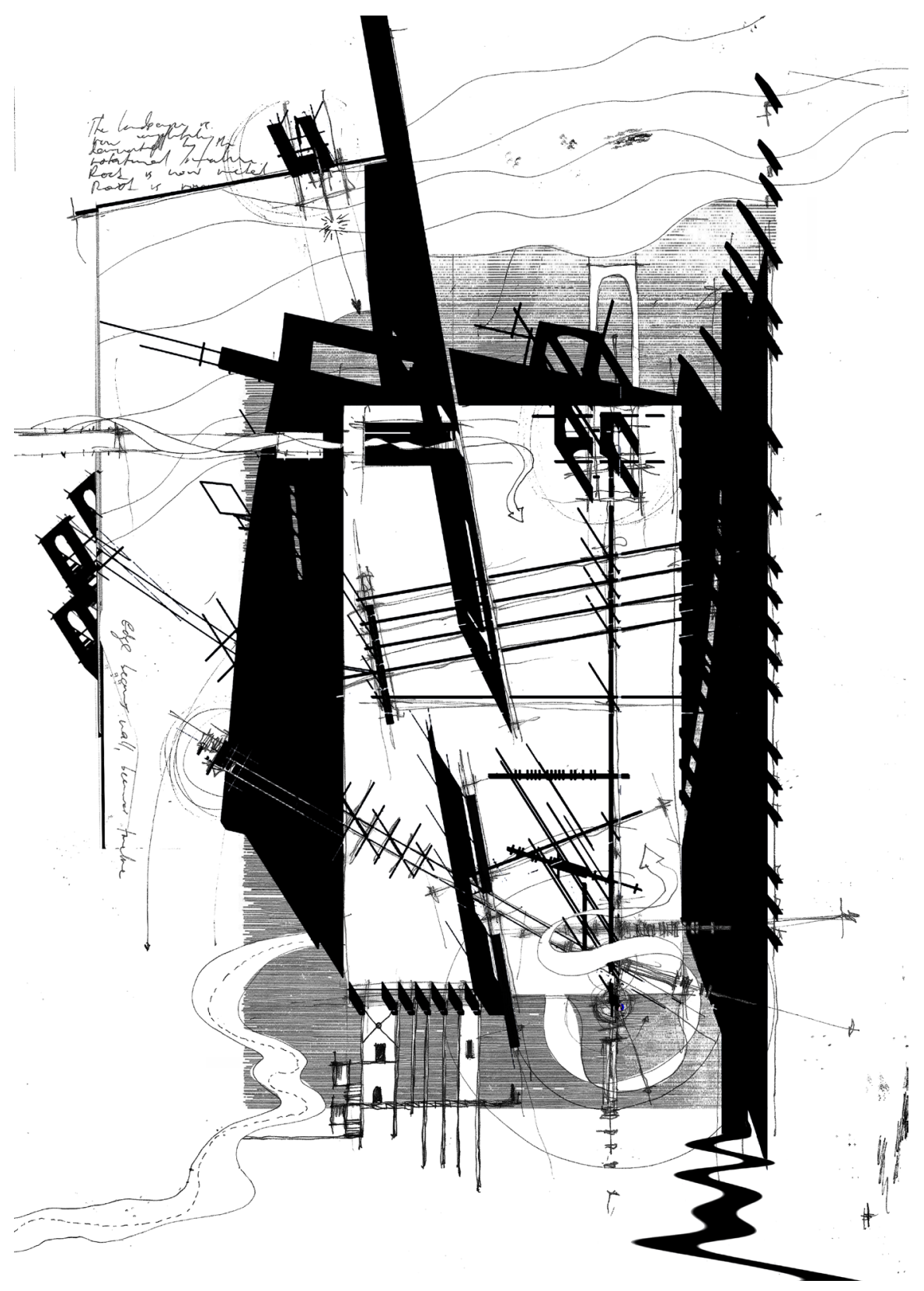

5.6.4 Conceptual plan exploring the axis the Water Race is located on versus the NSEW axis. Mechanised interventions shift back and forth, connected to a hidden machine underneath through cuts in the rectangular plane. 


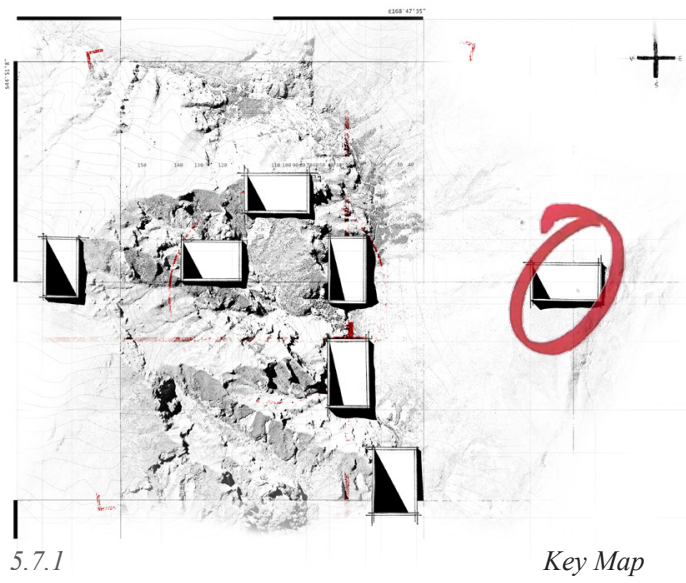

\section{2 .7}

\section{PLAN EXPERIMENT 7}

\section{Introducing the Mountain}

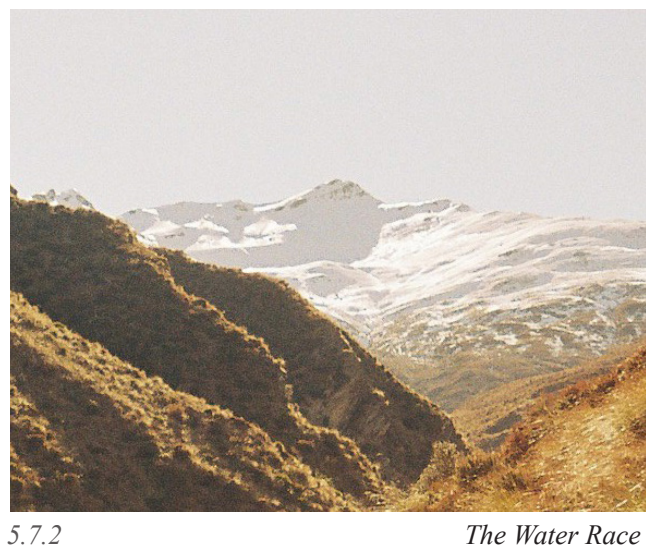

The distant Mountain represents a silent witness. The final Concept Design experiment in this series is the only one to sit on the eastern side of the Redirected Stream. Its position and altitude allow it to look back upon all the characters and proposed intervention sites, watching over the site like a silent witness.

This drawing applies principals of Form:uLA founder Bryan Cantley's project Batman Series, which is about witnessing time. Cantley's design proposes a form with a central pivot point, its anthropomorphised arm operating like a clock with drawn notations creating a timeline. This allegorical notation device is applied to Experiment 7 through the combination of mechanical arms and revealed structure beneath the page.

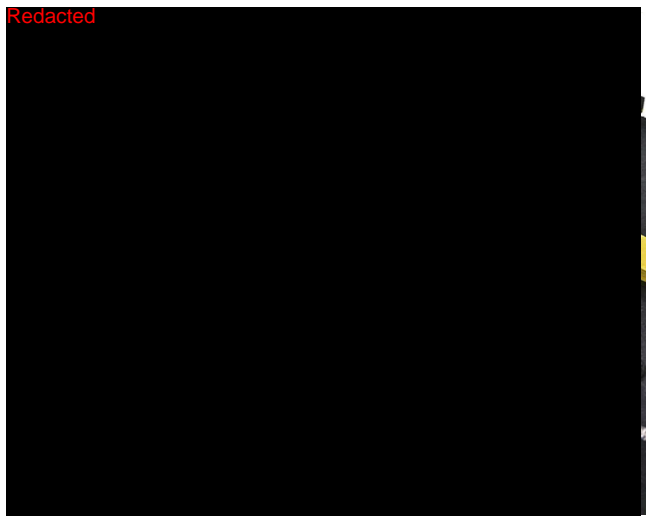

The monolithic wall from Experiment 6 continues across the wall lining the edge of the Homeward Bound site. A 'sentinel-like' architectural form extends from below the page, with two mechanised arms consisting of a framing device and viewing platform enabling elements to be silently witnessed individually as well as simultaneously. 


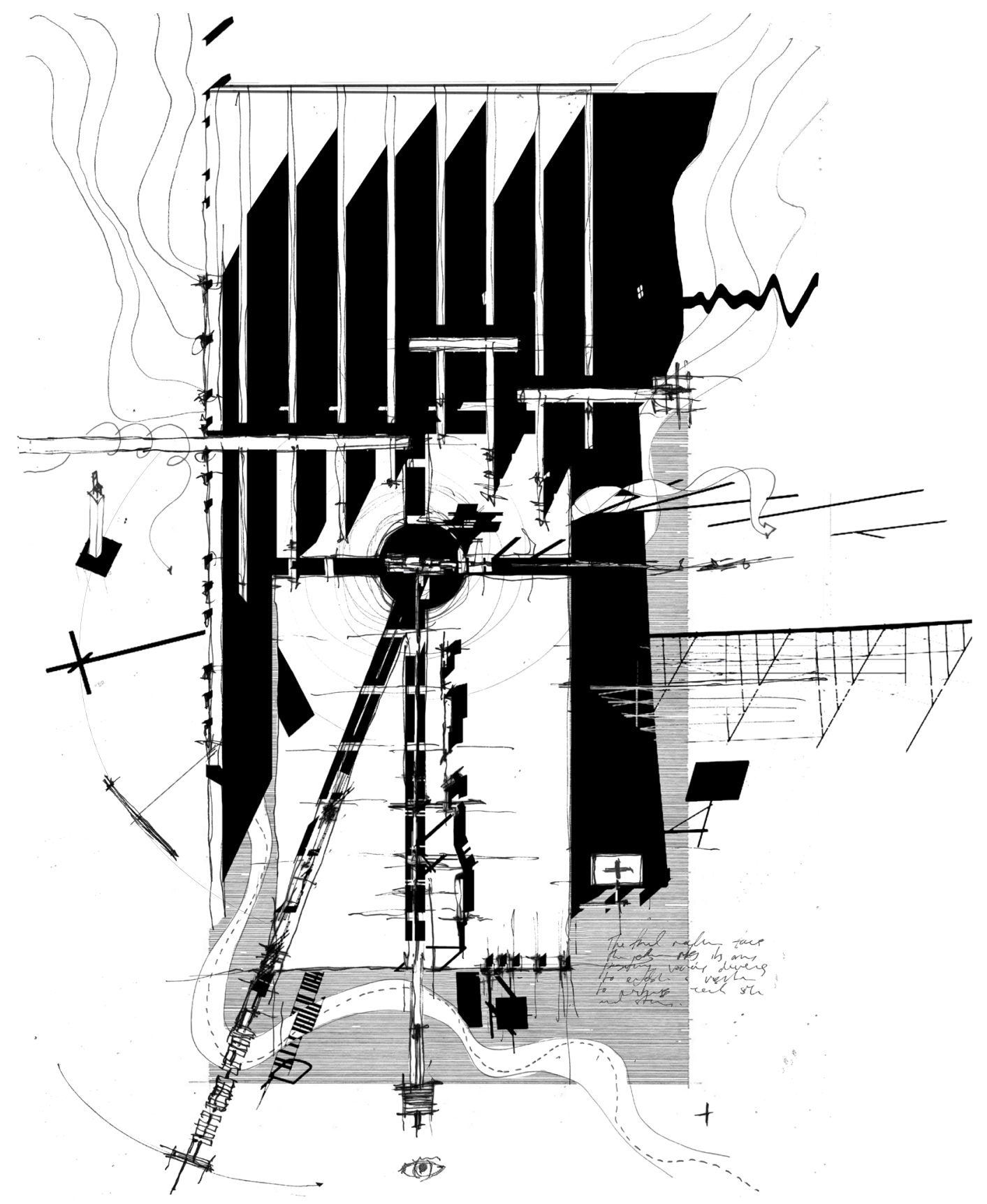

5.7.4 Conceptual plan exploring a point of pause that silently witnesses all other characters simultaneously, arms rotating around a central fulcrum to witness various confrontational relationships. 


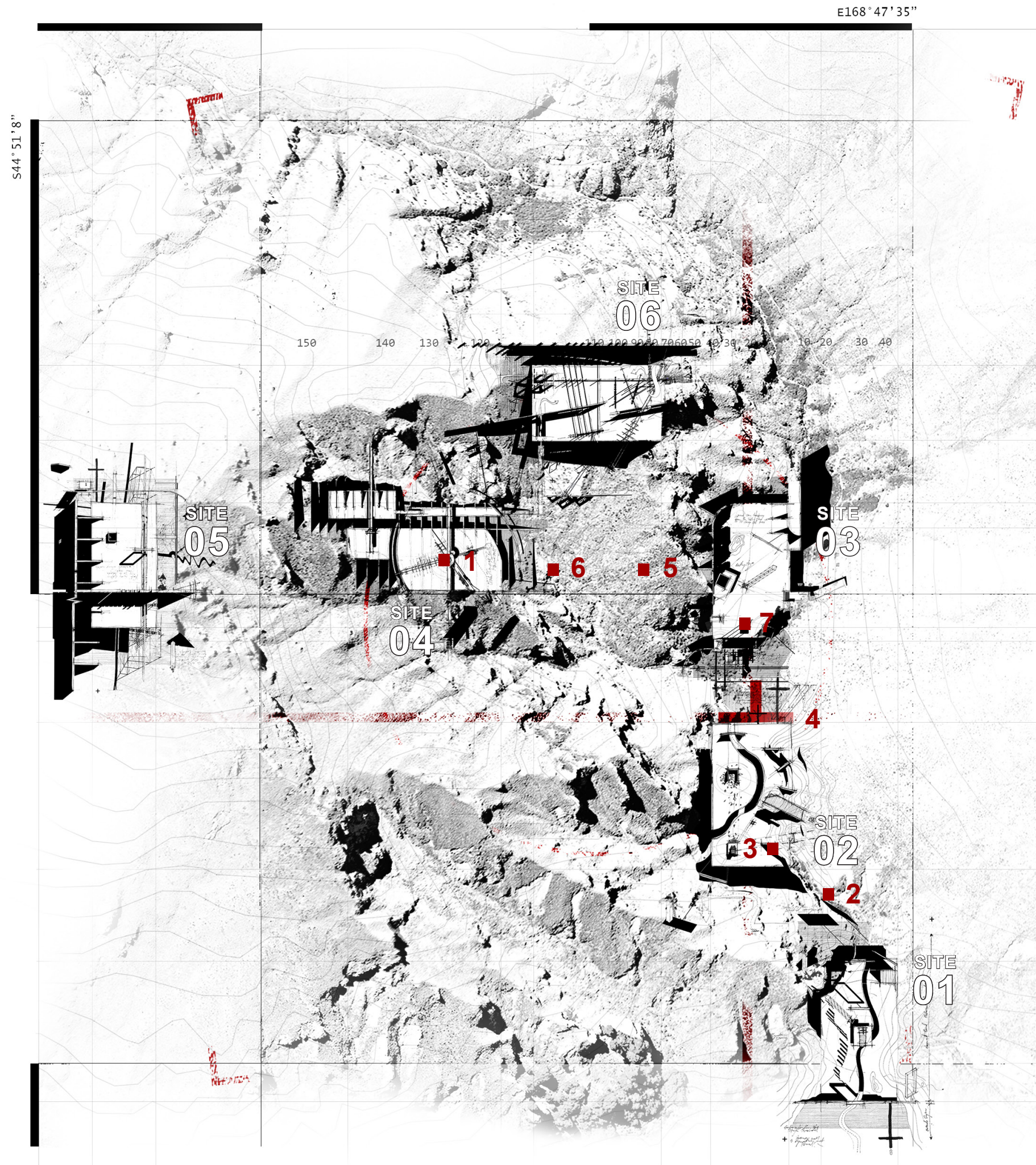

Fig 5.8 Master plan showing the Concept Design experiments situated upon the site in relation the seven remnant characters. 

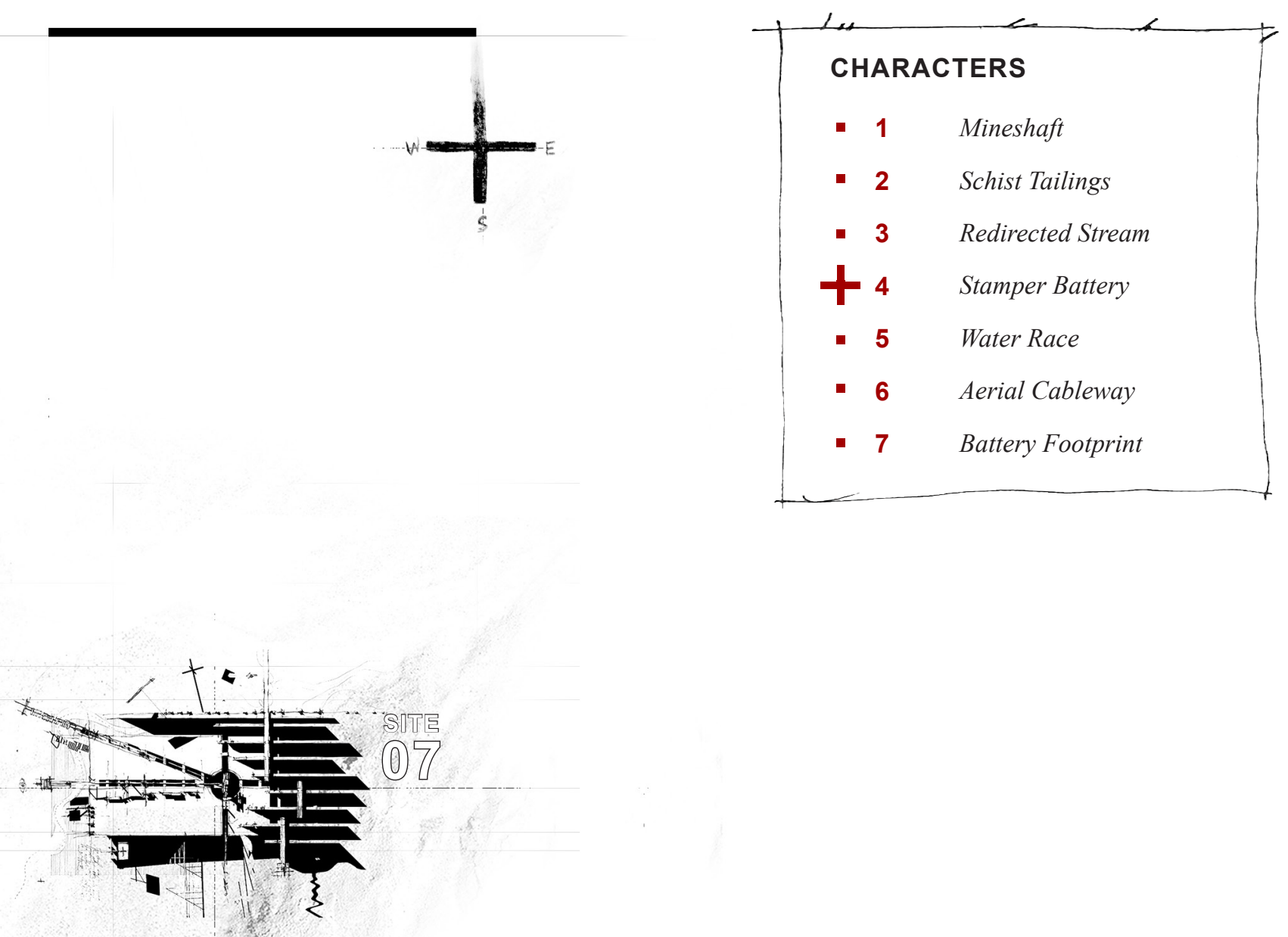

5.3 INTERVENTIONS SITED

This master plan situates the Concept Design chapter's seven plan view experiments into the Homeward Bound Site, where they represent the allegorical attributes of the seven characters of the site.

The speculative Master Plan indicates how some interventions like Site 07 are able to survey nearly the entire site - and watch the multiple confrontations of various characterswhile others like Site 02 are only able to witness a single relationship due to the obstructing landscape. 


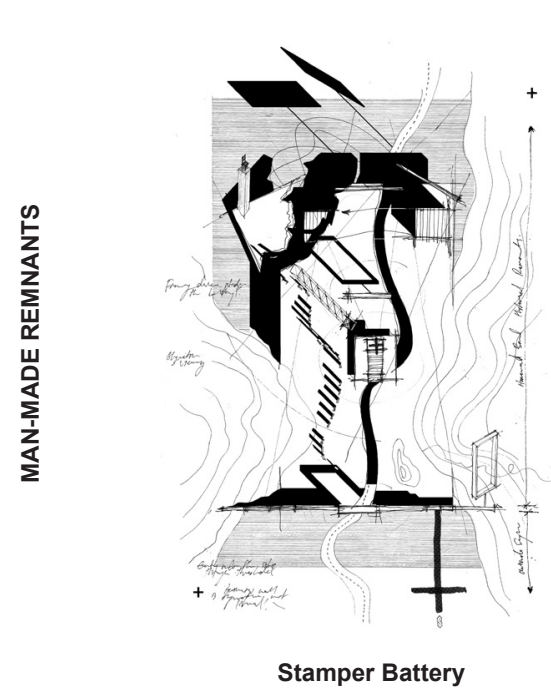

A story of place identity defined by convergence.

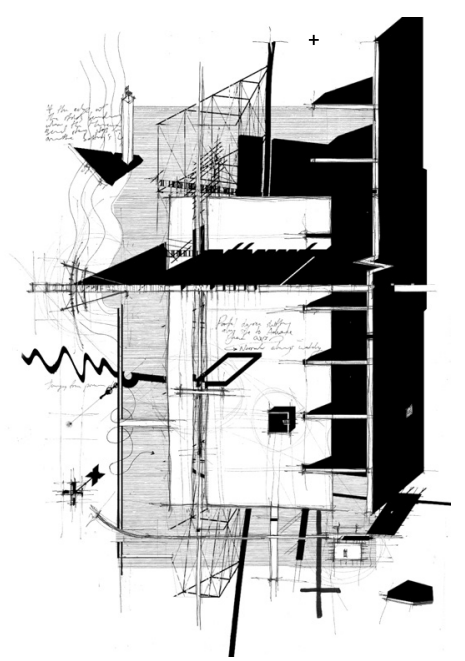

Aerial Cableway

A story of place identity defined by transition.

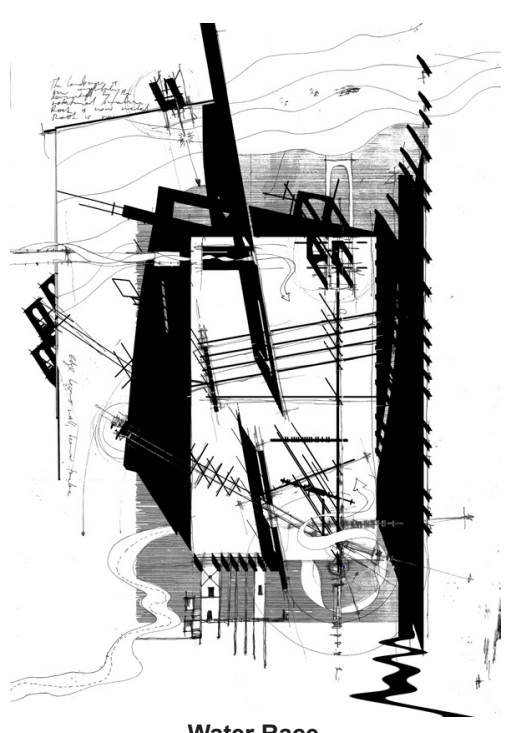

Water Race

A story of place identity defined by a cut.

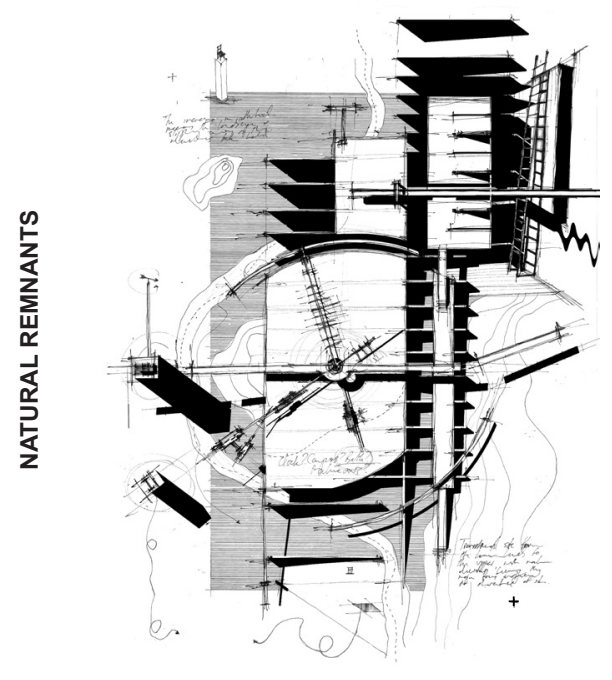

Mineshaft

A story of place identity defined by void.

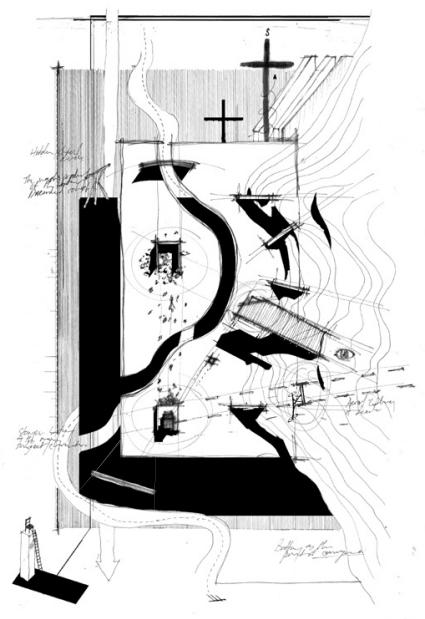

Schist Tailings

A story of place identity defined by displacement.

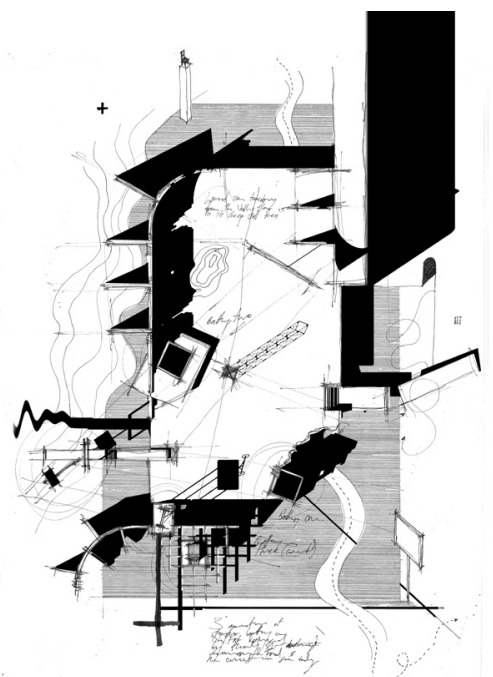

Battery Footprint / Redirected Stream A story of place identity defined by traces and deviation.

Fig 5.9 Concept Design: The Allegorical Architectural Project as speculative architectural drawings in plan view, representing place identity from the point of view of seven key remnants on the site-'actors' in an allegorical tale. The Mountain (opposite) stands as a silent witness over time. 


\subsection{CRITICAL REFLECTION}

The Concept Design stage of this investigation has taken the principal characters identified in the contextual analysis phase and interrogated them using orthographic and notational techniques outlined in the Literature and Project Review chapter. Relevant case studies were adapted and applied as architectural devices that enabled the narrative of the characters within each drawing to be unveiled through speculative drawing.

During this process, points of pause were identified as positions within the Homeward Bound Site to allow visitors to witness the tales of the selected characters. Each position presented a unique narrative born from the relationship between these remnants, and illustrating a conflict between environmental systems and man-made systems. As the Concept Design drawings progressed early in the thesis investigation it also became apparent that some points of pause witnessed a larger number of remnants and consequently more relationships-requiring more complex architectural interventions to enable all of these simultaneously.

The orthographic drawing technique of plan view was used in the Concept Design stage for its ability to clearly illustrate relationships using projection lines. As the relationships and drawings progressed, the edges of the drawings began to transform into liminal zones by incorporating other techniques such as axonometric and perspective in an attempt to gain a deeper understanding of spatial relationships.

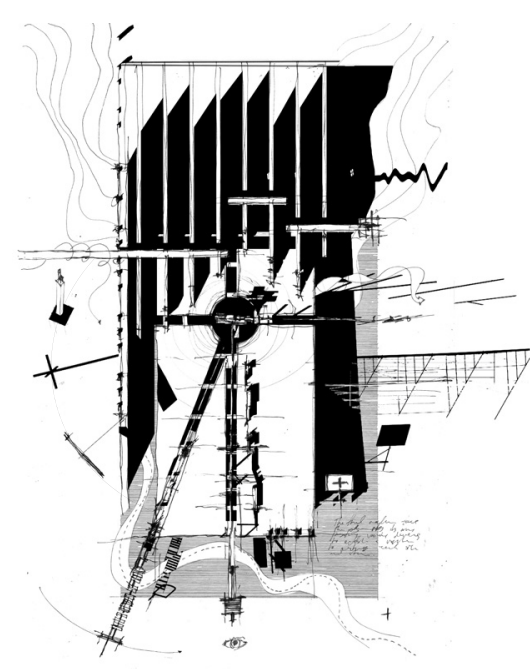

Mountain The silent witness. This suggests that the next stage of design should utilise a threedimensional orthographic technique to continue to develop these spatial relationships, and thus explore the confrontational narratives further.

The use of notational strategies and devices such as contours and shadows were initially applied in traditional ways, and as the drawings progressed, these were adapted through experimentation. Shadows began to warp and ripple, informing the contours beneath them, while their shifting also implied that the drawings took place over a passage of time.

The Concept Design phase interrogated the individual stories of the Homeward Bound site reasonably successfully in relation to RO1 and $\mathrm{RO} 2$, but is yet to bring those stories together into a meaningful and multilayered meta-narrative. The Preliminary Design phase will be used to continue extracting these polyvocal stories. 
'You talk as if a god had made the Machine,' cried the other.

'I believe that you pray to it when you are unhappy. Men made it, do not forget that.

Great men, but men.' 

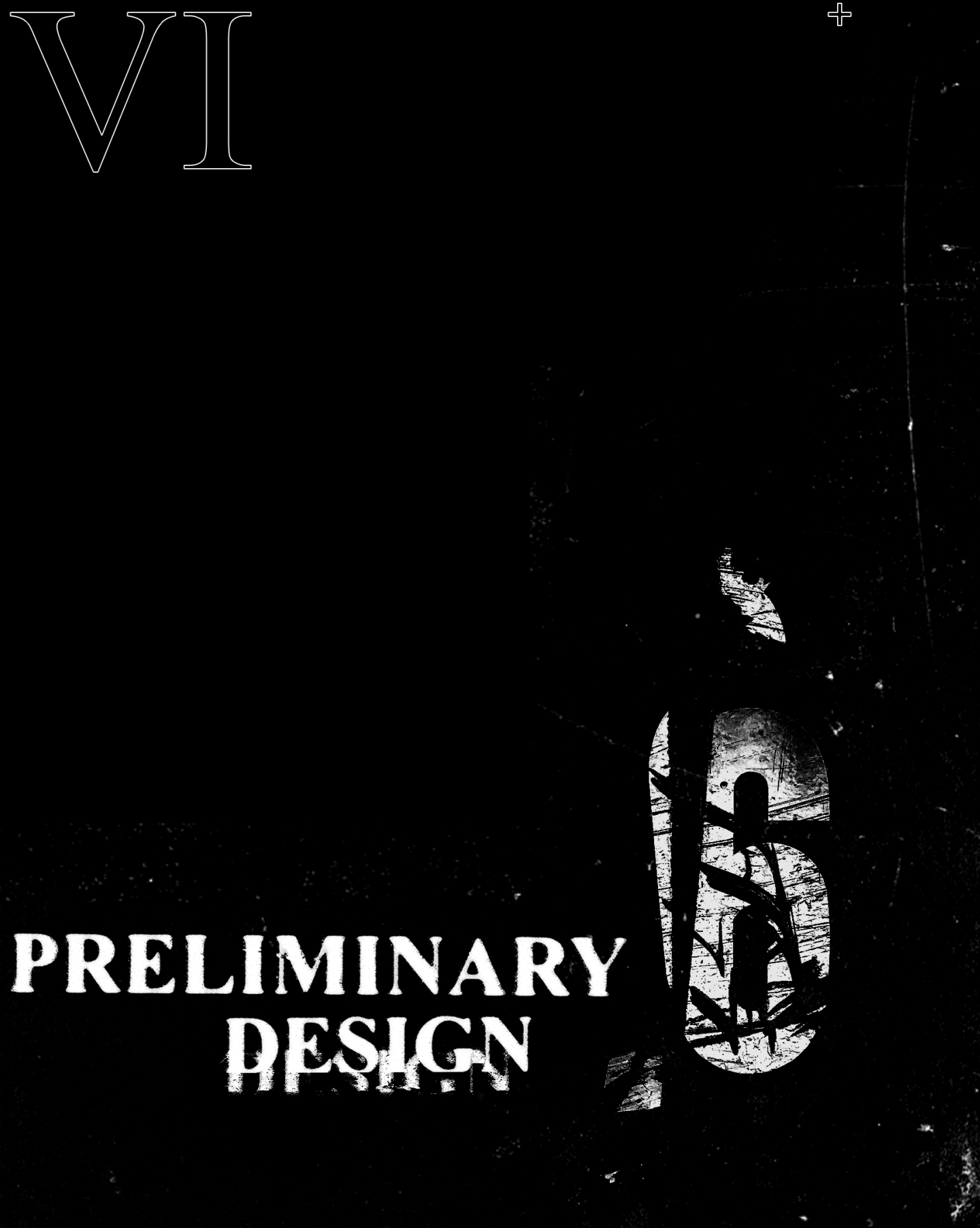


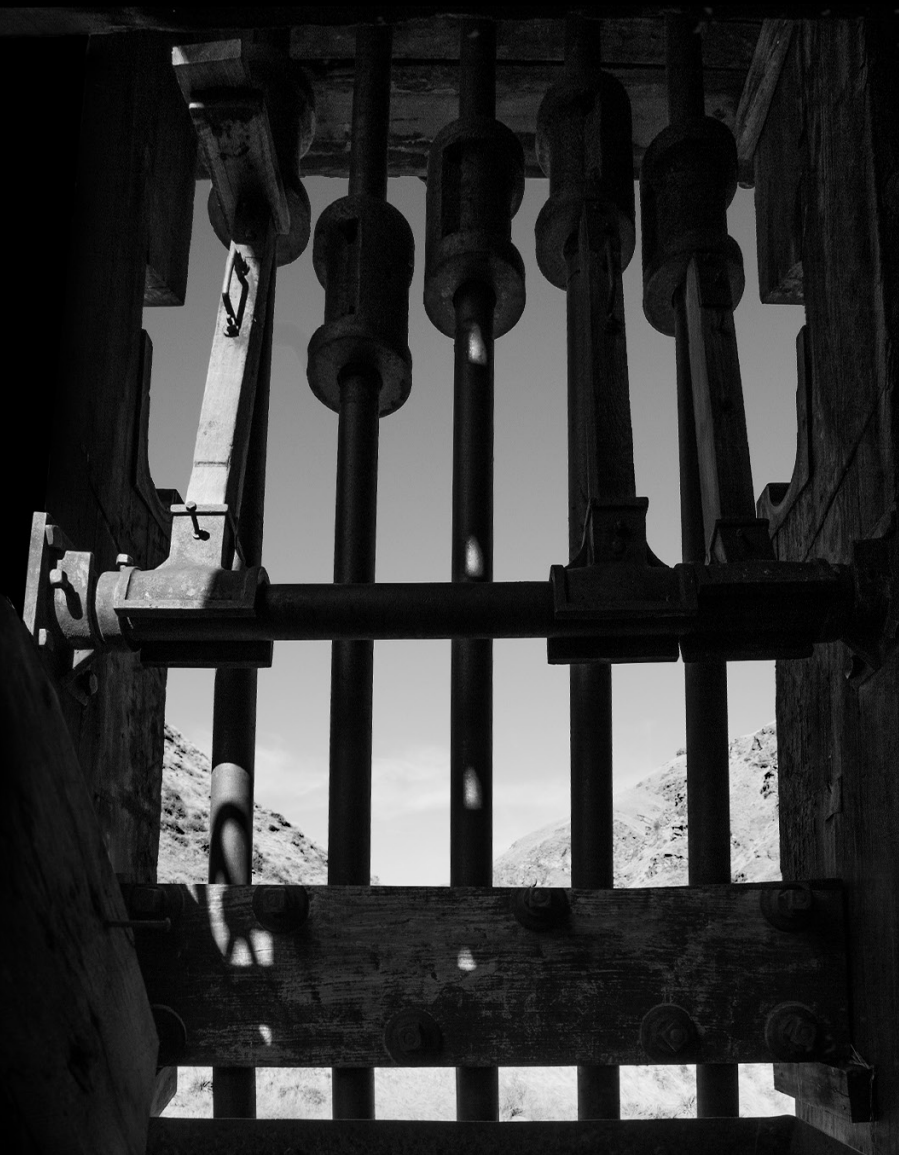




\subsection{INTRODUCTION}

The Preliminary Design chapter builds upon the plan view speculative drawings developed in the Concept Design chapter and develops them further using the three-dimensional technique of axonometric. This chapter aims to capture the individual narratives while also developing a method to allow visitors to witness multiple stories simultaneously in response to Research Objective 3:

To explore how layering allegorical drawings can enable relationships of time, place and point of view to be simultaneously recognised and understood.

The chapter begins with an interrogation of architectural designer and theorist Raimund Abraham's Cosmology of the House as a principle case study. Abhraham's project utilises orthographic drawing and projection lines to establish an allegorical dialogue between various architectural elements speculatively situated upon a rectangular plane. The project offers additional new notation devices such as text and projection lines to further manifest the narrative of these confrontations. The learnings from this interrogation is then applied in axonometric experiments that are ultimately conceptualised as an overall master plan situating the stories of the key interventions for the Homeward Bound site.

Following the principal case study interrogation and related experiments, the chapter presents seven rendered axonometric drawings, each re-imagining the initial plan experiments from the Concept Design chapter, this time in three dimensions. Additional notation devices such as allegorical clock mechanisms are used to integrate concepts of time, and the stories of different characters are encouraged to overlap.

These axonometrics are next layered using transparent paper and then digital processing to result in a final drawing that combines them all into a single composition-enabling all seven individual stories to be witnessed simultaneously, while the meta-narrative of the site also beings to emerge.

Fig 6.1 Inside the stamper battery—looking toward the fragmented landscape through the stone crushing mechanism, photo by author. 


\subsubsection{PRINCIPAL CASE STUDY}

\section{Interrogation}

Raimund Abraham's Cosmology of the House is interrogated in this chapter as an exploratory method that utilises orthographic drawing (specifically axonometric) to place landscape and architectural features together into a confrontation in relation to RO1. Abraham's speculative drawing also incorporates notational devices such as text, projection lines and his own cartoon symbols of landscape and architectural elements which are relevant to RO2.

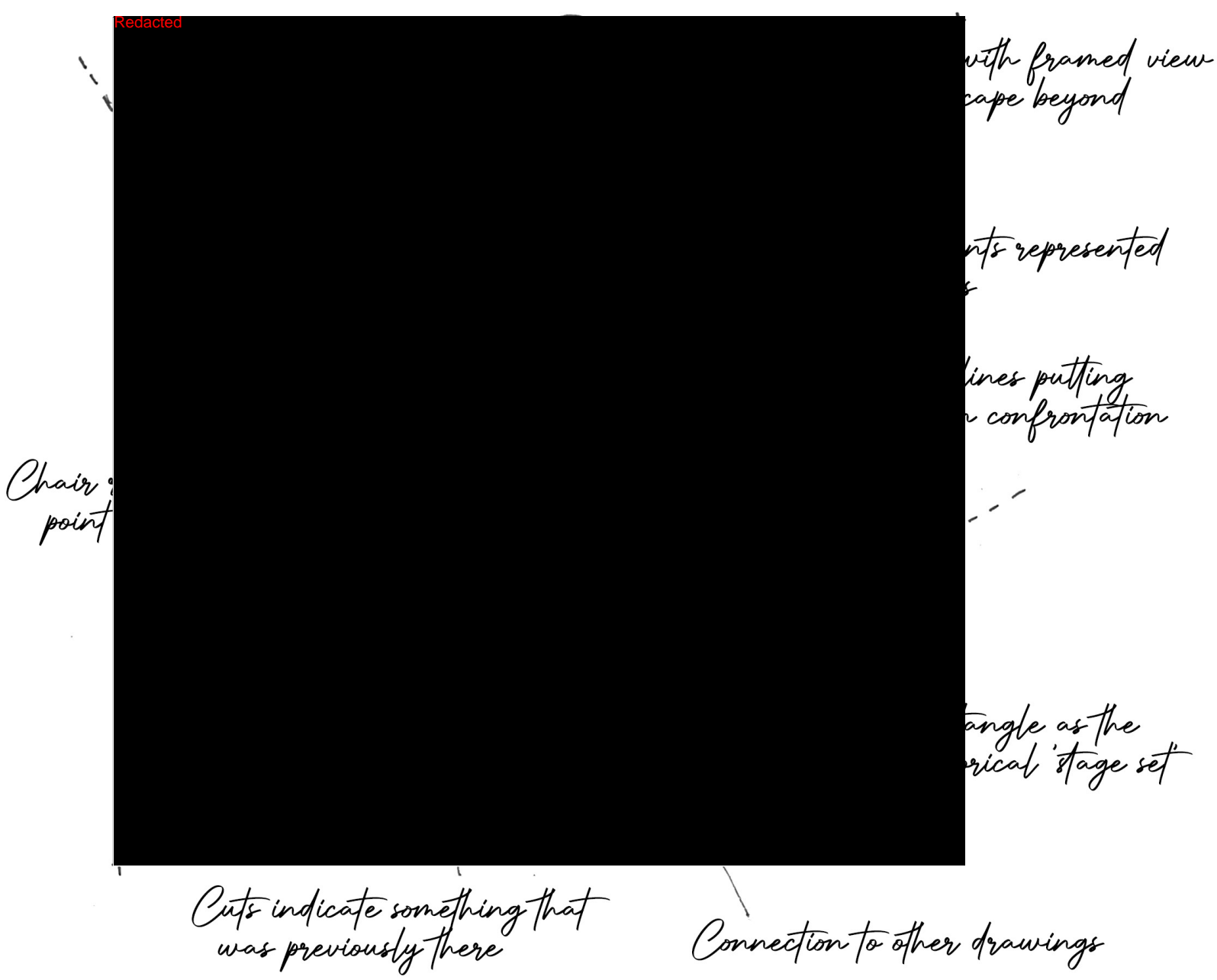

Fig 6.2.1 Cosmology of the House (1974) by Raimund Abraham. Notes by author interrogate the case study, and highlight Abraham's use of a rectangular plane as an allegorical stage set and the various interventions that inhabit the space. 


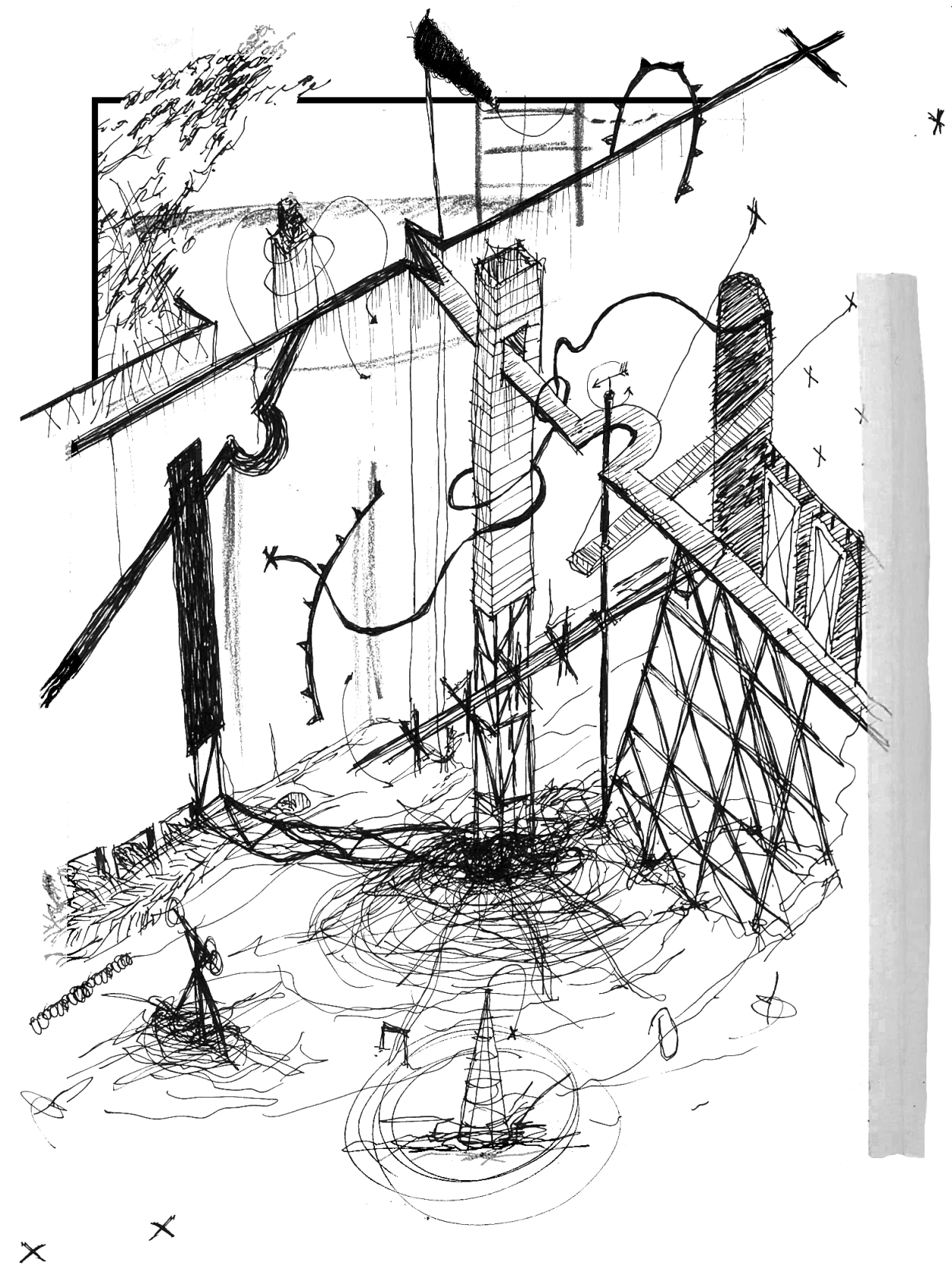

Fig 6.2.2 Axonometric sketch by author exploring how confrontation and notation techniques from Cosmoslogy of House can be applied in this investigation. 


\subsubsection{AXONOMETRIC EXPERIMENTS \\ The Master Plan}

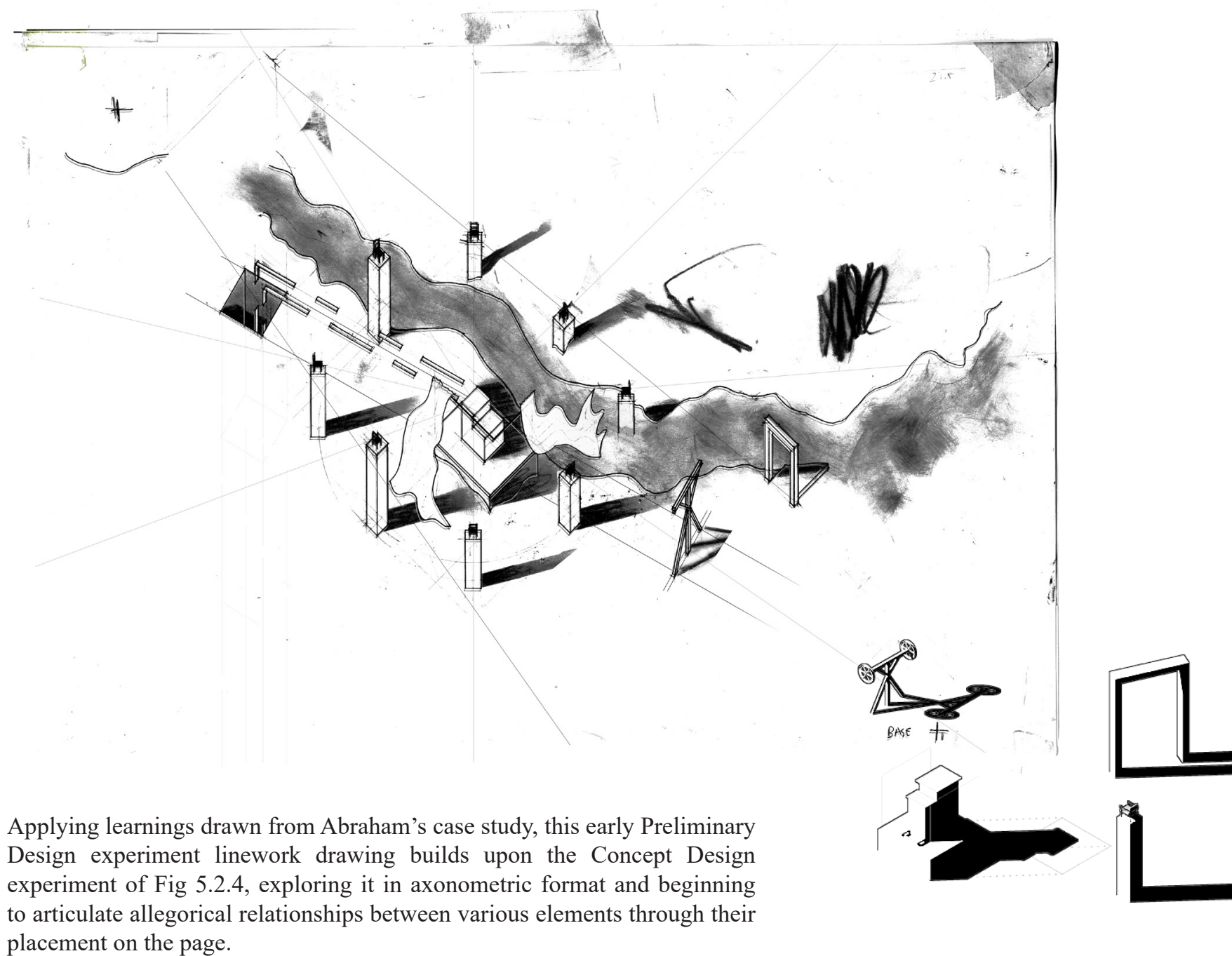




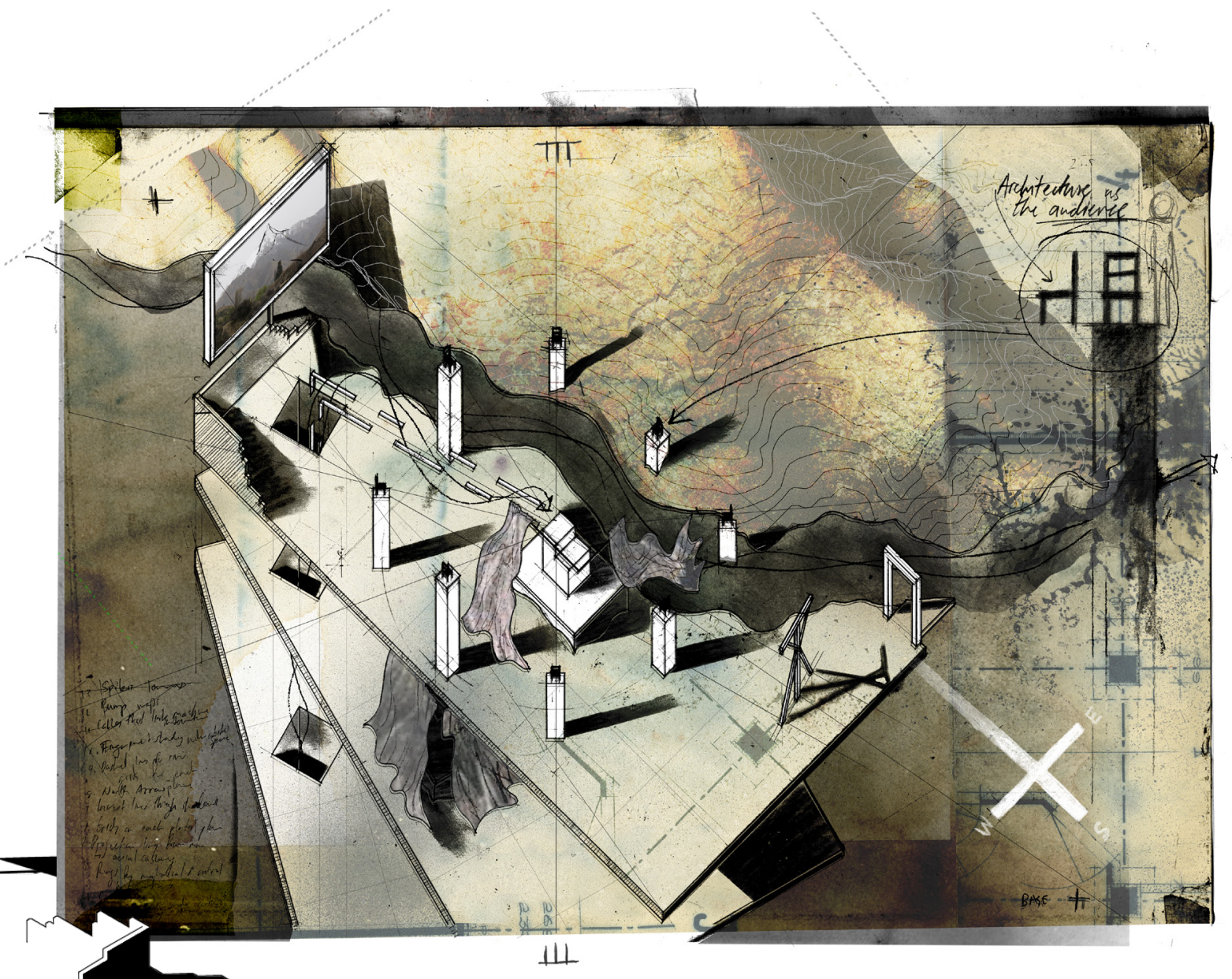

Axonometric Experiment 1 explores the site as a masterplan, with chairs upon columns allegorically representing the seven key characters plus the Mountain as the silent witness. In this preliminary design conceptualisation, the allegorical 'play' is represented as a 'stage' in the centre, with the narratives of the other similar mining operations in the area represented by the layers below. 


\subsubsection{AXONOMETRIC EXPERIMENT 1 \\ The Stamper Battery}

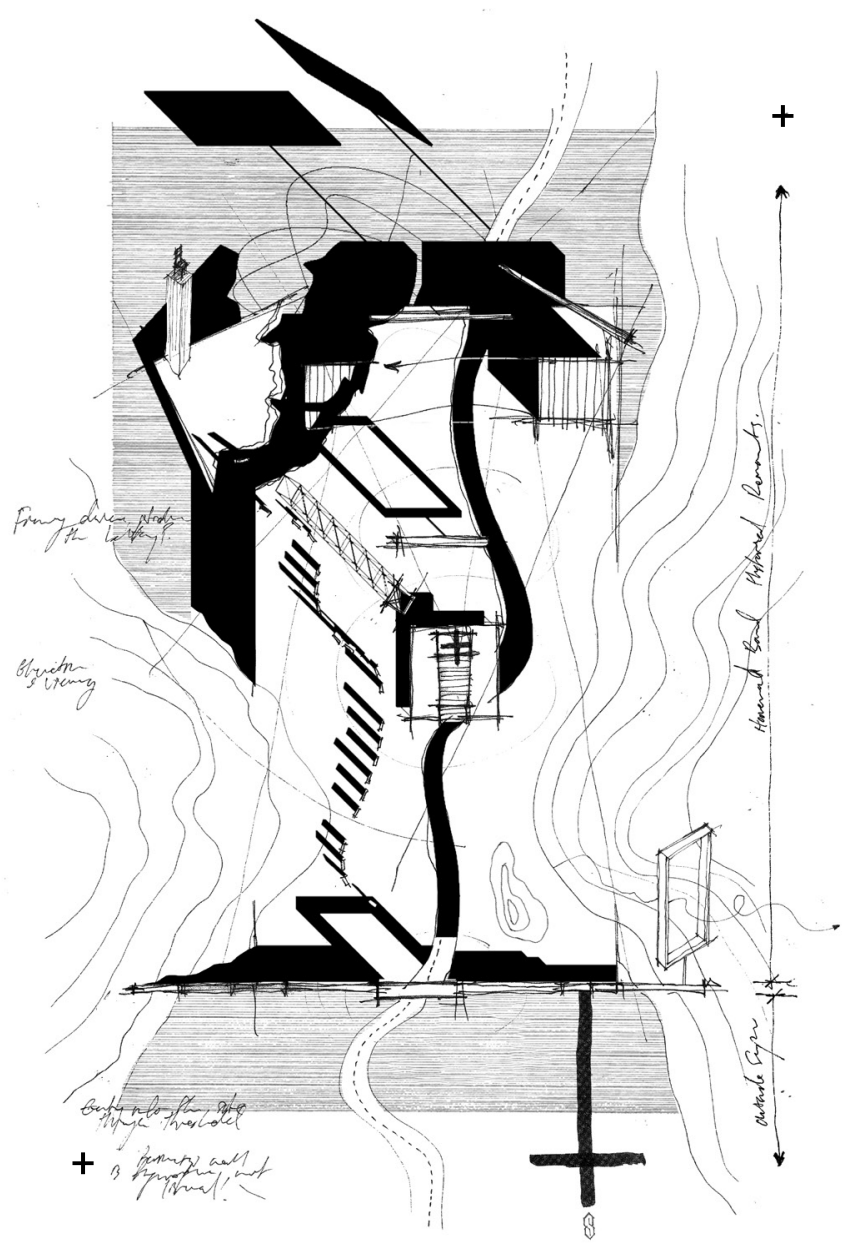

To apply the learnings from the interrogation and application of Raimund Abraham's Cosmology of the House, the schematics and devices of Concept Design Plan Experiment 1 are extracted to build a Preliminary Design stage axonometric drawing.

Individually (figure 6.3.2), the elements are simple architectural devices such as a frame, gate or billboard, but assembled strategically they begin to enable a narrative through their relationships.

The following series of drawing experiments take these elements and place them into allegorical confrontations using projection lines and the axonometric format, applying the theories of Catherine Hamel and Stan Allen to enable an allegorical narrative through critical relationships. 
...the axonometric can be seen as a generic technique for architecture, but when you find a way to appropriate it and make it into your own, it becomes a very particular way of drawing, a particular way of producing drawing.

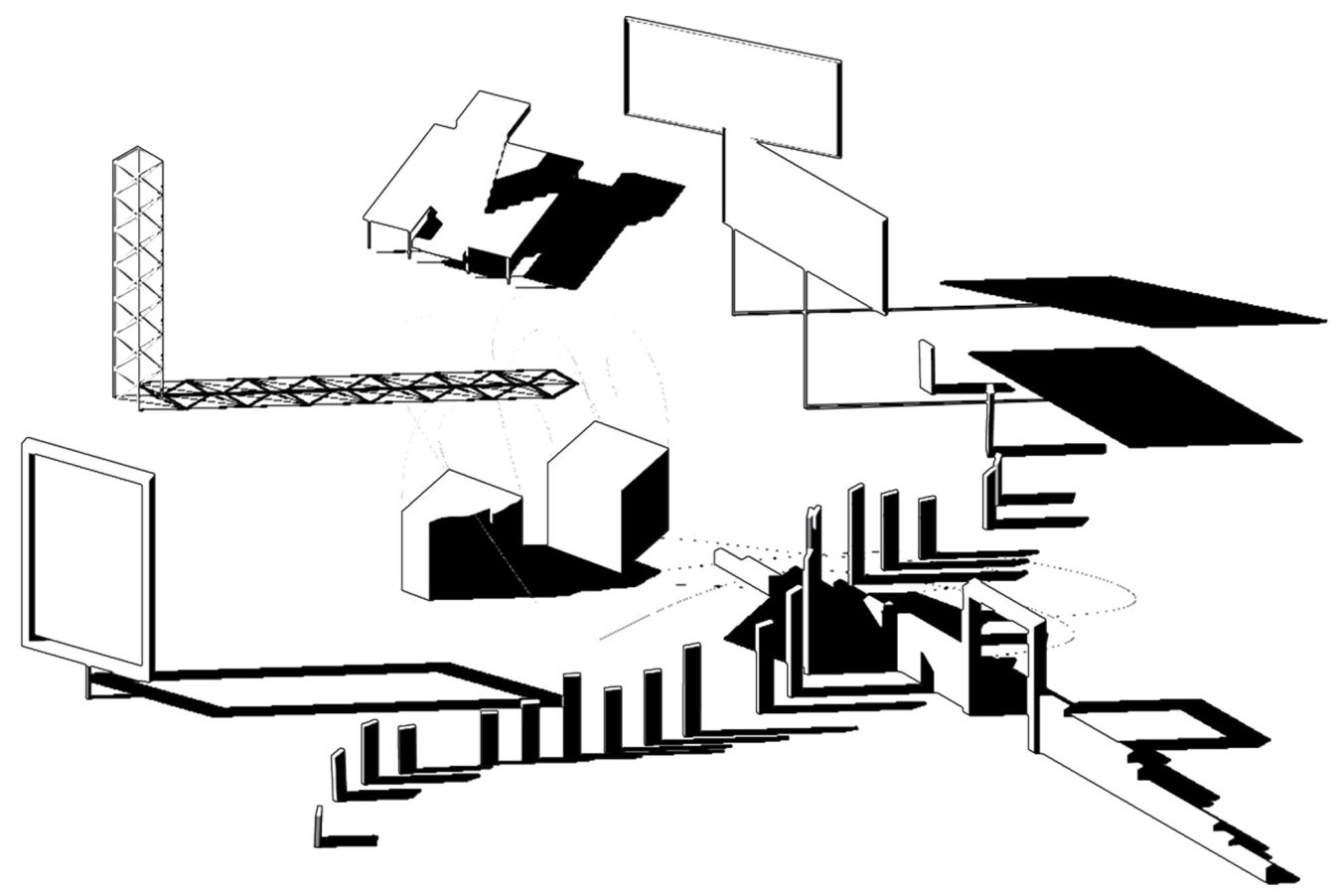




\subsubsection{AXONOMETRIC EXPERIMENT 1 The Stamper Battery}

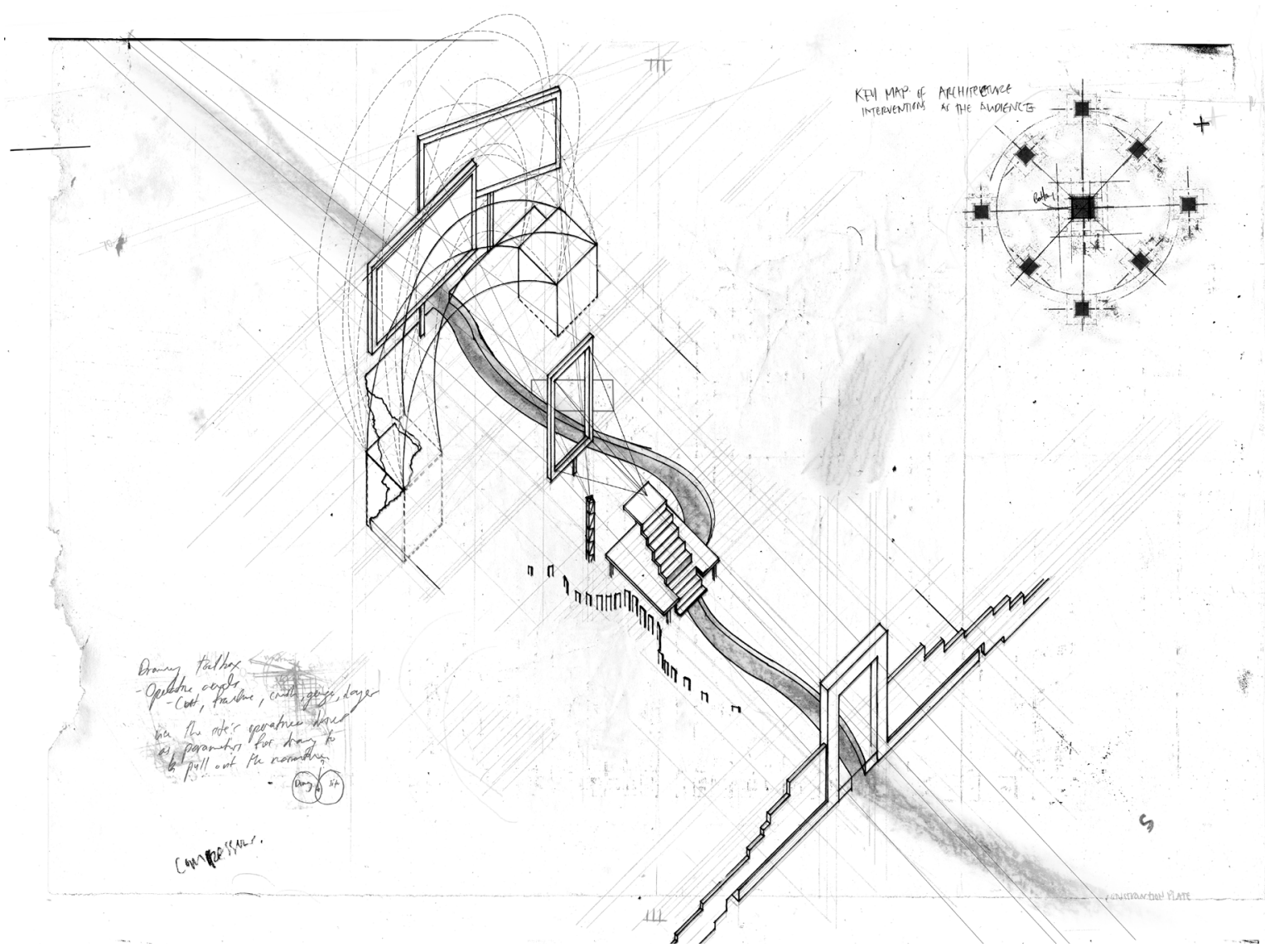

This preliminary experiment for the Stamper Battery drawing illustrates the use of projection lines and axonometric drawing techniques to place the extracted elements into a dialogue of confrontation. Notational devices such as text, dashed lines and the axonometric notational devices from figure 6.2.3 begin to inform relationships of time, place and point of view. 


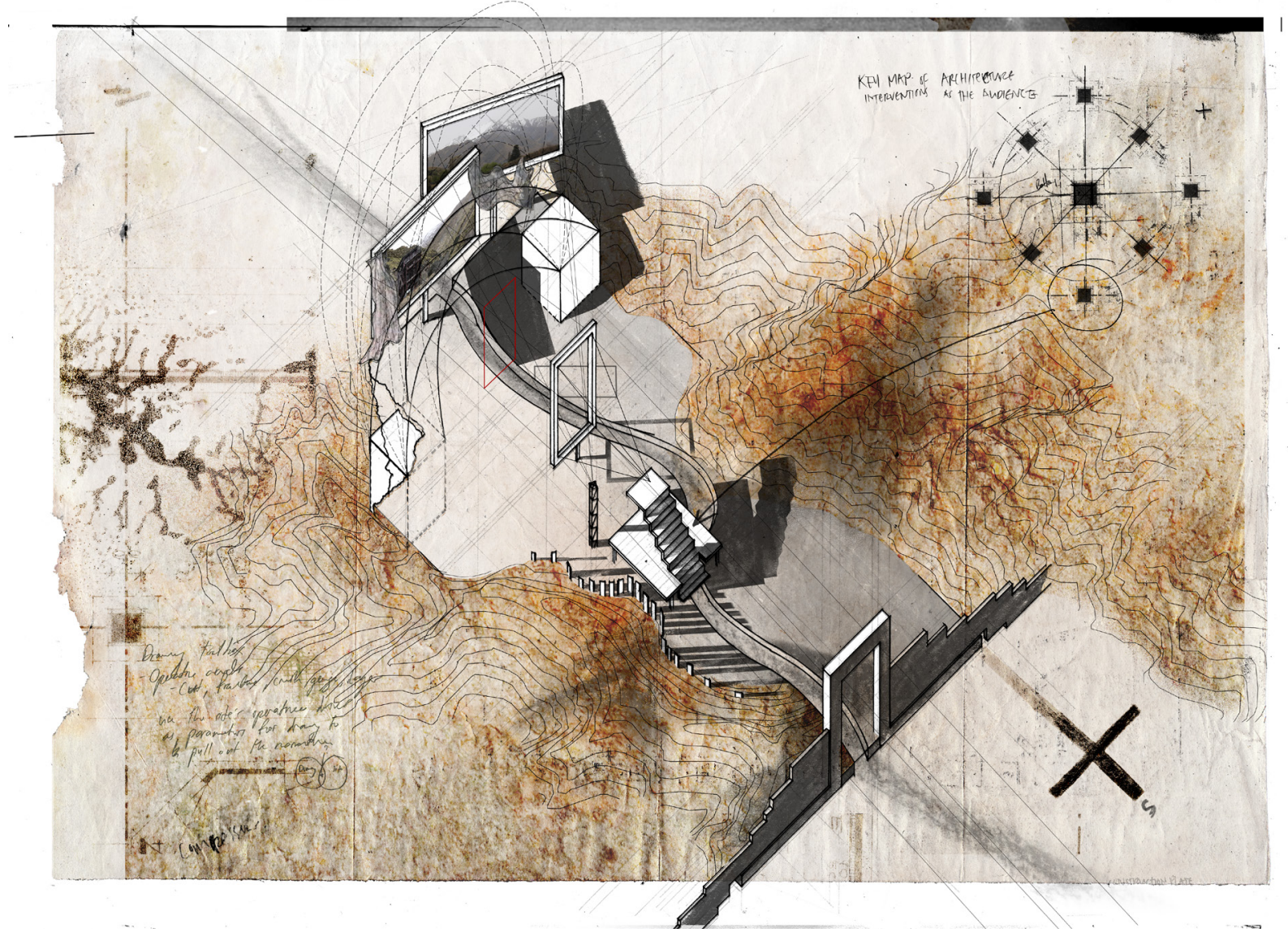

The Stamper Battery represents place identity as a convergence. In this case, natural resources and man-made systems met and mixed. Axonometric Experiment 2 explores a location on the threshold of the site, indicated by the wall and gateway entrance. A staircase above the river leads to a framing device that introduces the Stamper Battery as the first character. The landscape presses in on both sides while the Mountain can be seen in the distance. 


\subsubsection{AXONOMETRIC EXPERIMENT 2 The Schist Tailings}

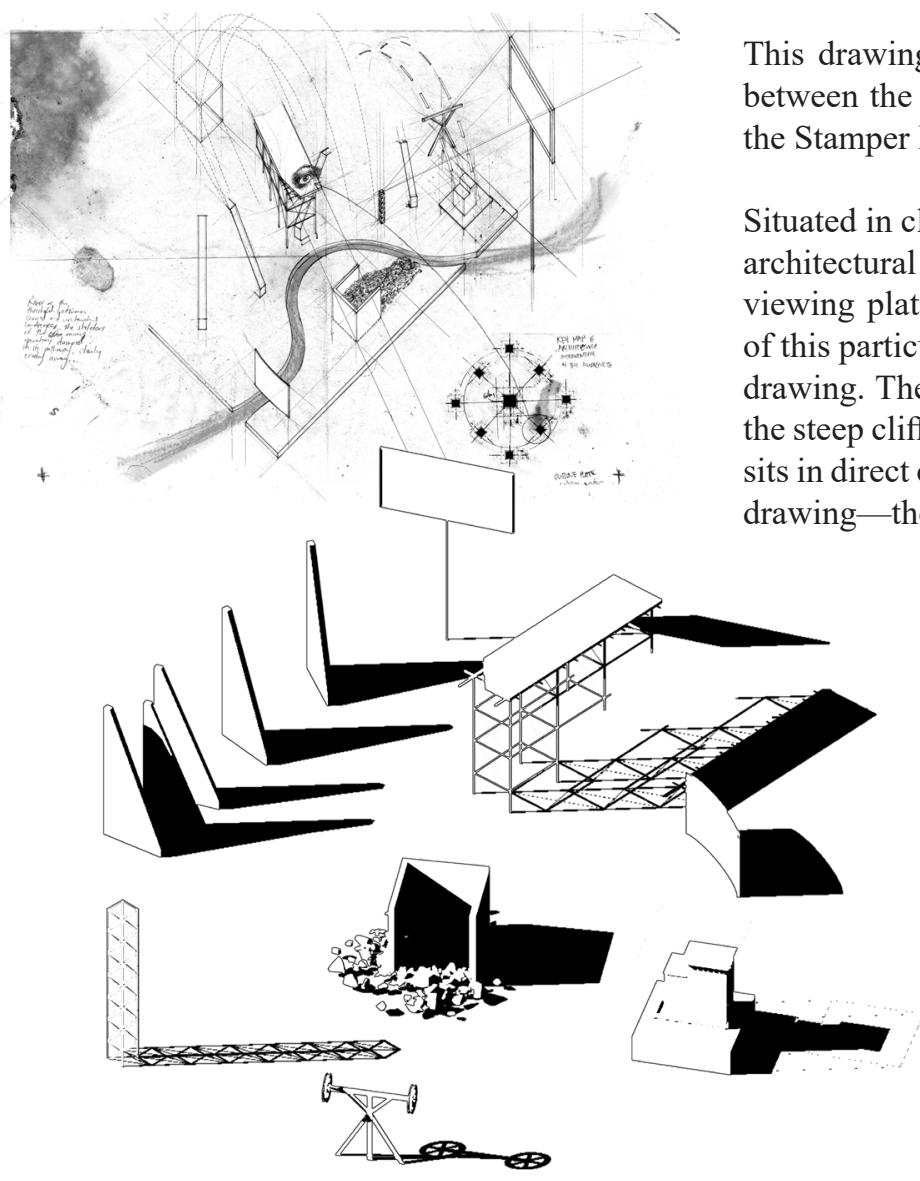




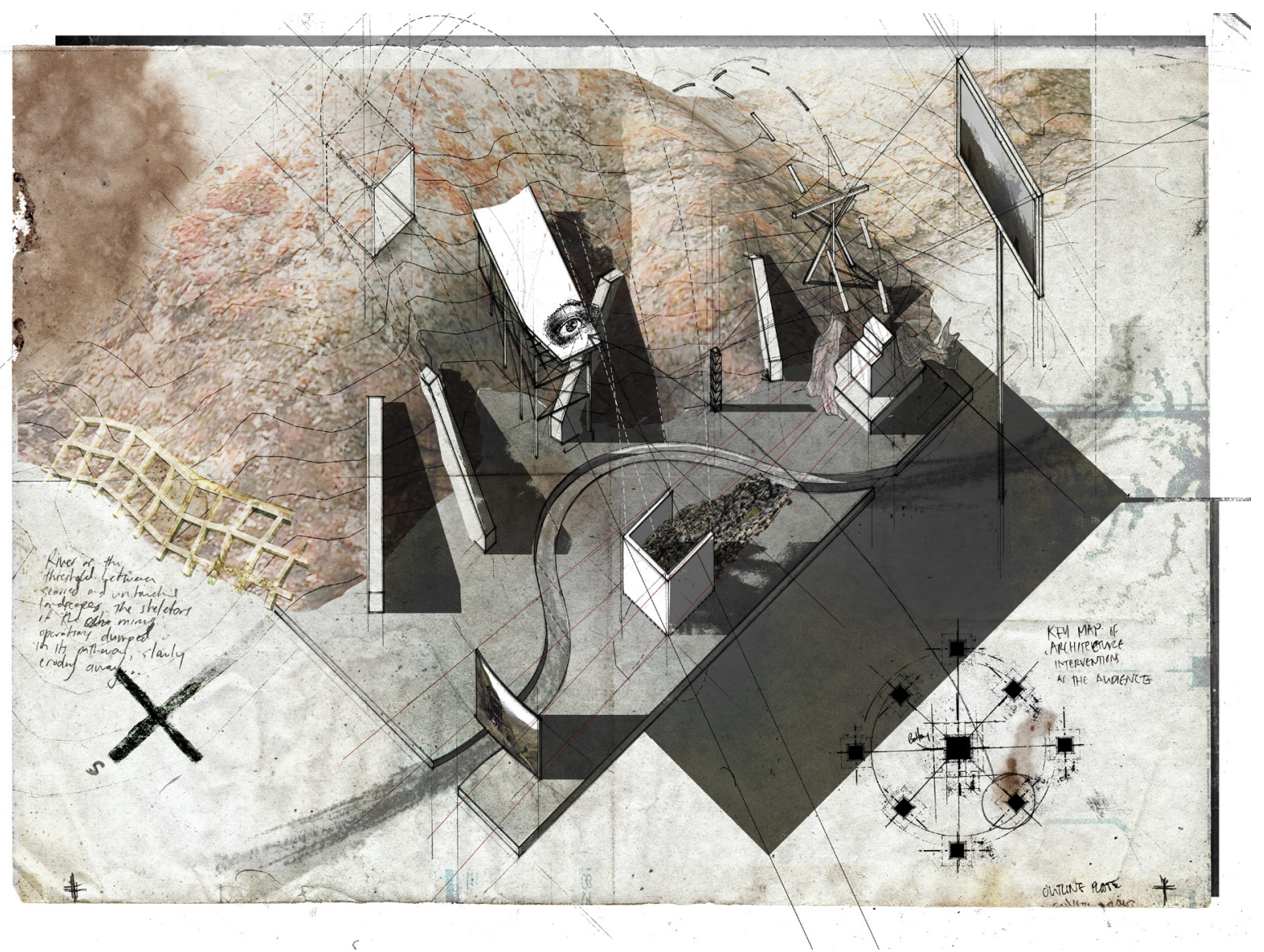

In Axonometric Experiment 3, the Schist Tailings represent place identity as a displacement. In this case, unwanted material from the rock-crushing process has been discarded in piles on the valley floor. The Redirected Stream represents place identity as a deviation. In this case, the stream has been redirected from its natural direction by the unwanted tailings discarded on the valley floor. The Stamper Battery sits in direct confrontation with the Tailings, while the steep landscape behind threatens to overrun the page. 


\subsubsection{AXONOMETRIC EXPERIMENT 3 The Battery Footprint and Redirected Stream}

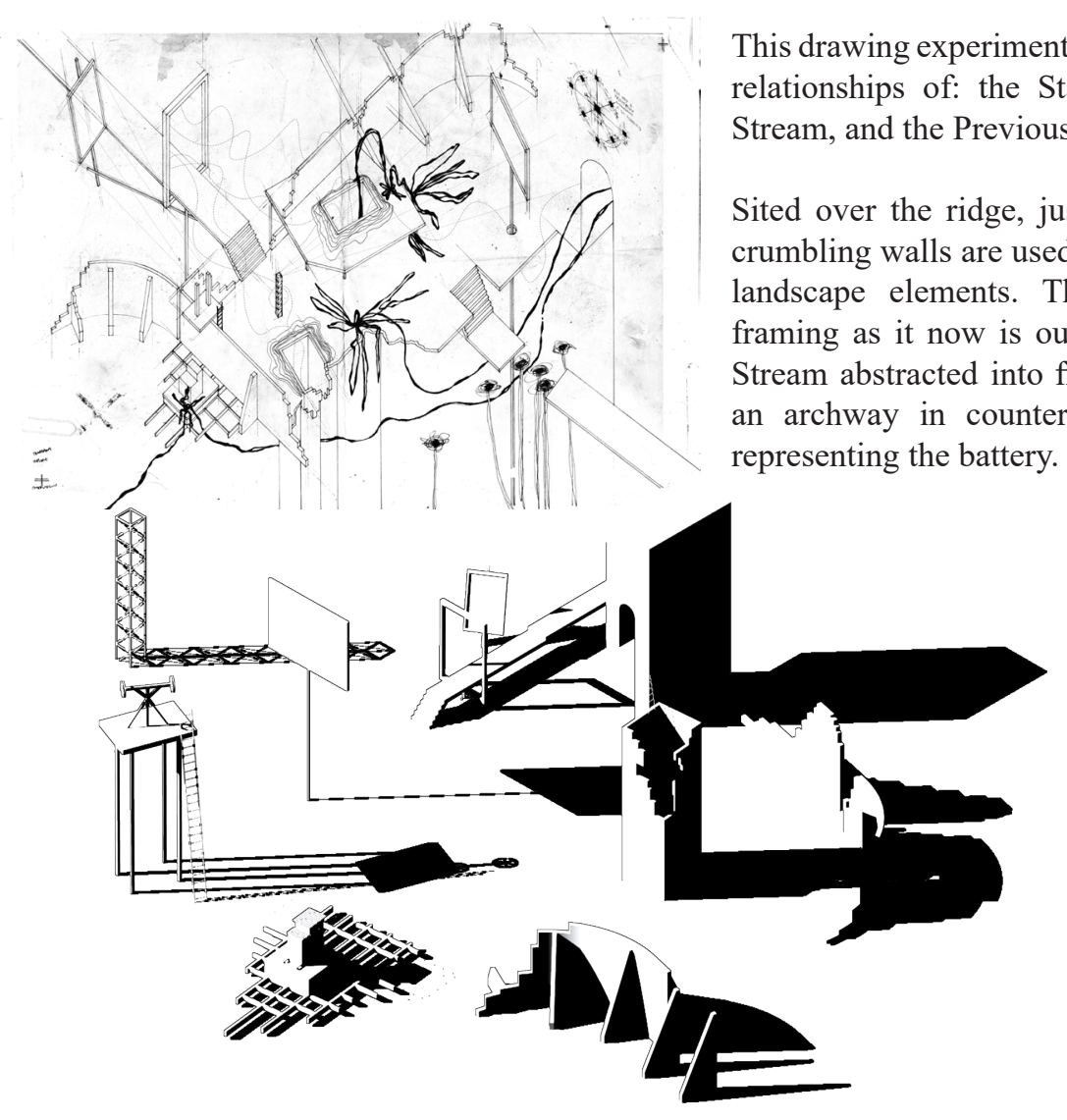




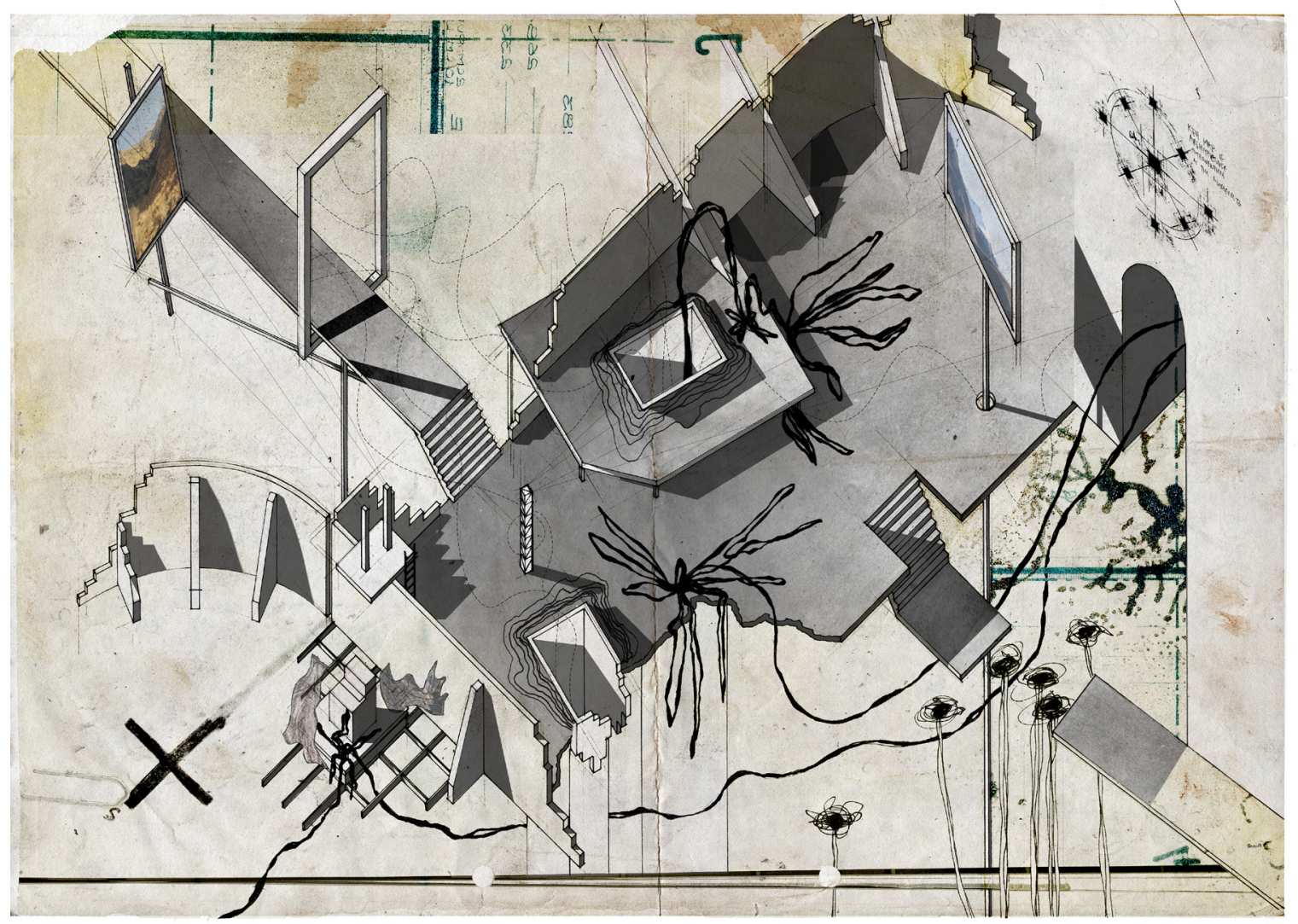

The Battery Footprint represents place identity as Traces left behind. In this case, a previous stamper battery was swept away in a flood, leaving only its foundations. In Axonometric Experiment 4, two traces represent the mining operation's previous stamper batteries, the first of which has already been eroded and is almost lost. The second trace, lifted up on its own stage, is the main character of this drawing - with the river deviating closer and closer, threatening to erase it as well. 


\subsubsection{AXONOMETRIC EXPERIMENT 4}

\section{The Mineshaft}

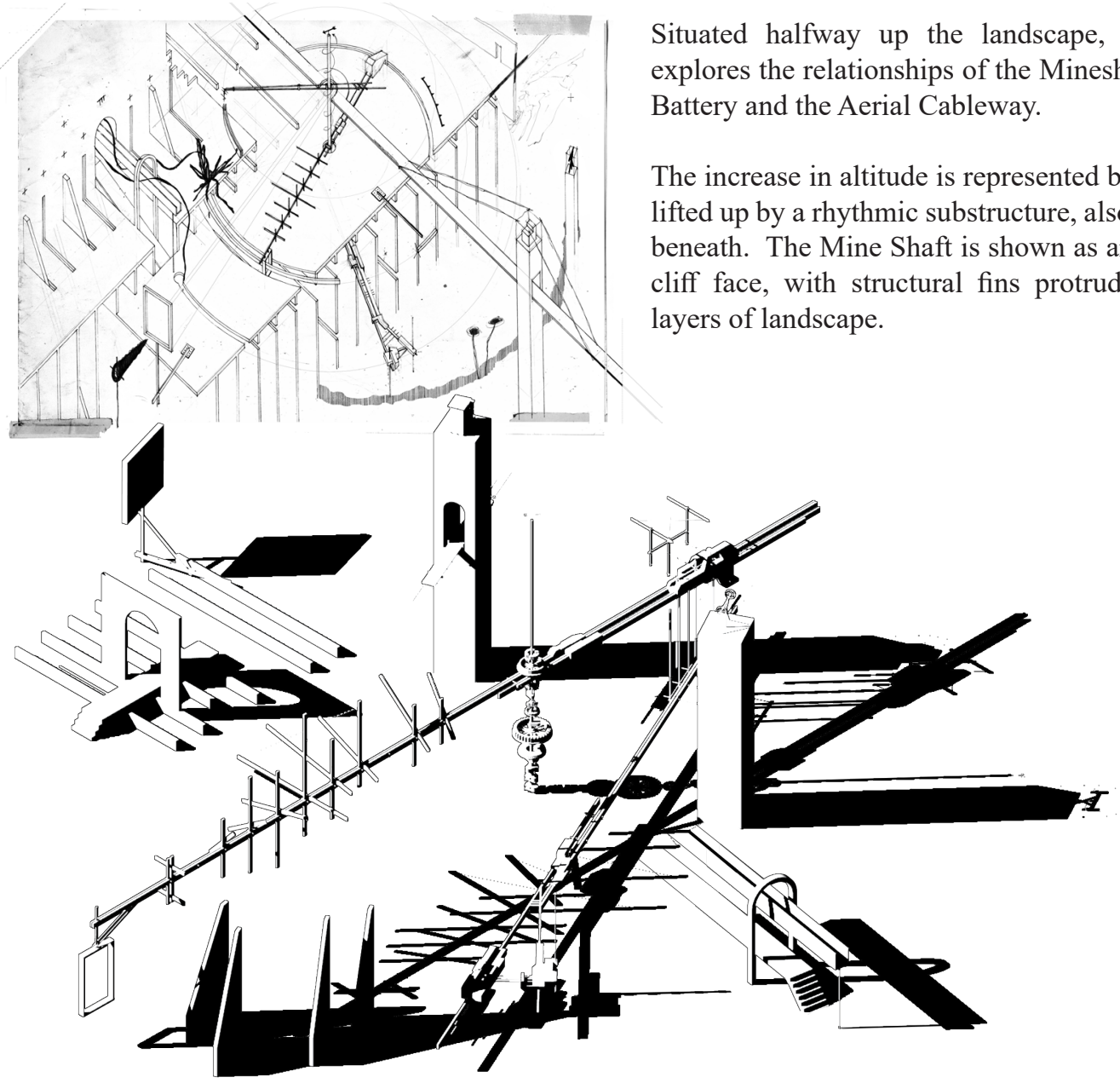




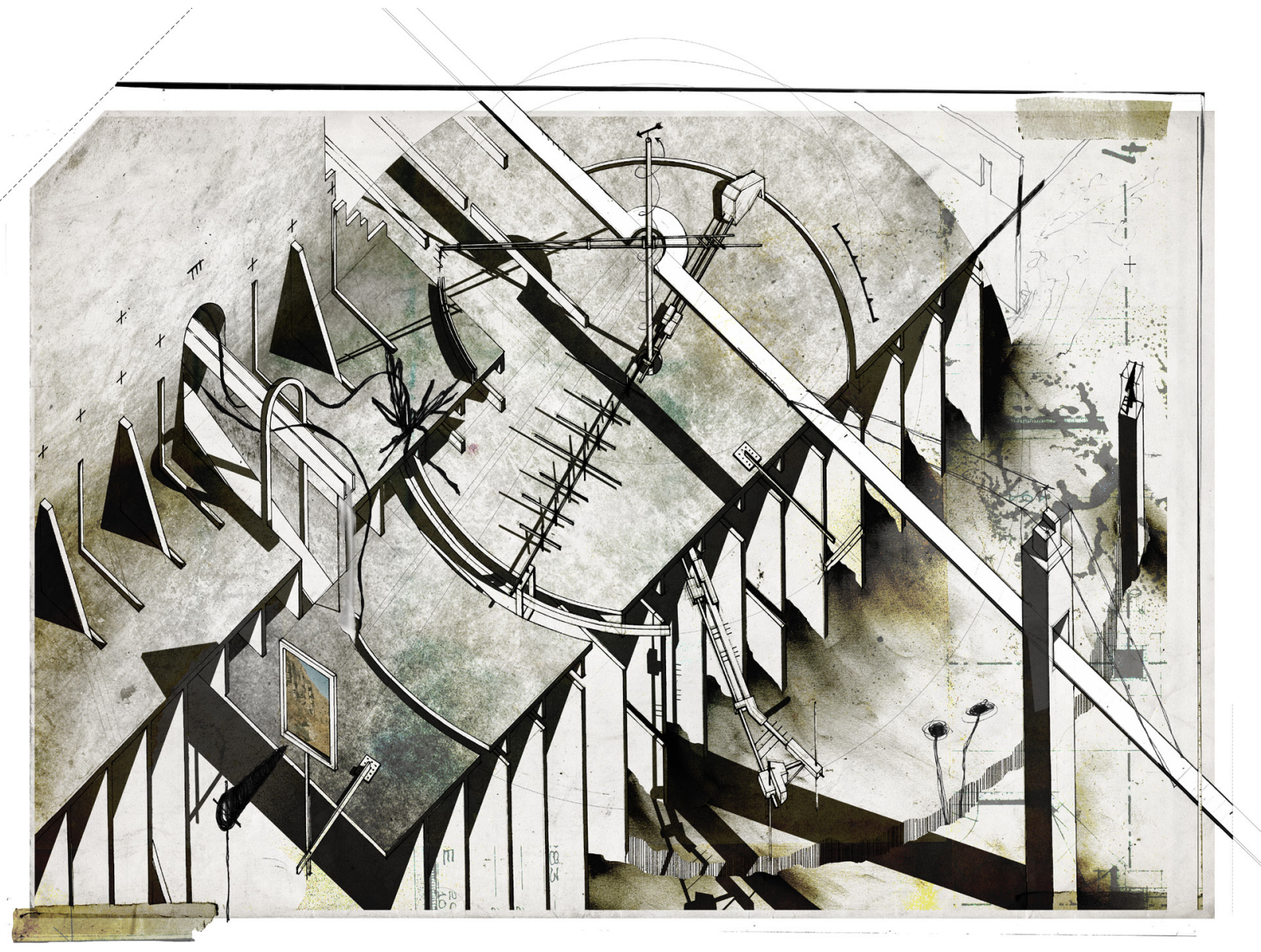

The Mineshaft represents place identity as a void-something that is absent, rather than something that is present. In this drawing, the void is represented by the deep space below. In Axonometric Experiment 5, an allegorical representation of a mechanised clock torques around a fulcrum point, with each of its arms occupying a different layer of the landscape. The Stamper Battery and Aerial Cableway can be seen in the distance-dwarfed by the immense landscape they dwell in. 


\subsubsection{AXONOMETRIC EXPERIMENT 5}

\section{The Aerial Cableway}

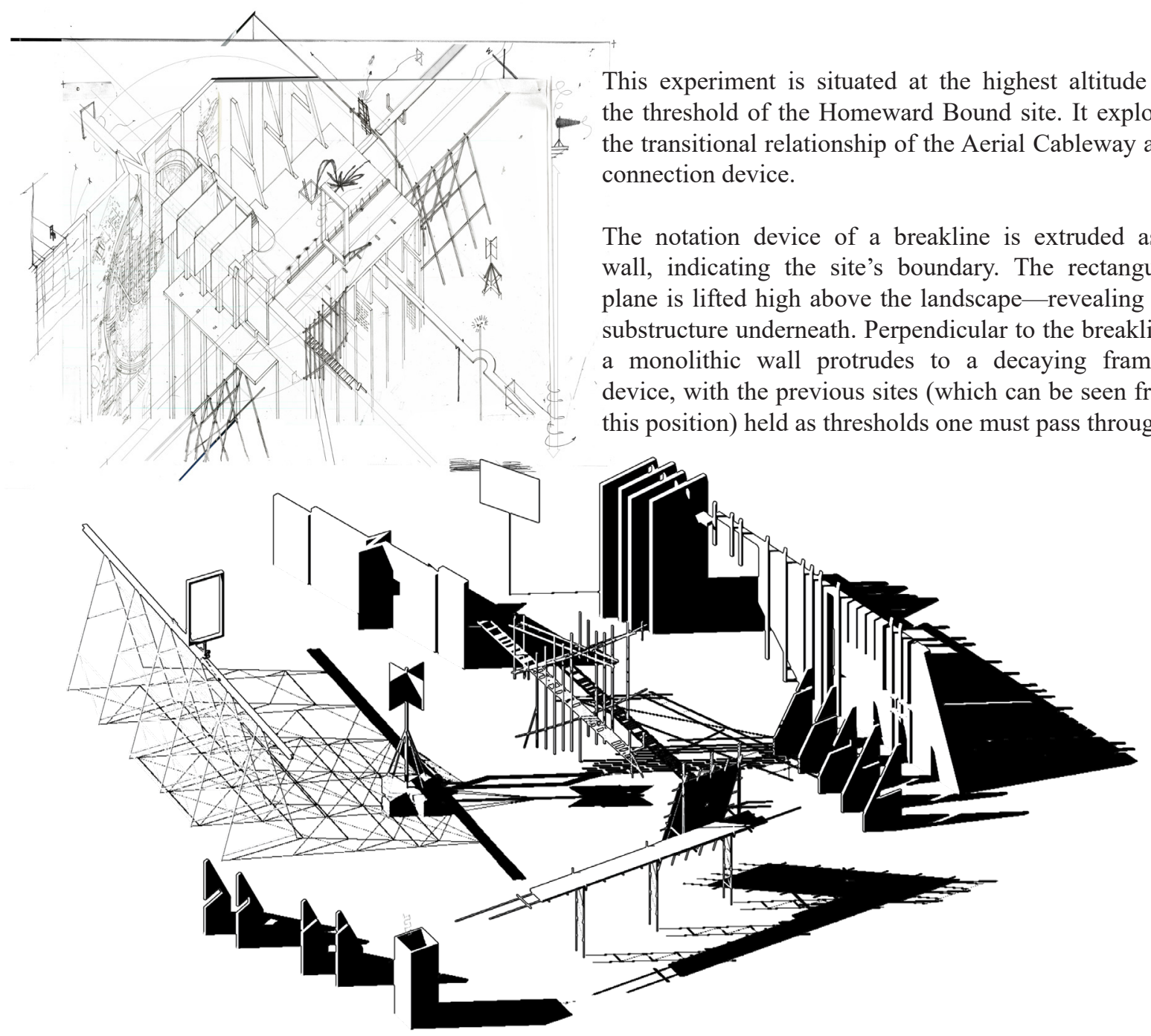

Fig 6.7.1 Axonometric linework drawing and extracted forms of the Aerial Cableway's point of view, as derived from the Concept Design stage plan experiment. 


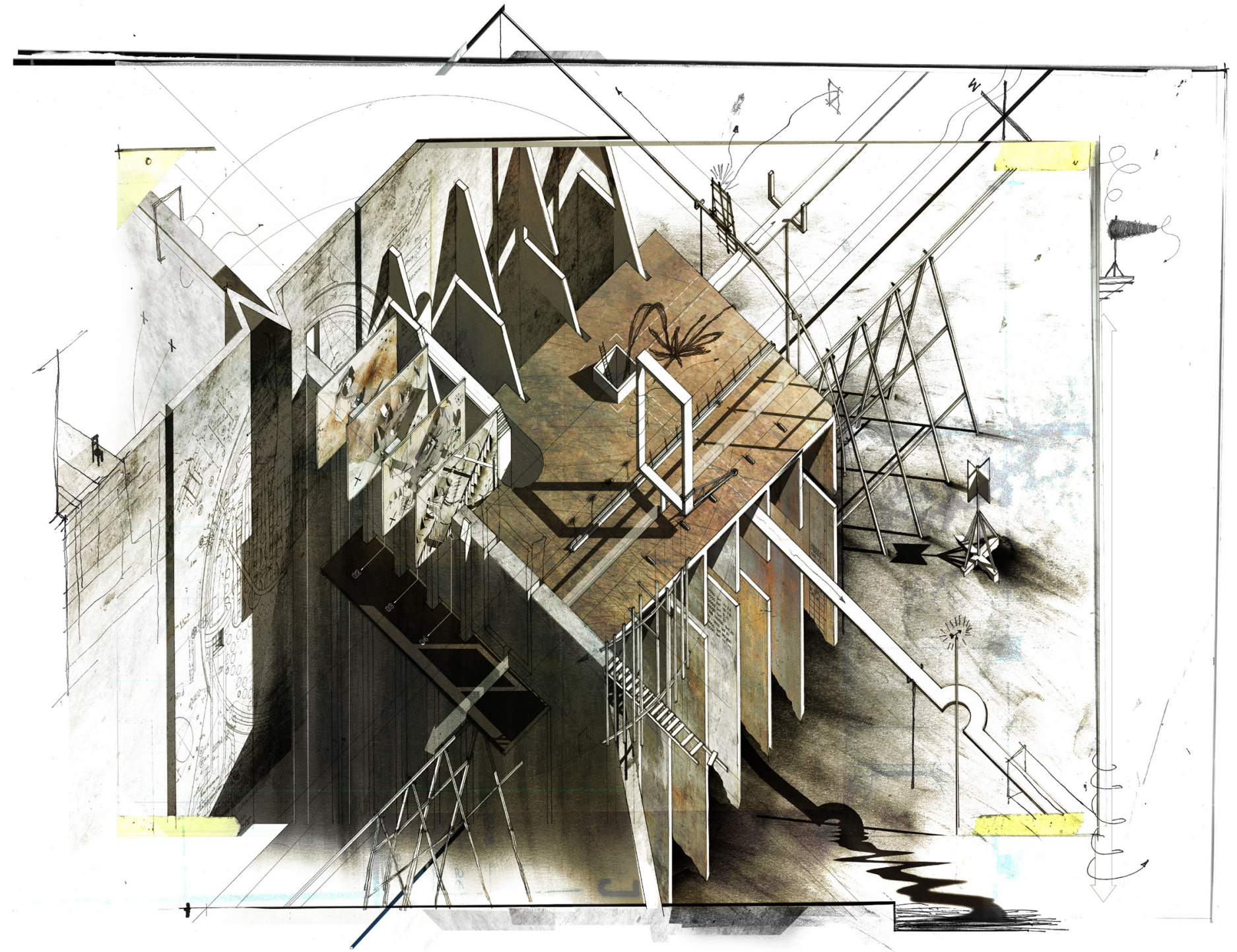

The Aerial Cableway represents place identity as a transition. In this case, buckets of ore from the mine above were transported to the battery below by steel cables suspended over the steep landscape. In Axonometric Experiment 6 , a framing device shifts back and forth mimicking this mechanism. It acts as a timekeeper, snapping the brittle saplings who grow underneath—manifesting a timeline expressed through vertical growth and horizontal position. 


\subsubsection{AXONOMETRIC EXPERIMENT 6}

\section{The Water Race}

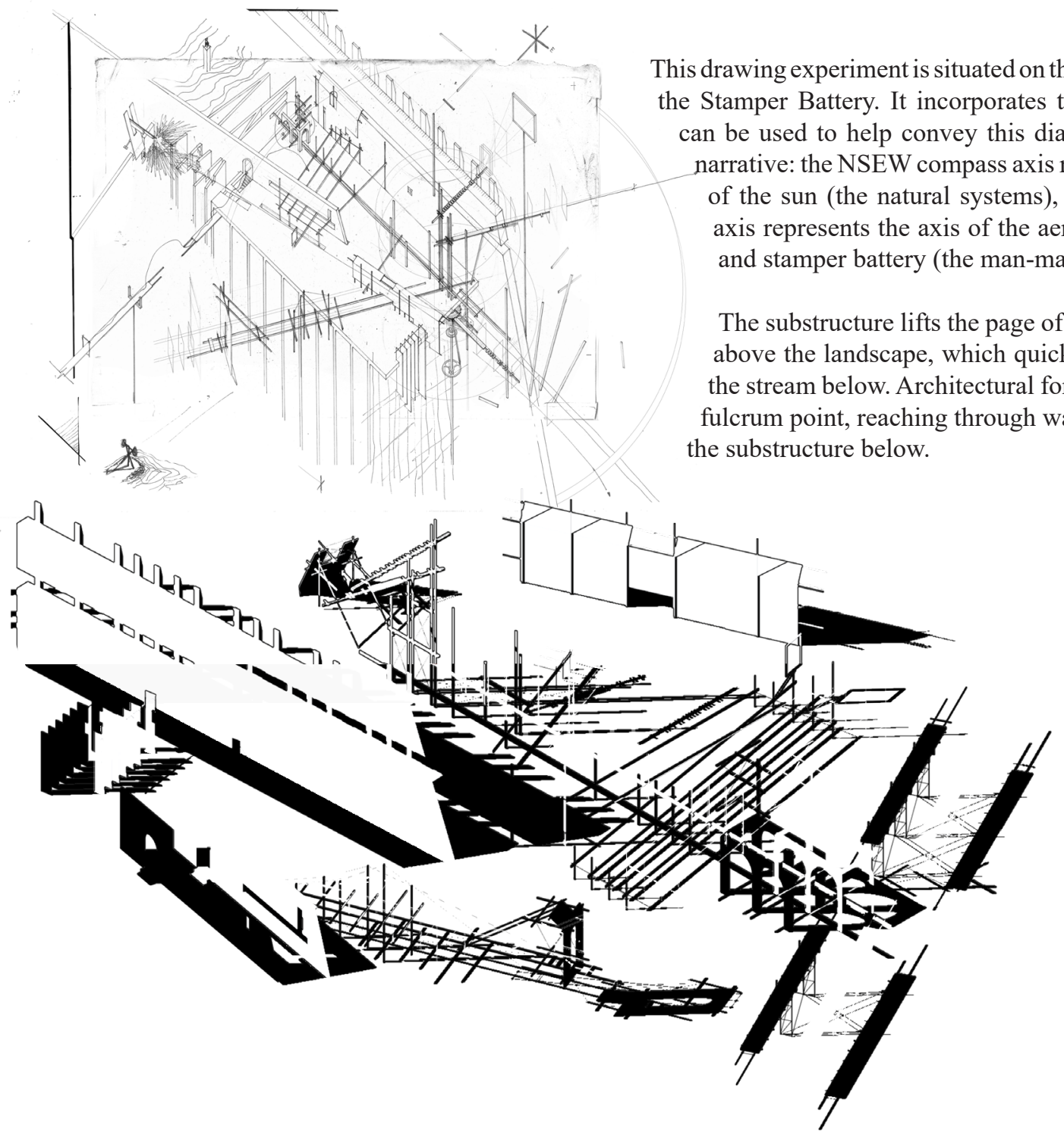

Fig 6.8.1 Axonometric linework drawing and extracted forms of the Water Race's point of view, as derived from the Concept Design stage plan experiment. 


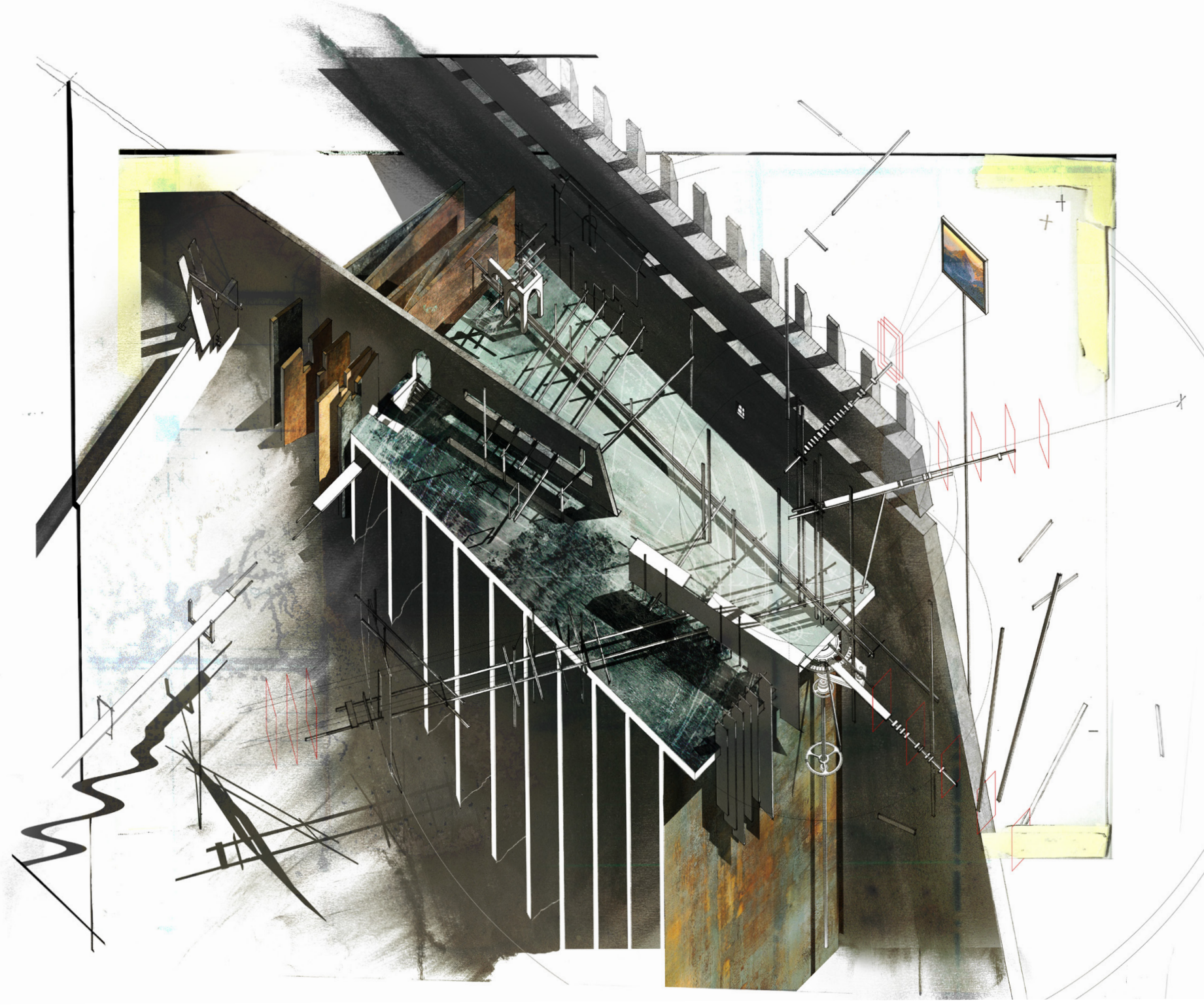

The Water Race represents place identity as a Cut, in this case, cuts dug horizontally in the hills to reach the quartz veins within the landscape. In Axonometric Experiment 7, two axis walls, one of stone and the other of metal, protect a sight line across the valley to Axonometric Experiment 8. 


\subsubsection{AXONOMETRIC EXPERIMENT 7}

\section{The Mountain}

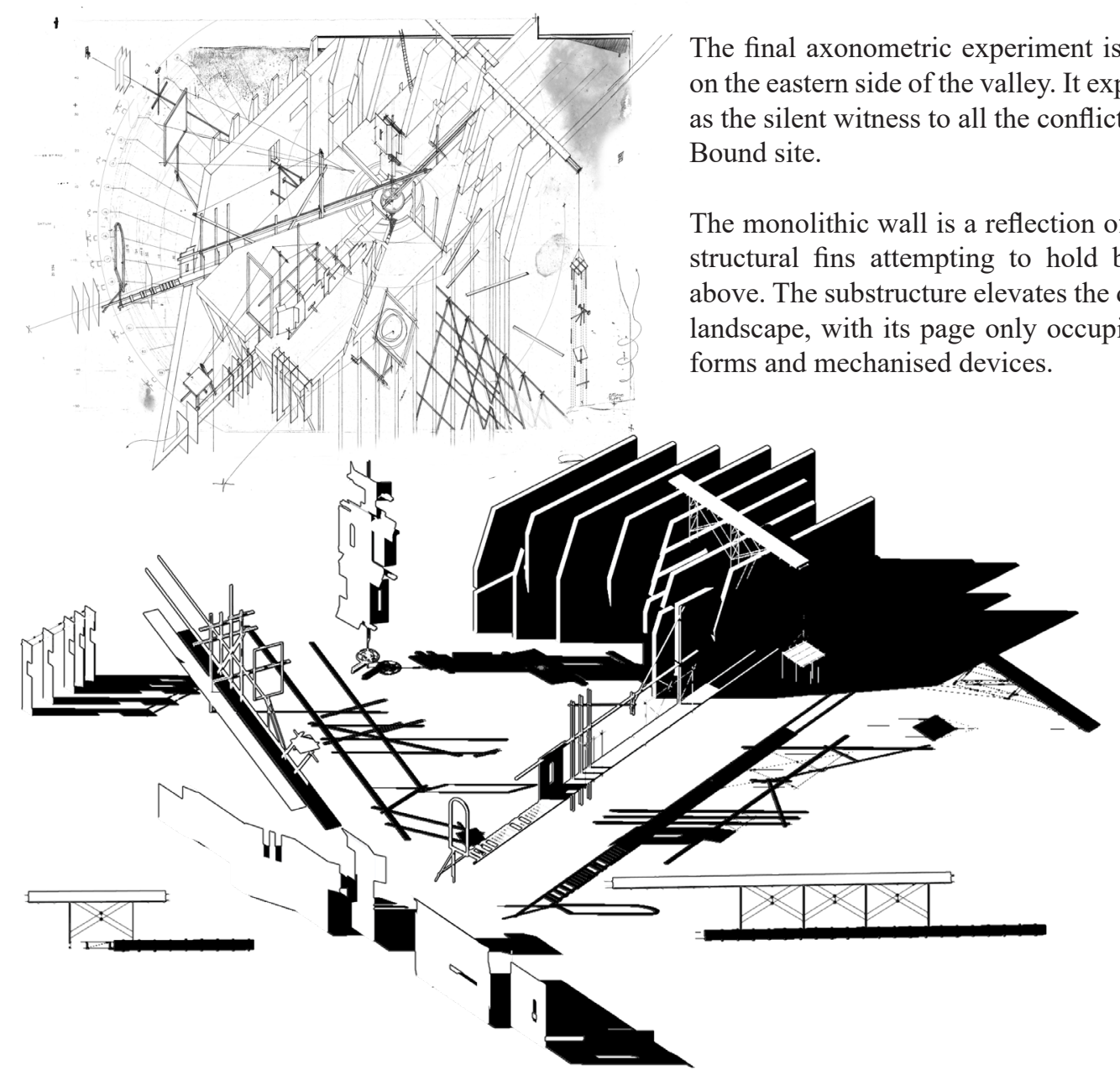




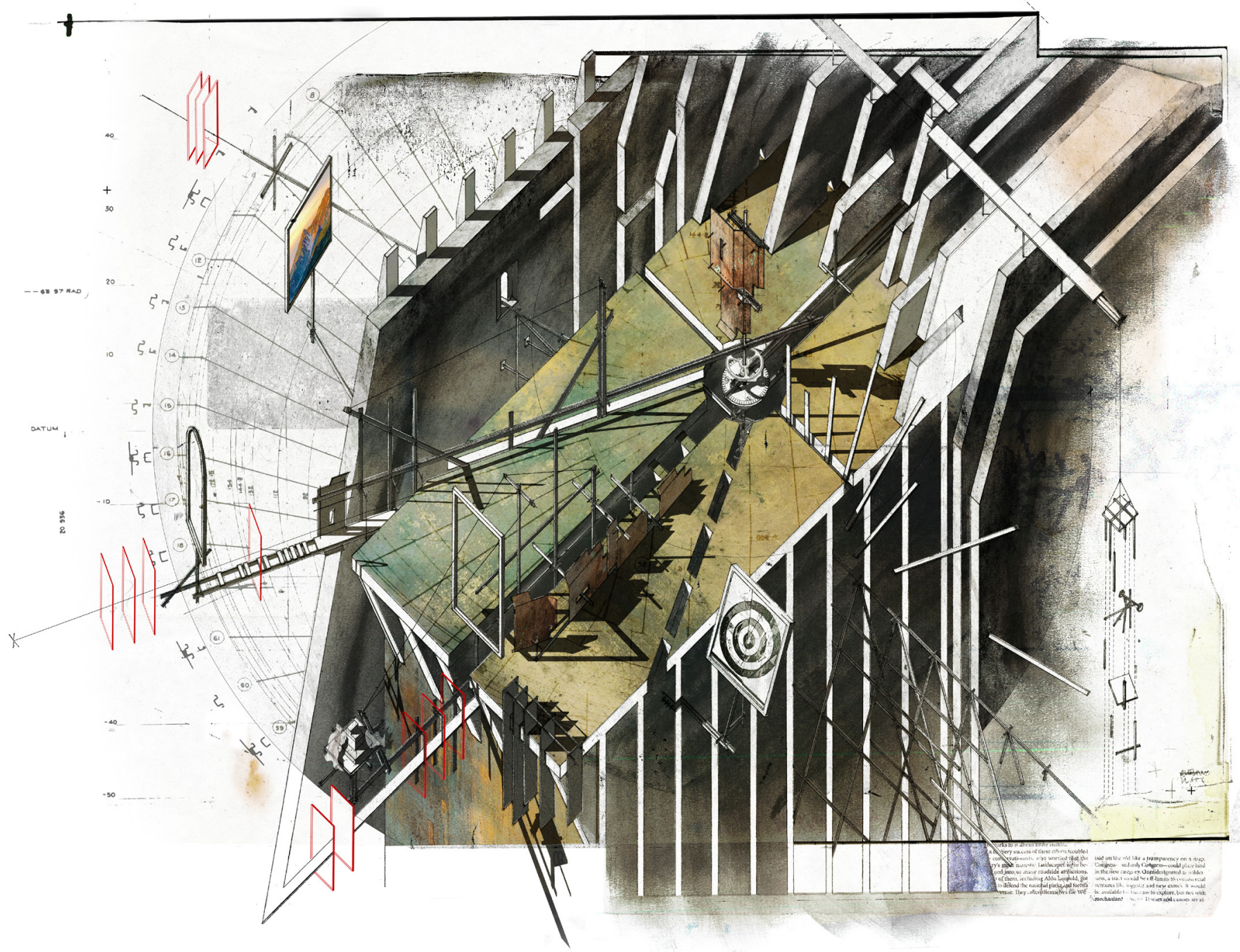

The Mountain represents a distant, silent witness. In Axonometric Experiment 8 , framing devices, pathways and viewing platforms reflect on the relationships of the characters of site. Rising from beneath the page, a 'sentinel-like' form protects the fulcrum point of the timepiece, while unprotected elements to the south begin to decay and deconstruct. 


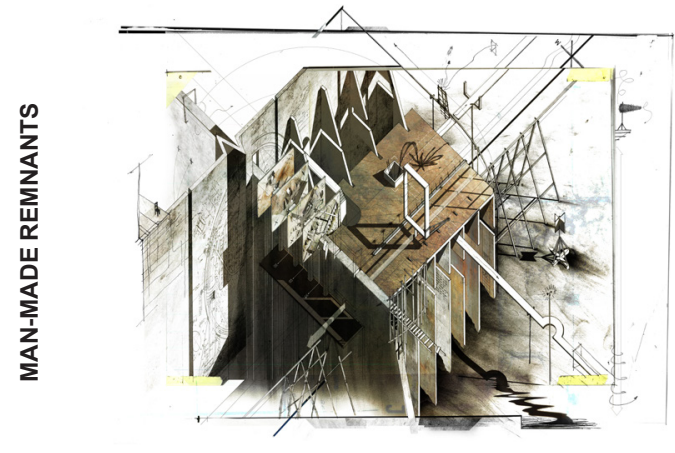

Aerial Cableway

A story of place identity defined by transition.

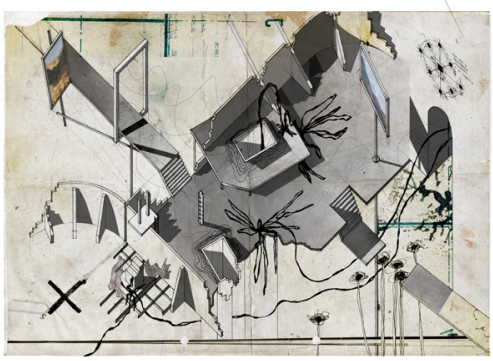

Battery Footprint / Redirected Stream A story of place identity defined by traces and deviation.

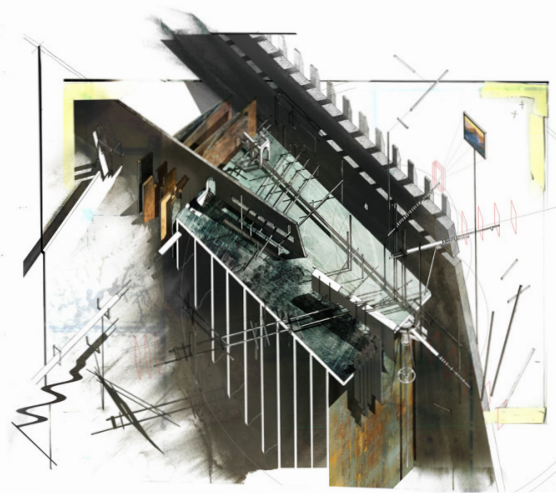

Water Race

A story of place identity defined by a cut.

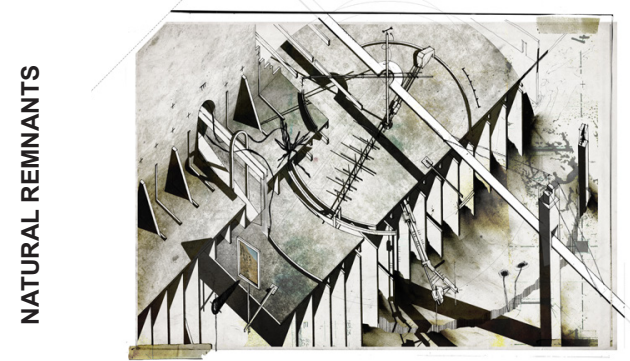

Mineshaft

A story of place identity defined by void.

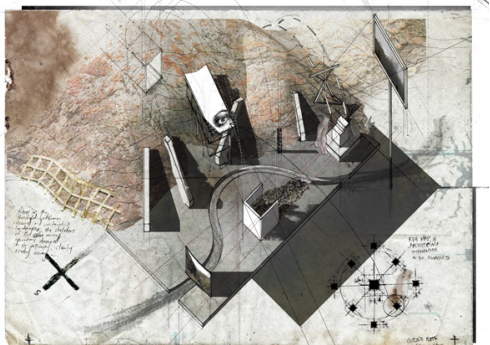

Schist Tailings

A story of place identity defined by displacement.

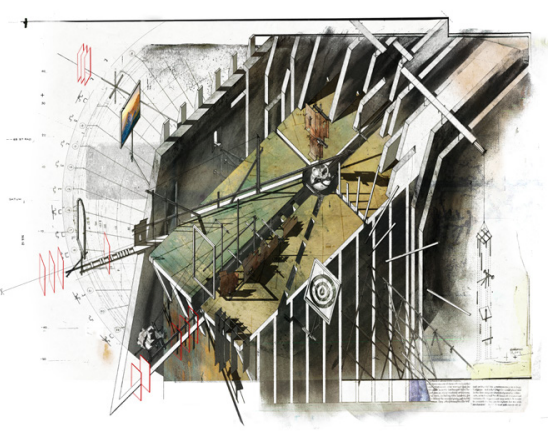

Mountain

The silent witness.

Fig 6.10 Preliminary Design: The Allegorical Architectural Project as speculative architectural drawings in axonometric view, representing place identity from the point of view of seven key remnants on the site-'actors' in an allegorical tale. The mountain is the silent witness over time. 


\subsection{CRITICAL REFLECTION PHASE ONE}

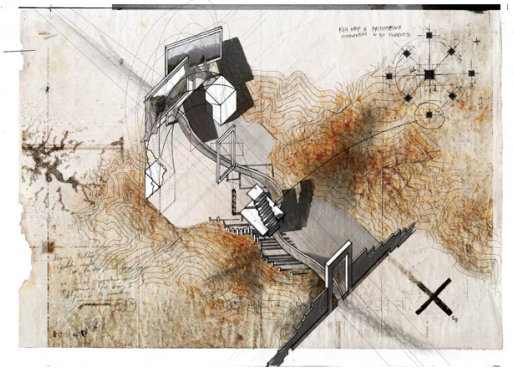

Stamper Battery

A story of place identity defined by convergence.
Phase One of the Preliminary Design stage of this investigation (Figure 6.10) have taken the principal seven characters identified in the contextual analysis phase and interrogated them using axonometric drawing techniques outlined in the Literature and Project Review chapter. Relevant case studies were adapted and applied as architectural devices that enabled the narrative of the characters within each drawing to be unveiled through axonometric speculative drawing.

In Figure 6.11 (overleaf), the axonometric notational devices are assembled together from each of the drawings in Figure 6.10. Some are unique to a particular point of view, while others appear on multiple drawings to indicate that their stories are related.

In Phase Two of the Preliminary Design stage (Figures 6.12 6.16), the previous experiments have been registration marked, layered, overlapped, shifted and sequenced, to investigate how the seven individual points of view in this dialectic narrative can be brought together into a cohesive whole-the larger overall allegorical meta-narrative, unveiled through layered speculative drawing. 


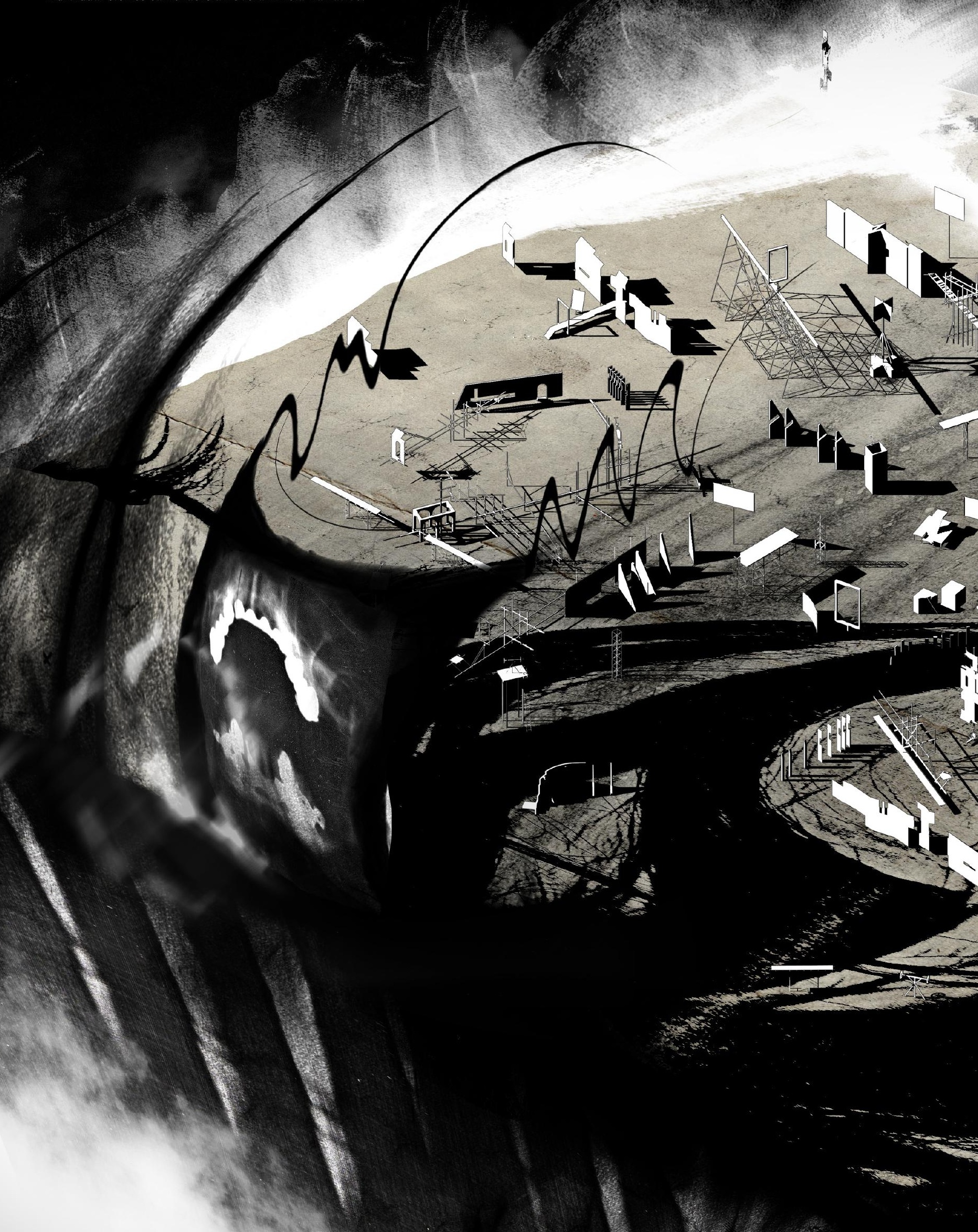




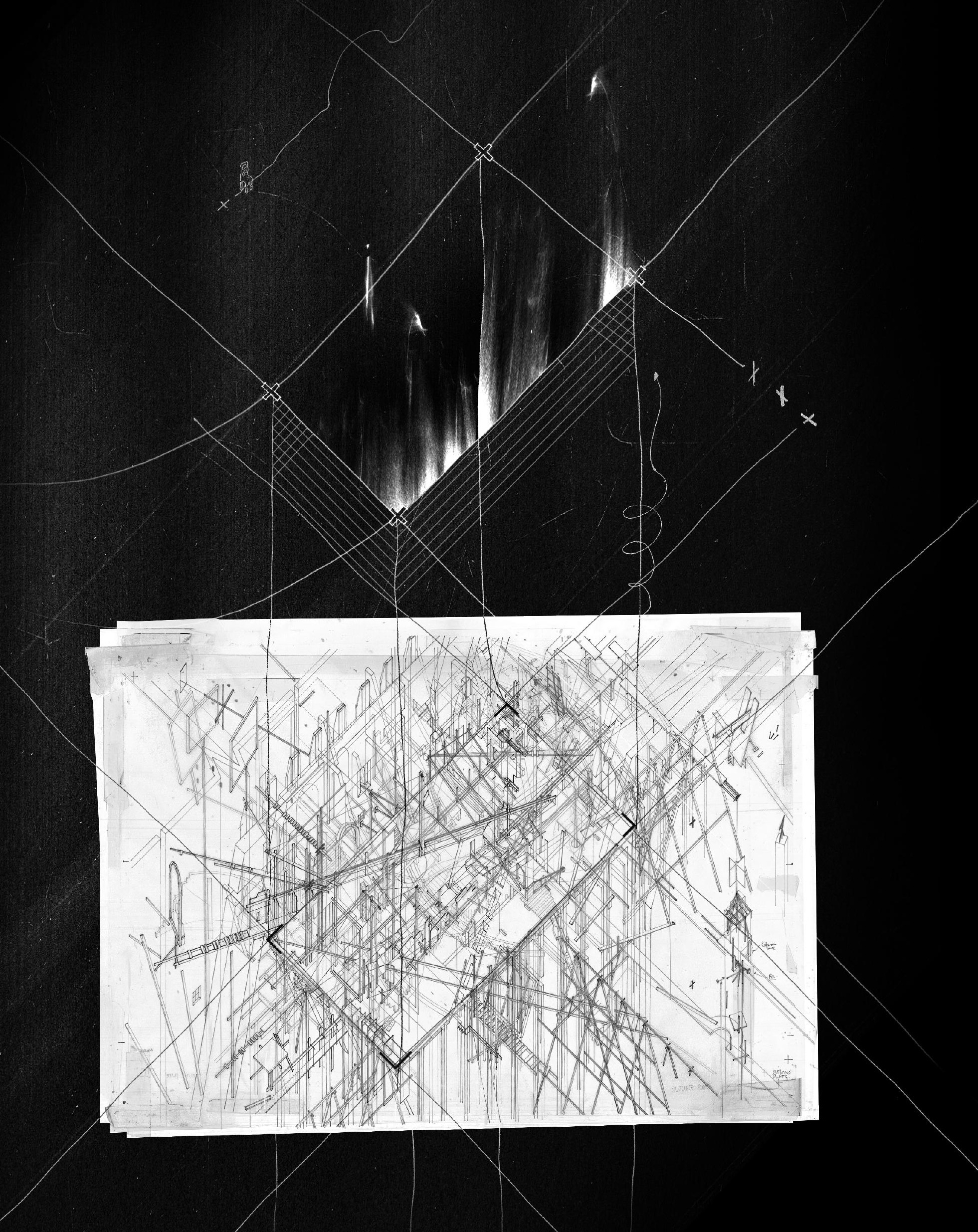




\section{6}

If one sees two or more figures partly overlapping one another, and each of them claims itself the common overlapped part, then one is confronted with a contradiction of spatial dimensions. To resolve this contradiction, one must assume the presence of a new optical quality. The figures are endowed with transparency; that is, they are able to interpenetrate without optical destruction of each other.

—Gyorgy Kepes, Language of Vision, 1969, 13

\subsection{PRELIMINARY DESIGN PHASE TWO}

In Phase Two of the Preliminary Design stage, the previous experiments are layered, overlapped and resequenced, to investigate how individual points of view in a dialectic narrative can be brought together into an overall allegorical meta-narrative that is unveiled through layered speculative drawing.

In Figure 6.12, experiments from the first phase of Preliminary Design are overlapped. The rectangular plane used in each previous drawing is used as an alignment tool, allowing new orthographic relationships to emerge as the transparent pages overlap one another - a spatial depth emerging as the drawings below become subordinated to the dominate drawing at the forefront. One 'voice' predominates, while all voices whisper together in the background.

Fig 6.12 Linework drawings from the axonometric series are taken and layered on semitransparent paper. 

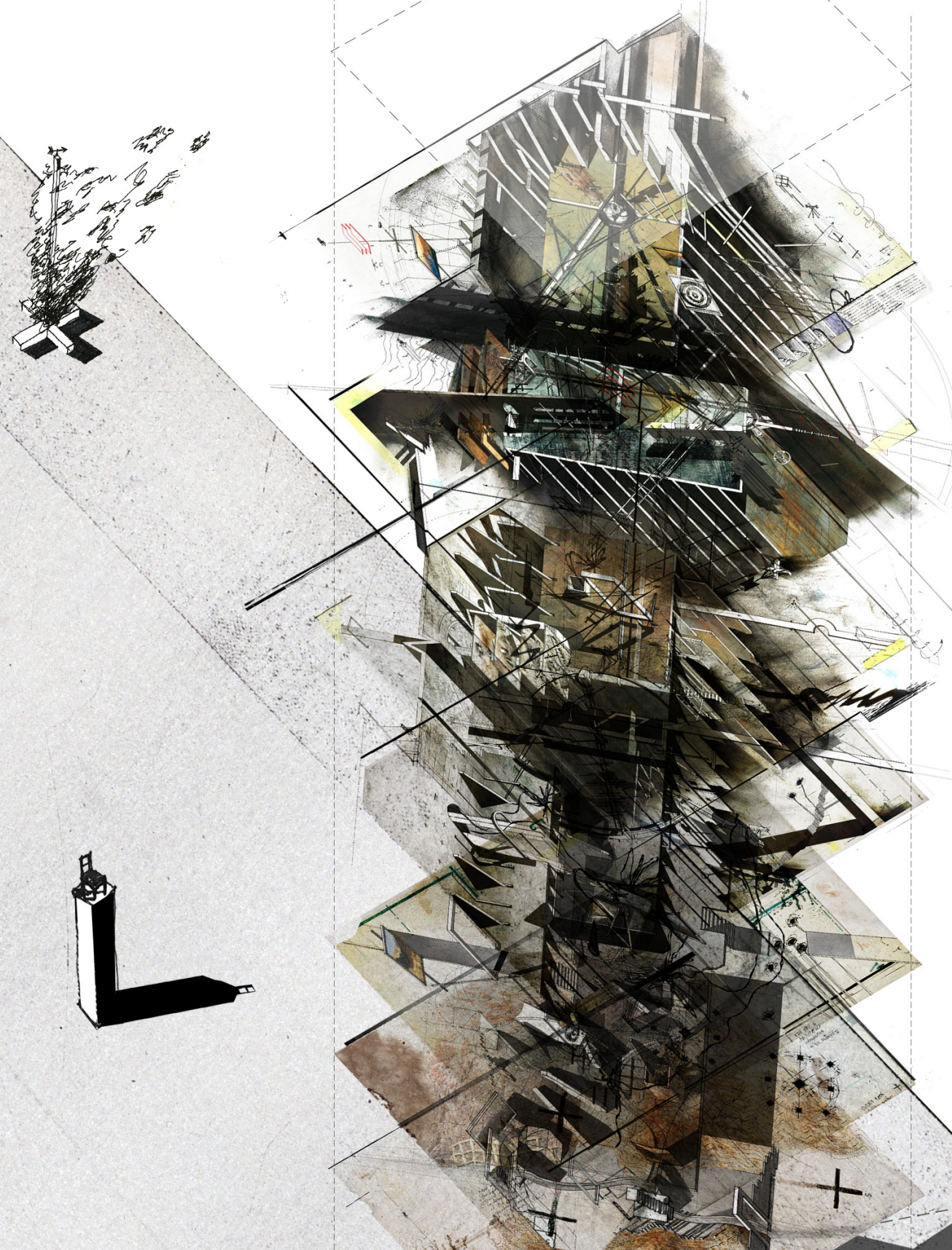


\title{
46
}

In order to make the layers perceptible, there need to be places of transition that function simultaneously as a link and separation. The frame and edges cause the form and material to stand out against surfaces that are meant to be differentiated. The process of layering separates individual planes, which are thus able to have their own meaning as an element and simultaneous part of a total complex.

\subsection{PRELIMINARY DESIGN FINAL OUTCOMES}

\begin{abstract}
After critically reflecting on the line work experiment in Figure 6.12, the rendered axonometrics were next layered using transparency and overlapping techniques to bring all of the individual stories of each character into one composition (Figure 6.13). The Preliminary Design outcome represents one way of expressing the meta-narrative of the Homeward Bound Site.

The final outcome drawings of the Preliminary Design stage are shown in Figures 6.14-6.15. Titled Lamentations, Series I, the meta-narrative drawings are an allegorical expression of grief for the environmental disaster left behind by the search for prosperity.
\end{abstract}





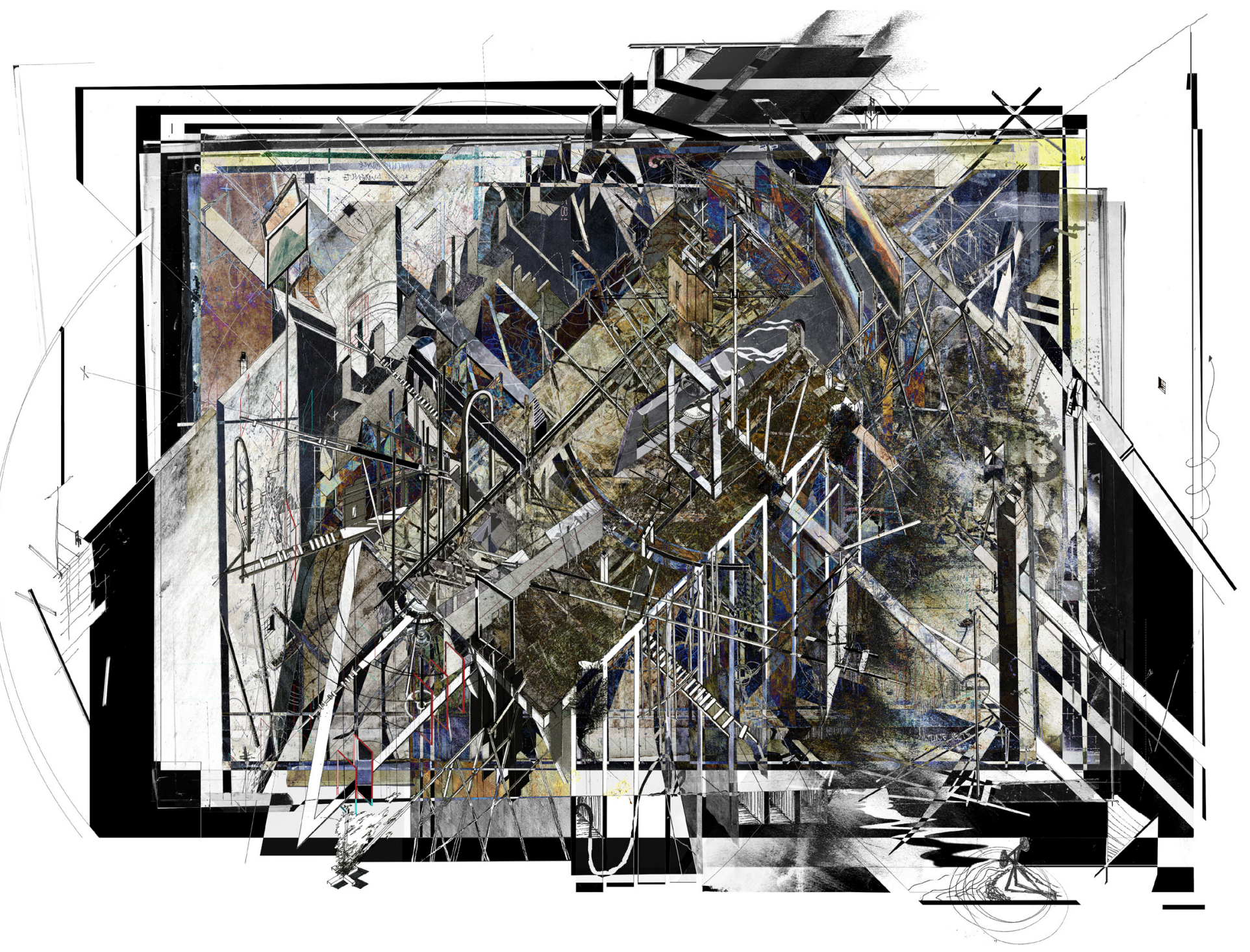




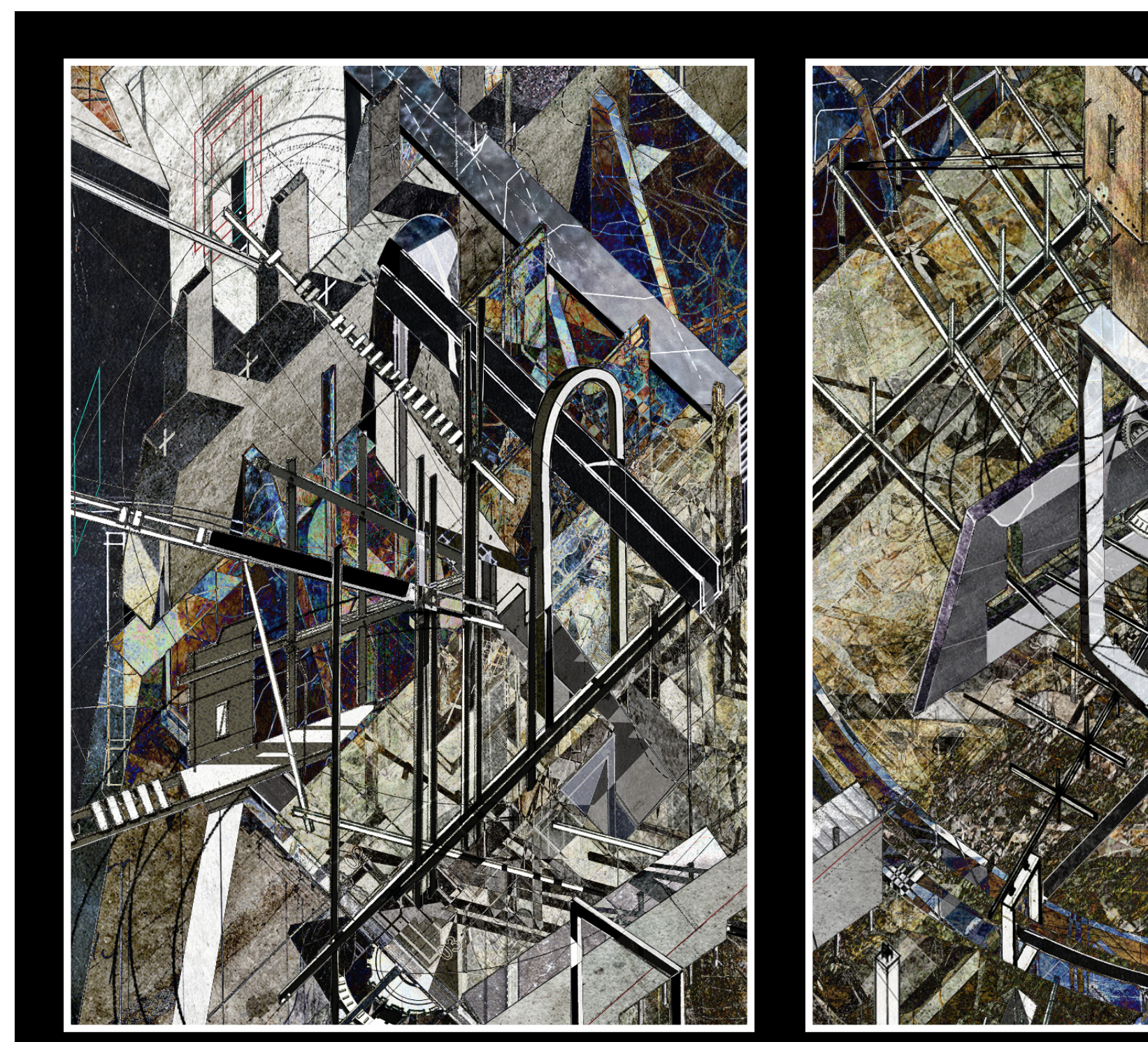




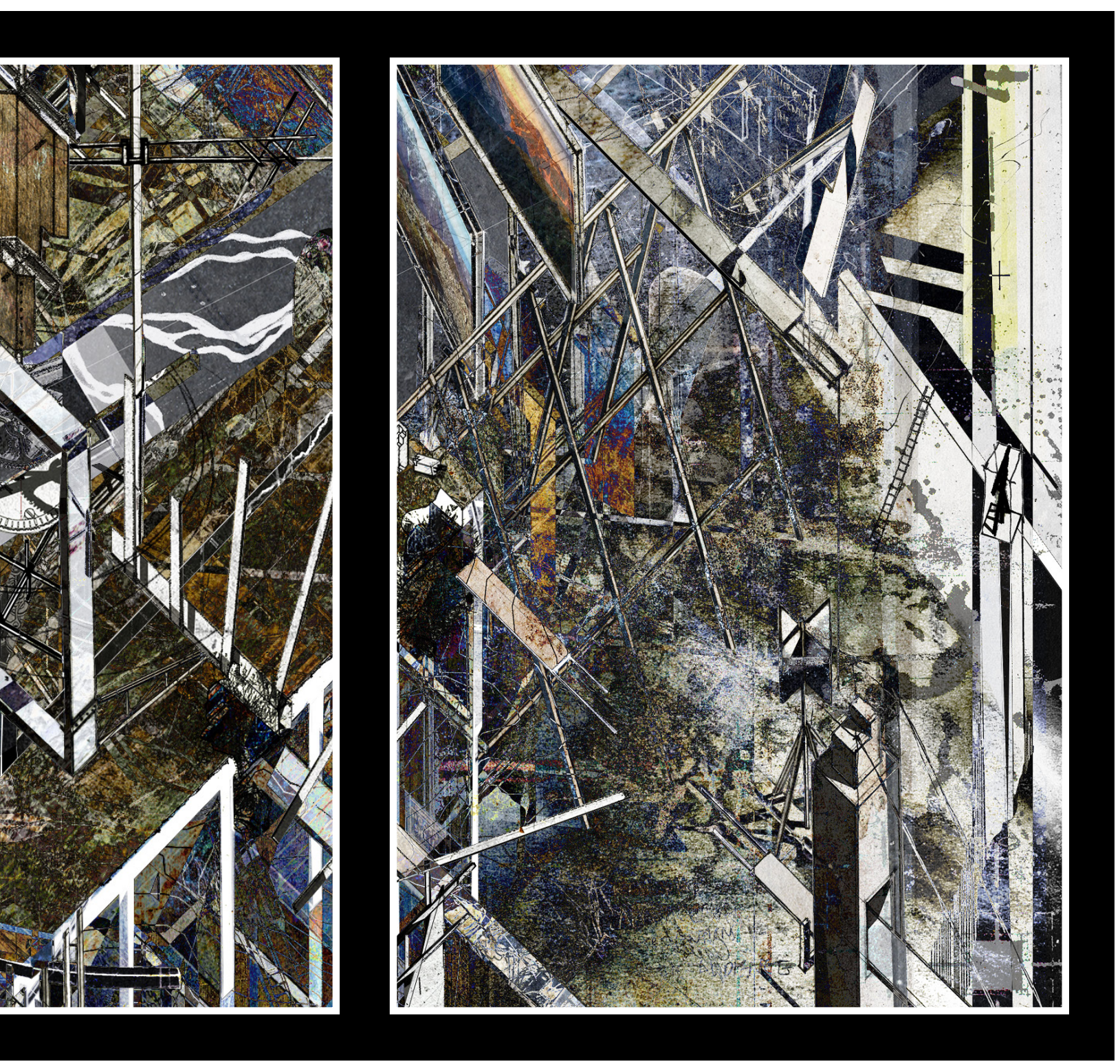

Fig 6.15 Lamentations Series I (cont): Layering seven individual stories into a meta-narrative composition allows all of the characters' voices to be heard at once-some as quiet whispers in the background, others crying out in the forefront. From this metacomposition the confrontation between environmental systems and man-made systems becomes apparent. This is represented through the axonometric relationships of elements as well as the reclaiming force of nature shown through decay and ruin. 


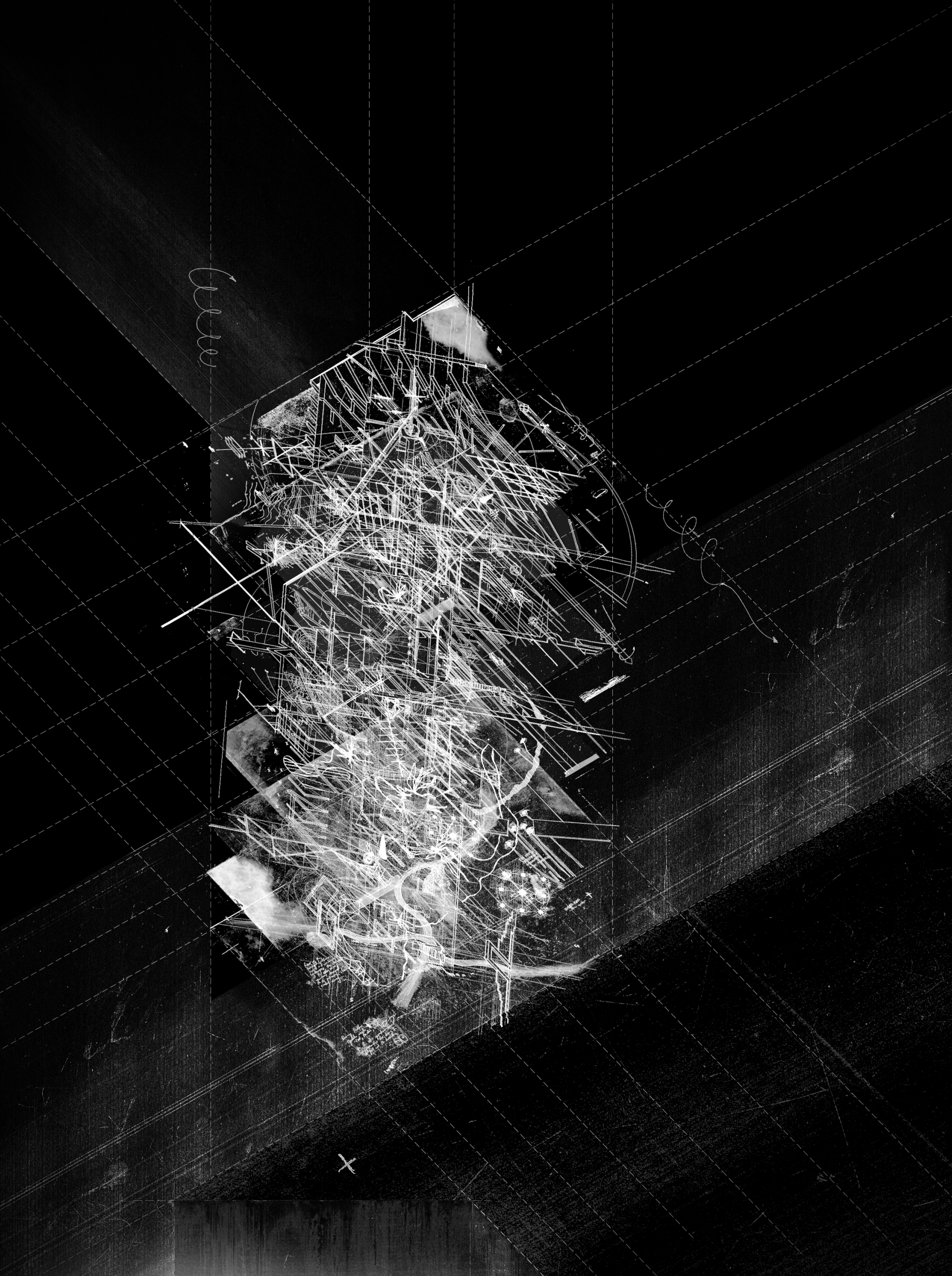




\subsection{CRITICAL REFLECTION PHASE TWO}

This chapter interrogated the individual stories of the seven characters of site using the axonométric drawing techniques to explore their confrontational relationships in three dimensional space. These drawings were then layered using transparency and overlapping techniques to allow them to blur into a single composition - allowing people to witness the individual stories simultaneously.

The use of axonometric allowed the critical relationships of the seven characters to develop in more detail. The drawings now convey more spatial depth and materiality, allowing the allegorical dialectic of the additive ('prosperity') in dialogue with the transformative/ subtractive ('environmental decay') to emerge as a theme across the series. Á result of conflict between environmental systems and man-made systems, the allegory of decay can be seen as a primary tool in enabling the dialectic narrative of confrontation in relation to RO1.

Notation devíces are implemented throughout the series, some traditional and others transitioning from two-dimensional into three-dimensional forms within each of the drawings. Notation devices such as registration marks were essential to the final outcome drawings, allowing the drawings to be layered in a meaningful manner. Other devices such as projection lines, shadows, mechanical drawings and kinetic arrows have all acted as allegorical elements that enable the narrative of each drawing in relation to $\mathrm{RO} 2$.

The investigation into the layering the drawings into a single composition is the most successful moment within this chapter, allowing all seven stories to be witnessed simultaneously in response to RO3. The integrations of transparency and overlapping were essential, but the ordering of the layers also has important implications. By resequencing the layers into different order, the drawings at the forefront and bottom change - resulting in a different character's voice becoming the loudest on top, while others are reduced to whispers below. This factor will be investigated in more depth in the Developed Design stage.

The Preliminary Design stage explored the individual stories further and composed them into a single image that began to unveil a dialectic meta-narrative of confrontation and lamentation. The Developed Design stage will address each of the character's composited voices as a layered drawing, allowing each remnant to have their turn as the voice crying out at the forefront of the drawing. 
The Machine,' they exclaimed, 'feeds us and clothes us and houses us; through it we speak to one another, through it we see one another, in it we have our being. The Machine is the friend of ideas and the enemy of superstition: the Machine is omnipotent, eternal; blessed is the Machine.'

-E.M. Forster, "THE MACHINE STOPS", P 15 of 19 

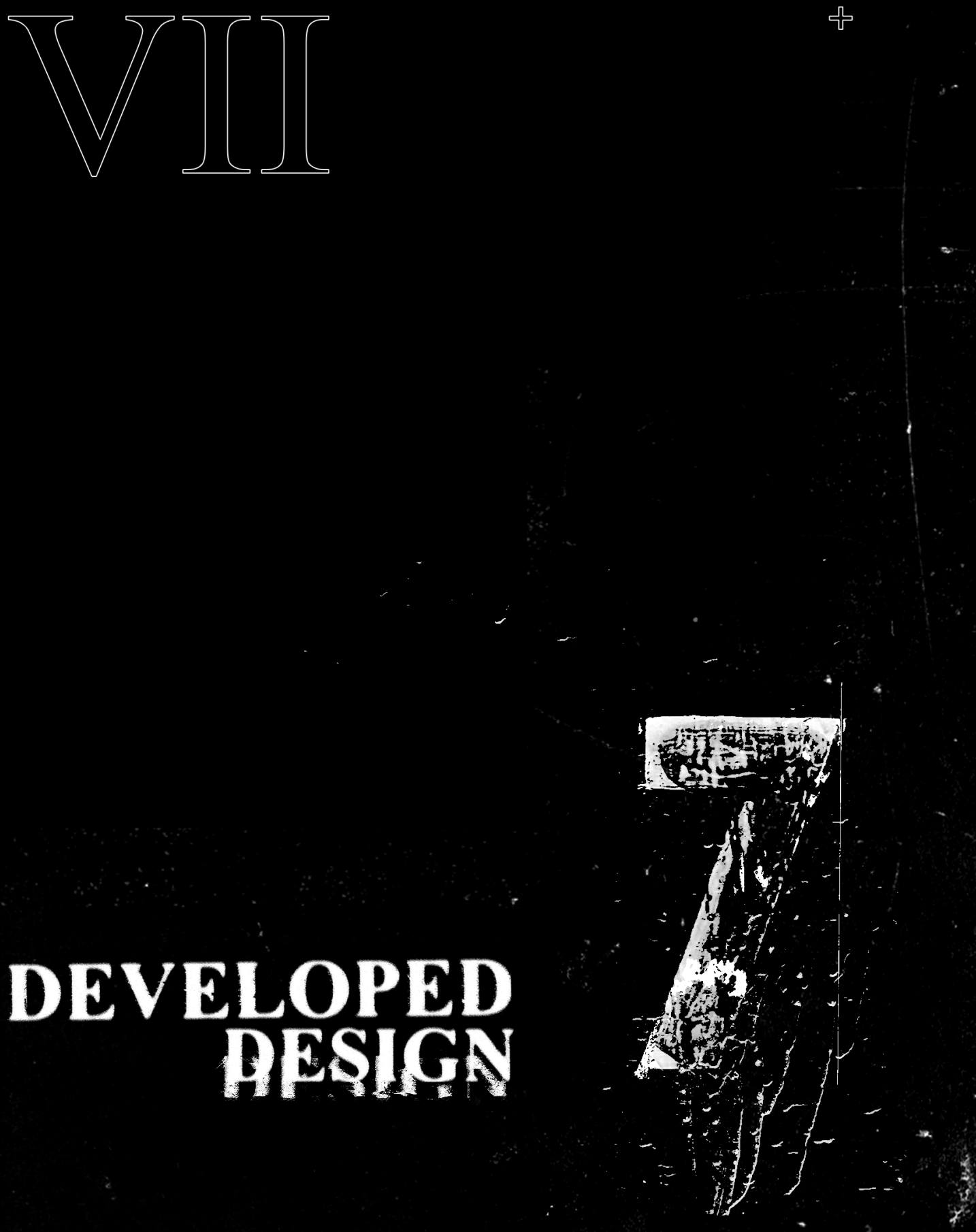


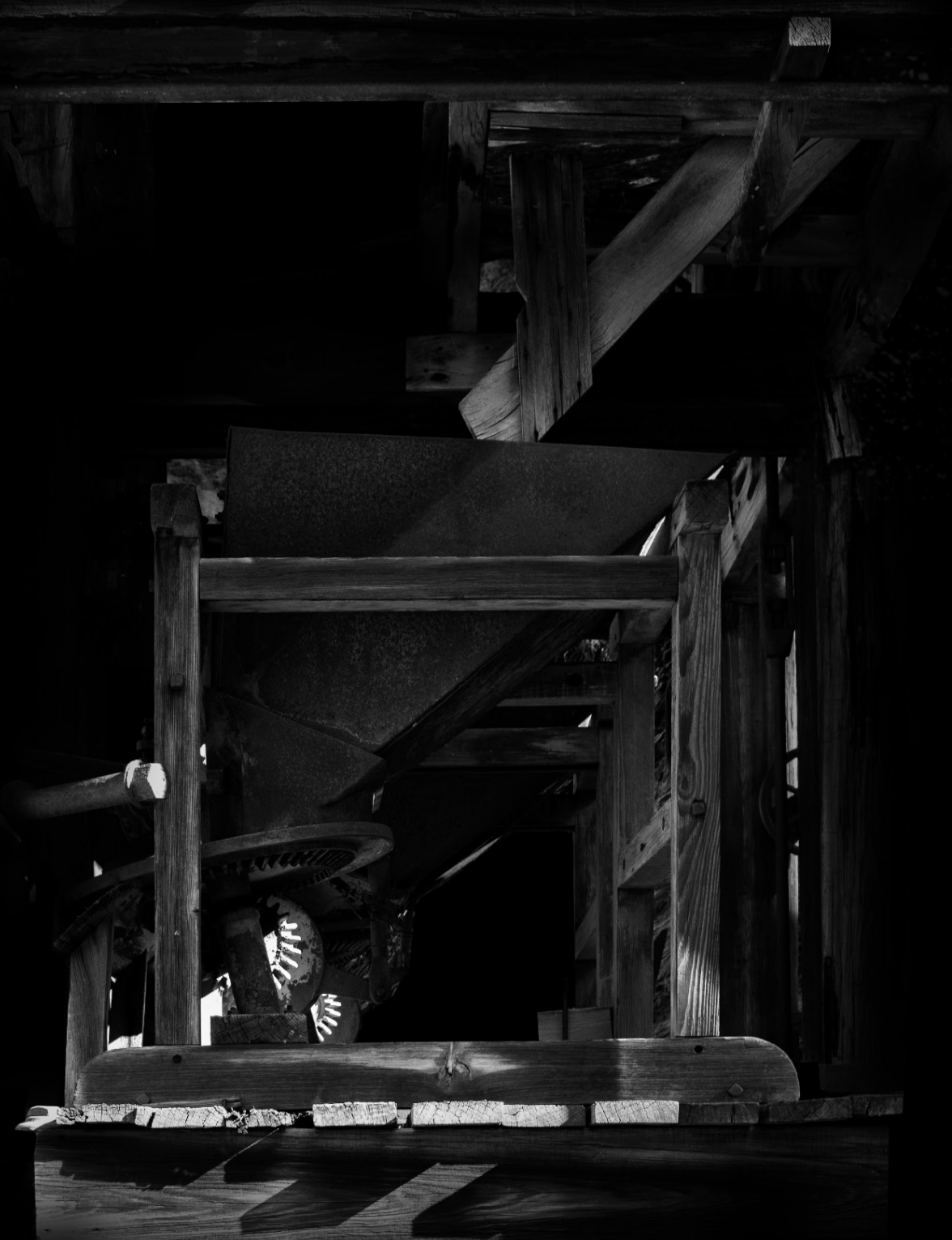




\subsection{INTRODUCTION}

In the previous chapter, the axonometric drawing research outcomes were overlaid, as a way to explore how to unveil a larger meta-narrative where all seven voices are able to be heard simultaneously. In this chapter, the plan drawing research outcomes are overlaid. These layered plan drawings are then integrated with elements from the axonometric experiments, so that the conveyance of multiple voices - combining the learnings from both the Conceptual Design experiments and the Preliminary Design experiments - occurs through multiple architectural points of view, as well as the strategic application of notation devices and layering. In this way, the final outcomes seek to simultaneously address RO1 (orthographic drawing techniques), RO2 (architectural notation strategies) and RO3 (layering allegorical drawings).

The plan experiment series from the Concept Design stage is used as a foundation for this next polyvocal series. They are layered in a sequential order that changes with each speculative drawing, giving each composition a unique identity. This phase applies the techniques explored in the Concept Design and Preliminary Design stages to address all three Research Objectives, resulting in a layered final series that integrates orthographic drawing, notation strategies and layering techniques.

Each of the seven Developed Design outcome drawings is first presented as a trace drawing with specific areas highlighted to evidence how it has applied the integrated approaches of orthographic, notations and layering as allegorical enablers within the drawing. The corresponding axonometric, and plan experiments from the two previous design stages are also shown, to identify which drawing is at the forefront of the layered composition, and which character's story is the focus.

In the Concept Design and Preliminary Design chapters, each of the seven 'characters' represented place identity by a unique characteristic responding to its contribution to the allegorical narrative: Void for Mineshaft, Displacement for Schist Tailings, Deviation for Redirected Stream, Convergence for Stamper Battery, Cut for Water Race, Transition for Aerial Cableway, and Trace for Battery Footprint. In the Developed Design chapter, these key characteristics are fully integrated into the final drawing outcomes. The drawings are intended to be able to stand as individual representations, telling a character's story from multiple perspectives, while also being able to be understood as a cohesive series that informs viewers of the dialectical metanarrative of the overall site, by combining seven unique points of view.

Fig 7.1 Internal fragment of the stamper battery - the ore bin that fed the machine, photo by author. 


\subsection{PRINCIPAL CASE STUDY}

\section{Interrogation}

Neil Spiller's 1999 project Schizophrenic Railing is interrogated in this chapter as an exemplar of speculative drawing that integrates orthographic drawing, notation devices and layering to present and enable a narrative from multiple points of view simultaneously.

Spiller composes the drawing using a combination of one point perspective, plan view, elevation view and section cuts to present multiple views at the same time. He lets each drawing technique extend beyond their border, essentially allowing them to overlap and influence each other. The one point perspective at the top of the drawing evidences this as it protrudes beyond its frame over the plan below it, with Spiller carefully aligning the grids to allow the viewer's eyes to transition from one view to the next.

The frame at the top of the drawing is populated with small squares depicting different scenes that transform through the sequence. This use of notation creates a horizontal timeline that conveys to the viewer that the drawing occurs over a passage of time. Spiller also applies his unique language of notation throughout the drawing, placing fluid organic forms in relation to orthogonal architectural informsillustrating a dialectic narrative through this confrontation.

By layering multiple drawing techniques into a single composition, Spiller's drawing allows the viewer to comprehend the design from different points of view simultaneously. The overlap of these layers becomes an important interaction that informs the viewer of new spatial relationships not normally apparent in traditional drawing practice.

The techniques of integrating different orthographic views, confrontational notation, and overlapping layers will be applied in the Developed Design chapter to enable the polyvalent narratives of each the seven selected characters to come to life. 


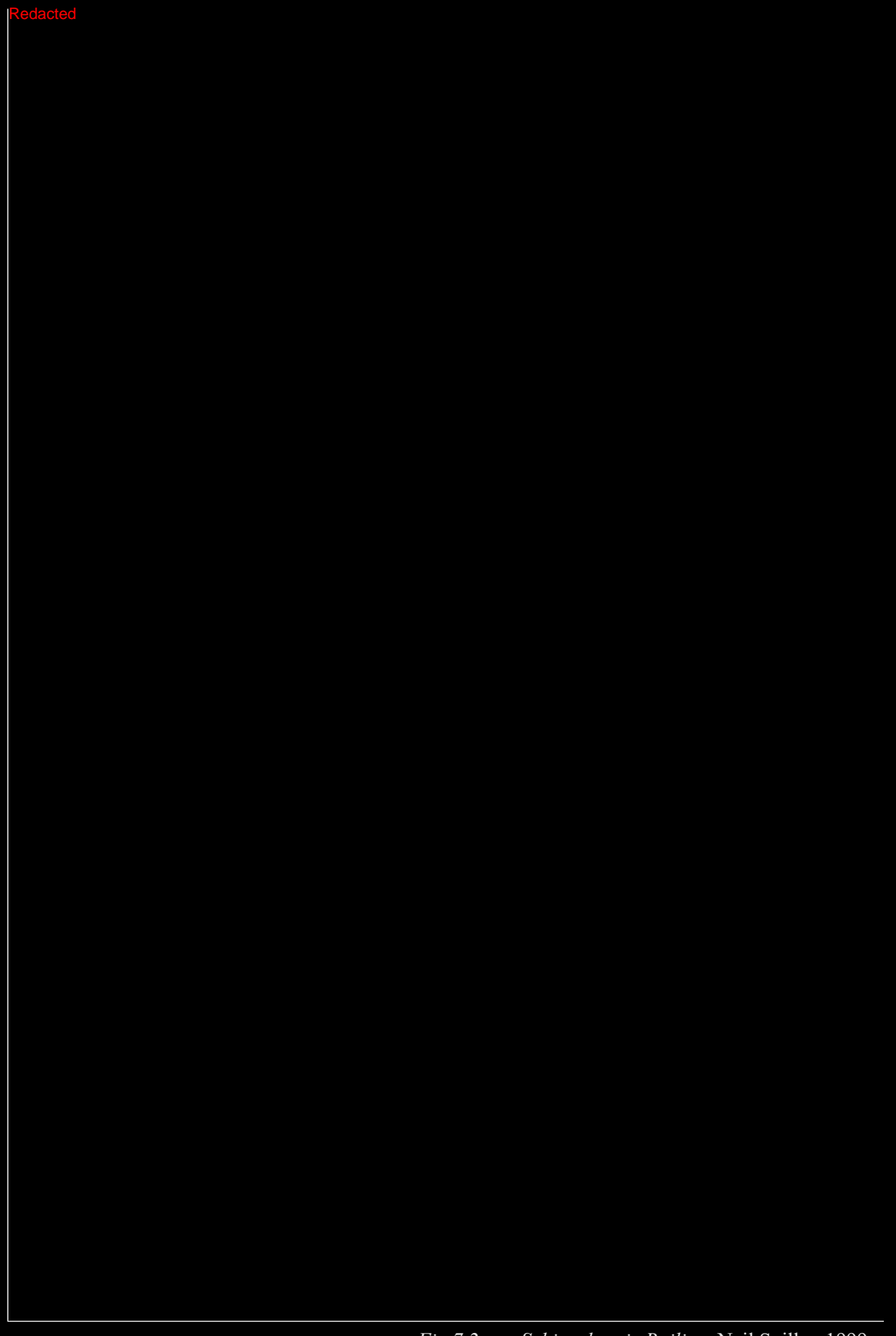

Fig 7.2 Schizophrenic Railing, Neil Spiller, 1999 


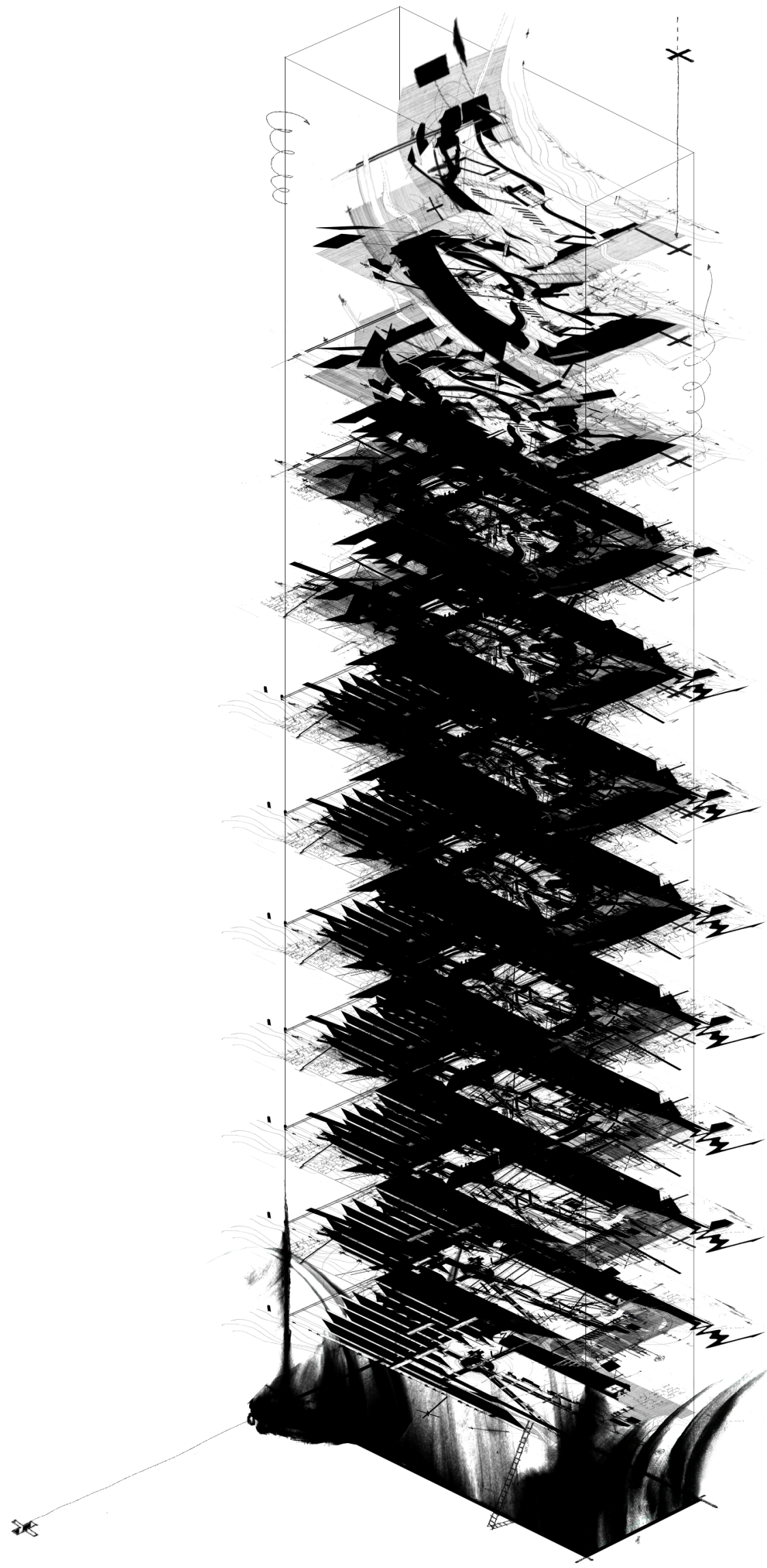



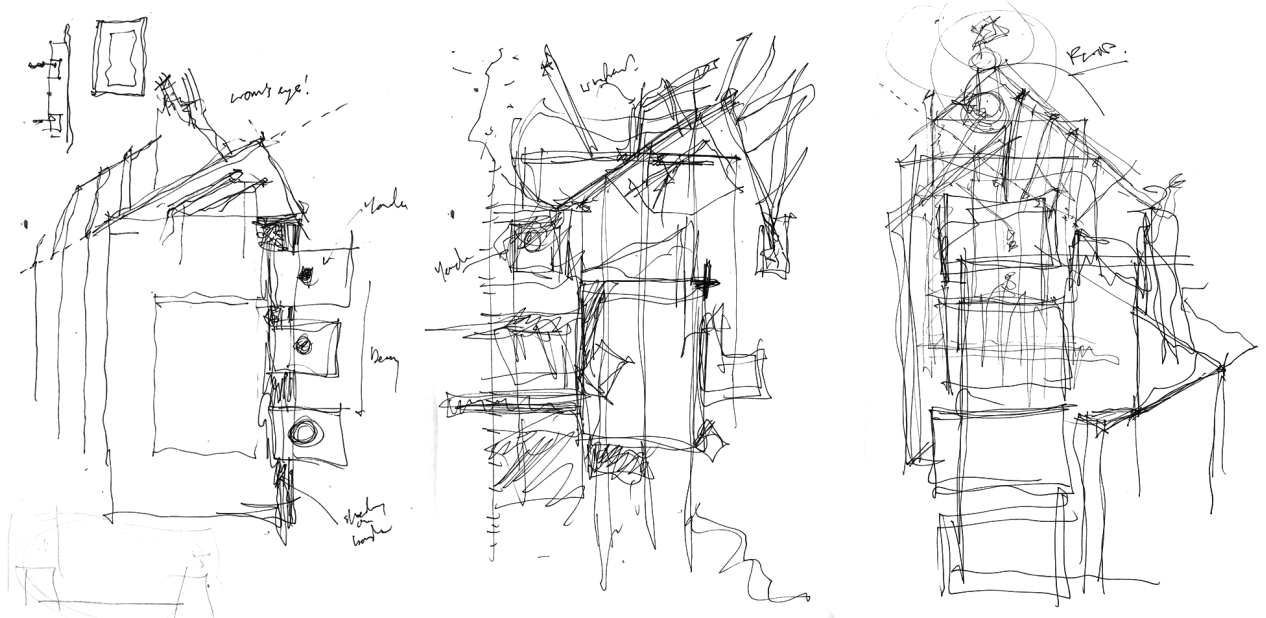

Fig 7.4 Iterative sketch development combining multiple perspectives into a single composition.

\subsection{POLYVOCAL DRAWINGS}

This new series of speculative drawings is constructed from a base of layered orthographic plan view experiments, with the drawing on top corresponding to the character whose story is being told.

Similar to the final layered experiments in the Preliminary Design chapter (figure 6.12-6.16), the rectangular planes acting as the allegorical stage sets of these drawings are used along with registration notations to align them. This created a legible orthographic drawing surface to begin with, while the edge conditions became blurred and enigmatic. These interactions between drawings began to inform the confrontational aesthetic of the allegorical architectural project — becoming a major theme across the ultimate Developed Design series. 
Fig 7.5 Concept drawing by author indicating the layering process where the order of the experiments are reordered for each polyvocal drawing allowing a different character to come to forefront as the principal voice in the composition.
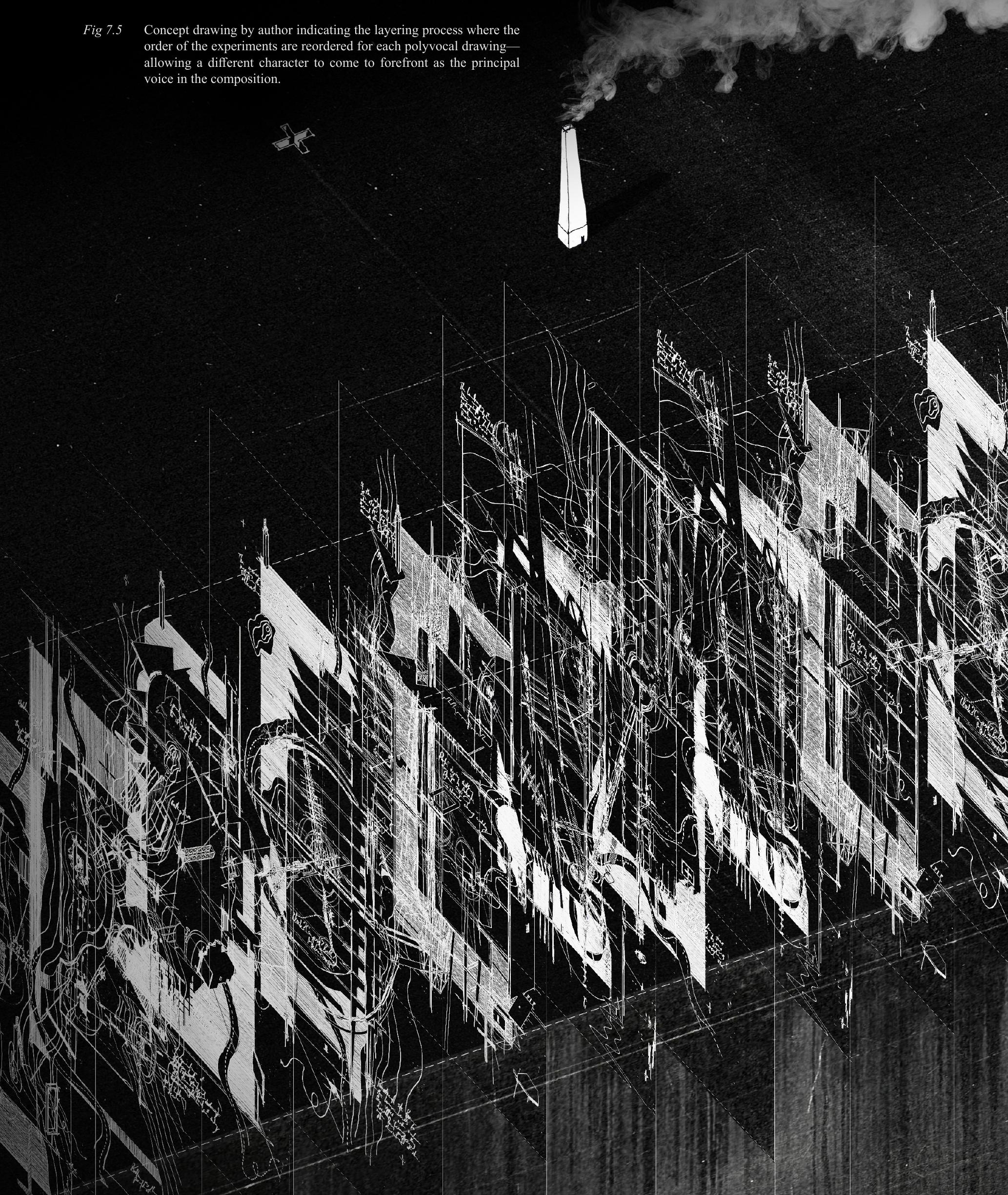

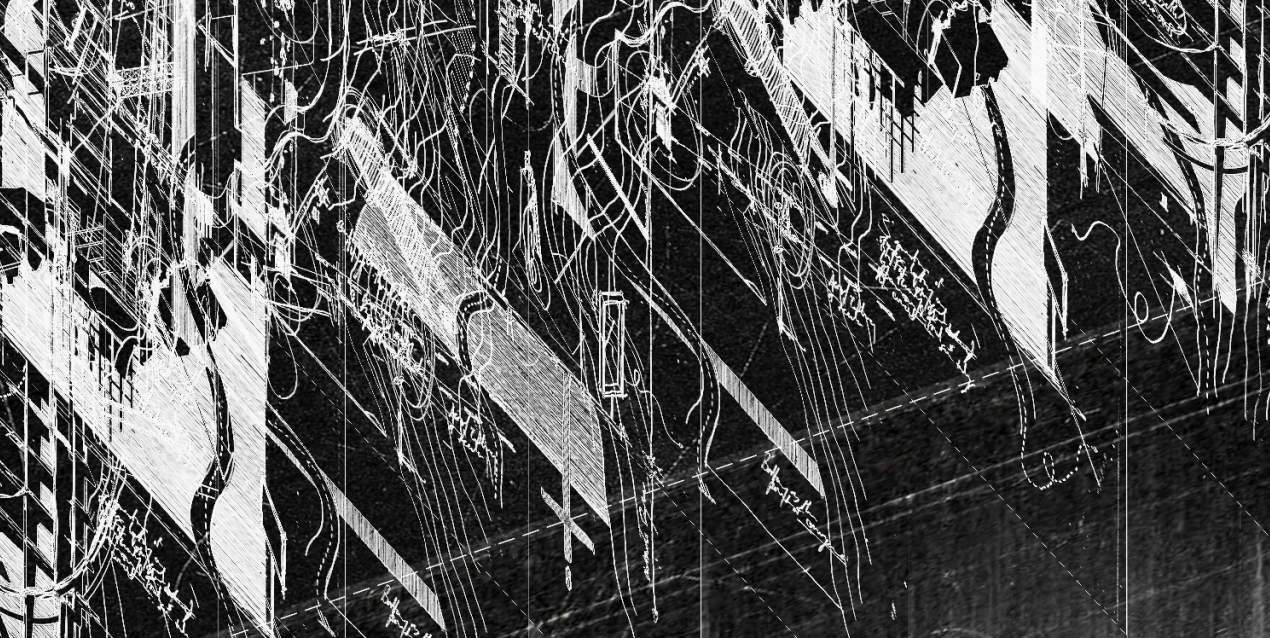

Montage, on the other hand, works with surfaces and images. Its construction no longer tries to model depth, either the finite depth of perspective or the infinite depth of axonometric. Place is created out of fragments distant in time and space. Construction "with intervals" recognizes the discontinuities that are now built into the fabric of time and space. ... It registers a faith in ability of the machine to assist in this construction of a new reality. The machine/eye makes difference visible. ... But the machine also threatens the unity of the subject. ...

Construction "with intervals" suggests that in montage, it is not the elements that are significant, but the space in-between that defines the potential depth. The space of the interval is a shallow, compressed space, unfolding in time and linked together by the perception and recall of the observer. 


\subsubsection{THE MINESHAFT}

It represents a story about place identity established by a void-something that is missing, rather than something that is present.

\section{RO1 Orthographic Drawing}

Elements presented in plan view have their shadows extruded back towards the central pivot point, implying that there is a driving mechanism hidden in the void behind the drawing.

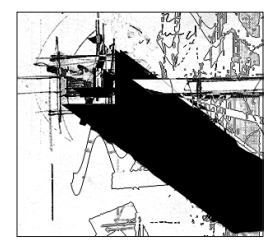

\section{RO2 Notation Devices}

Empty portals represent voids within the drawing, creating a vaccum that begins to warp elements such as shadows and smudges. The shifting + notation acts as a registration mark aligning the voices below.

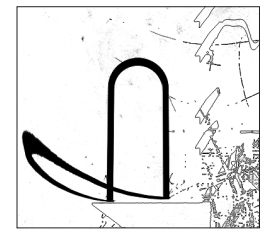

\section{RO3 Layering Technique}

Layers from past and future drawings begin to form an architectural construct with a central pivot point emerging from beneath. Layers below are halfsubmerged, but remain visible as glimpses from above.
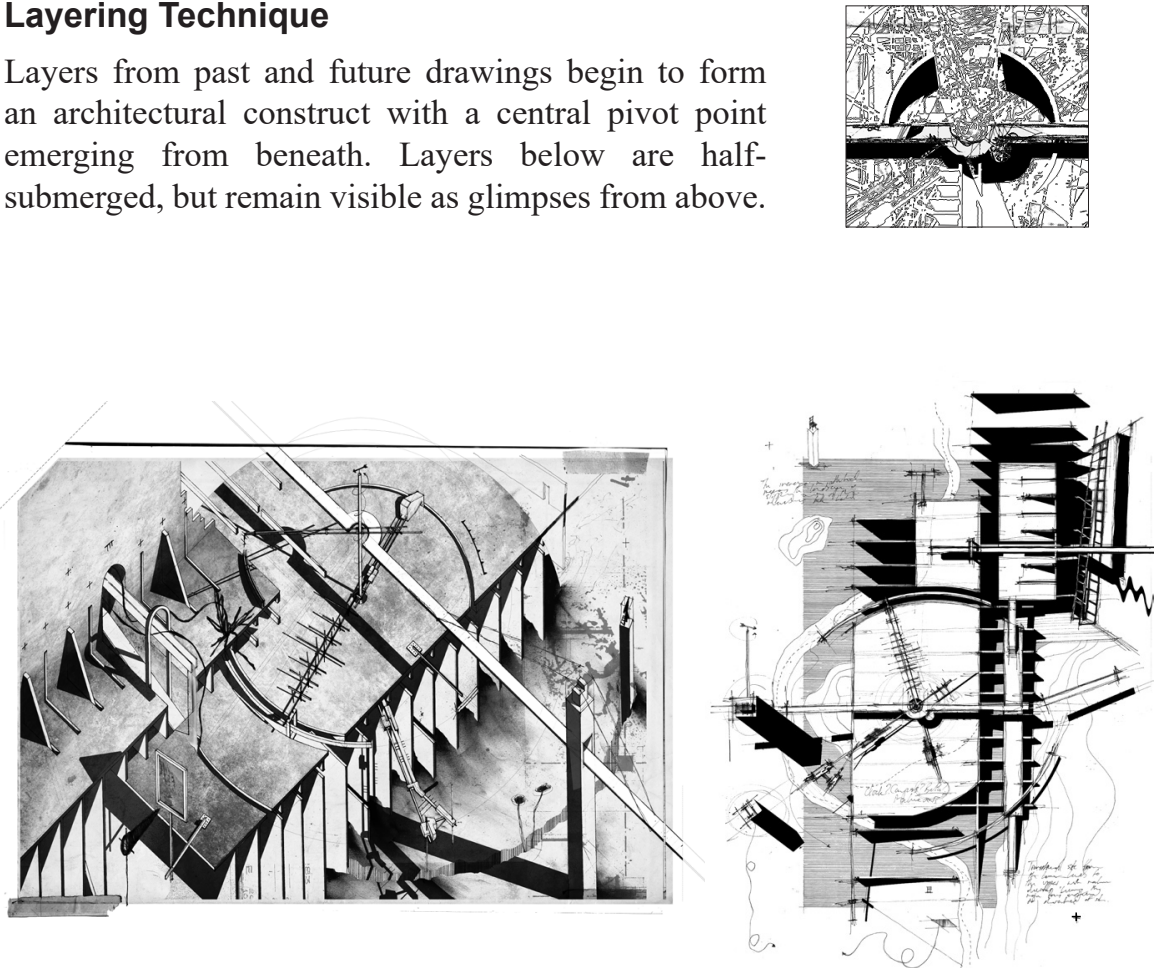


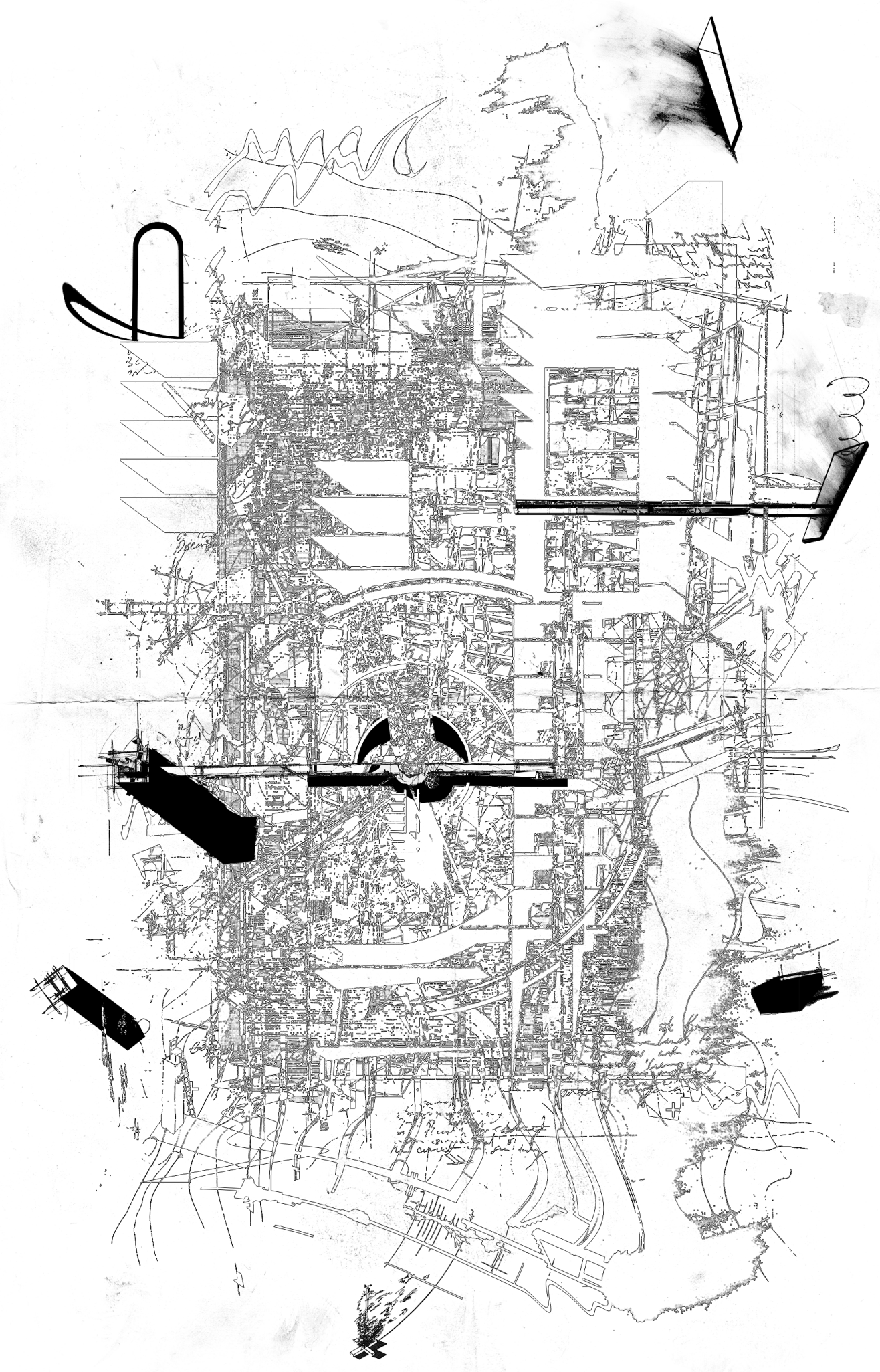

Fig 7.8 Polyvocal trace drawing interrogating the Mineshaft as the principal character. 


\subsubsection{THE MINESHAFT}

Place identity defined as a void.

The tale's hollow cry reverberates, an echo in the darkness...

Pen and ink on paper + digital drilling

$841 \times 594 \mathrm{~mm}$

William du Toit

46

Man the flower of all flesh, the noblest of all creatures visible,

man who had once made god in his image,

and had mirrored his strength on the constellations,

beautiful naked man was dying,

strangled in the garments that he had woven.

Century after century had he toiled, and here was his reward.

Truly the garment had seemed heavenly at first,

shot with colours of culture, sewn with the threads of self-denial.

And heavenly it had been so long as man could shed it at will

and live by the essence that is his soul,

and the essence, equally divine, that is his body. 


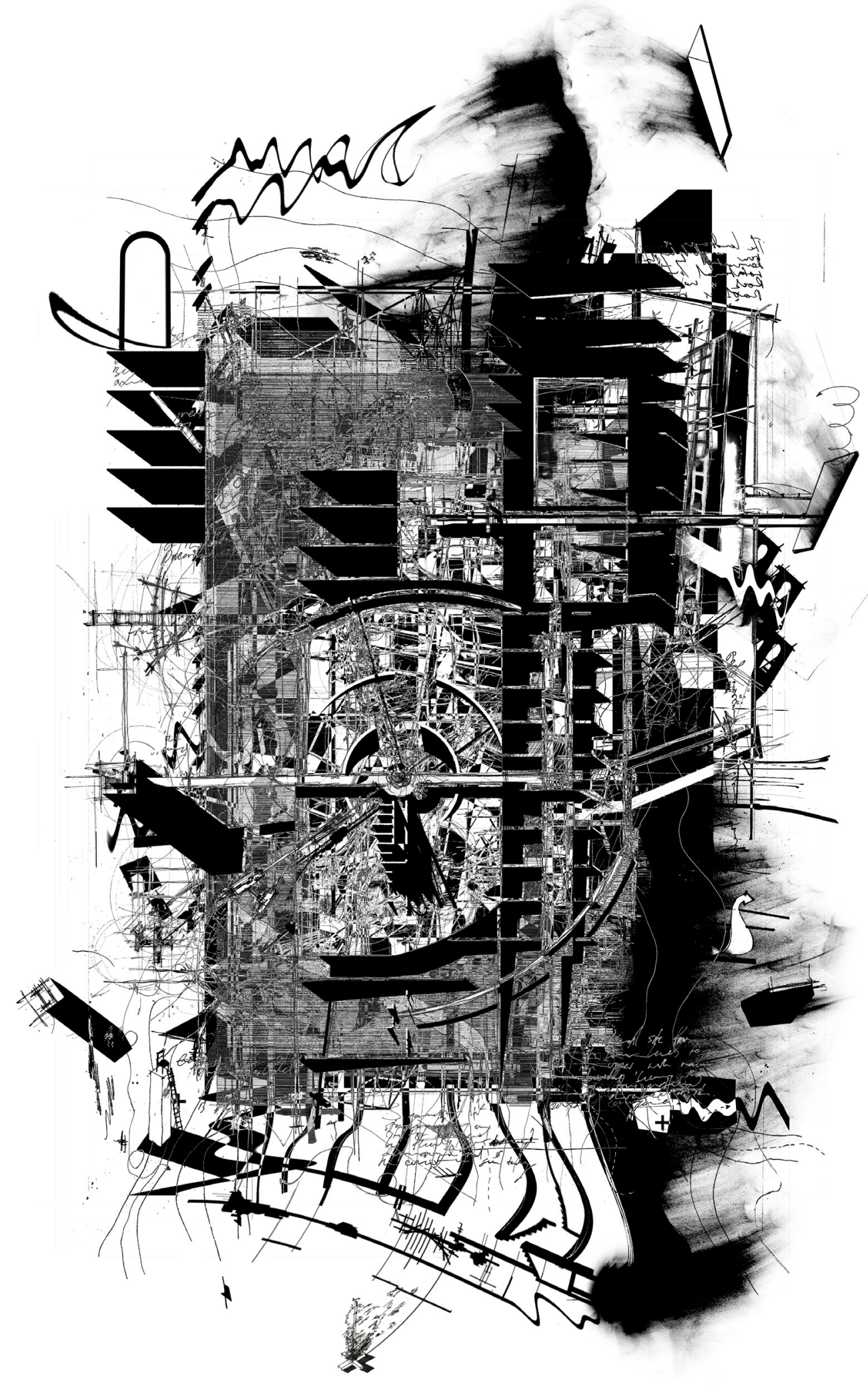




\subsubsection{THE AERIAL CABLEWAY}

It represents a story about place identity established by transition-a connecting system defined as the inbetween.

\section{RO1 Orthographic Drawing}

Like the steel cables that connected the Aerial Cableway, projection lines are traced along and between important elements, highlighting the critical relationships between various elements.

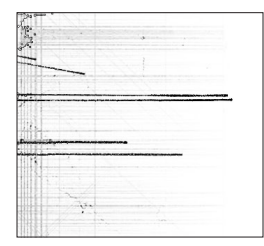

\section{RO2 Notation Devices}

Important projection lines are highlighted with registration markers, identifying them as primary axes while simultaneously acknowledging the transitional nature of the narrative of the layered construction lines.

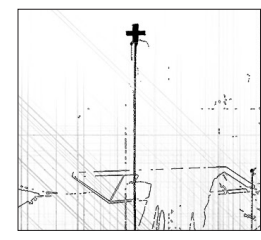

\section{$\mathrm{RO} 3$ Layering Technique}

Construction lines are drawn from the seven layered drawings and woven into a web of transitional connections that form the basis of figure 7.4.2-with layers half submerged, but visible below.
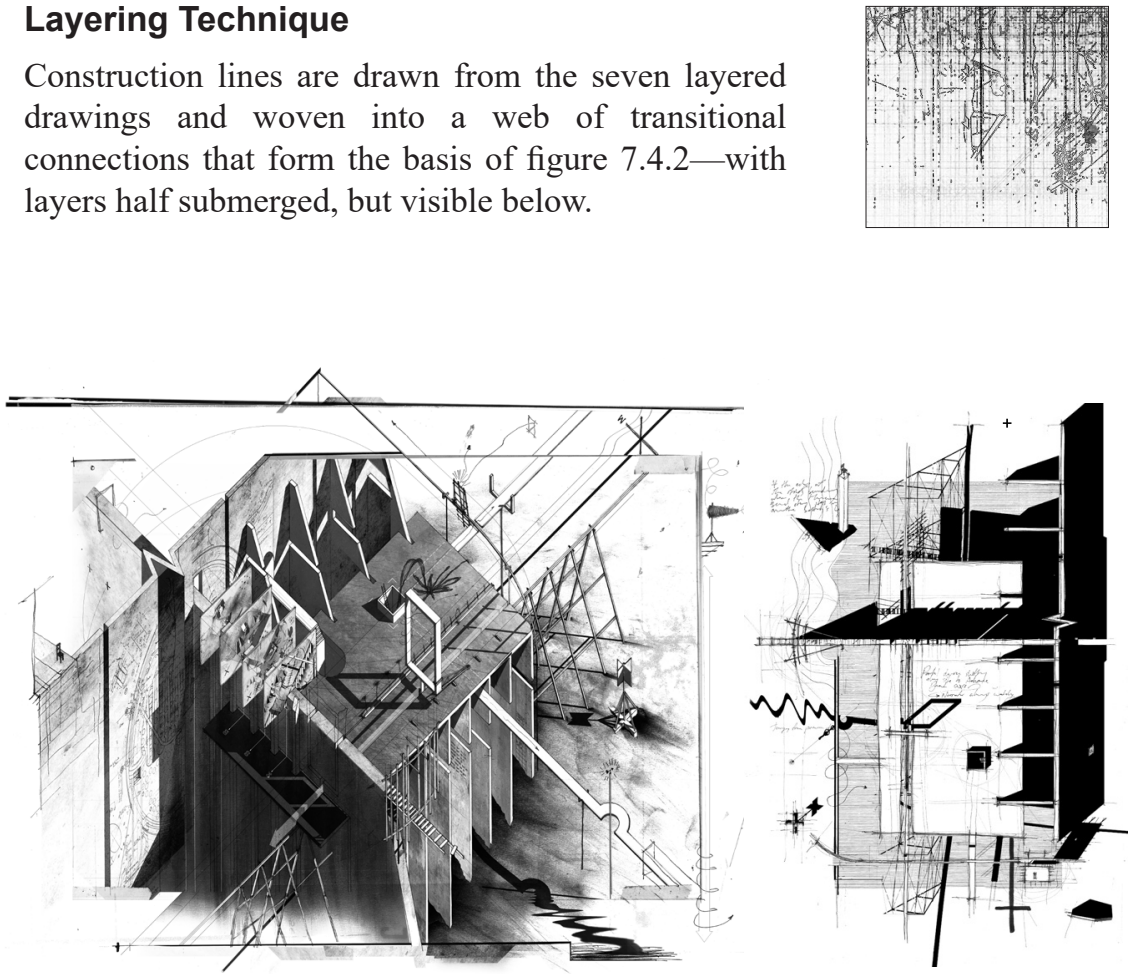

Fig 7.9 Corresponding Preliminary and Concept Design stage drawings, with the concept design drawing being the top layer of Figure 7.5.2. 


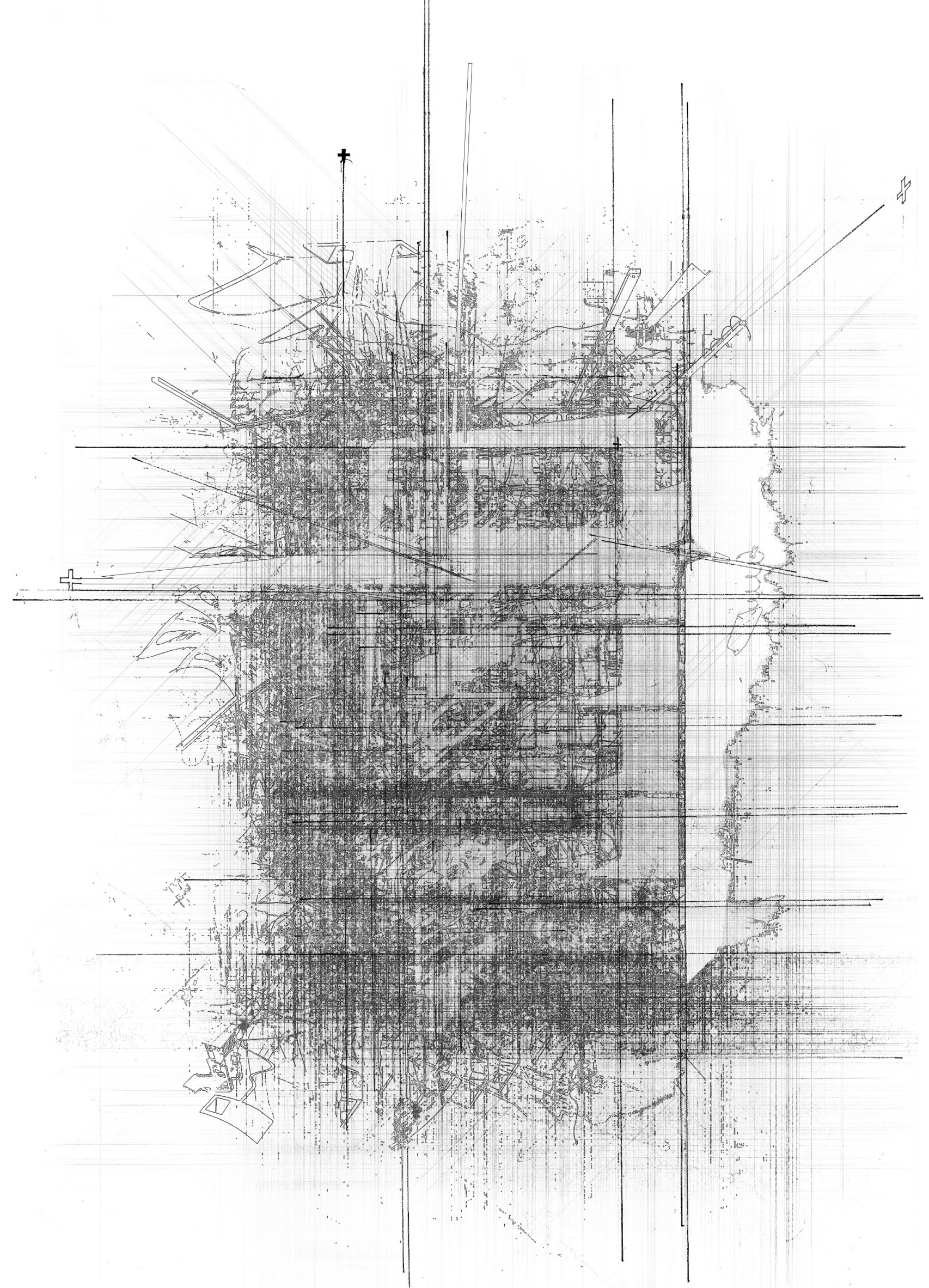

Fig 7.10 Polyvocal trace drawing interrogating the Aerial Cableway as the principal character. 


\subsubsection{THE AERIAL CABLEWAY}

Place identity defined by transition.

The tale is told by the spaces between cries...

Pen and ink on paper + digital weaving

$841 \times 594 \mathrm{~mm}$

William du Toit

46

Man the flower of all flesh, the noblest of all creatures visible,

man who had once made god in his image,

and had mirrored his strength on the constellations,

beautiful naked man was dying,

strangled in the garments that he had woven.

Century after century had he toiled, and here was his reward.

Truly the garment had seemed heavenly at first,

shot with colours of culture, sewn with the threads of self-denial.

And heavenly it had been so long as man could shed it at will

and live by the essence that is his soul,

and the essence, equally divine, that is his body. 

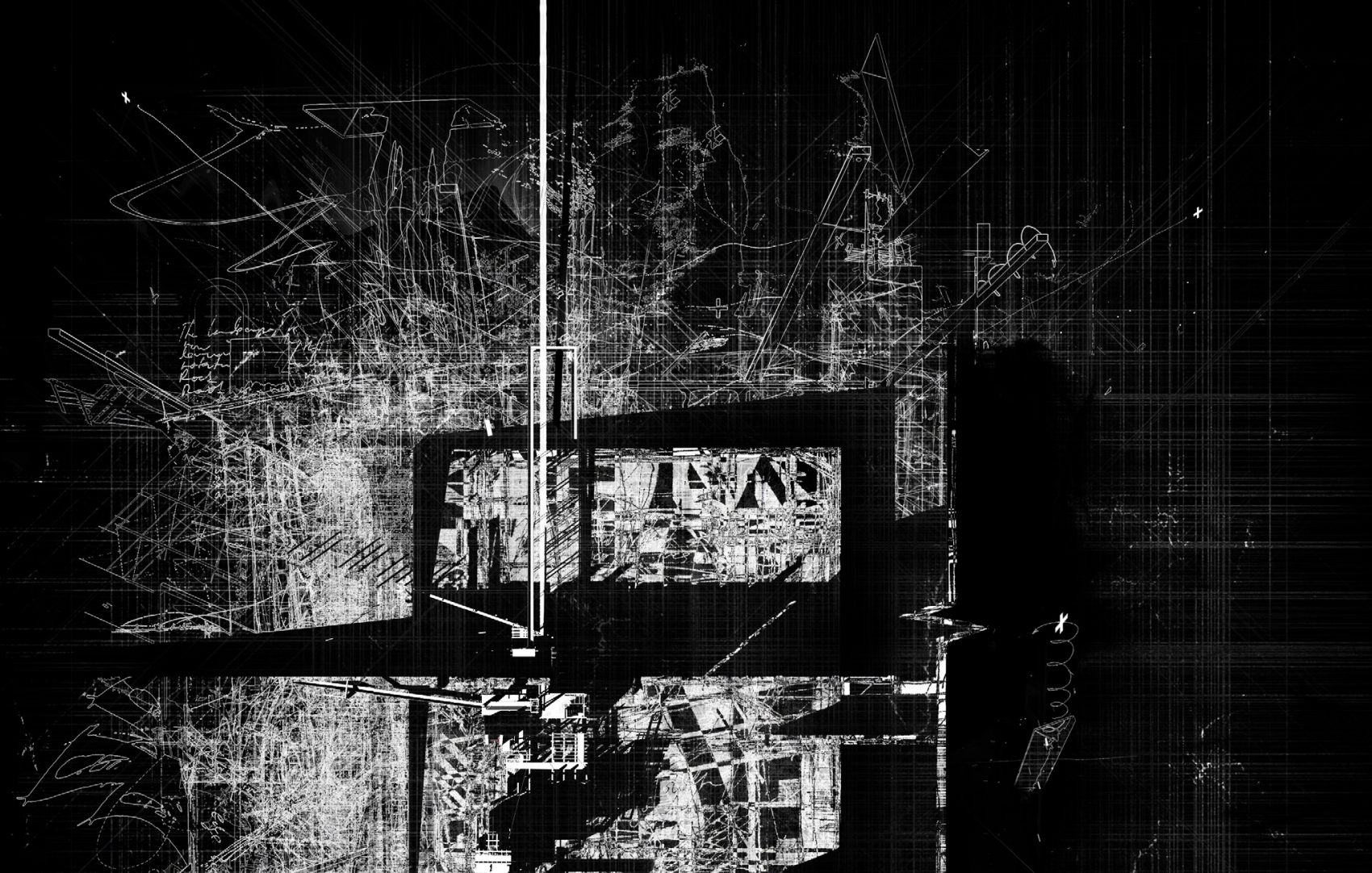


\subsubsection{THE SCHIST TAILINGS}

It represents a story about place identity established by displacement-a tale of annihilation told by a thousand shattered souls, their broken voices crying out in anguished whispers.

\section{RO1 Orthographic Drawing}

Structural fins are shown shifting in their tracks relative to each other, conveying that the rectangular platform has shifted and been displaced from its orthographic foundation.

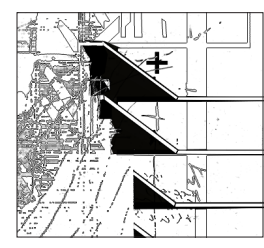

\section{RO2 Notation Devices}

Registration marks are added and then displaced, implying that some of the layers of the drawing have shifted relative to each other while other elements blur and warp due to this displacement.

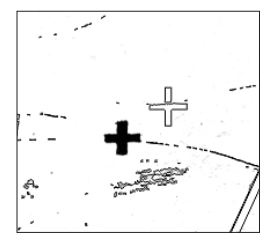

\section{RO3 Layering Technique}

Under layers are revealed as the layers shift, unveiling the substructure beneath the page while the elements that occupy the lower levels begin to blur and warp as a result of the displacements.
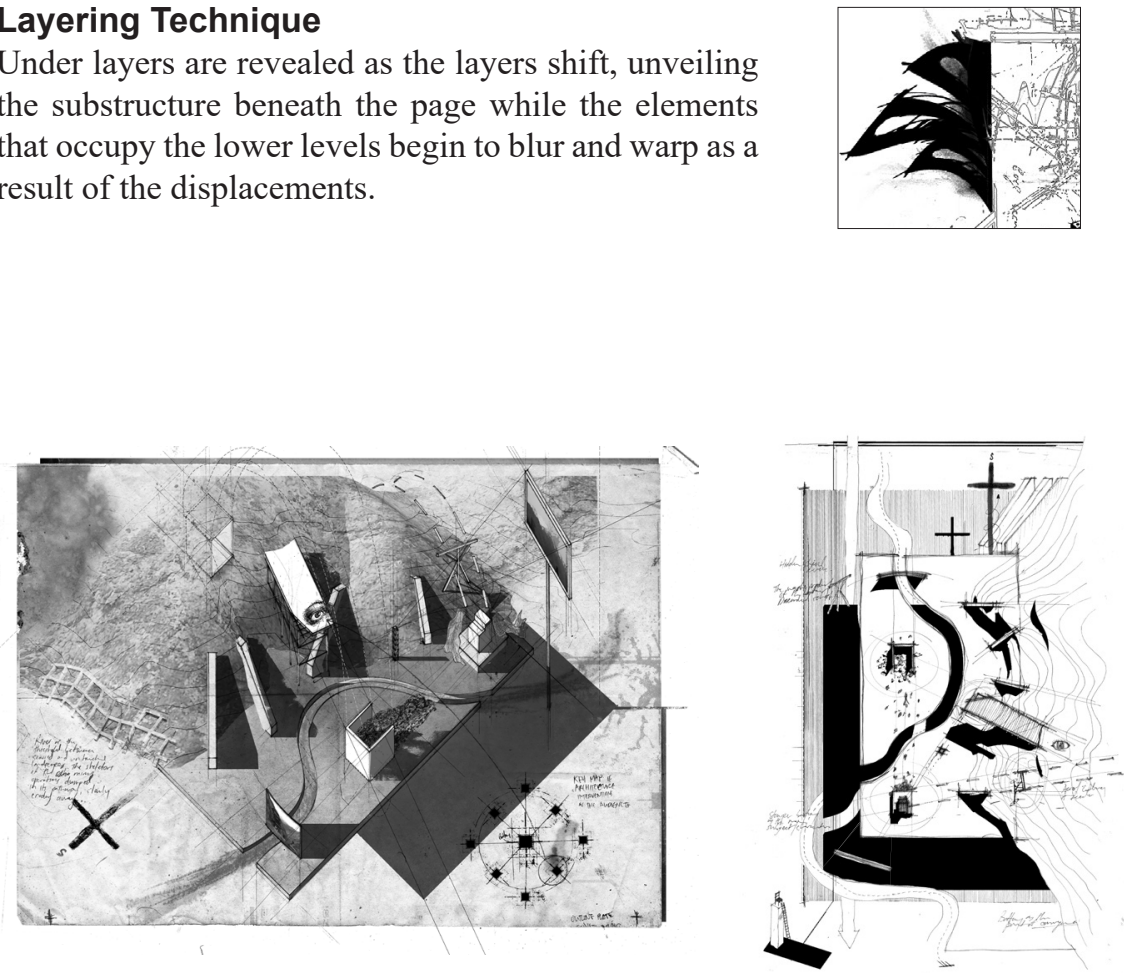


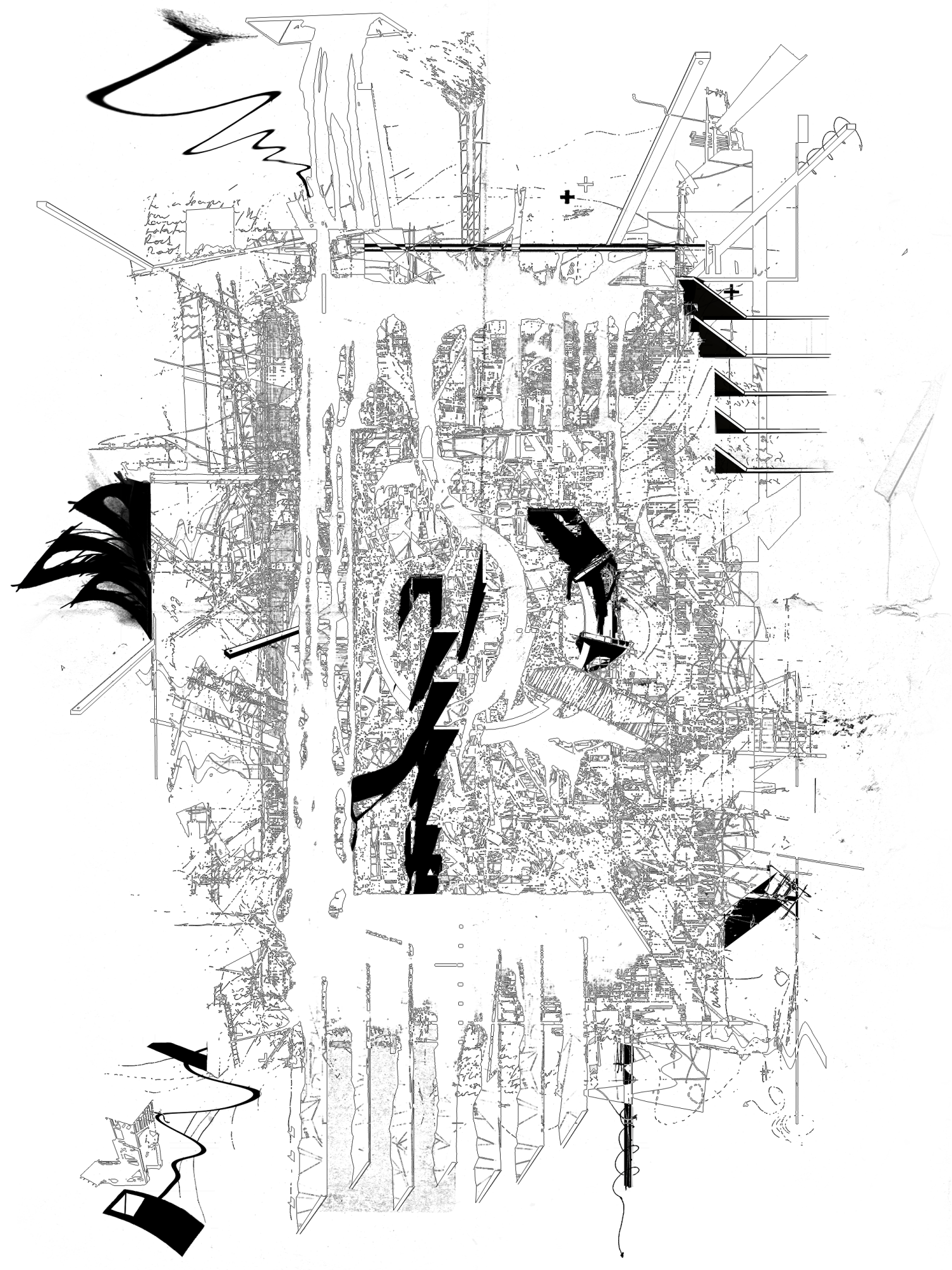

Fig 7.12 Polyvocal trace drawing interrogating the Schist Tailings as the principal character. 


\subsubsection{THE SCHIST TAILINGS}

Place identity defined by displacement

The tale is told by a thousand shattered souls, their broken voices crying out in anguished whispers...

Pen and ink on paper + digital dripping

841 x $594 \mathrm{~mm}$

William du Toit

46

Man the flower of all flesh, the noblest of all creatures visible,

man who had once made god in his image,

and had mirrored his strength on the constellations,

beautiful naked man was dying, strangled in the garments that he had woven.

Century after century had he toiled, and here was his reward.

Truly the garment had seemed heavenly at first, shot with colours of culture, sewn with the threads of self-denial.

And heavenly it had been so long as man could shed it at will and live by the essence that is his soul,

and the essence, equally divine, that is his body. 


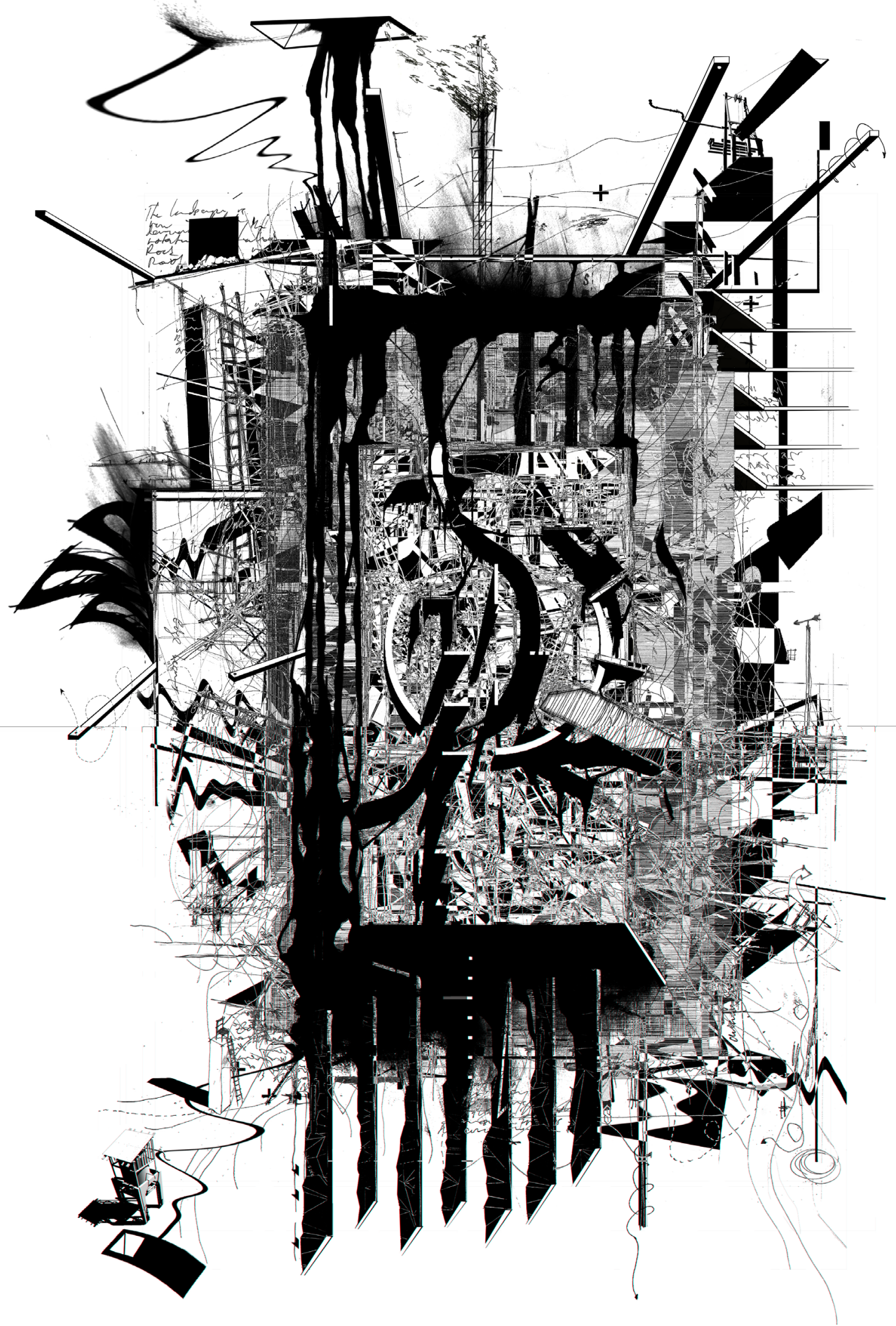




\subsubsection{THE WATER RACE}

It represents a story about place identity defined by cuts, tears and scars-lines drawn deep into the landscape.

\section{RO1 Orthographic Drawing}

Flat planes are cut into and morphed to begin to inform the substructure beneath the drawing's layers, changing from plan view into partial elevation views - allowing the overall rhythm of the underworld to be read.

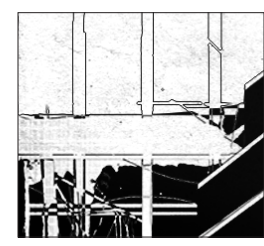

\section{RO2 Notation Devices}

Construction and projection lines from the drawing are peeled back to inform the allegory of the cut, revealing a quote from "The Machine Stops' which was previously hidden within the substructure.

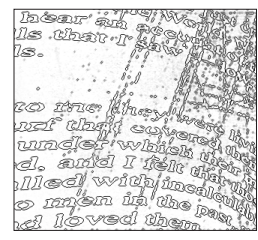

\section{RO3 Layering Technique}

The uppermost layer is folded back, while the second layer is cut with parts removed and the third is exposed - revealing deep chasms into the world below through the cut.
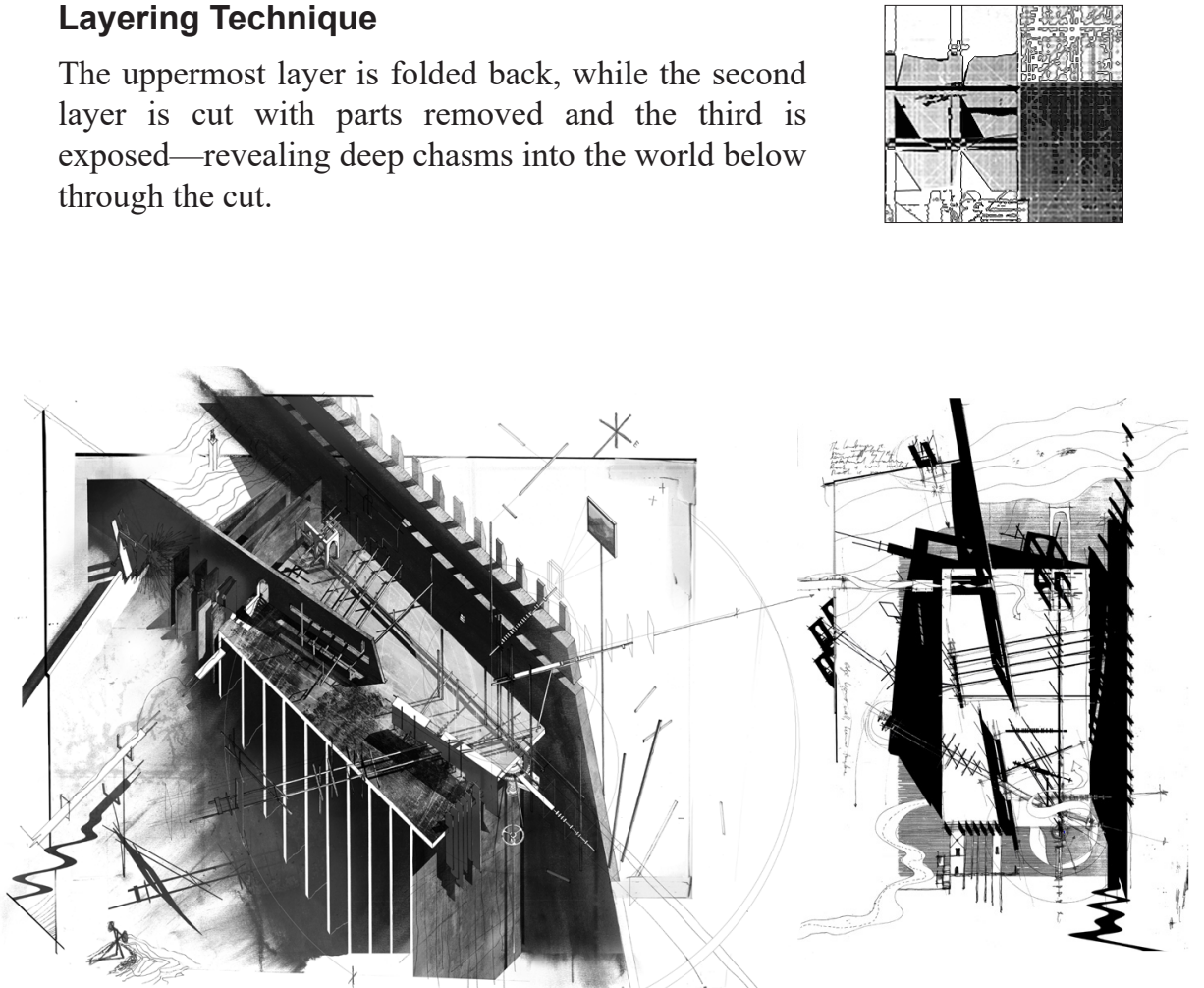

Fig 7.13 Corresponding Preliminary and Concept Design stage drawings, with the concept design drawing being the top layer of Figure 7.7.2. 


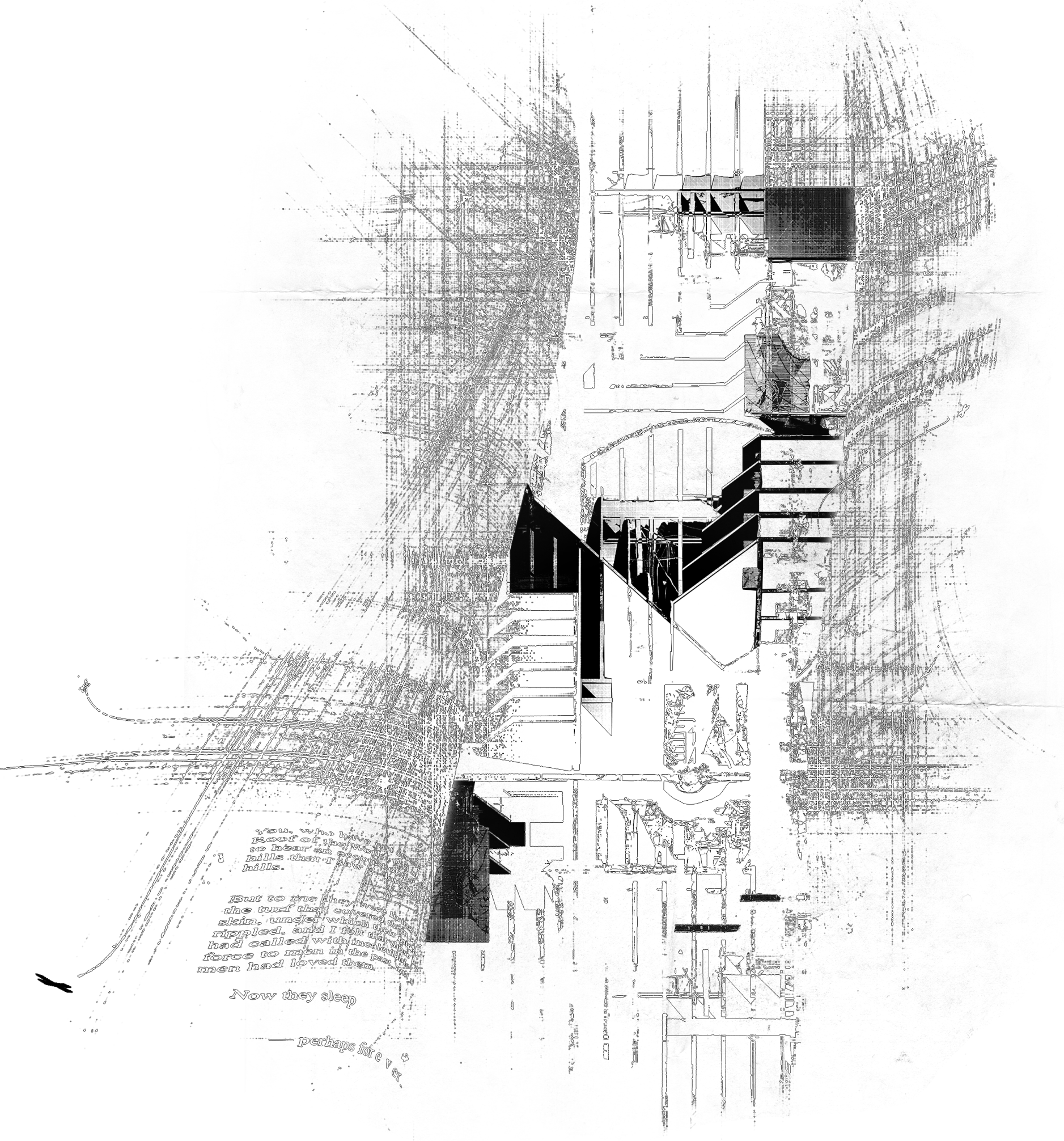

Fig 7.14 Polyvocal trace drawing interrogating the Water Race as the principal character. 


\subsubsection{THE WATER RACE}

Place identity defined as a cut.

The tale's soft sounds merge with the susurration of the stream below...

Pen and ink on paper + digital excavation

841 x $594 \mathrm{~mm}$

William du Toit

46

Man the flower of all flesh, the noblest of all creatures visible,

man who had once made god in his image,

and had mirrored his strength on the constellations,

\section{beautiful naked man was dying, strangled in the garments that he had woven.}

Century after century had he toiled, and here was his reward.

Truly the garment had seemed heavenly at first, shot with colours of culture, sewn with the threads of self-denial.

And heavenly it had been so long as man could shed it at will and live by the essence that is his soul,

and the essence, equally divine, that is his body. 


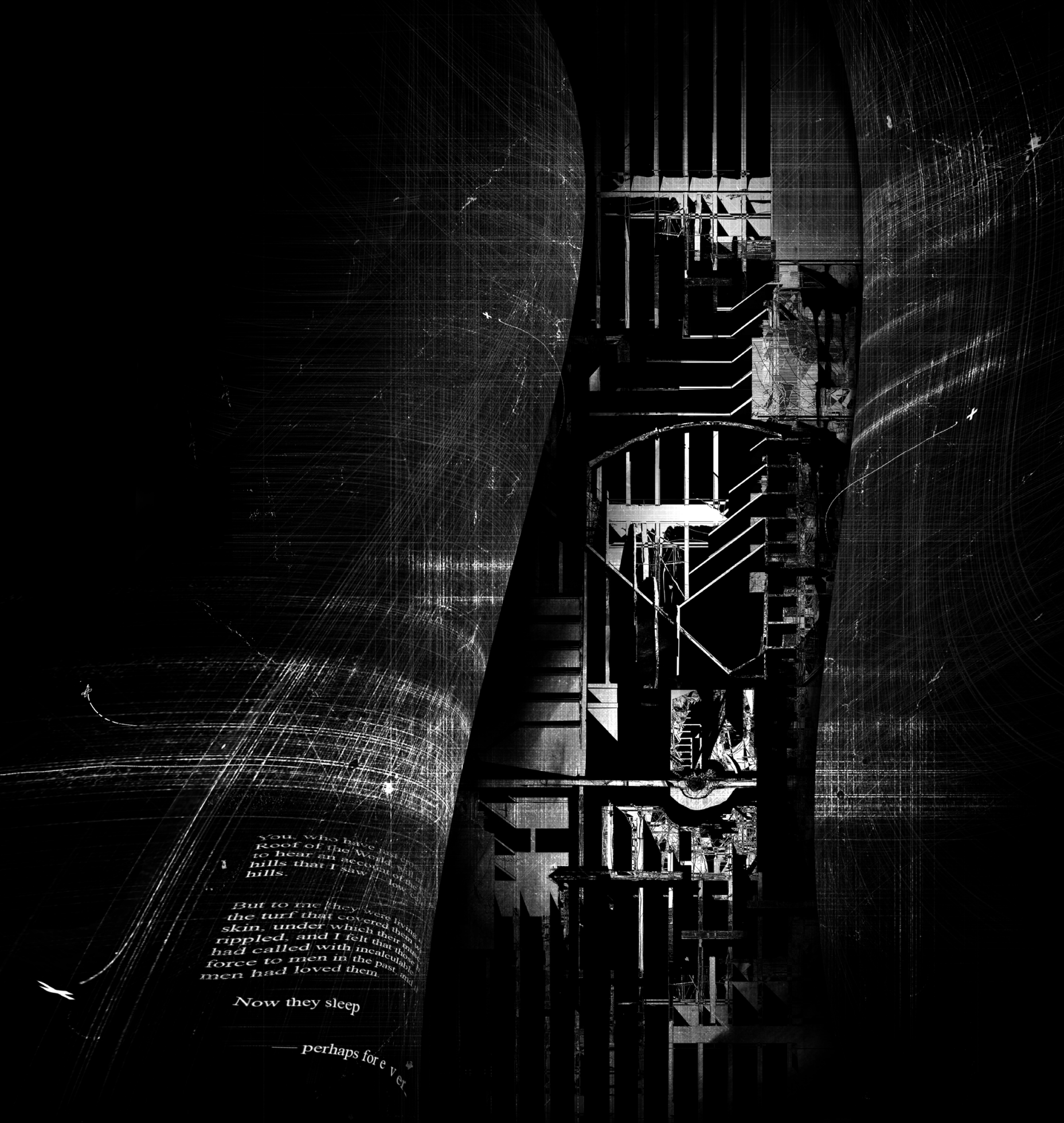




\subsubsection{THE STAMPER BATTERY}

It represents a story about place identity defined by convergence-where elements are fractured amalgamated.

\section{RO1 Orthographic Drawing}

Axonometric view of the architectural construction shifts to plan view then back to axonometric, with orthographic drawing techniques converging in the centre.

\section{RO2 Notation Device}

Multiple orthographic views presented simultaneously allow different scales and orientations to be witnessed, with elements having dual meanings as they shift and then converge again between perspectives.
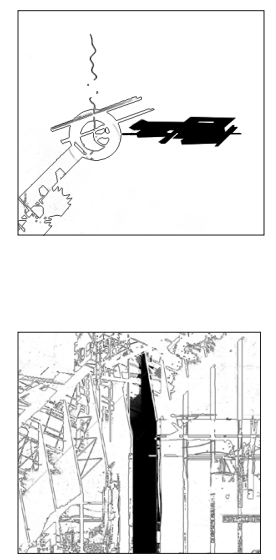

\section{RO3 Layering Technique}

The convergence of the upper, middle and lower layers enables the drawing's narrative of convergence to be understood as taking place over a passage of time, rather than a static moment.
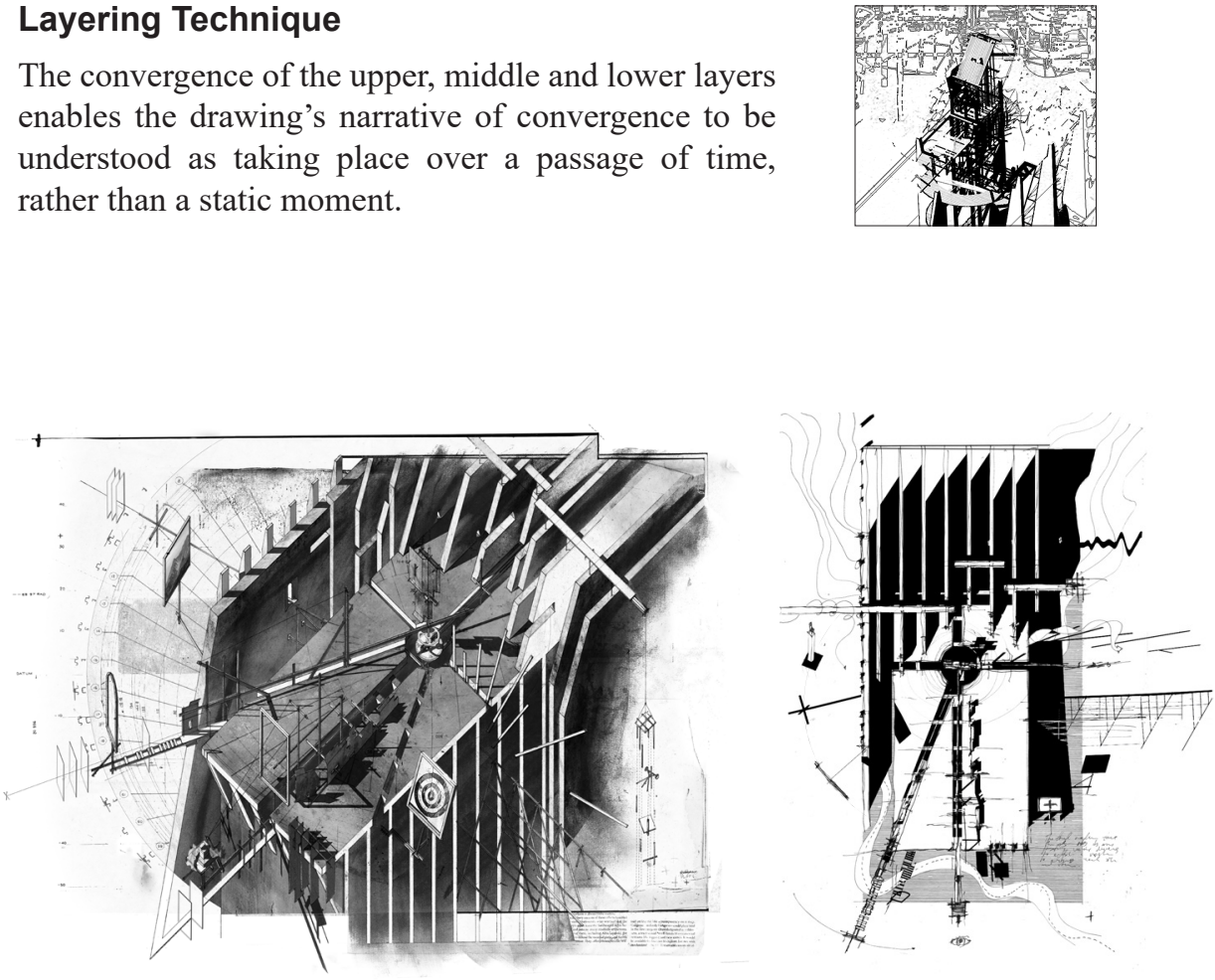


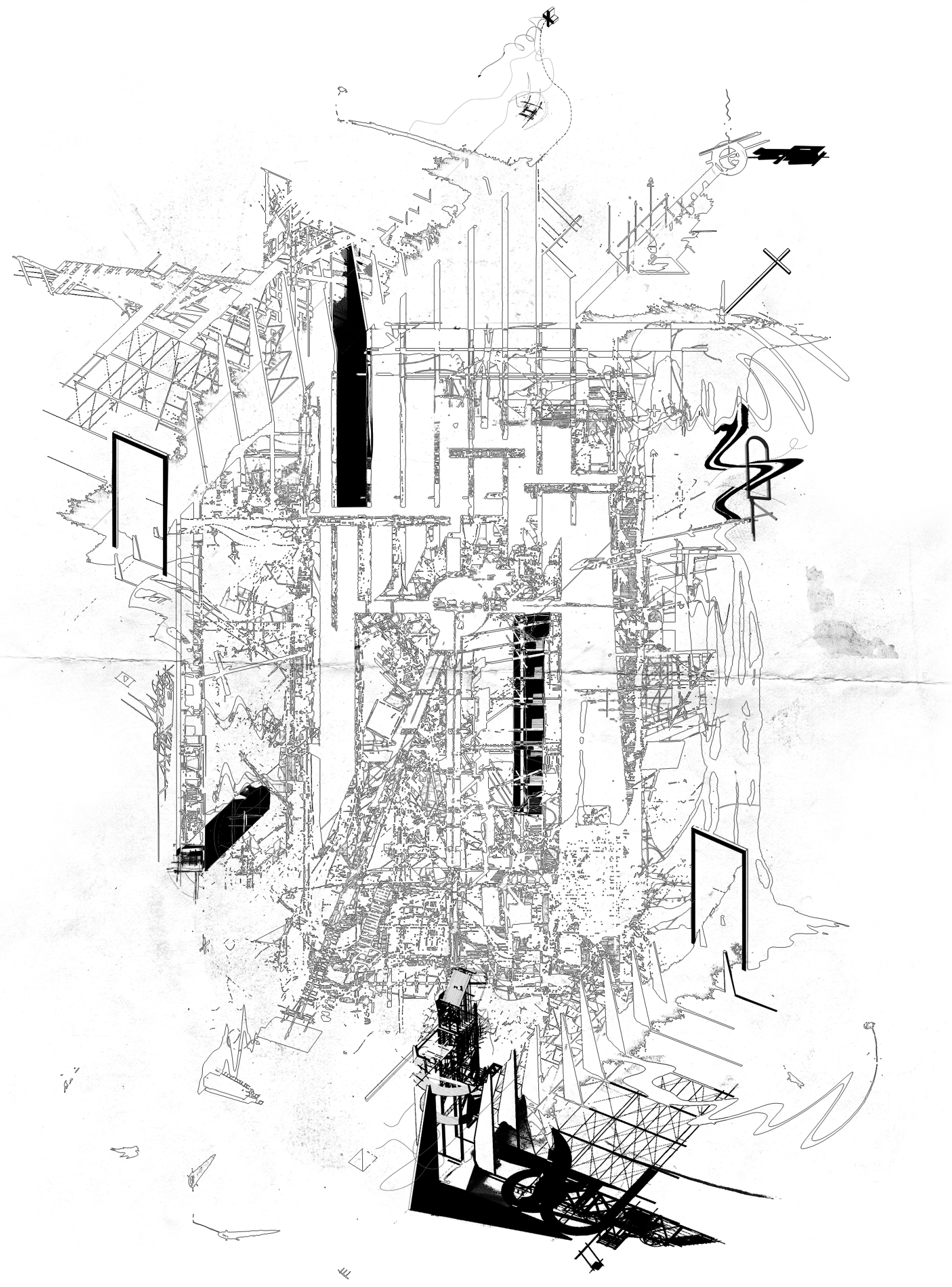

Fig 7.14 Polyvocal trace drawing interrogating the Stamper Battery as the principal character. 


\subsubsection{THE STAMPER BATTERY}

Place identity defined by convergence.

The tale is told by the past echoes of grinding gears, explosive salvos and discordant wails...

Pen and ink on paper + digital amalgamation

841 x $594 \mathrm{~mm}$

William du Toit

46

Man the flower of all flesh, the noblest of all creatures visible,

man who had once made god in his image,

and had mirrored his strength on the constellations,

beautiful naked man was dying, strangled in the garments that he had woven.

Century after century had he toiled, and here was his reward.

Truly the garment had seemed heavenly at first, shot with colours of culture, sewn with the threads of self-denial.

And heavenly it had been so long as man could shed it at will and live by the essence that is his soul,

and the essence, equally divine, that is his body. 


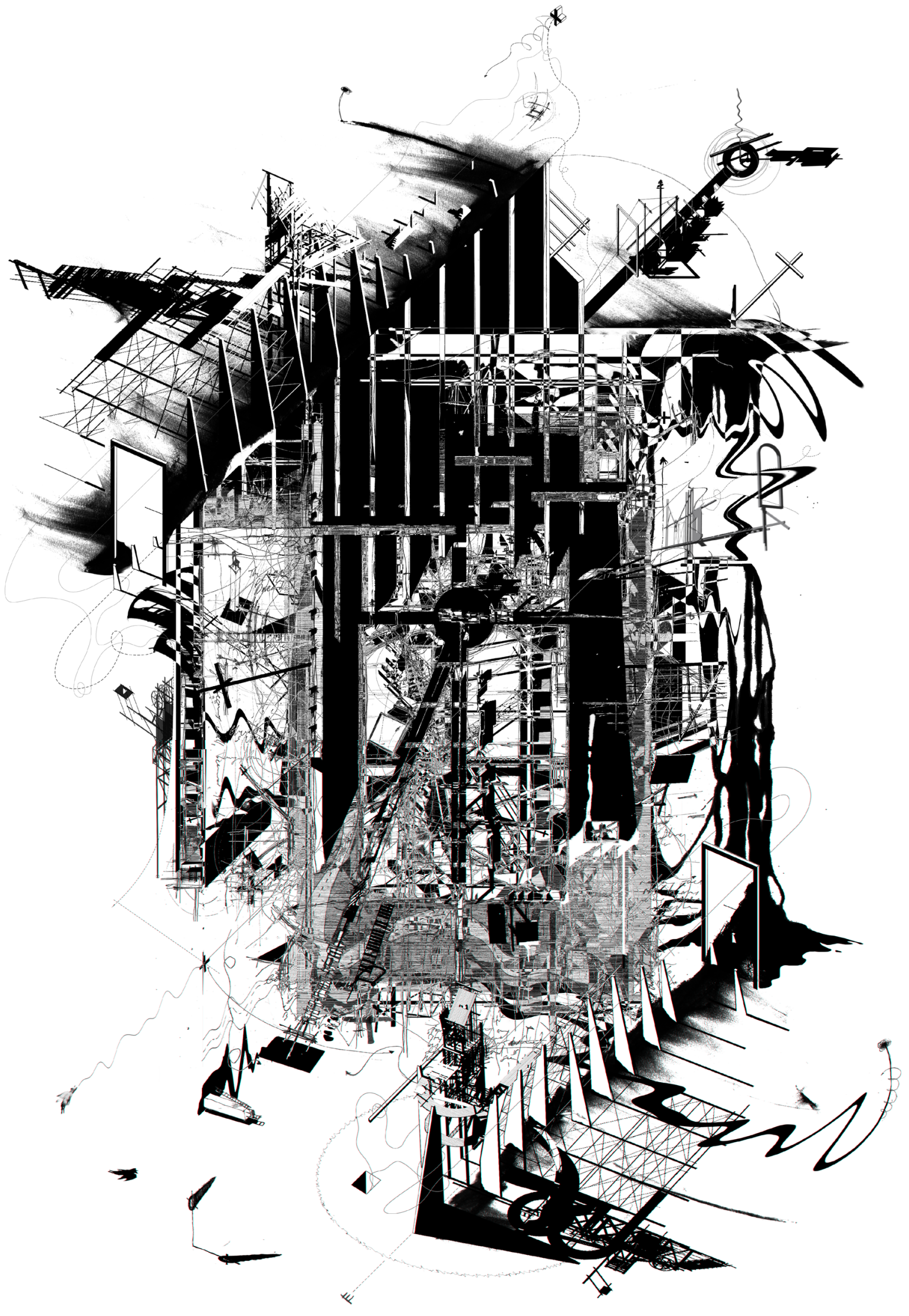




\subsubsection{THE BATTERY FOOTPRINT}

It represents a story about place identity defined by traces left upon the landscape - a palimpsest of impressions.

\section{RO1 Orthographic Drawing}

Multiple orthographic perspectives create an echo that allows us to hear a fragment - a trace — of the story that is no longer whole.

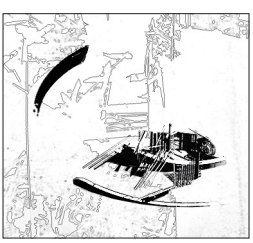

\section{RO2 Notation Devices}

A compass overlaid with a timepiece and its corresponding axis provide a principal framework for the other six points of view. The compass notations are only visible as traces upon the fragile landscape.

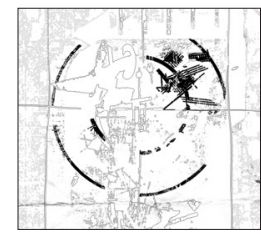

\section{RO3 Layering Technique}

This lost setout drawing is erased or revealed when other polyvocal drawings are composed, lying beneath the layers as a trace of its former self.
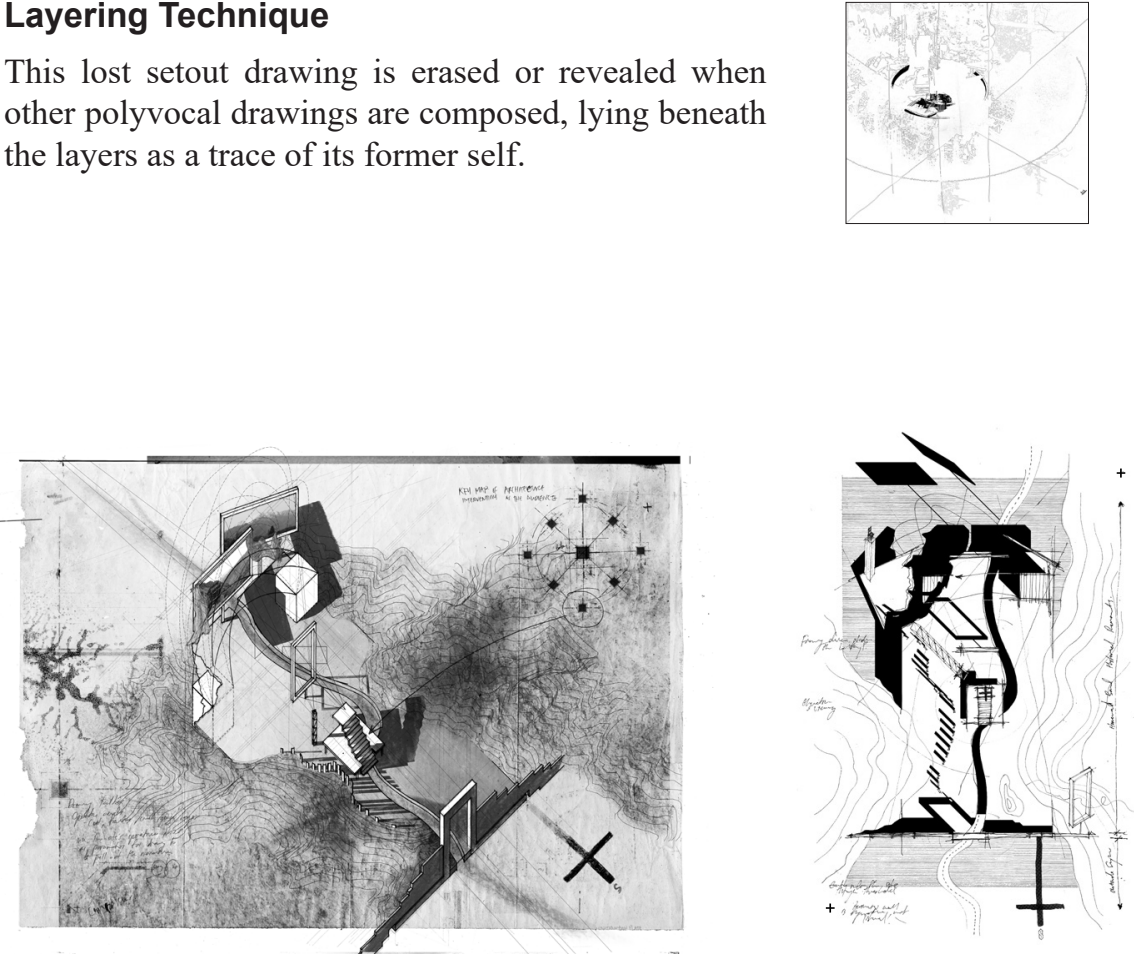


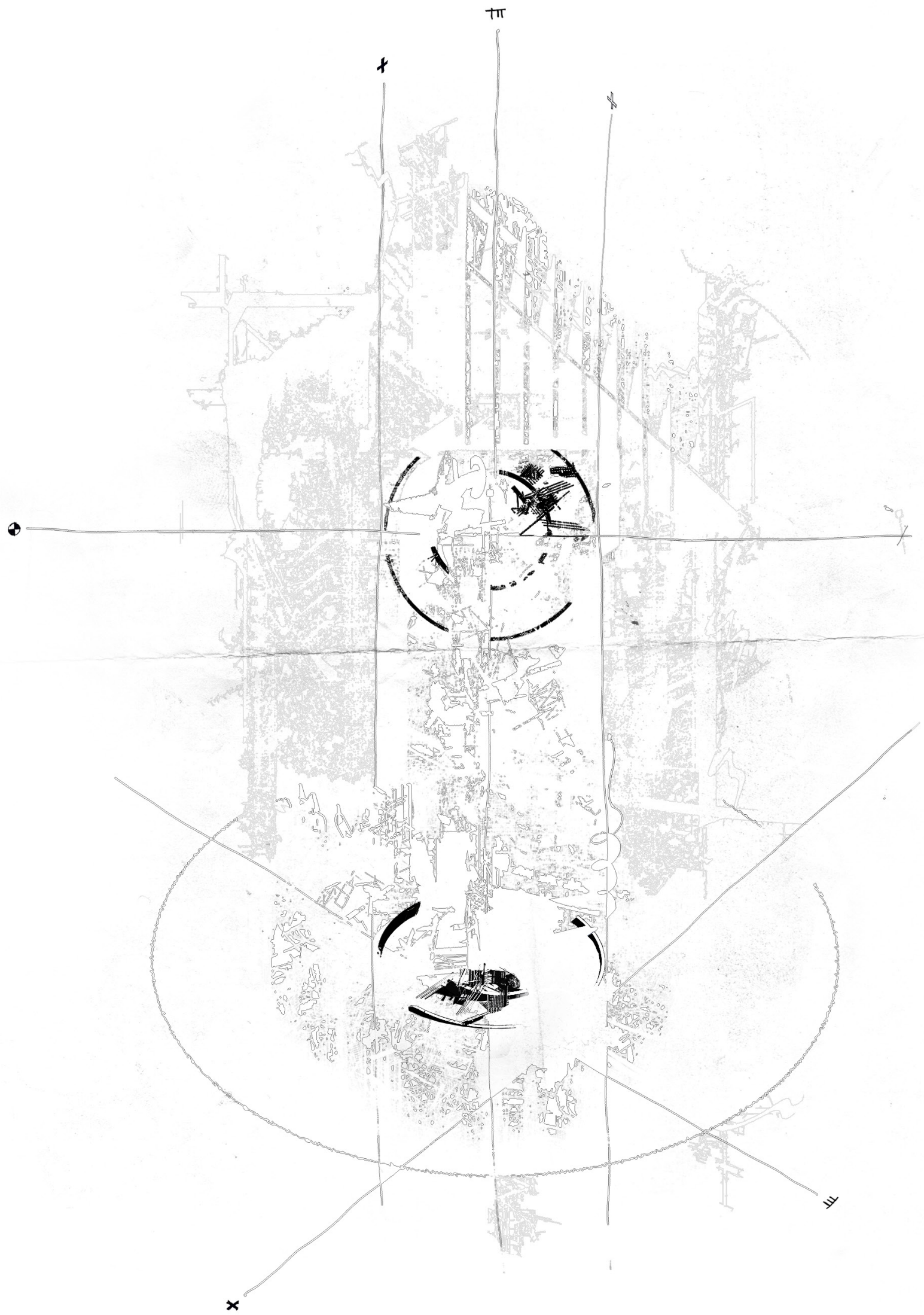

Fig 7.16 Polyvocal trace drawing interrogating the Battery Footprint as the principal character. 


\subsubsection{THE BATTERY FOOTPRINT}

Place identity defined as a trace.

The tale is told in barely concealed whispers..

Pen and ink on paper + digital summoning

841 x $594 \mathrm{~mm}$

William du Toit

46

Man the flower of all flesh, the noblest of all creatures visible,

man who had once made god in his image,

and had mirrored his strength on the constellations,

beautiful naked man was dying,

strangled in the garments that he had woven.

Century after century had he toiled, and here was his reward.

Truly the garment had seemed heavenly at first, shot with colours of culture, sewn with the threads of self-denial.

And heavenly it had been so long as man could shed it at will and live by the essence that is his soul,

and the essence, equally divine, that is his body. 


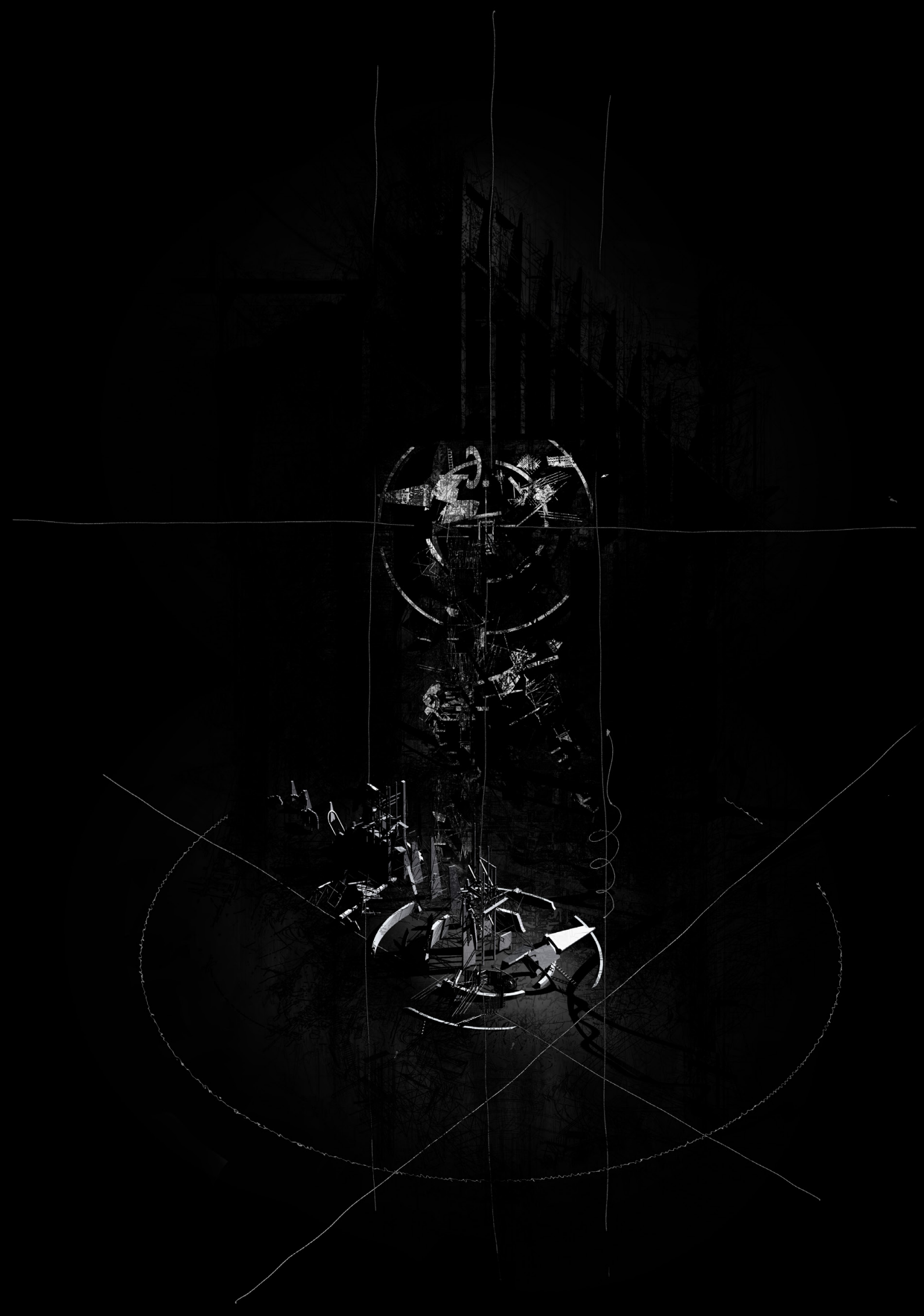




\subsubsection{THE REDIRECTED STREAM}

It represents a story about place identity defined by deviation-a tale of the conflicts between natural and man-made forces.

\section{RO1 Orthographic Drawing}

The shift from orthogonal grid lines to fluid lines allows the drawing to be read in relation to deviations from its original position, with the fluid lines (representing the natural systems) being harmed and pulled away.

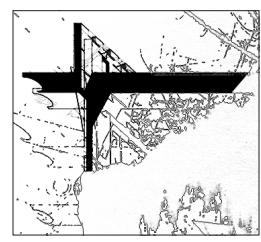

\section{RO2 Notation Devices}

The lost setout drawing is revealed beneath as it shifts and deviates from its original position due to a cataclysmic event, while areas above the layer also succumb to external forces.

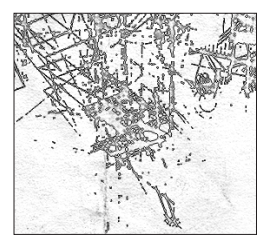

\section{RO3 Layering Technique}

A layer of the drawing is unfurled and peeled back in a different direction to the layer below, enabling the drawing's narrative of deviation from the original path to be recognised.
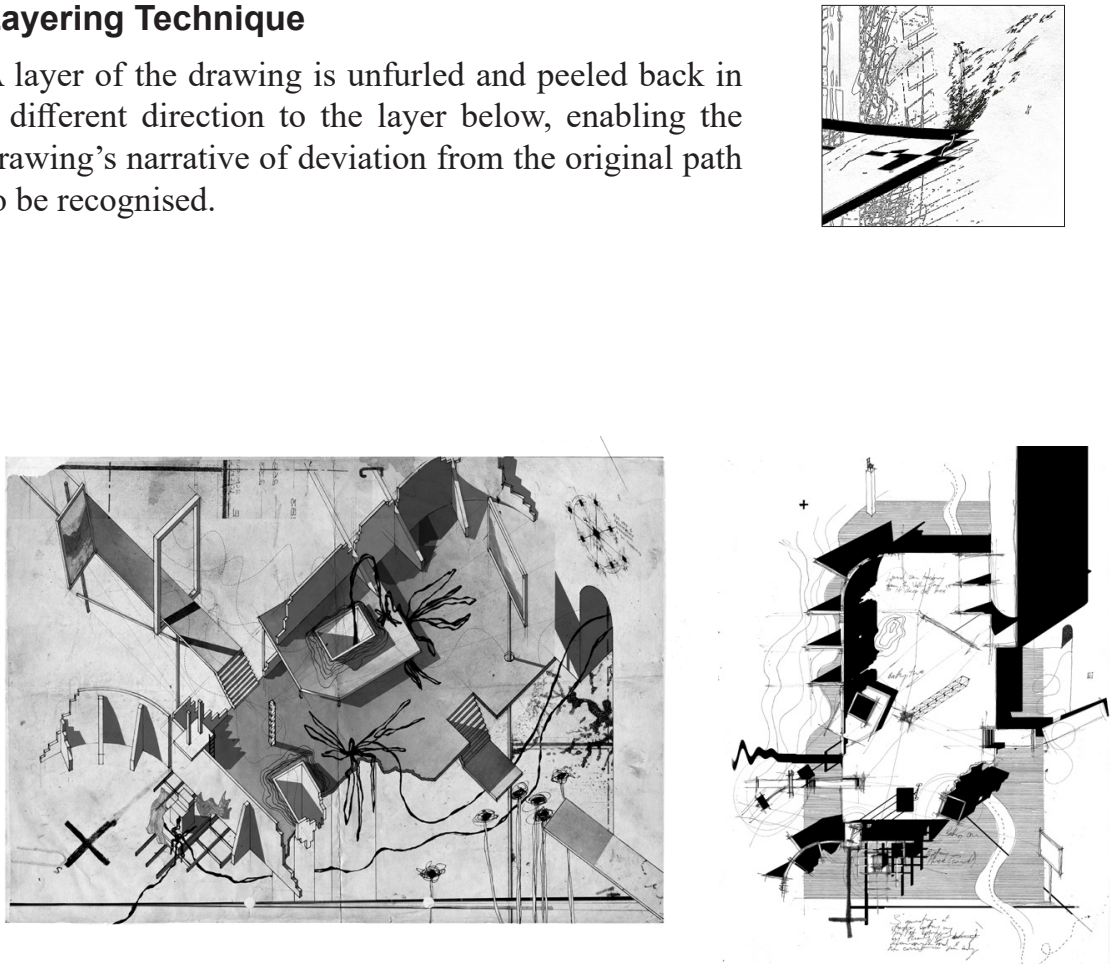

Fig 7.17 Corresponding Preliminary and Concept Design stage drawings, with the concept design drawing being the top layer of Figure 7.10.2. 


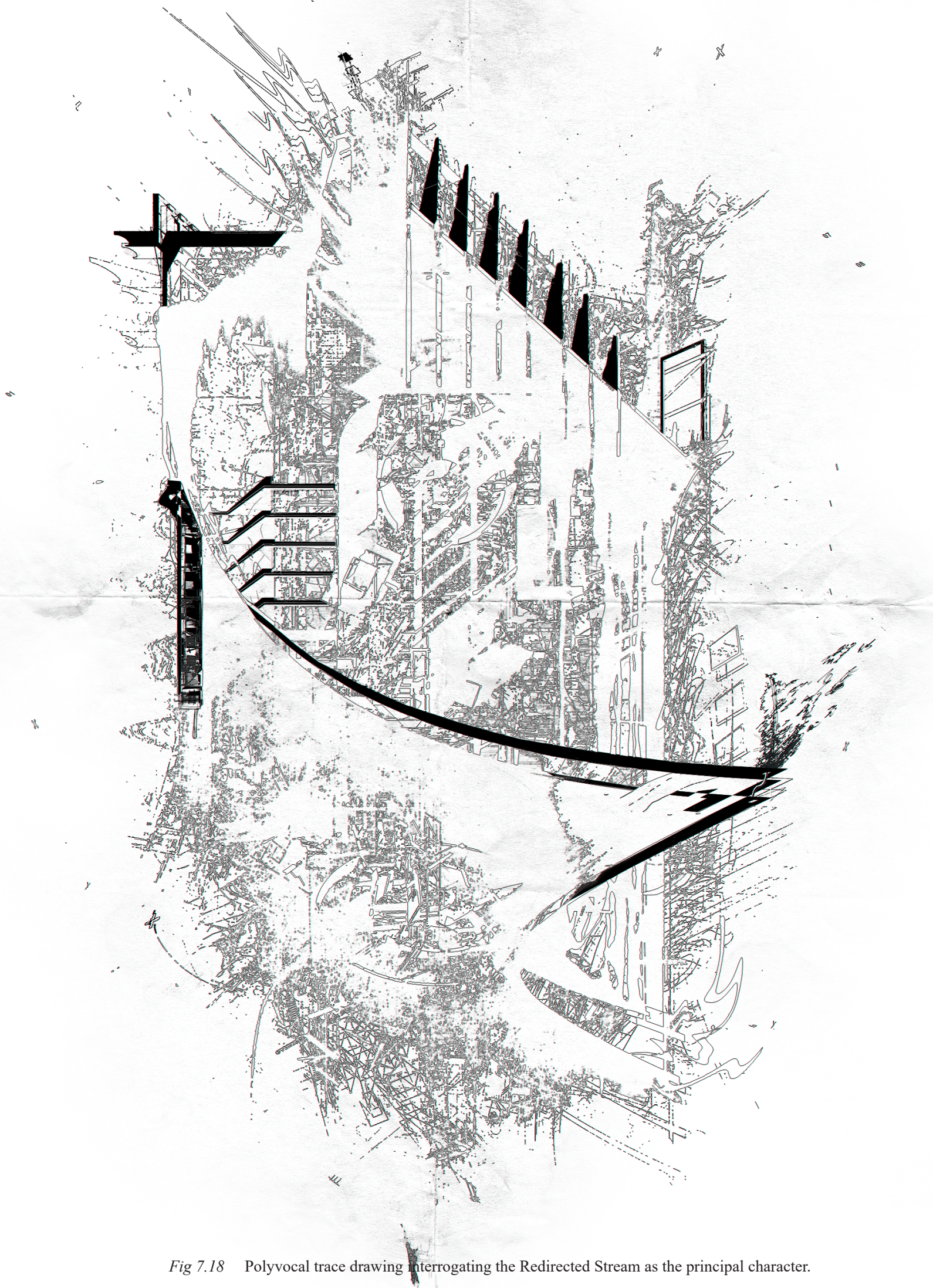




\subsubsection{THE REDIRECTED STREAM}

Place identity defined by deviation.

The tale is told by the sound of keening...

Pen and ink on paper + digital sluicing

$841 \times 594 \mathrm{~mm}$

William du Toit

46

Man the flower of all flesh, the noblest of all creatures visible,

man who had once made god in his image,

and had mirrored his strength on the constellations,

beautiful naked man was dying,

strangled in the garments that he had woven.

Century after century had he toiled, and here was his reward.

Truly the garment had seemed heavenly at first, shot with colours of culture, sewn with the threads of self-denial.

And heavenly it had been so long as man could shed it at will and live by the essence that is his soul,

and the essence, equally divine, that is his body. 


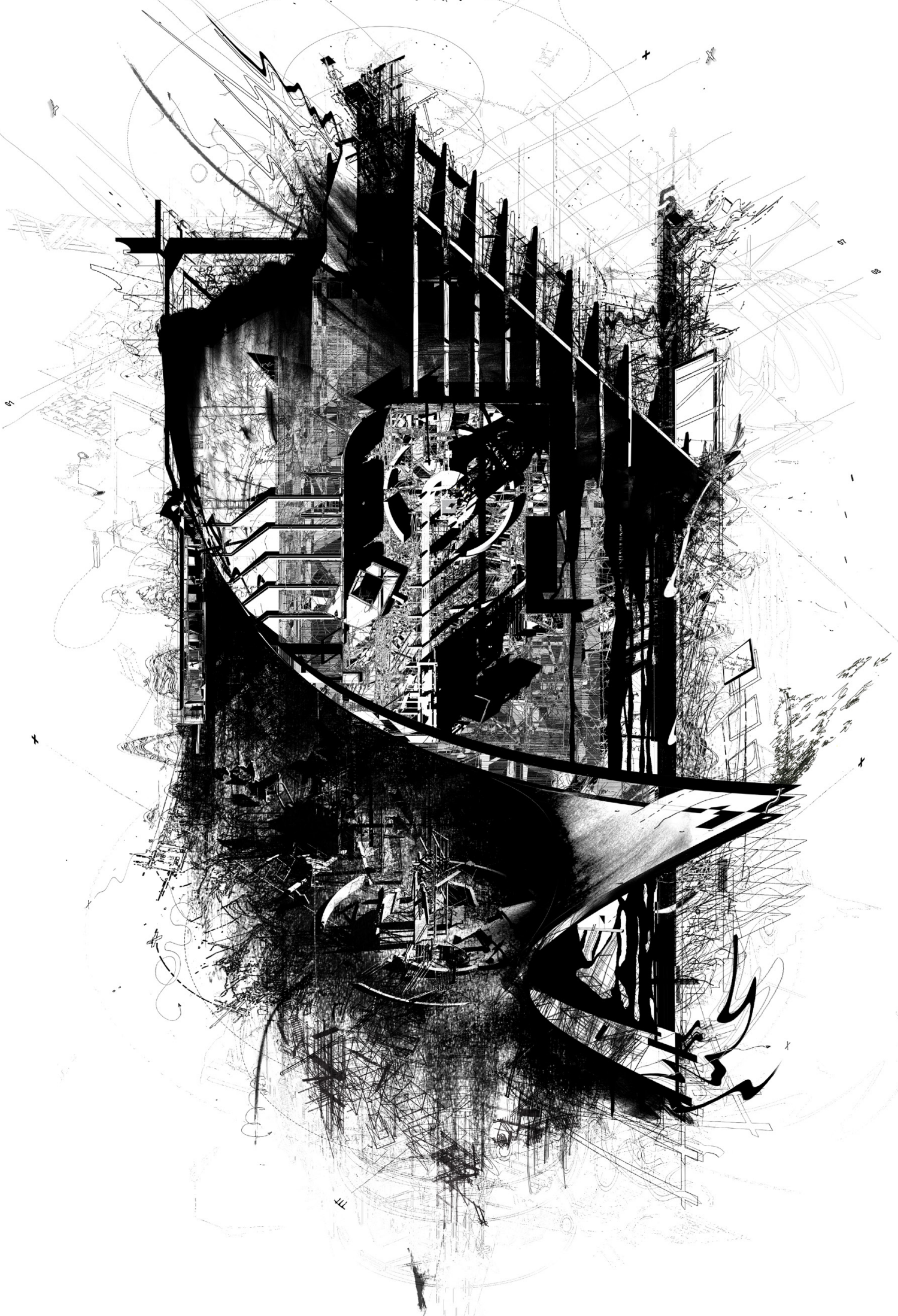




\subsection{LAMENTATIONS Series II}

Series of seven characters' points of view,

while the other characters whisper softly in the background...

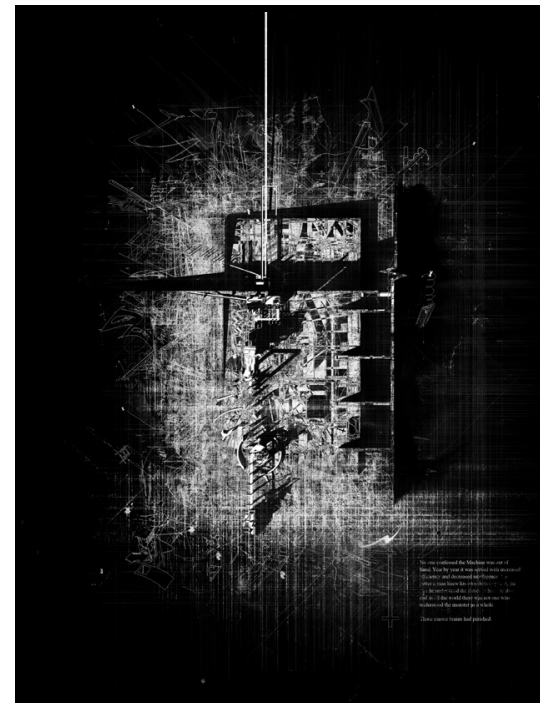

Aerial Cableway

A story of place identity defined by transition.

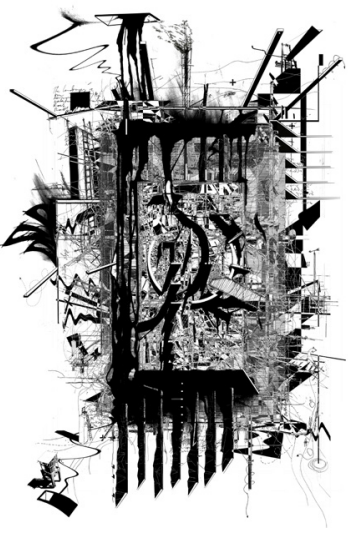

Schist Tailings

A story of place identity defined by displacement.

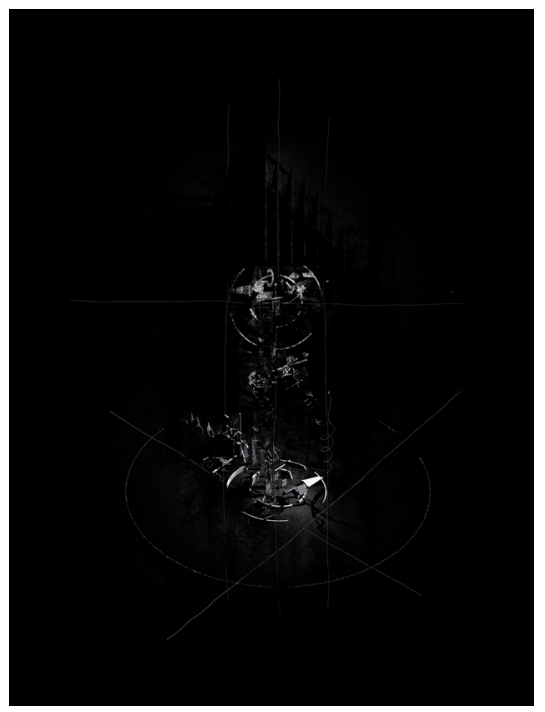

Battery Footprint
A story of place identity defined by traces.

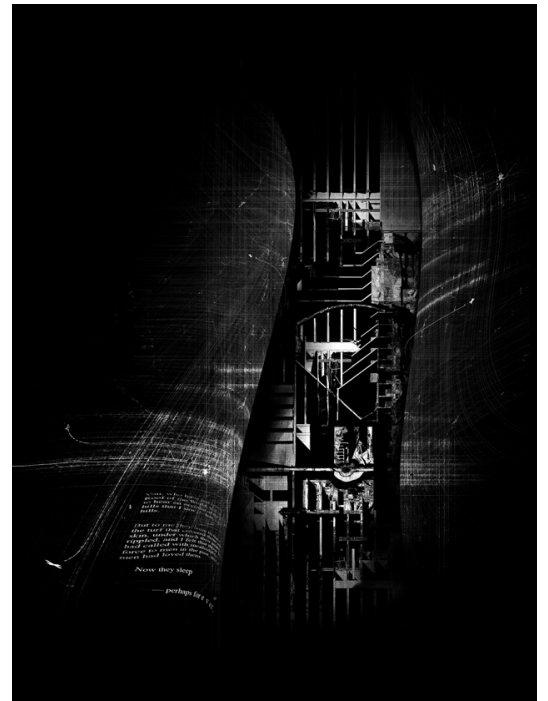

Water Race

A story of place identity defined by a cut.

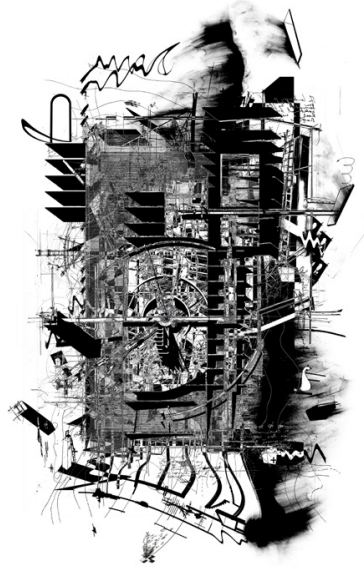

Mineshaft

A story of place identity defined by void.

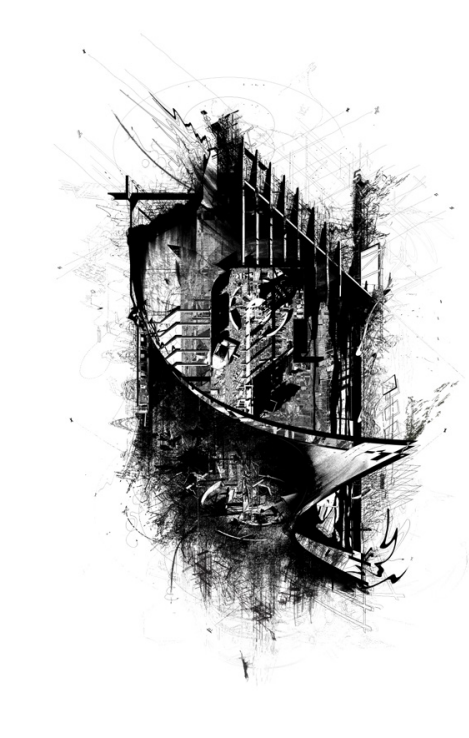

Redirected Stream

A story of place identity defined by deviation.

Fig 7.19 Developed Design: The Mineshaft, Schist Tailings and Redirected Stream (white backgrounds) represent the voices of the Natural World. The Aerial Cableway, Battery Footprint and Water Race (black backgrounds) represent the voices of the Man-made World. The Stamper Battery (opposite) represents the zone of Convergence between the two worlds. 


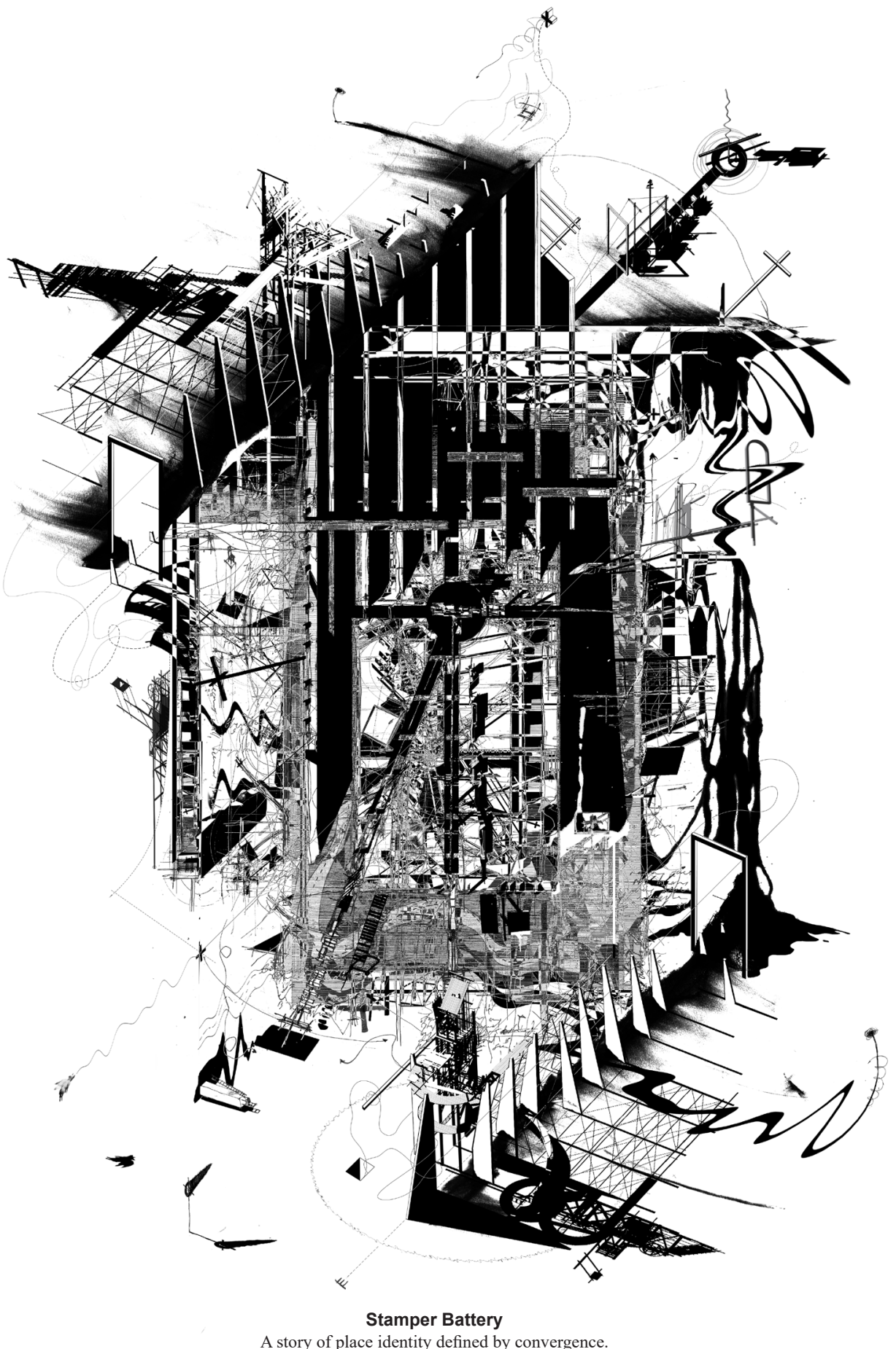


If Claude Debussy's quote that "music is the space between the notes..." is taken as a condition of spatial occupancy, then the documentation, or at least the exploration of that space is a state of the ghost note. ... If the space between the notes is an indiscernible layer found within the totality of music, then the obscure information of the architectural drawing is as much a component of the discipline of architecture as the object itself. 


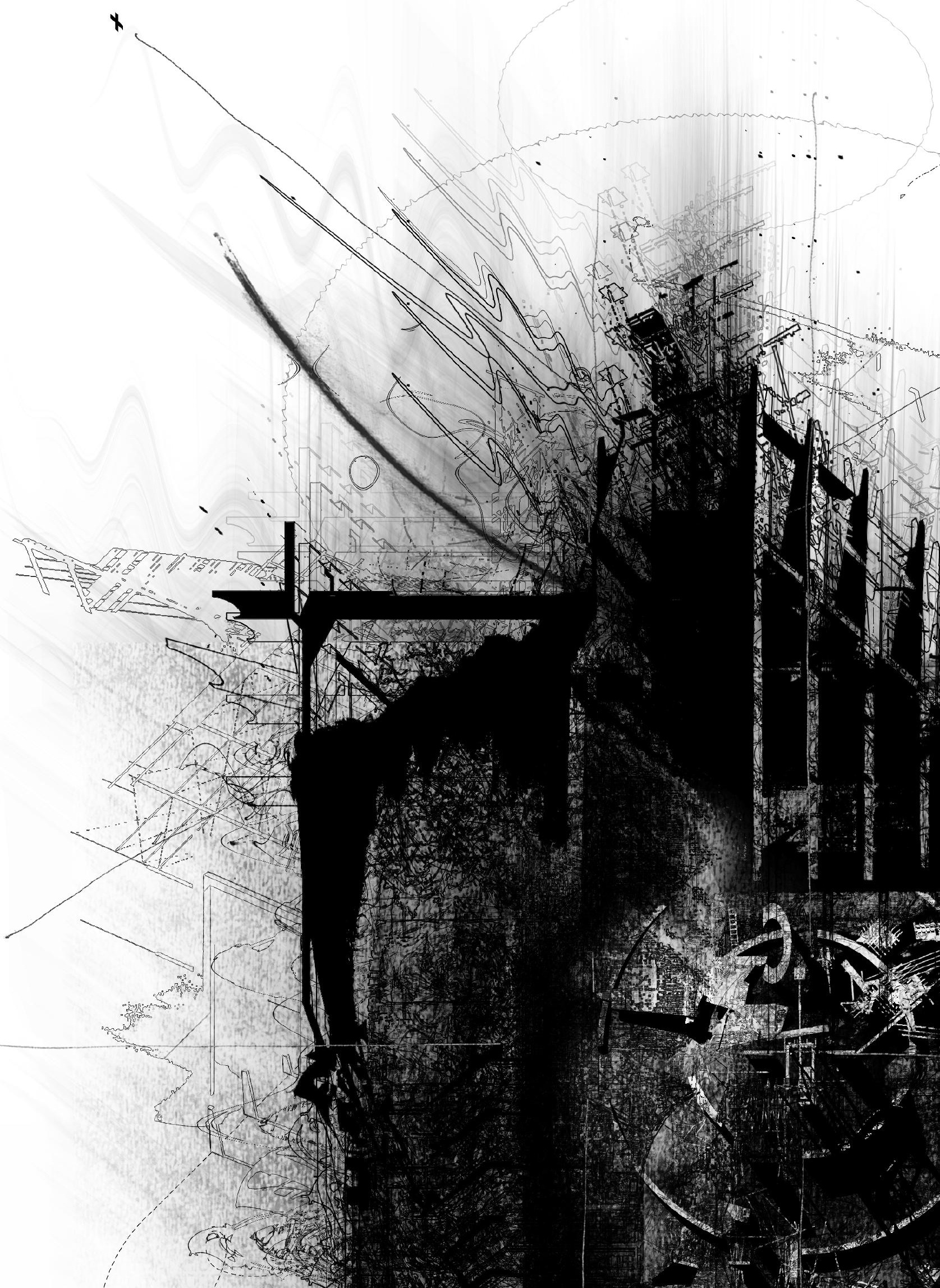



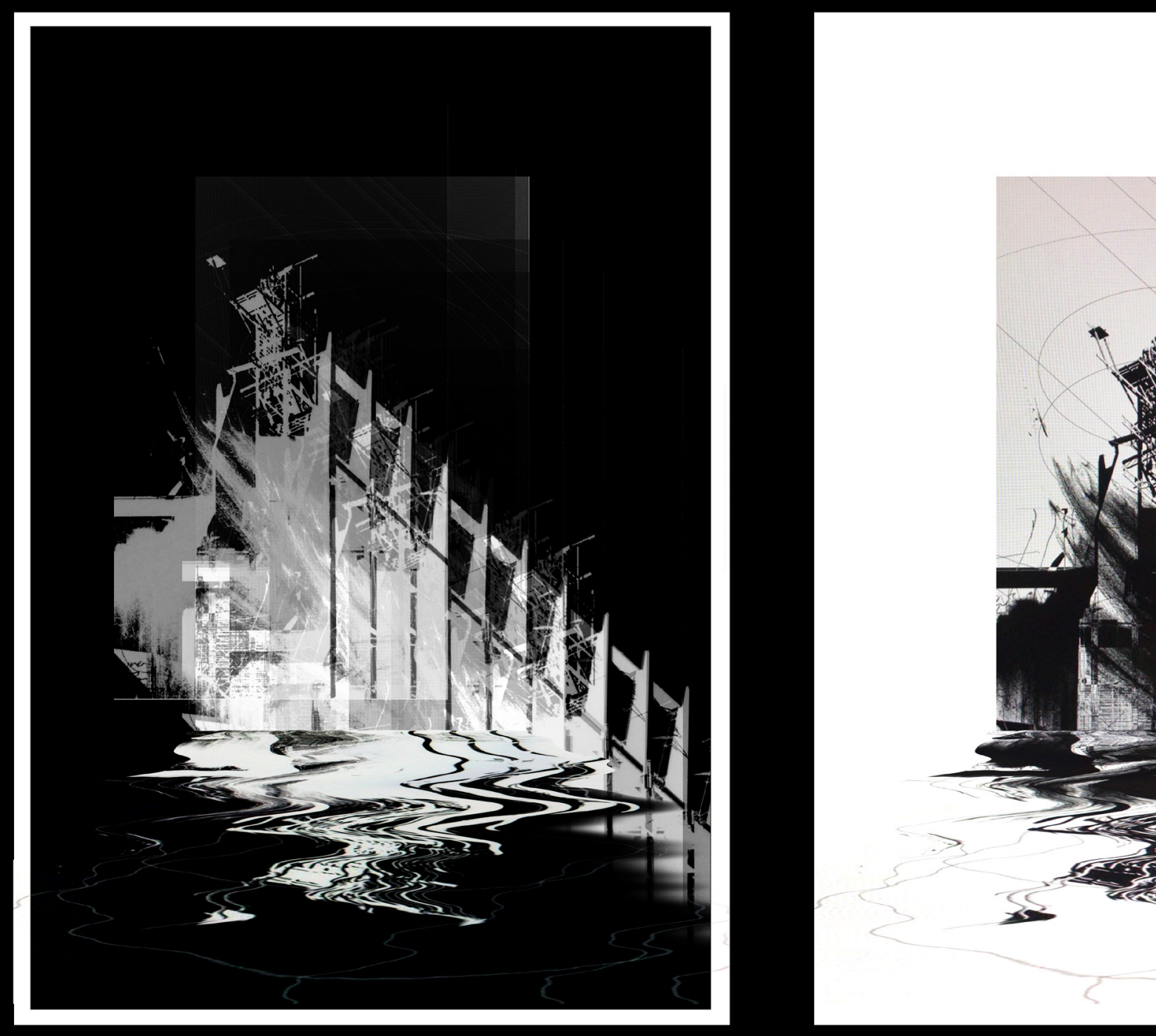


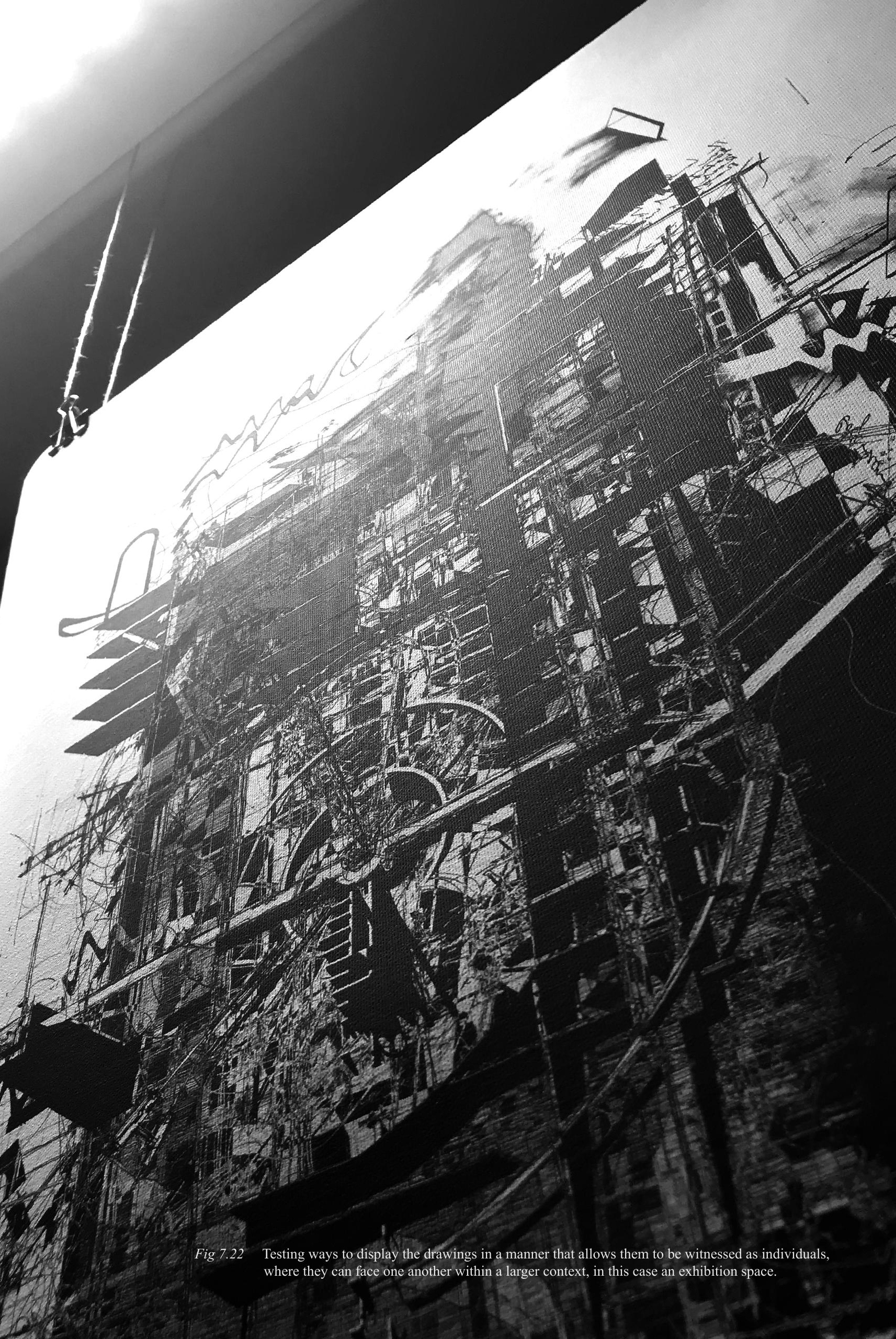




\subsection{DEVELOPED DESIGN CRITICAL REFLECTION}

The allegorical framework of E.M. Forster's literary narrative "The Machine Stops" is centred around a 'confrontation' between two opposing points of view: the controlling forces and the subjugated people. The controlling forces are represented by three principal characters: the Machine, the Air Ship, and the Central Committee. The subjugated people are represented by three principal characters: a mother (Vashti), her son (Kuno), and unnamed individuals in the background. A central element acts as the 'convergence point' where the two groups come together: the Book.

This design-led thesis investigation engages this framework taken from allegorical literary fiction to tell a similar story about the Homeward Bound site. It uses three main characters to represent the Man-made world, three main characters to represent the Natural World, and it uses the Stamper Battery to represent the convergence point between these worlds.

The final outcome for the Developed Design stage was a series of seven polyvocal drawings, each constructed or deconstructed by layering the Conceptual Design stage plan drawings upon each other. Axonometric details and notation devices from the Preliminary Design stage drawings were integrated into the final series. This technique allowed the narrative of seven very different points of view to be brought together and experienced simultaneously, with the drawing layer on top having the loudest voicereducing the others to soft whispers in the background. The application of speculative drawing techniques relating the primary narrative of each polyvocal drawing began to differentiate each drawing, creating its own unique identity-while still allowing the entire set to be read as a family with a compelling tale to tell.

As an Allegorical Architectural Project framed around a work of literary fiction ("The Machine Stops"), the outcome represents a confrontation - in this case, between the Natural World and the Man-made World. The voices of the Natural World (Mineshaft, Schist Tailings and Redirected Stream) were told using fluid lines and freehand drawing techniques - gathered together upon white backgrounds. The voices of the Man-made World (Aerial Cableway, Battery Footprint and Water Race) were told using walls, foundations and orthogonal grid lines - gathered together upon black backgrounds. The Stamper Battery drawing represented the zone of Convergence, gathering together the threads of both the Natural and the Man-made worlds.

By reflecting upon each drawing individually, each unique point of view begins to emerge as the allegorical drawing techniques morph the base drawing. Highly detailed areas provoke closer viewing, bringing the viewer deep into the borderless, drawn world and inviting imaginative interpretation. A confrontation between two forces begins to emerge, with black and white areas of each drawing decaying, blurring and amalgamating - informing the dialectic narrative about the built world and the natural world transforming one another.

The layered base of these drawings establishes an aesthetic foundation that supports the entire family of drawings. Small experiments on the edge of the page became familiar reoccurring forms that act as notational indicators of changes in time, place and point of view. A textured rectangle in the centre of each drawing forms a cartesian plane on which to orientate oneself and then travel off as the drawing begins to transform and evolve. Combined with the duality of a black and white colour palate, these moments help provoke awareness of the dialectic meta-narrative across all seven drawings. 
Thesis work by

William du Toit
Whistling Sisters Brewery 100 Taranaki Street

\section{FLASH EXHIBITION}

\section{The Machine Stops}

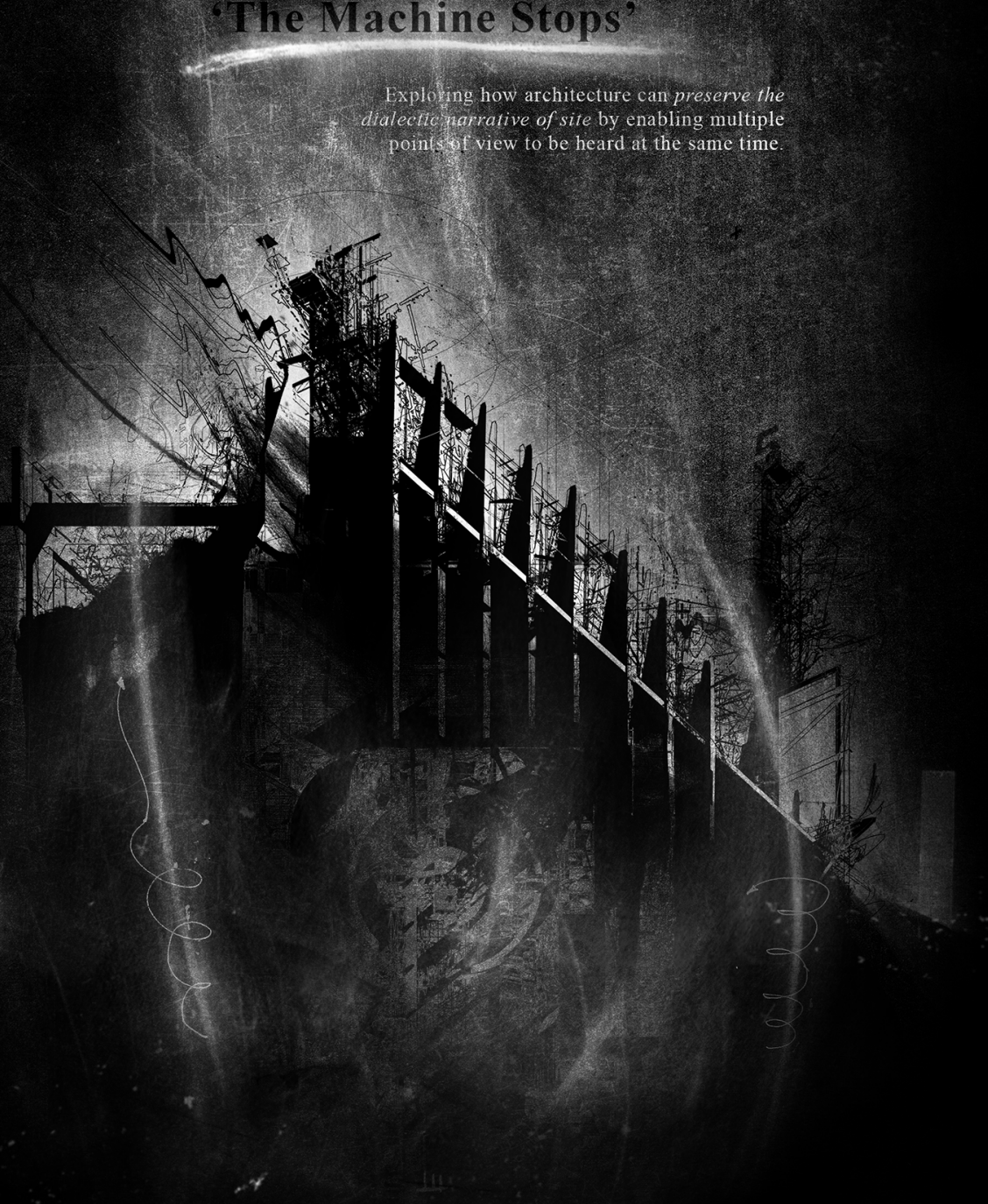




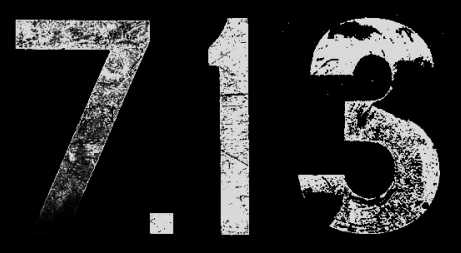

\section{EXHIBITION CURATION \\ \& TESTING}




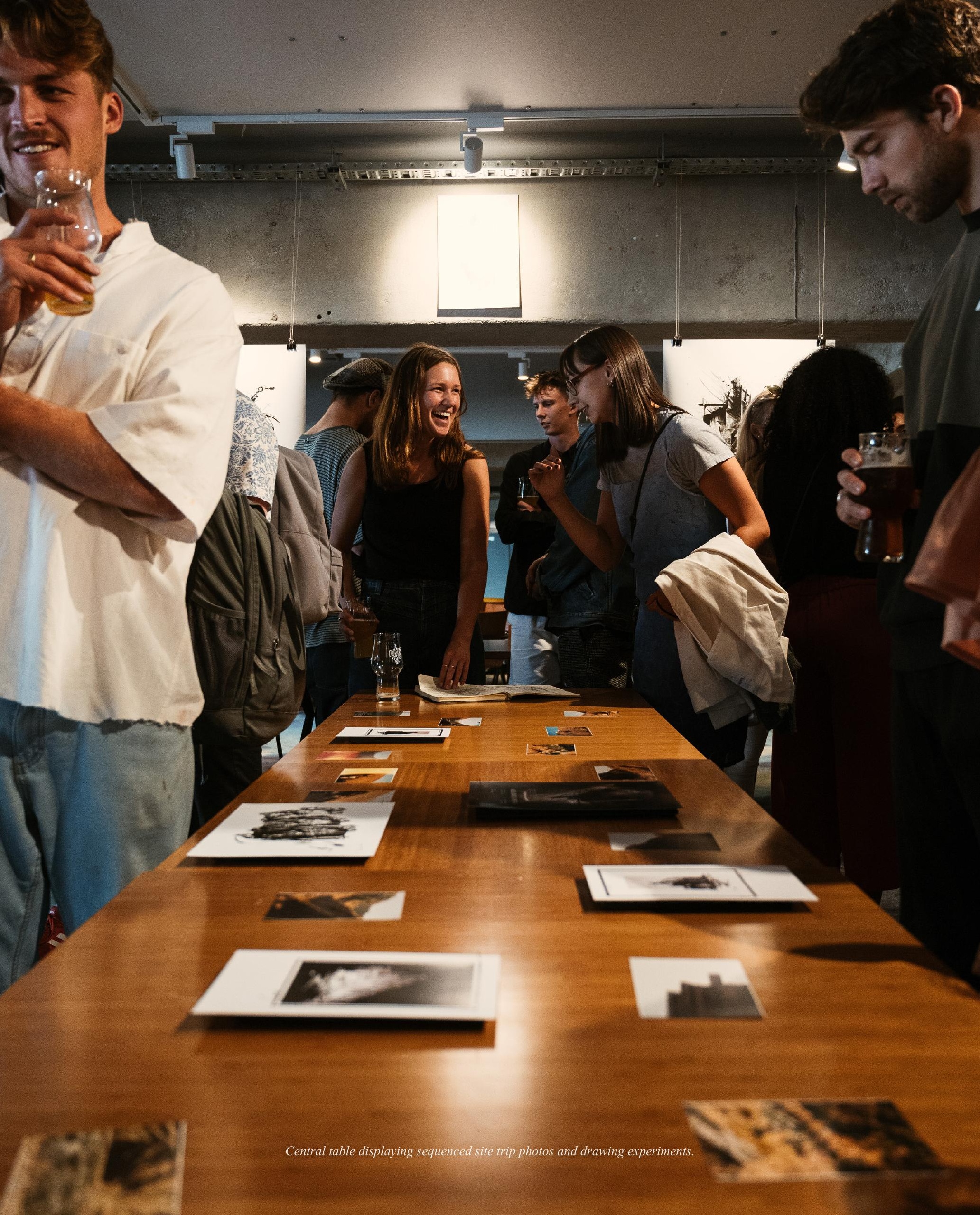




\subsection{EXHIBITION CURATION \& TESTING}

Once the final set of Developed Design stage drawings had been completed, they were curated and hung in a public gathering space, to test how well the polyvocal series addresses the principal Research Aim:

To explore how, through speculative architectural drawing, an allegorical architectural project can be used as a critical method to help preserve heritage stories that are destined to be lost.

Both the Plan-view series of final drawings (from the conclusion of the Developed Design stage) and the Axonometric-view series of final drawings (from the conclusion of the Preliminary Design stage) were exhibited, along with the notebooks, sketch experiments and site photographs that supported them.

The Flash Exhibition was mounted on 19 February 2021 at Whistling Sisters in Wellington. The exhibition examined how well the speculative drawings were able to convey the individual stories of this site, while also enabling the viewers to critically reflect on the overall dialectic narrative of the Homeward Bound Site. It was a great exercise in organising the work as well as explaining it to a variety of people from a mostly architectural background. These discussions were extremely helpful in my understanding of how people experienced the drawings, what they saw in them, as well as what they did not fully understand.

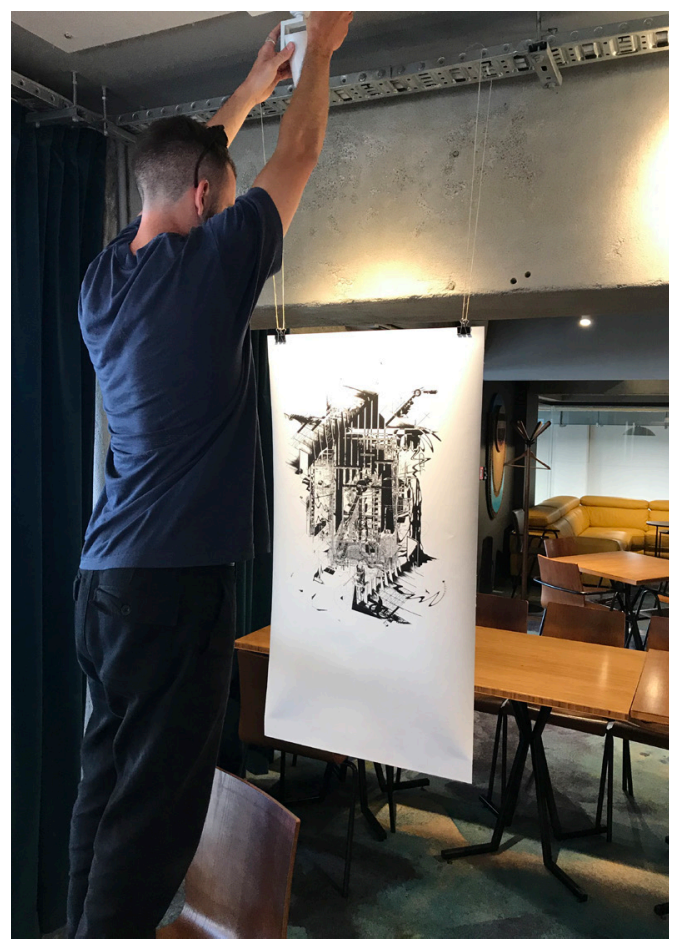

Illuminating the polyvocal stamper battery drawing. 


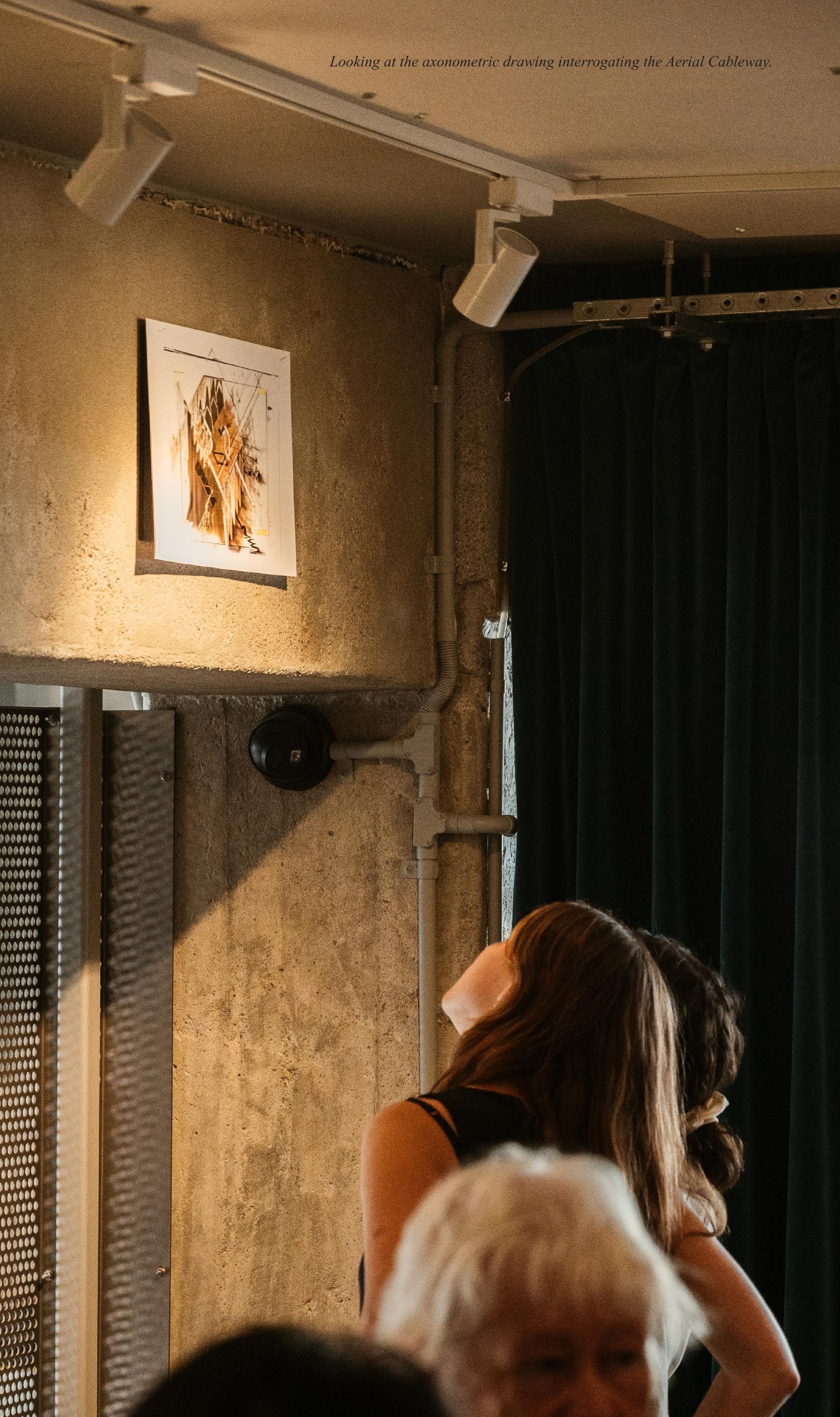




\section{LAYERED AXONOMETRIC SERIES}

\section{Lamentations, Series I}

All axonometric drawings composed around the final layered drawing.
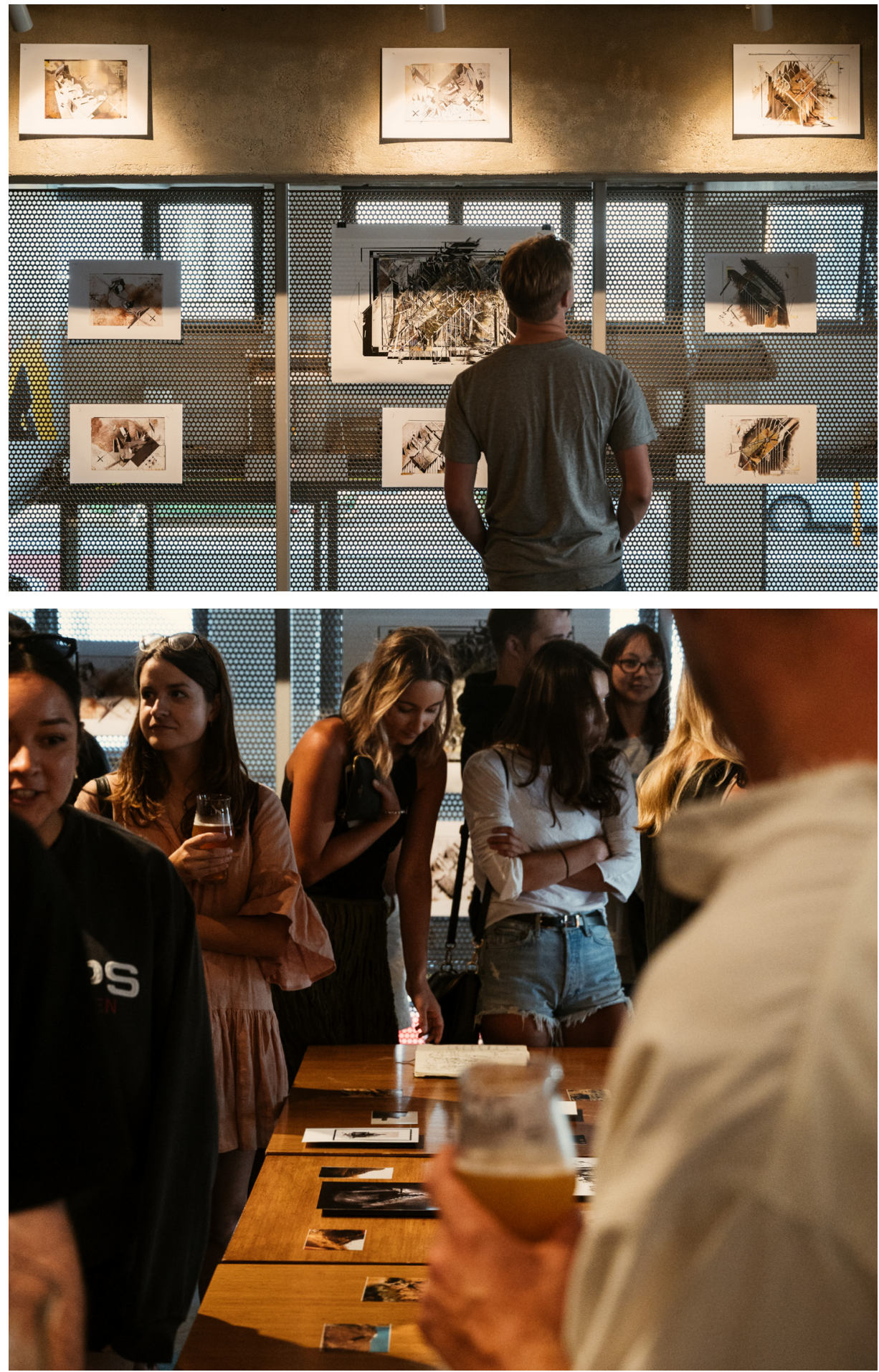
LAYERED POLYVOCAL SERIES

Lamentations, Series II

Larger prints and individual spacing inviting prolonged and intimate viewing.
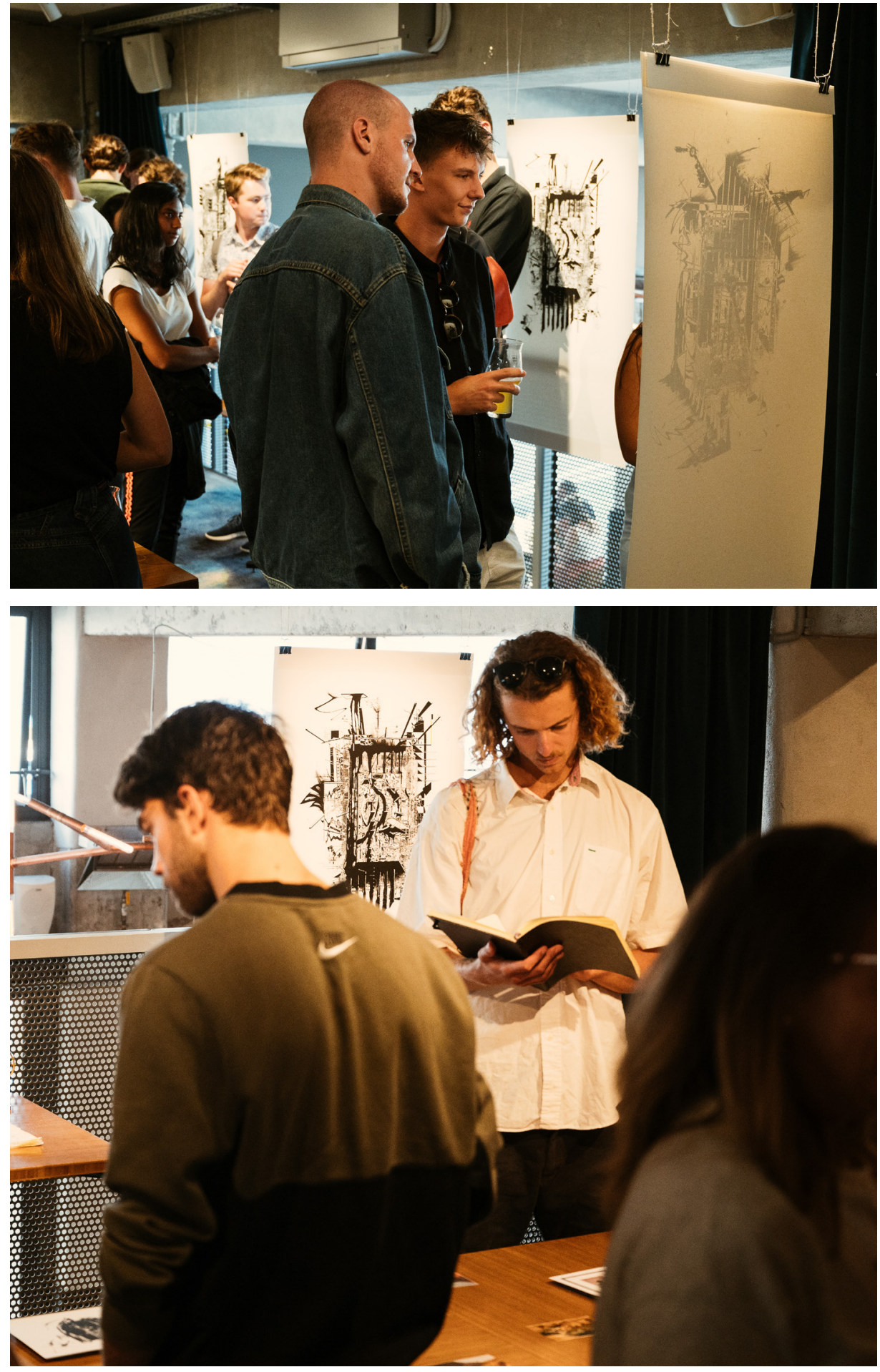

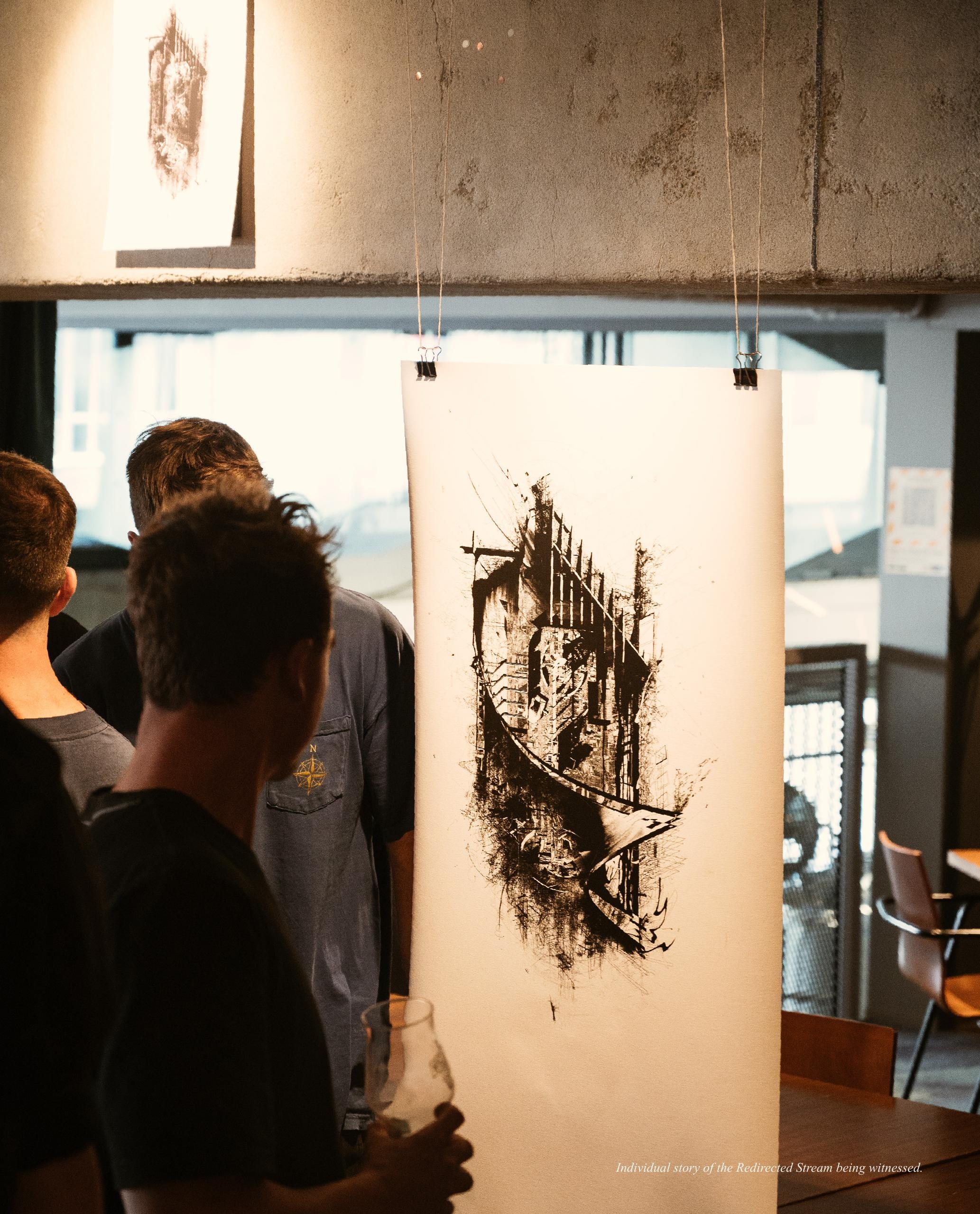


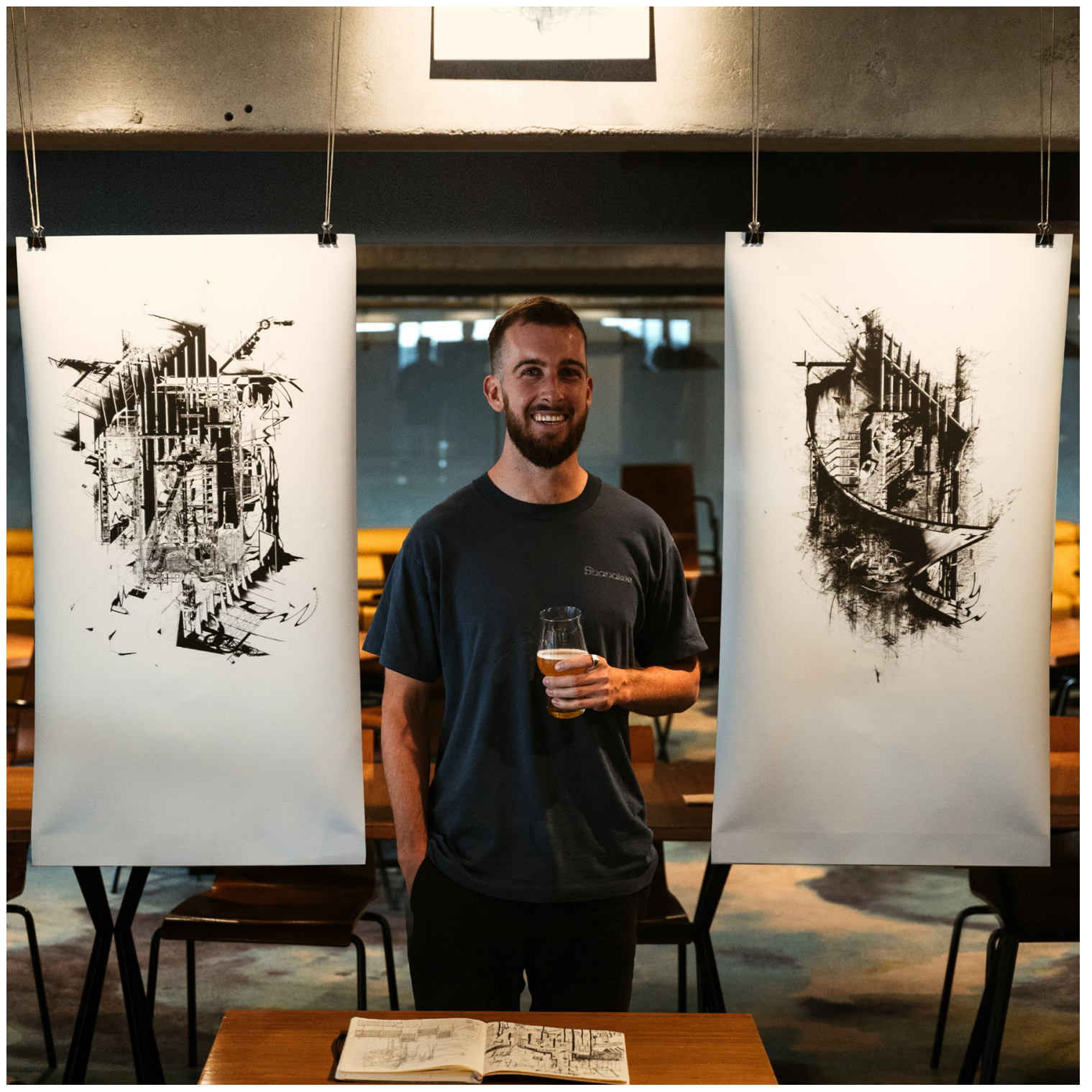

Author enjoying a beer after talking for two hours straight. 


\subsection{EXHIBITION CRITICAL REFLECTION}

To test the allegorical ability of these speculative drawing series, the axonometric (Preliminary Design stage) and polyvocal (Developed Design stage) drawing families were curated into an exhibition setting. The exhibition presented the opportunity to sequence the drawings in a manner that enabled visitors to comprehend their unique individual stories as well as the overall dialectic metanarrative about the impact of the man-made upon the natural systems.

The axonometric drawings were presented together on the same wall, respectively spaced to allow them to be seen individually. This composition resulted in the majority of people viewing from a distance, taking in the series as a whole rather than leaning in to inspect the individual stories.

The final Developed Design polyvocal series of drawings were printed at a larger size and individually suspended from the ceiling, giving each drawing a physical presence in the exhibition space. Combined with more generous spacing between them, this invited viewers to approach and inspect each drawing in detail and in relation to one another. This method of exhibition yielded far more engagement but fell short of communicating the overall series' meta-narrative, as the small exhibition space meant the drawings were often obscured by other viewers.

The architectural background of most of the viewers was an important advantage as they were able to read and understand the speculative drawings. This set up a type of confrontation between the viewer and the drawings, leading to the ultimate confrontation of the viewer and their recognition of the ethical question of economic prosperity at the cost of environmental devastation.

In future testing scenarios it might be better to exhibit a single series in the exhibition space, with large prints individually suspended within the space at different orientations to enable their unique stories to be unveiled. A larger exhibition space with only one series on display would provide the opportunity for people to view each allegorical drawing individually before stepping back to witness the meta-narrative (and all seven drawings) simultaneously. 
46

\section{Others were yelling}

blaspheming the Machine...

... And behind all the uproar was silence - the silence which is the voice of the earth and of the generations who have gone. 


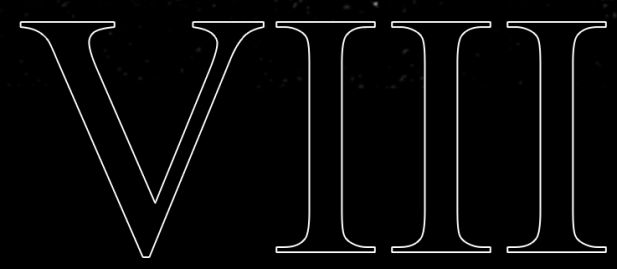

†

CONCLUSION \& CRITICAL REFELCTION
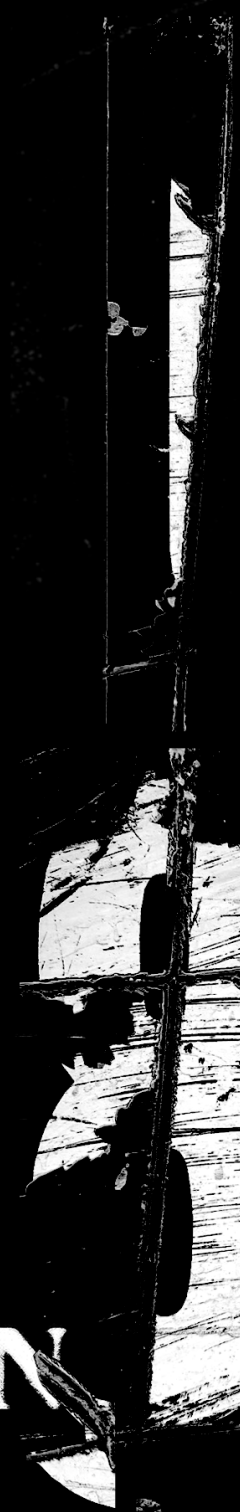


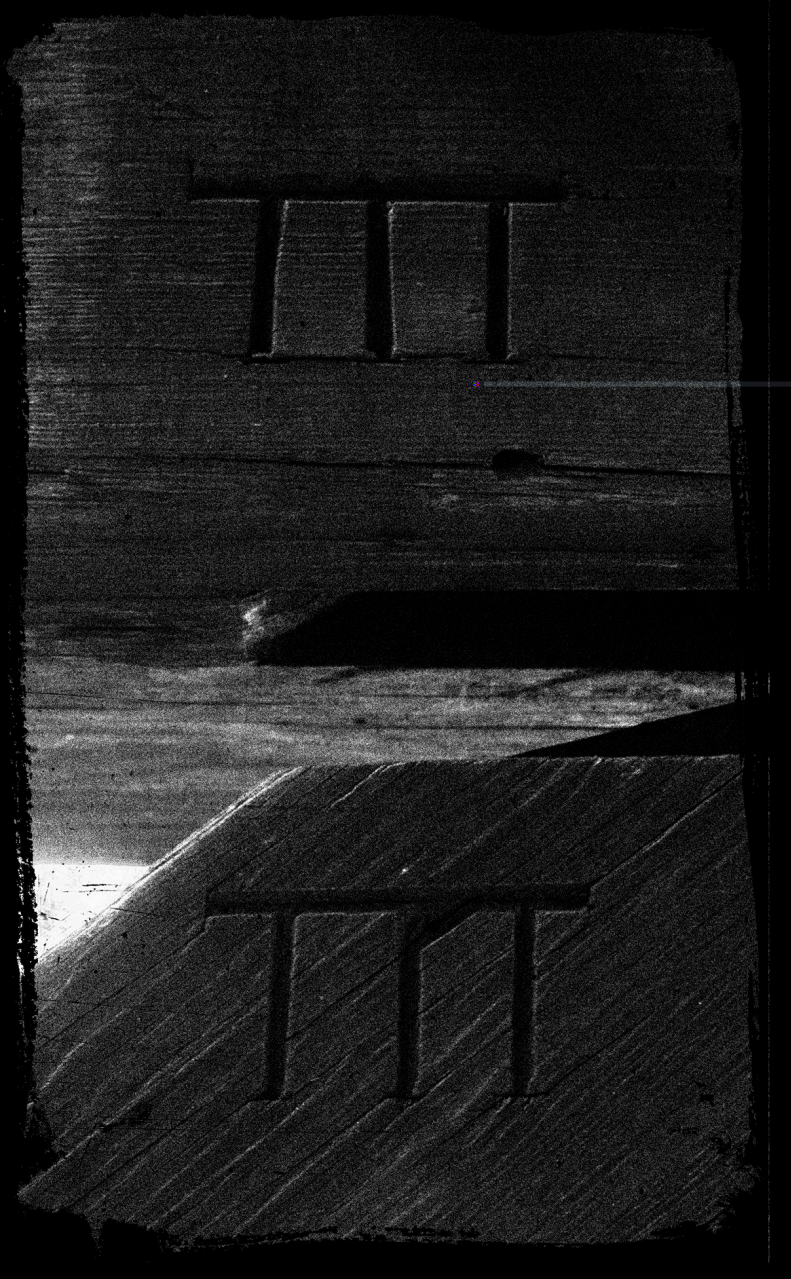

Fig 8.1 Historic, mechanical notation marks on the Stamper Battery used for construction. 
8.1 CONCLUSION \& The Homeward Bound mining operation was the site of CRITICAL REFLECTION

extensive goldmining operations that played an important role in the economic prosperity of the Otago region. The scars upon the landscape as well as the machine remnants left behind are evidence of this conflict between mankind and the natural environment, presenting the challenging issue of how speculative architectural drawing can preserve a dialectic narrative where both side of the story need to be heard. Within each sides of this narrative are unique perspectives from various characters in different places over a range of timeframes that represent unique points of view of the overarching meta-narrative. By using speculative architectural drawing to allow people to understand each of these individual stories as well as the meta-narrative, an important heritage story of New Zealand regional place identity can be preserved, and its lessons thoughtfully conveyed.

One of the most important discoveries made by the author during the course of this design-led research investigation is that place identity is about far more than simply what you may initially perceive through a superficial viewing of place. Place identity is rich and complex and layered. Place identity is defined by many opposing points of view, merging and converging over time: stories of transition, convergence, deviation, displacement, voids, cuts and mere traces left behind.

This thesis engaged the three speculative drawing techniques of orthographic drawing, notation strategies and devices, and layering techniques to address its primary Research Objects and modes of investigation. These were applied through three series of seven drawings, with the final two series tested in a curated exhibition setting. Upon reflection, the most evocative method involved the layering of multiple drawings into a single composition. While the other devices and techniques played essential secondary roles, layering's ability to not only allow multiple voices to heard simultaneously, but control which voices were heard crying out — while others whisper in the background - was essential in expressively conveying the individual narratives situated within the polyvocal drawings.

As my confidence and abilities grew throughout progressive series of drawings, concepts for actual architectural forms began to emerge, subsequently becoming more detailed as the investigation progressed. These forms stemmed from the cyclical process of drawing and redrawing elements from different perspectives, creating ample opportunity to tweak and refine them and eventually evolving into concepts for habitable spaces in the final polyvocal series. If this thesis were to progress further, the exploration and refinement of architectural forms could be enhanced by reinterpreting the speculative drawings as buildable habitable spaces within the Homeward Bound site.

While this investigation has focused on the Homeward Bound site, a dialectical narrative drawing from historical remnants with a valuable tale to tell is not unique to this particular site. The immediate area surrounding the research site is replete with other mining operations consisting of similar fragments also decaying due to the ravages of time, all sharing the common narrative of prosperity at the cost of environmental devastation. Outside the realm of goldmining, this framework could also be applied to other fragmented heritage stories across Aotearoa, preserving at-risk stories through speculative drawings safeguarded for view within a gallery setting - allowing those stories to be witnessed by future generations even when the true fragments are lost forever. 


\subsection{PRINCIPAL CASE STUDY}

\section{Interrogation}

Japanese architect, urban designer and theorist Arata Isozaki's drawing of his project Tsukuba Center Building (Figure 8.2) is an example of the confrontation of nature and the man-made. Isozaki originally designed the building as a ruin, embracing decay, and challenging him to envision how it would transform over a passage of time.

Even before it is actually constructed, he presents his architectural design as a building being transformed into ruins by the ravages of time, with cracked facades and caved in ceilings - framed by a dark shading that obscures and veils parts of the drawing (Martinoglio, 2020).

This drawing portrays the allegory of the confrontation of environmental systems versus man-made architecture over time by speculating on the future of the building and capturing it in a state of future decay. The use of speculative drawing techniques such as dark shading also adds to the narrative as the visualisation itself becomes fragmented and incomplete like the ruin it depicts.

The following design-led thesis drawings apply these principals, first illustrating four buildable architectural concepts developed within the polyvocal drawing series, then composing them into a final drawing that depicts their transformation to a ruin over a passage of time. 
46

What has led the building upward is human will; what gives it its present appearance is the brute, downward-dragging, corroding, crumbling power of nature... Nature has transformed the work of art into material for her own expression, as she had previously served as material for art.

- Georg Simmel, 1958, 371

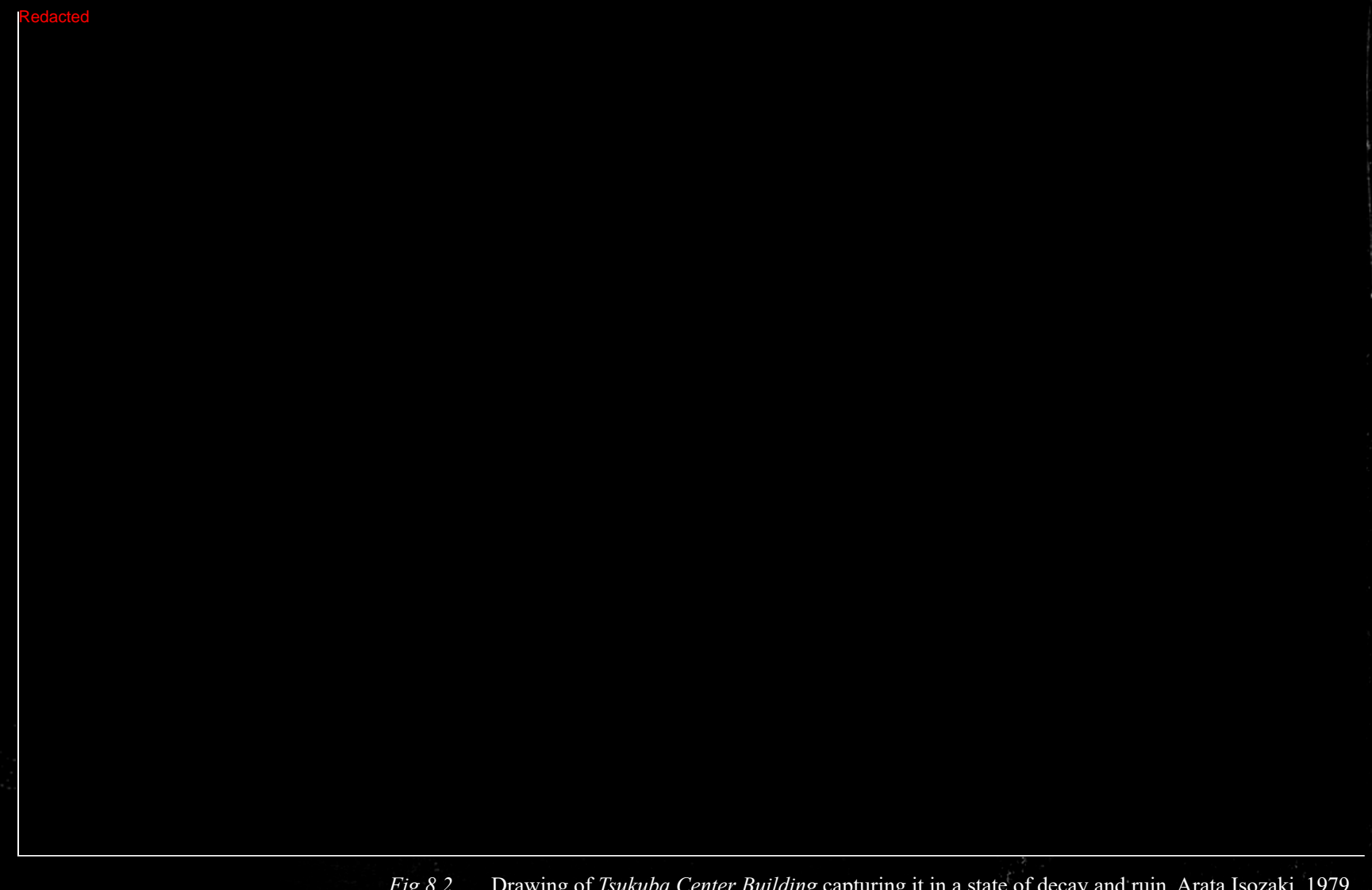

Fig 8.2 Drawing of Tsukuba Center Building capturing it in a state of decay and ruin, Arata Isozaki, 1979 


\subsection{PROPOSED ARCHITECTURAL INTERVENTION}

The final stage of this research investigation draws upon the previous design stages to propose an architectural intervention that sits just outside of the Homeward Bound Mining site. This intervention consists of four buildable architectural forms linked by various pathways and bridges - intending to act programmatically as the spirit of a campsite that simultaneously enables visitors to witness the dialectic metanarrative of this site.

Architectural forms developed in the Concept Design and Preliminary Design drawing series are extracted, rescaled and combined with the Developed Design iterations into a buildable structure. Reclaimed and reconstructed material from other stamper batteries are then added and the four interventions are arranged using a masterplan of a compass with two axes - one aligned to true north, and the other aligned to the machine remnants on site.

The four interventions programmatically address four important rituals of daily life, expressed by four elements of nature: crossing a threshold (earth), sharing a meal (fire), sleeping (air), and cleansing (water). The first acts as a gateway threshold, welcoming the visitor in and framing their view of the Stamper Battery in the distance. The second acts as a central fire pit for cooking and socialising and is located in the centre of the area of intervention. The third acts as a sheltered sleeping quarters, with three rooms populated with bunk beds enclosed by movable façade panels. The final intervention acts as an area for ablution, collecting rainwater in reconstructed water races and protected by movable panels for privacy.

Four construction materials are integrated throughout the design, and each intervention privileges one of the four primary materials: stone, timber, glass, and metal. Over a passage of time, each material will decay at a different rate - embracing the confrontation of environmental versus man-made systems and presenting it for visitors to witness and critically reflect upon. 


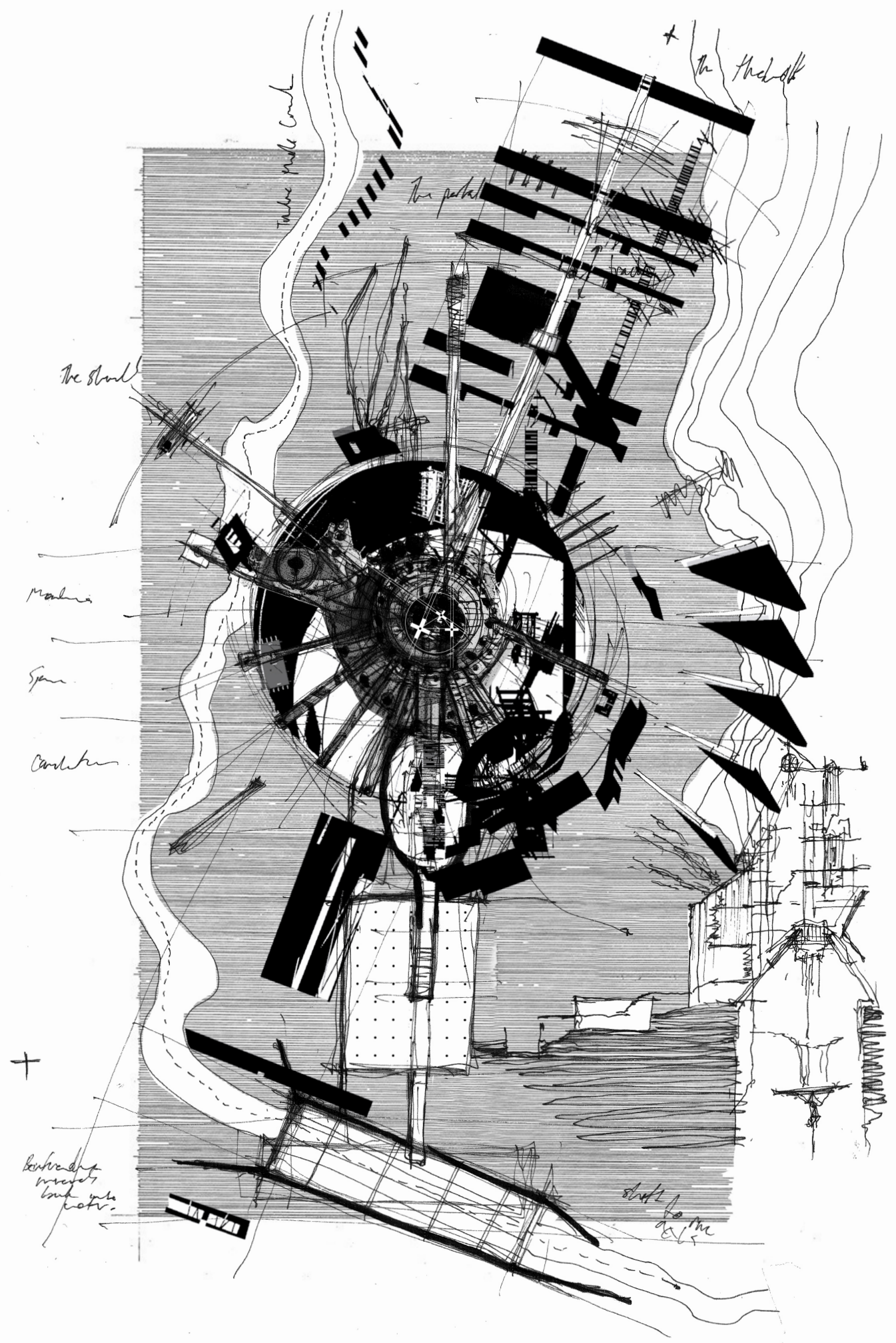

Fig 8.3 Conceptual masterplan of the four buildable interventions arranged on site. 


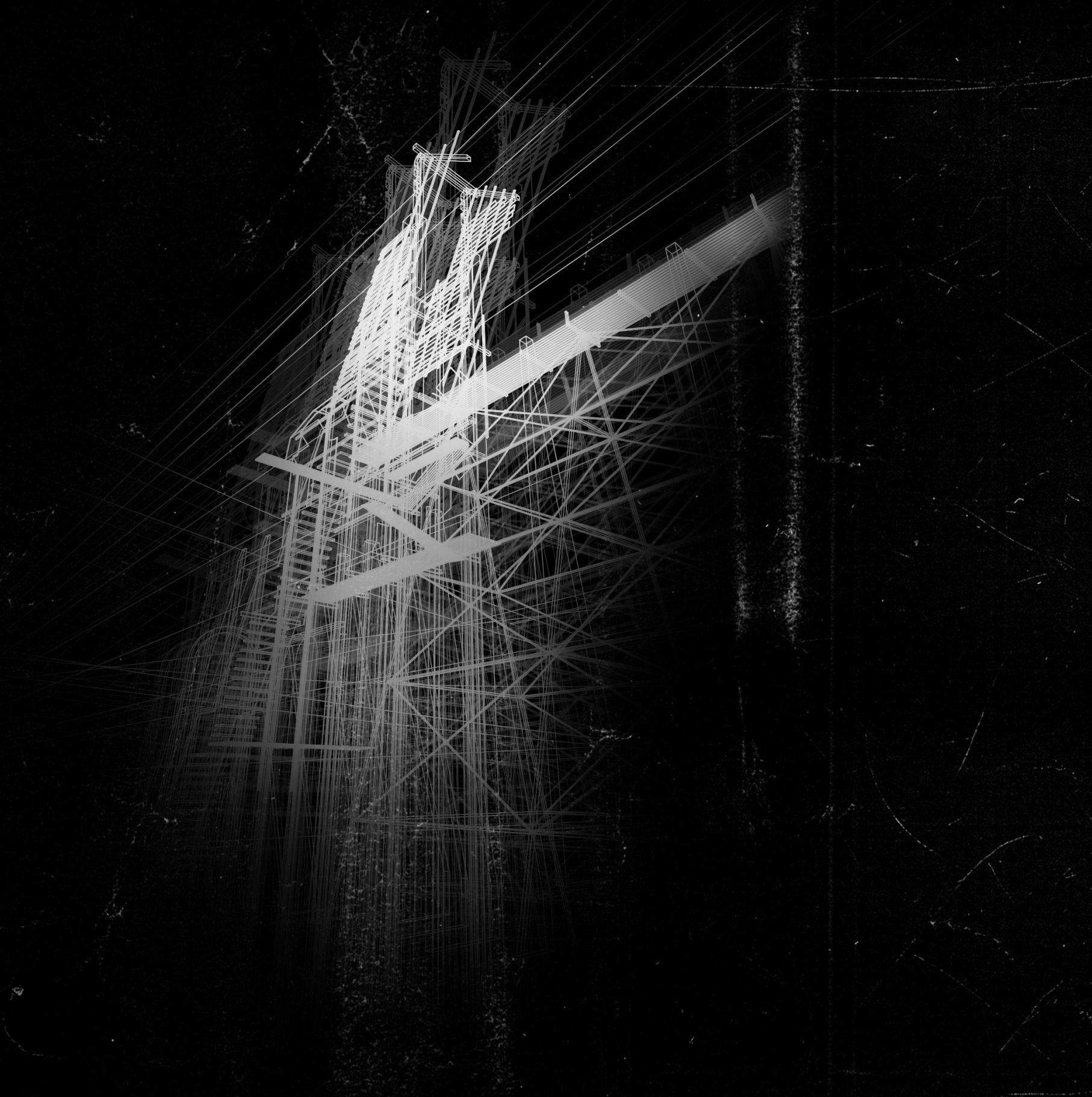

\section{Fig 8.4 Architectural Concept 1:}

Threshold entry to the area of intervention, raising the viewer above the landscape to frame the Stamper Battery in the distance. 
Fig 8.5 Architectural Concept 2:

Central intervention reconstructed from reclaimed fragments of other stamper batteries. It functions as a viewing platform and central fire pit for socialising. 


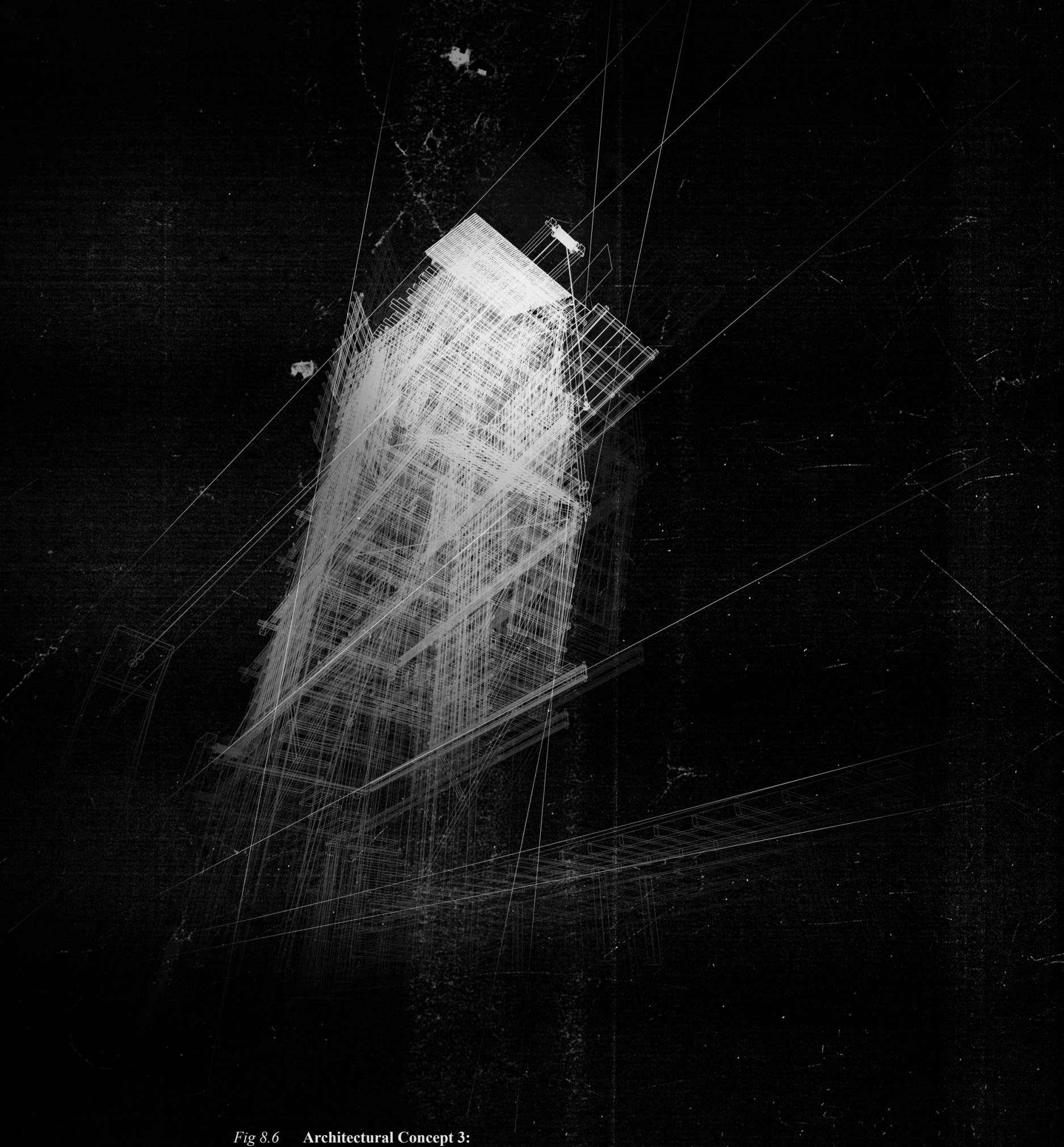

Fig 8.6 Architectural Concept 3:

The third building holds three separate sleeping quarters filled with bunk beds. Exterior panels encase the rooms and can be opened or closed depending on visitor's requirements. 
Fig 8.7 Architectural Concept 4:

Fed by reconstructed water races, the bathing area is constructed of monolithic fins and movable exterior panels-allowing visitors privacy as required. 


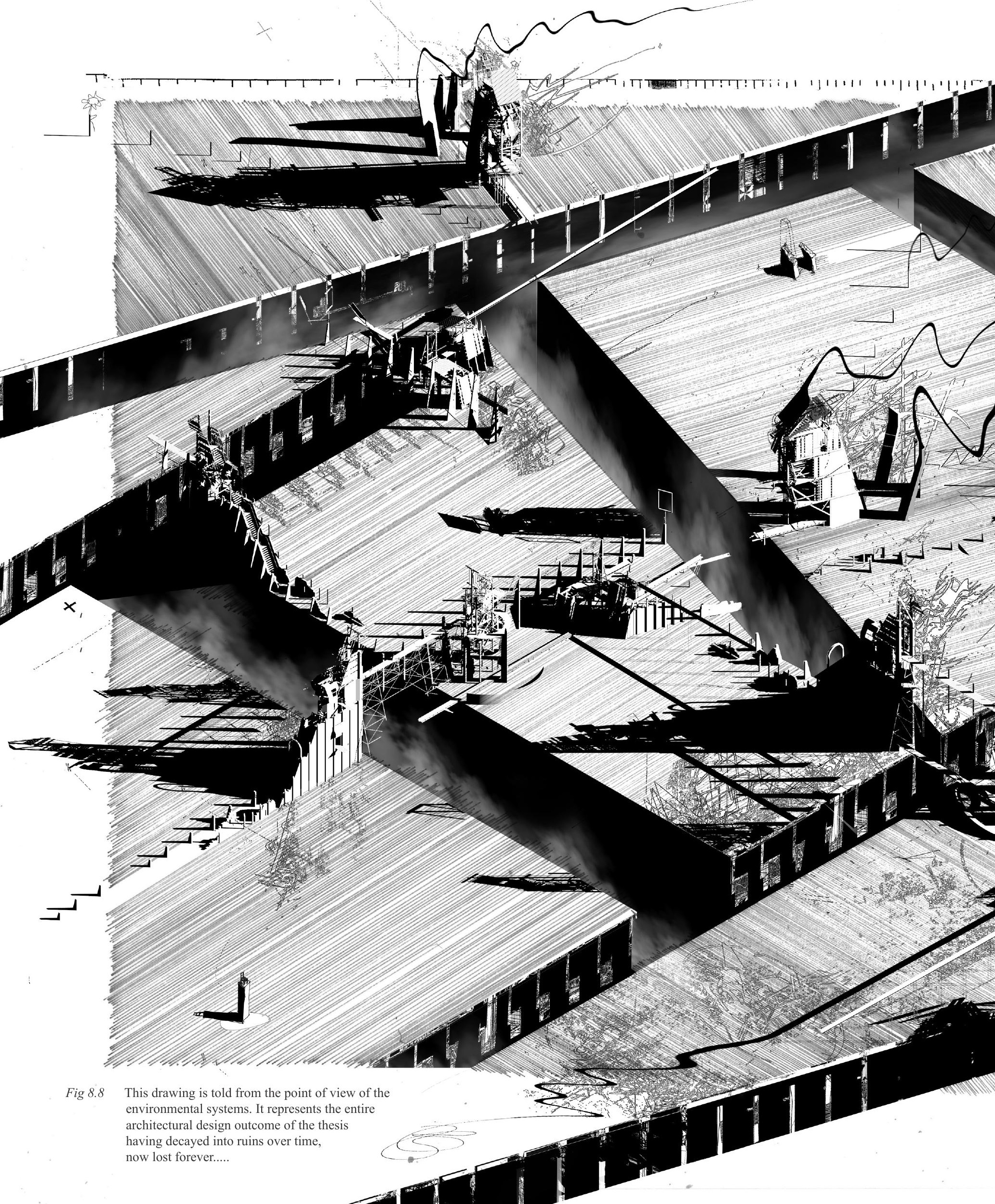



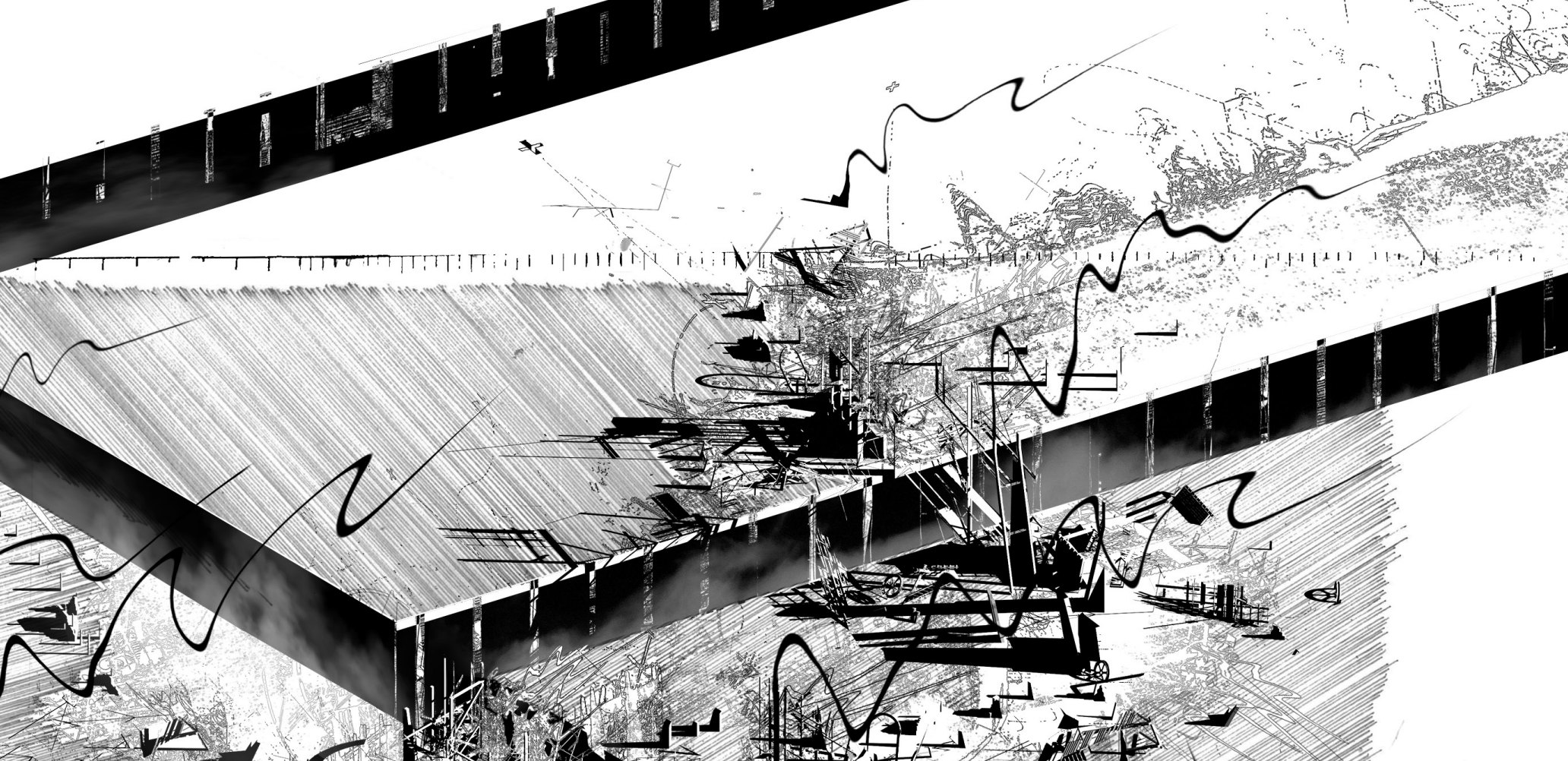

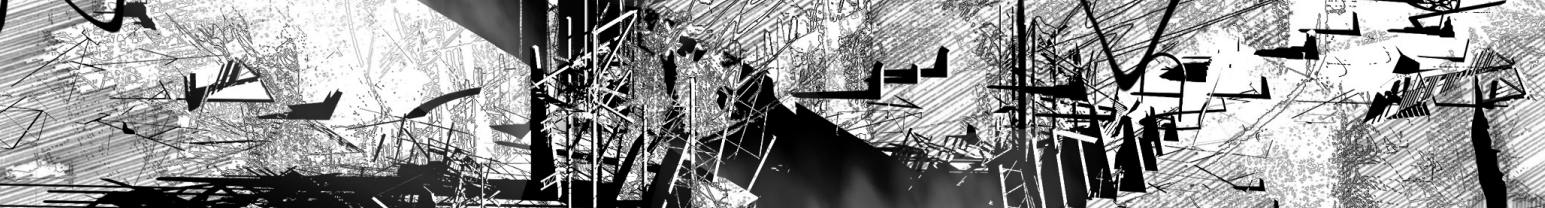

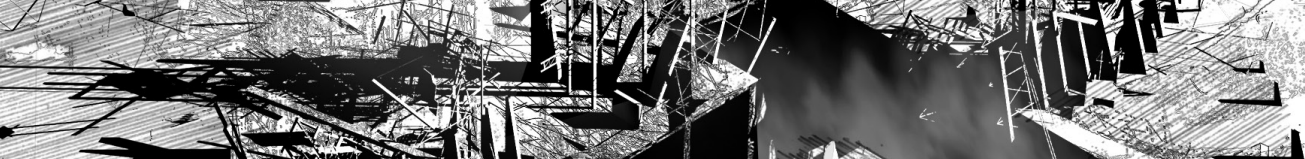
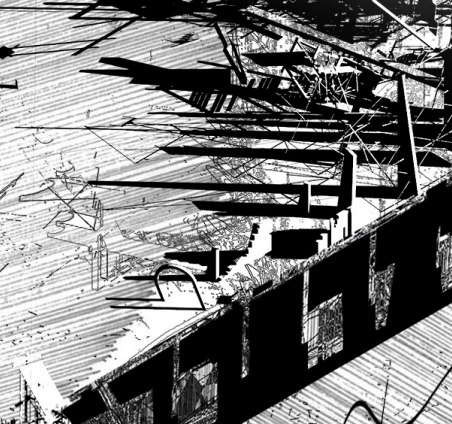

(1)

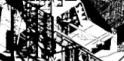

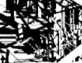
in
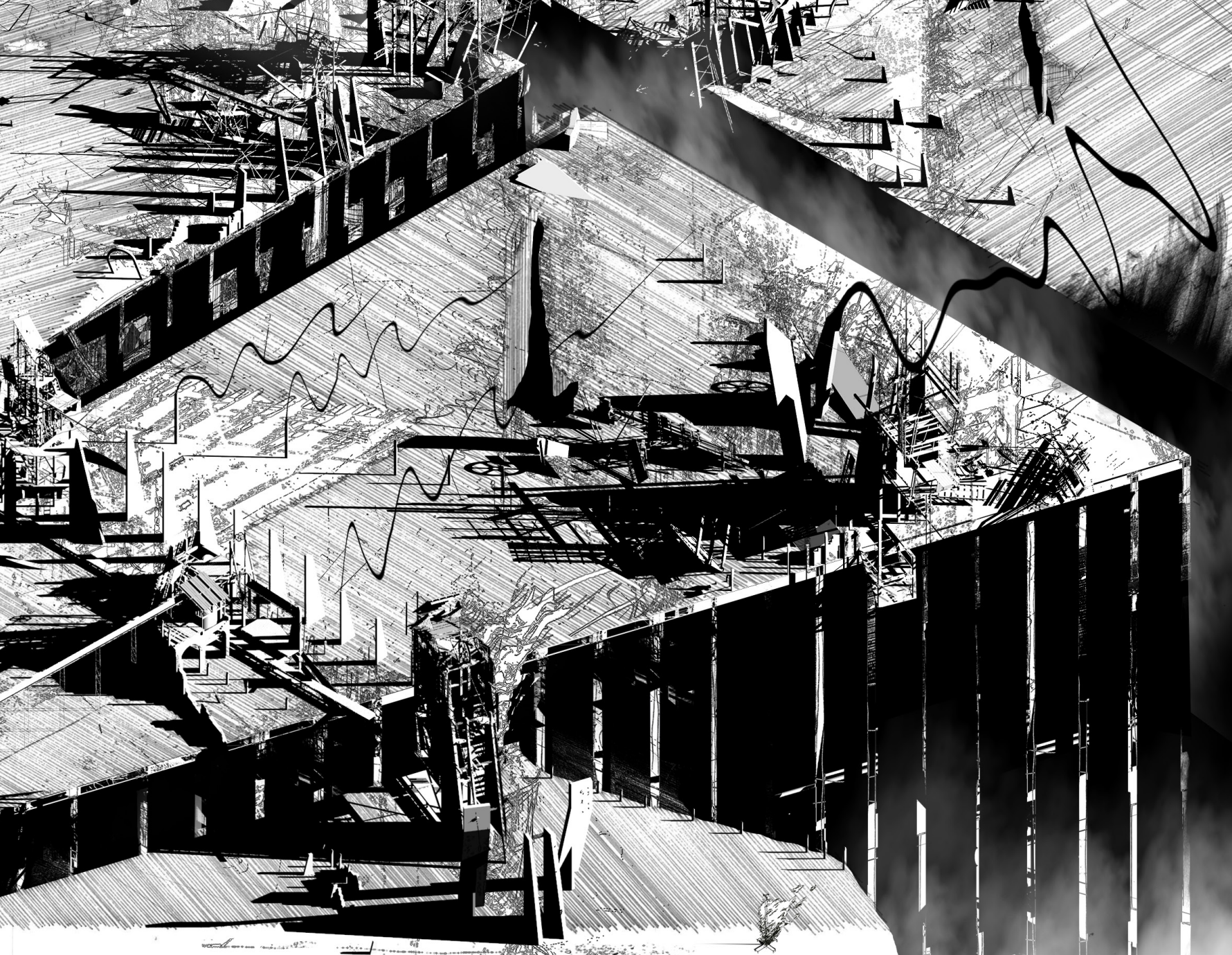

$+4-14$

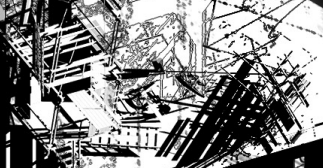
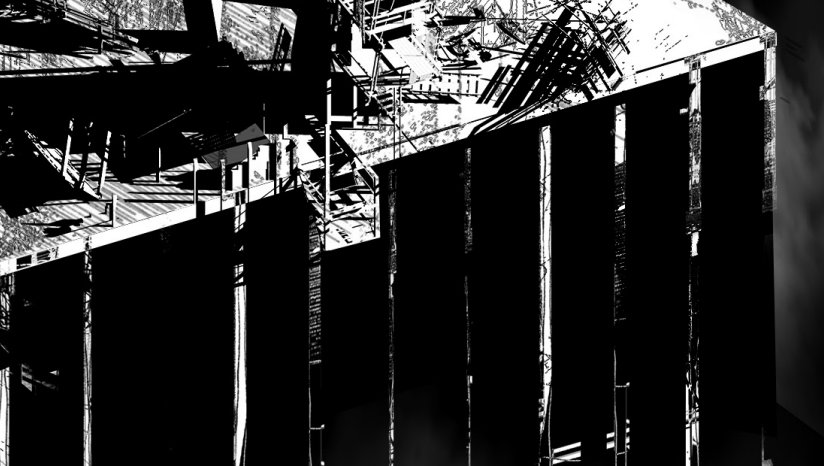


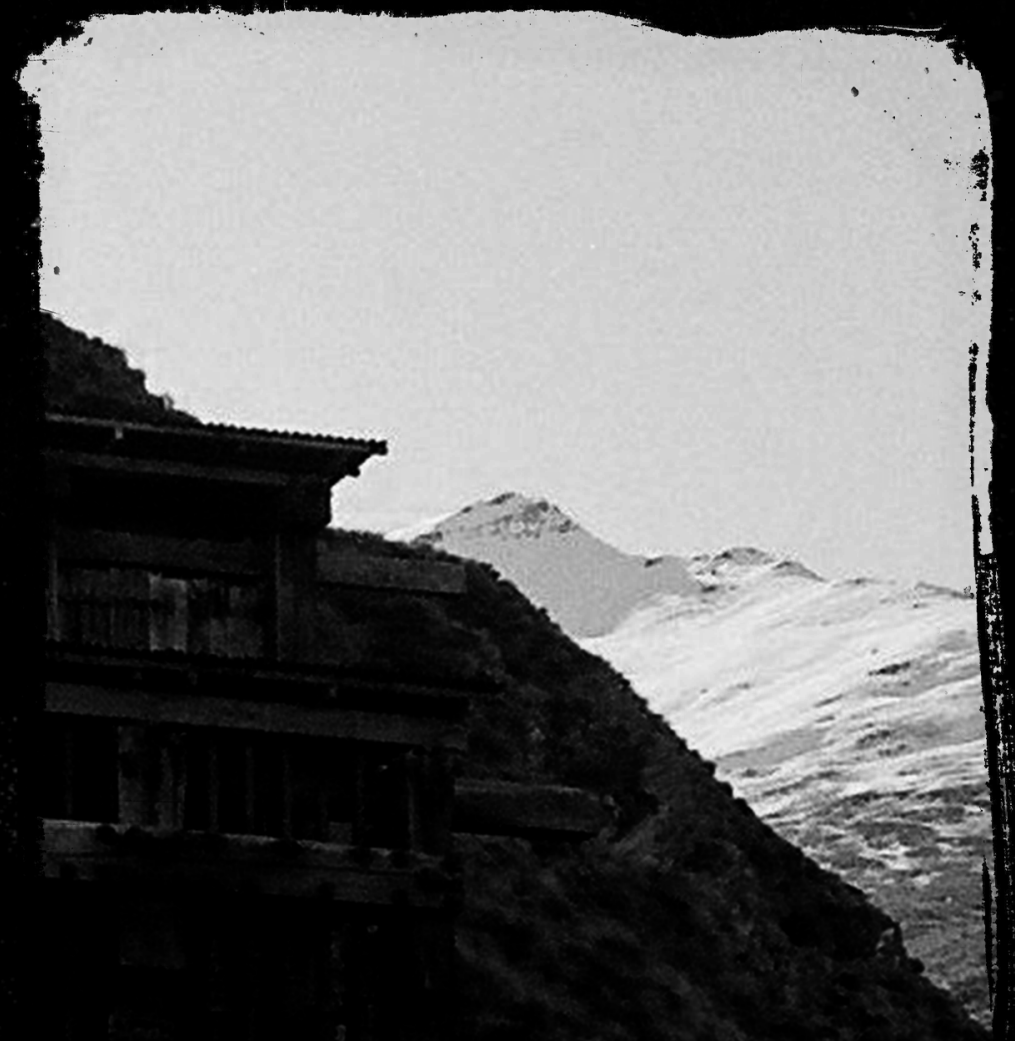

Fig 8.9 The Mountain in the distance stands in silence, the final witness..... 
Idea and matter are the poles of architecture.

Their future differs.

For thought, the idea prevails.

For matter it turns into waste.

The idea is the manifestation of thought totally encased and protected by the individual power of its inventor but violated by the intention of implementation and consequently of its realisation.

The utterance of thought is silenced as soon as it is pronounced, while the silence of matter is violated by its own fate of decay.

Knowing that only what appears evident can be translated, the enigma of unknown fragments remains.

Matter will only survive its own fate through the memory of desire: an adventure across the real and the imaginary, an adventure of work in pursuit of itself.

While you build the wall

You shall destroy the stones

While your eyes long for the window

You shall destroy the wall

While you form sheets of glass

You shall destroy the crystals

While you extrude the iron bar

You shall destroy the mountains of ore

While you reach for the sky

You shall destroy the earth. 


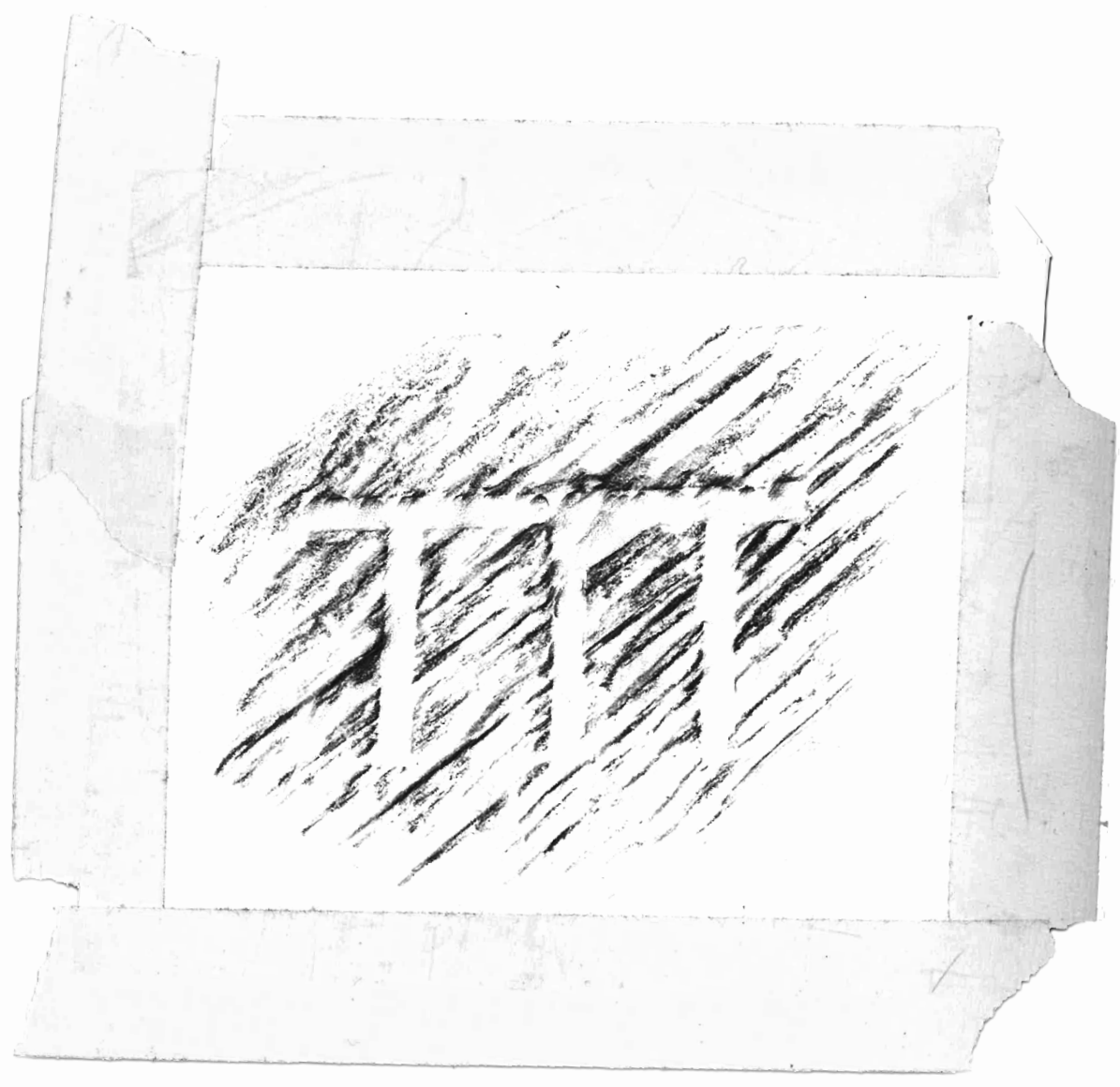

Fig 8.10 Author's rubbing from the site visit — preserving a fragment of the Stamper Battery's notational system to bring back to studio as the machine is slowly lost to time. 


\subsection{CODA}

\section{PERSONAL REFLECTION}

This thesis has been a journey of unexpected discoveries and personal revelations over the course of a very tumultuous year. Beginning with my love for machines, the preservation of decaying industrial remnants quickly evolved from a research investigation into a personal endeavour that strove to not only save their heritage story but also celebrate and share it with the people around me.

The trip to site was a pivotal moment in this year, proving how generous my friends are and how important it is to visit the place you are trying to preserve. Seeing and touching the stamper battery after half a year of study galvanised my personal investment in this investigation-and my only regret is being so excited I forgot to take a photo of myself together with this extraordinary machine.

Exhibiting my work was a truly special experience; bringing the drawings into the physical world and curating them was a wonderful way to bring attention to the machines I was trying to save. It also allowed me to reflect on the journey of this year and see how my architectural skills have grown over the past twelve months.

Each drawing in this thesis acts as a freeze frame, capturing my drawing abilities, imagination and confidence at the moment of their conception. As the work progressed they continued to evolve and transform-some taking weeks of grinding and others taking me completely by surprise-as new aesthetics emerged and compositions locked into place. Within the drawings are moments of epiphany, frustration and jest as they became a manifesto of my own personal journey through the year.

This thesis has allowed me to dive into the world of speculative drawing and resurface with drawings that evoke my own personal identity and position in the architectural spectrum. It has shown me the power of architecture that is driven by a heroic cause, and I look forward to revisiting this project with fresh eyes and renewed energy in the years to come.

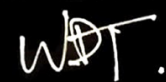


46

Only the whispers remained, and the little whimpering groans.

She burst into tears.

Tears answered her.

They wept for humanity, those two, not for themselves. They could not bear that this should be the end. Ere silence was completed their hearts were opened, and they knew what had been important on the earth...

'But 1 is it true? Are there still men on the surface of the earth? Is this - tunnel, this poisoned darkness - really not the end?'

He replied:

'I have seen them, spoken to them, loved them. They are hiding in the midst and the ferns until our civilization stops.

'Oh, tomorrow - some fool will start the Machine again, tomorrow.'

'Never,' said Lr.,'never. Humanity has learnt its lesson.'

and, before they joined them, scraps of

...For a moment they saw the nations of the dead the<smiles></smiles>

sky. 
Tा

$+$ 


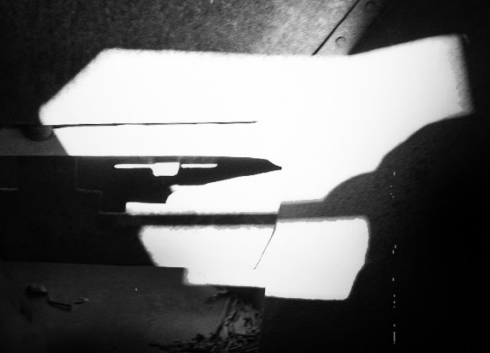




\subsection{BIBLIOGRAPHY}

Abraham, R. (1996). [UN]BUILT. Slovenia: Springer.

Allen, S. (2000). Practice: Architecture Technique + Representation. New York: Routledge.

Alonso, H. D., \& Mayne, T. (2009, Fall). “Generation(s) and The Generative”. Log, pp. 127-135.

Brook, P. (1995). The Empty Space: A Book About the Theatre: Deadly, Holy, Rough, Immediate. New York: Scribner.

Cantley, B. (2011). MECHUDZU. Austra: Springer.

Cantley, B. (2014, Sept 16). Ghost Notes: The Space between Notes. Retrieved from Metalocus: https://www.metalocus.es/en/news/imaginary-body-and-sections-imagination-formula-bryancantley

Cantley, B. (2018). "Towards a taxonometric architecture: D-con: an" Design Ecologies vol 7, 49-69: Intellect.

Carpo, M. (2013). “The Art of Drawing. Architectural Design” - Drawing Architecture, 128-133.

Clark, J. (1997). Drawing on Architecture : Gender, Subjectivity, Surface. Wellington: Victoria University of Wellington.

Corbusier, L. (2007). Towards a New Architecture. Los Angleles: Getty Publications.

Corner, J. (2014). "Drawing and Making in the Landscape Medium.” In Alison Bick Hirsch, The Landscape Imagination : Collected Essays of James Corner, 1990-2010 (p. 174). New York: Princeton Architectural Press.

Deleuze, G., \& Guattari, F. (1987). A Thousand Plateaus : Capitalism and Schizophrenia. London: Continuum.

Fletcher, A. (1964). Allegory: the Theory of a Symbolic Mode. New York: Cornell University Press.

Forster, E. M. (1909, November). “The Machine Stops.” Retrieved from Plexus: https://www. plexus.org/forster/index.html

Frye, N. (1964). The Educated Imagination. Bloomington: Indiana University Press.

Goodman, N. (1968). Languages of Art; An Approach to a Theory of Symbols. Indianapolis: Bobbs-Merrill.

Halso, I. (1994, December 23). Cultural Landscape. Retrieved from The skin of the earth: http:// www.saunalahti.fi/halso/pagenglish/cultlandtxt.html

Hamel, C. (2007). "Drawing Lines of Confrontation.” In J. H. Marco Frascari, From Models to Drawings: Imagination and Representation in Architecture New York: Routledge. (pp. 201-207).

Hara, M. (2010, May 18). Thesis Presentation. Retrieved from The Architecture of Possibility: https:/thearchitectureofpossibility.wordpress.com/2010/05/18/thesis-presentation/ 
Haralambidou, P. (2007). "The Fall: The Allegorical Architectural Project as a Critical Method." In J. Rendell, J. Hill, M. Fraser, \& M. Dorrain, Critical Architecture (pp. 225-236). New York: Routledge.

Hejduk, J. (2006). Victims. In N. Spiller, Visionary Architecture (p. 167). New York: Thames \& Hudson.

Herron, S. (2013, Sept/Oct). "Plug-In, Clip-On, Tune-Up. Architectural Design" - Drawing Architecture, pp. 94-101.

Hill, J. (2004). “Six Degrees of Intervention”. In J. Hill, The Double Dimension: Heritage \& Innovation (pp. 64-85). Royal Australian Institute of Architects.

Kepes, G. (1969). Language of vision. Chicago: Paul Theobald and Company.

Koetter, F. (1980, Spring). "Notes on the In-Between". Harvard Architecture Review, pp. 68-69.

Kulper, P. (2013, Sept/Oct). “A World Below”. Architectural Design, pp. 56-63.

Lim, C. (2013, Sept/Oct 2013). "London Short Stories: Drawing Narratives". Architectural Design: Drawing Architecture, pp. 102-107.

Martinoglio, M. (2020, May 19). Arata Isozaki: Western drawing veiled by Oriental taste. Retrieved from Nonarchitecture: https:/www.nonarchitecture.eu/2020/05/19/arata-isozakiwestern-drawing-veiled-oriental-taste/

Miss, M. (2004). Mary Miss. New York: Princeton Architectural Press.

Petchey, P. (2002, Nov). Archaeological survey of the Arrow River and Macetown, Otago. Wellington, New Zealand: DOC Science Publishing, Science \& Research Unit.

Potteiger, M., \& Purinton, J. (1998). Landscape Narratives. New York: Wiley.

Schneider, P. (2007, September). "Disegno: On Drawing out the Archi-texts". Journal of Architectural Education, pp. 19-22.

Schultz, A.-C. (2007). Carlo Scarpa Layers. London: Edition Axel Menges.

Simmmel, G. (1958). “Two Essays: The Handle, and The Ruin”. The Hudson Review, Vol 11, 371.

Smout, M., \& Allen, L. (2013, Sept/Oct). "Augmented Landscapes and Delicate Machinery". Architectural Design: Drawing Architecture, pp. 88-93.

Spiller, N. (2000). Maverick Deviations. Chichester: Wiley.

Spiller, N. (2006). Visionary Architecture. New York: Thames \& Hudson.

Spiller, N. (2016). "Future Fantasticals". In L. Allen, \& L. C. Pearson, Drawing Futures: Speculations in Contemporary Drawing for Art and Architecture (pp. 139-204). London: UCL.

Terragni, G. (1938). 'Relazione sul Danteum' (1938), in Thomas Schumacher, The Danteum: A Study in the Architecture of Literature. Princeton Architectural Press.

"War and Relatively in the Age of Memorial Mechanics". (2006). In N. Spiller, Visionary Architecture - Blueprints of the Modern Imagination (pp. 164-182). Thames \& Hudson.

Yendo, M. (2001). Ironic Diversions. Austria: Springer. 


\subsection{SOURCE OF FIGURES}

Figure 1.6

Figure 1.7

Figure 1.8

Figure 1.9

Figure 2.2

Figure 2.3

Figure 2.4

Figure 2.7

Figure 3.1.1

Figure 3.1.3

Figure 3.2.1

Figure 3.2.2

Figure 3.2.3

Figure 3.2.4

Figure 3.3.1

Figure 3.3.2

Figure 3.3.3

Figure 3.4.1

Figure 3.4.2

Figure 5.1.3

Figure 5.2.3

Figure 5.3.4

Figure 5.4.3

Figure 5.5.3

Figure 5.6.3

Figure 5.7.3

Figure 6.2.1

Figure 7.2

Figure 9.2
Spiller, Visionary Architecture, 2006

https://www.archiobjects.org/museo-castelvecchio-verona-italy-carlo-scarpa/

Yendo, 2001

http://nobuhironakanishi.com/gallery/layer-drawings/

https://hocken.recollect.co.nz/nodes/view/34849

https://hocken.recollect.co.nz/nodes/view/34849

https://hocken.recollect.co.nz/nodes/view/34849

https://data.linz.govt.nz/set/4702-nz-aerial-imagery/

https://archiveofspace.tumblr.com/post/22734898643/berlin-masque-john-hejduk

https://www.designboom.com/art/takayuki-hori-oritsunagumono/

https://mapoesie.tumblr.com/post/187759616625/carlo-scarpa-museo-di-castelvecchio-verona https://inhabitat.com/the-museum-ofnature-by-ilkka-halso

http://www.neilspiller.com/\&/projects/communicating-vessels/frustum-upper-chamber/

Abraham, 1996

Yendo, 2001

Cantley, 2011

http://www.neilspiller.com/projects/communicating-vessels/the-object-beside-itself/

Schneider, 2007

http://nobuhironakanishi.com/gallery/layer-drawings/

https://dsrny.com/project/slow-house

https://holtsmithsonfoundation.org/rocks-and-mirror-square-ii

Yendo, 2001

Miss, 2004

https://www.archdaily.com/782297/bologna-shoah-memorial-set

https://jollycontrarian.com/index.php?title=File:Double_negative.jpg

Cantley, 2011

Abraham, 1996

Maverick Deviations, 2000

https://www.nonarchitecture.eu/2020/05/19/arata-isozaki-western-drawing-veiled-oriental-taste/ 



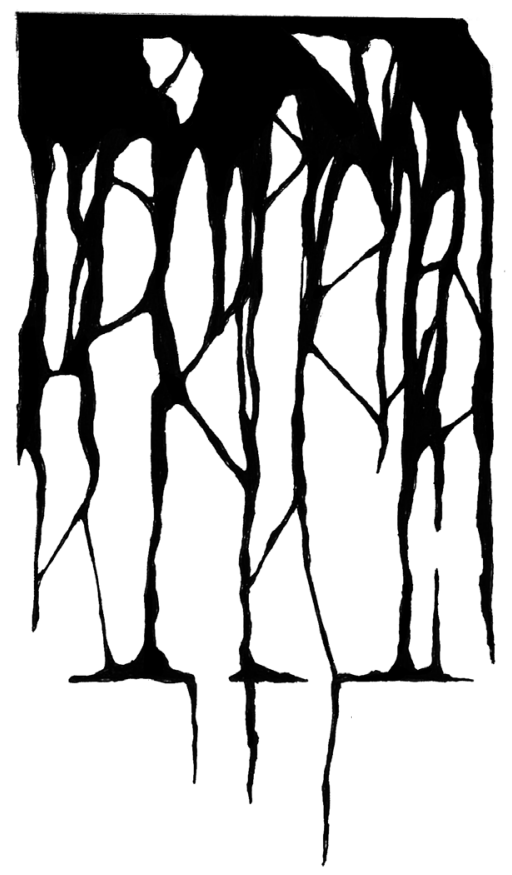

